\title{
The Use of Singing, Storytelling and Chanting in the Primary EFL Classroom: Aesthetic Experience and Participation in FL Learning
}

\author{
Annett Kaminski
}

Submitted to Swansea University in fulfillment of the requirements for the Degree of Doctor of Philosophy

Swansea University

2016 


\begin{abstract}
The Use of Singing, Storytelling and Chanting in the Primary EFL Classroom: Aesthetic Experience and Participation in FL Learning
\end{abstract}

This longitudinal small-scale study, which is based on data collected between 2007 and 2010 in Rhineland-Palatinate in Germany, analyses the use of songs, stories and chants in primary EFL classrooms. A multi-method design is applied involving quantitative research instruments, such as a questionnaire distributed to primary school teachers, as well as qualitative research instruments, such as extensive participant observation and in-depth interviews with learners as well as teachers.

Questionnaire data indicates regular use of songs, stories and chants in primary FL classrooms in the area under investigation. Audio-recorded classroom and interview discourse reveals that musical and literary texts spark learners' interest due to the aesthetic qualities they exhibit. Learners' non-verbal and verbal responses show that they construct meaning from visual and acoustic cues that accompany songs, stories and chants and that they are eager to participate in the performance of these texts. Learners imitate language items immediately, their verbal participation increasing with every encounter of a song, chant or story. Learners are able to recall individual and multi-word sequences from high-interest musical and literary texts shortly after repeated exposure as well as 12 to 15 months later. There is evidence of them breaking up memorized language chunks and recombining them for generative language use. Furthermore, learners are able to jointly reconstruct the storyline of a picture book 12 months after their first and only encounter with it, suggesting that a meaningful context has been created which is accessible over an extended period of time.

On the basis of these findings, it is argued that the aesthetic qualities of songs, stories and chants foster FL learning in various ways. They support comprehension and retrieval, sustain learners' interest and invite joint performances, all of which paves the way for the mastery of multi-word sequences and creative FL use. 


\section{DECLARATION}

This work has not previously been accepted in substance for any degree and is not being concurrently submitted in candidature for any degree.

Signed

Date

\section{STATEMENT 1}

This thesis is the result of my own investigations, except where otherwise stated.

Other sources are acknowledged by giving explicit references. A bibliography is appended.

Signed

Date

\section{STATEMENT 2}

I hereby give consent for my thesis, if accepted, to be available for photocopying and for inter-library loan, and for the title and summary to be made available to outside organisations.

Signed

Date 


\section{Table of Contents}

Acknowledgments $\quad x$

List of Tables and Figures $\quad x i$

Abbreviations $\quad$ xvi

Transcription Conventions $\quad$ xvii

1 Introduction 1

1.1 The Problem 1

1.2 The Purpose of this Study 4

1.3 Outline of Chapters 5

\section{PART ONE: Literature Review}

2 History and Current Trends in Primary FL Teaching Practice 6

2.1 The Introduction of Primary FL Teaching in Germany 6

2.1.1 Primary FL teaching in East and West Germany (1945-90) 7

2.1.2 Primary FLT as part of the European initiative 8

2.1.3 The integrated FL programme (IFA) in Rhineland-Palatinate $\quad 10$

2.2 The Situation of Primary FLT in other European Countries 13

$\begin{array}{ll}\text { 2.2.1 Variation and trends } & 13\end{array}$

$\begin{array}{ll}\text { 2.2.2 Problematic issues } & 14\end{array}$

2.3 Empirical Studies on Primary FL Teaching Practice 16

2.3.1 Timetabling and qualified staff 16

2.3.2 Exposure to FL inside and outside the classroom 18

2.3.3 Popular activities in primary FL classrooms 20

$\begin{array}{ll}\text { 2.3.4 Learners’ FL output } & 21\end{array}$

2.4 Concluding Remarks 23

3 Songs, Chants, Rhymes and Stories in Primary FL Teaching 25

$\begin{array}{ll}3.1 \text { Theoretical Positions } & 26\end{array}$

3.1.1 General cognitive and emotional development 28 
3.1.2 Linguistic development $\quad 34$

3.1.2.1 Song, rhyme and chant $\quad 35$

3.1.2.2 Stories 41

3.2 Empirical Research 43

3.2.1 Musical texts and young learners’ progress in formal FL learning 43

3.2.2 Stories and young learners’ progress in formal L2 or FL learning 47

3.3 Concluding Remarks 53

4 Methodology $\quad 54$

4.1 Traditions and New Trends in Classroom Research 55

4.1.1 Quantitative studies on FL teaching methods and classroom interaction

55

4.1.2 Questioning the suitability of quantitative research instruments 56

4.1.3 The paradigm shift in language learning and research 58

4.1.4 Implications for this research project 58

$\begin{array}{ll}\text { 4.2 The Ecological Perspective } & 61\end{array}$

4.3 The Ethnographic Approach 62

4.4 The Case Study Design 65

4.5 Discourse Analysis 66

$\begin{array}{ll}\text { 4.6 Concluding Remarks } & 69\end{array}$

\section{PART TWO: Analysis of Data}

5 The Questionnaire $\quad 71$

$\begin{array}{ll}5.1 \text { Methodology and Data Collection } & 71\end{array}$

5.1.1 Questionnaire construction 72

5.1.1.1 Cover letter $\quad 72$

5.1.1.2 Questions on aspects of primary-level EFL teaching 73

5.1.1.3 Demographic questions $\quad 75$

$\begin{array}{ll}\text { 5.1.2 Piloting } & 76\end{array}$

$\begin{array}{ll}\text { 5.1.3 Administration of questionnaire } & 78\end{array}$

$\begin{array}{ll}\text { 5.1.4 Questionnaire return } & 80\end{array}$ 
5.2 Procedures for Data Analysis $\quad 81$

$\begin{array}{ll}\text { 5.2.1 Data entry and coding procedures } & 81\end{array}$

5.2.2 Problematic issues $\quad 82$

5.3 Questionnaire Results 83

5.3.1 Demographic information 83

5.3.2 Integrating EFL into various subject areas and using it in various contexts $\quad 89$

$\begin{array}{ll}\text { 5.3.3 Teaching material } & 92\end{array}$

5.3.4 Favourite activities in the primary EFL classroom 97

5.3.5 Musical and literary texts in the primary EFL classroom 99

$\begin{array}{ll}\text { 5.3.6 Likert scales } & 106\end{array}$

5.3.7 Problematic issues in primary EFL 114

$\begin{array}{ll}\text { 5.4 Discussion of Results } & 117\end{array}$

5.4.1 Lesson organisation, choice of materials, activities and $\begin{array}{ll}\text { teaching objectives } & 117\end{array}$

5.4.2 The role of songs, chants, rhymes and stories in teachers' lesson organisation in comparison to other activities and with reference

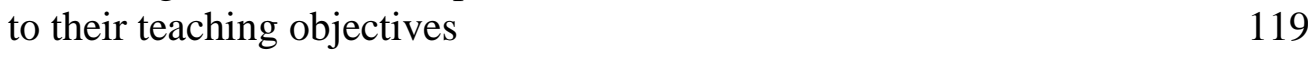

$\begin{array}{ll}5.5 \text { Concluding Remarks } & 121\end{array}$

6 Participant Observation in Primary EFL Classrooms 123

6.1 Methodology and Data Collection 123

6.1.1 Choice of research tools 123

$\begin{array}{ll}\text { 6.1.2 Procedures for data collection } & 124\end{array}$

6.1.3 The participating school, children and teachers 126

$\begin{array}{ll}\text { 6.2 Procedures for Data Analysis } & 127\end{array}$

$\begin{array}{ll}\text { 6.2.1 Transcription procedures } & 128\end{array}$

6.2.2 Criteria for the analysis of classroom data 129

6.3 Results of Classroom Observation Data 130

6.3.1 Quantitative aspects of the lessons 131

6.3.2 Analysis of songs, chants and stories used in the primary EFL classrooms 135

$\begin{array}{ll}\text { 6.3.2.1 Songs } & 136\end{array}$ 
6.3.2.2 Chants 140

$\begin{array}{ll}\text { 6.3.2.3 Stories } & 141\end{array}$

6.3.3 Lesson organisation: Analysis of example lessons 150

6.3.3.1 Sophie’s lesson on April Weather 151

6.3.3.2 Julia’s lesson on Easter Bunny’s Book 153

6.3.3.3 Ruth’s lesson on The Three Little Pigs 155

6.3.4 Analysis of learners’ response to songs, chants and stories 157

$\begin{array}{ll}\text { 6.3.4.1 Songs } & 157\end{array}$

6.3.4.2 Chants 165

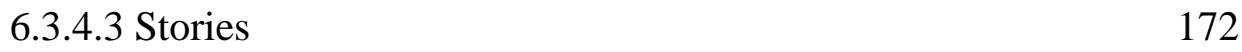

6.3.5 The participant observer as teacher - analysis of a picture book $\begin{array}{ll}\text { session } & 180\end{array}$

6.4 Discussion of Findings 186

6.4.1 Lesson organisation, teaching objectives, materials and activities 186

6.4.2 The nature of FL input and its impact on FL learning 188

6.4.3 The teaching of vocabulary, the role of visualization and acoustic cues

189

6.4.4 Learners’ response to songs, chants and stories 190

6.4.5 The nature of learners’ FL output 191

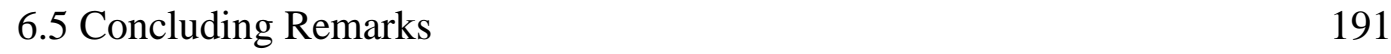

7 Interviews with Participating Learners and Teachers 193

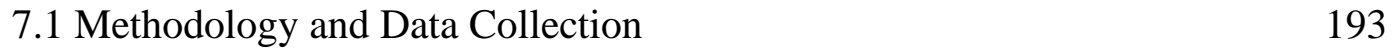

$\begin{array}{ll}\text { 7.1.1 Procedures for learner interviews } & 197\end{array}$

7.1.2 Procedures for teacher interviews 200

$\begin{array}{ll}7.2 \text { Procedures for Data Analysis } & 201\end{array}$

7.3 Results of the Analysis of Interview Data 204

7.3.1 Learners’ views on popular activities and their FL production 204

7.3.2 Teachers' views on learner participation, visualization and $\begin{array}{ll}\text { acoustic cues } & 215\end{array}$

$\begin{array}{ll}7.4 \text { Discussion of Findings } & 229\end{array}$

$\begin{array}{ll}\text { 7.4.1 Popular activities } & 230\end{array}$ 
7.4.2 Long-term impact of songs, chants and stories in learners' FL output

7.4.3 Learner response, multimodal features and the role of repetition

8.1 Imitation and FL Learning

8.2 Visualization and FL Learning

8.3 Memorized Language Chunks and Fluency in the FL

9.1 Aspects of Teaching

9.2 Aspects of Learning

9.3 Implications for Teaching

9.4 Limitations

9.5 Closing words

\section{Appendices}

1 Statement of Ethics, letters to teachers and parents

2 Copy of original German version of questionnaire

3 English translation of questionnaire

4 Return rates of questionnaire

5 Analysis of questionnaire data, questions 1a and 15

6 List of titles of songs, chants and stories as mentioned by teachers

7 Analysis of frequency of genres being used

8 Analysis of songs, chants and stories for repetition, visualization \& acoustic cues

9 Additional example extracts from lessons

10 Cards for learner interview 
11 Interview guide for teacher interviews

12 Analysis of contextual features in interviews

13 Overview of learners' FL production 


\section{Acknowledgements}

I would like to express my gratitude to the many people who have supported me during the time it took to complete this research project.

I am indebted to my supervisors Professor Geoff Hall, Professor Julian Preece and Dr Cornelia Tschichold, who guided me through all the stages of this dissertation. Their constructive feedback was invaluable and has greatly enriched my understanding of research in teaching and communication.

I am most grateful to all the teachers and children who welcomed me into their classrooms, who let me experience their everyday school life and who shared their ideas with me. Without their willingness to participate in the research project, this study would not have been possible.

My thanks also go to my family for their constant moral support, encouragement and for being there to help when I most needed them. Lastly, I owe much to my children, from whom I learn so much just by watching them grow. 


\section{List of Tables, Figures and Extracts}

\section{Tables}

Table 1 EFL teaching experience at primary school 85

Table 2 Analysis of different types of teachers’ EFL training 86

Table 3 Integrating English into other subject areas

(kind of subject areas \& no. of teachers) 90

Table 4 Integrating English into other subject areas

(no. of subject areas \& no. of teachers) 90

$\begin{array}{lll}\text { Table } 5 & \text { EFL provision in form of a separate session } & 91\end{array}$

Table $6 \quad$ Using English in different teaching contexts 92

$\begin{array}{lll}\text { Table } 7 & \text { Availability of textbook } & 94\end{array}$

$\begin{array}{lll}\text { Table } 8 & \text { No. of different teaching materials available }\end{array}$

Table 9 Teaching materials that teachers favour 96

$\begin{array}{lll}\text { Table } 10 & \text { Reasons for preference of teaching materials } & 97\end{array}$

$\begin{array}{lll}\text { Table } 11 & \text { Top five popular activities } & 98\end{array}$

$\begin{array}{lll}\text { Table } 12 \text { Frequency of using musical and literary texts } & 100\end{array}$

$\begin{array}{lll}\text { Table } 13 & \text { Reasons for suitability of genre } & 102\end{array}$

$\begin{array}{lll}\text { Table } 14 & \text { No. of songs, rhymes, poems and stories }\end{array}$

$\begin{array}{lll}\text { Table } 15 & \text { Titles of songs, rhymes, poems and stories } & 103\end{array}$

$\begin{array}{lll}\text { Table } 16 & \text { Top five follow-up activities } & 105\end{array}$

Table 17 Likert scales, Reliability analysis of questions 6 and $9 \quad 107$

$\begin{array}{lll}\text { Table } 18 & \text { Teaching objectives in primary-level FLT } & 107\end{array}$

$\begin{array}{lll}\text { Table } 19 & \text { Teachers' year groups } & 111\end{array}$

$\begin{array}{lll}\text { Table } 20 & \text { Reasons for using stories, rhymes/poems and songs }\end{array}$

Table 21 Problematic issues with regard to songs, rhymes and stories 114

Table 22 Problematic issues with regard to primary EFL 116

$\begin{array}{lll}\text { Table } 23 & \text { Observation matrix } & 125\end{array}$

$\begin{array}{lll}\text { Table } 24 & \text { Observation data } & 127\end{array}$

$\begin{array}{lll}\text { Table } 25 & \text { Transcription data } & 127\end{array}$

$\begin{array}{lll}\text { Table } 26 & \text { Frequency of songs, chants and stories } & 131\end{array}$

$\begin{array}{lll}\text { Table } 27 & \text { Use of different genres } & 132\end{array}$ 
Table 28 Number of different texts according to genre

Table 29 Proportion of time and word count for song, chant and story

Table 30 Minimum \& maximum proportions of recorded classroom time related to song, chant and story

Table 31 Minimum \& maximum proportions of recorded classroom interaction related to song, chant and story

Table 32 Proportion of repetition of lexical items in songs

Table 33 Visualization, sound and literary devices in songs

Table 34 Proportion of repetition of lexical items in chants

Table 35 Visualization, sound and literary devices in chants

Table 36 Proportion of repetition of lexical items in stories

Table 37 Overview of Lesson 7/ Year 3 (Sophie)

Table 38 FL input during preparation, core \& follow-up activities in Lesson 7

Table 39

Overview of Lesson 10 (Julia)

Table $40 \quad$ FL input during preparation, core \& follow-up activities in Lesson 10

Table 41 Overview of Lesson 34 (Ruth)

Table 42 Interview matrix

Table 43 Learners’ FL output 207

Table 44 Examples of learners' contributions 207

Table 45 Traces of songs, chants and stories in learners' FL output 208

\section{Figures}

Figure 1 Research perspective, approach, design \& method of analysis 60

Figure 2 Working experience as a primary school teacher 84

Figure 3 EFL teaching experience at primary school 84

$\begin{array}{lll}\text { Figure } 4 & \text { Teacher's subjects } & 87\end{array}$

$\begin{array}{lll}\text { Figure } 5 & \text { Teachers' year groups } & 87\end{array}$

Figure 6 Teachers' experience with music and literature 88

Figure 7 Availability of different teaching materials 93

Figure 8 No. of different teaching materials available 95 
$\begin{array}{lll}\text { Figure } 9 & \text { Suitability of different genres } & 101\end{array}$

Figure 10 Teaching objectives with regard to receptive language use 109

$\begin{array}{lll}\text { Figure } 11 \text { Teaching objectives with regard to productive language use } & 109\end{array}$

Figure 12 Teaching objectives with regard to metalinguistic awareness, cultural knowledge and attitudes

Figure 13 Reasons for using stories, rhymes/poems and songs with regard to language use

Figure 14 Reasons for using stories, rhymes/poems and songs with regard to cultural knowledge and attitudes

Figure 15 Actions in the Easter Chant and Easter Bunny Chant

Figure 16 Look At Me (Hunt and Brychta, 2000)

Figure 17 The use of pictures in the Easter Bunny's Book (Englisch begegnen 16)

Figure 18 The use of pictures in April Weather (Diekmann, 2008b)

Figure 19 Actions in the April Weather story (Diekmann, 2008b)

Figure 20 Pictures in The Three Little Pigs

(Grundschule Englisch 23, 2008)

Figure 21 Froggy Gets Dressed (London and Remkiewicz, 1992) 147

Figure 22 The Smartest Giant in Town (Donaldson and Scheffler, 2002) 148

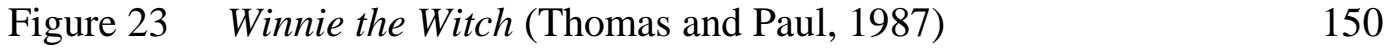

Figure 24 Drawing for Weather Song according to Sophie’s instructions 152

Figure 25 Drawing for the Football Warm-up according to Sophie’s Instructions

$\begin{array}{lll}\text { Figure } 26 & \text { One learner’s drawing of Froggy } & 173\end{array}$

Figure 27 Double spread no. 2, The Smartest Giant in Town 182

Figure 28 Two examples of mandalas that children produced 199

$\begin{array}{lll}\text { Figure } 29 & \text { Examples of interview cards } & 199\end{array}$

\section{Extracts}

Extract 1 Joining in actions and instructions for the Weather Song (L. 4) 158

Extract 2 Joining in actions and instructions for the Weather Song (L. 5) 159

Extract 3 Joining in onomatopoeic utterances for the Weather Song 160

Extract 4 Joining in onomatopoeic utterances for the Weather Song 160 
Extract 5 Joining in the singing with presenter of the Weather Song

Extract 6 Joining in with teacher for the Weather Song 162

$\begin{array}{lll}\text { Extract } 7 & \text { Singing the Weather Song } & 163\end{array}$

Extract 8 Trying to remember the Weather Song 164

Extract 9 Children using visual clues for comprehension 166

$\begin{array}{lll}\text { Extract } 10 & \text { Joining in the Football Warm-up } & 167\end{array}$

Extract 11 Moving \& speaking simultaneously in post-listening activity 169

Extract 12 Increasing verbal participation in the Football Warm-up 170

Extract 13 Learners' determination to participate in storytelling 174

Extract 14 Joining in the story April Weather 175

$\begin{array}{lll}\text { Extract } 15 & \text { Increasing verbal response from children }\end{array}$

Extract 16 Lack of participation with the Easter Bunny's Book 177

Extract 17 Low levels of engagement during question-answer activity 179

Extract 18 Children's first response to illustrations 182

$\begin{array}{lll}\text { Extract } 19 & \text { Predicting how the story goes on } & 184\end{array}$

Extract 20 Learner interview: Popular activities 204

Extract 21 Learner interview: Children commenting on vocabulary activity 205

Extract 22 Learner Interview: Learners start singing 209

Extract 23 Learner interview: Responding to card featuring giant George 211

Extract 24 Learner interview: Children retrieving an individual word 213

Extract 25 Learner interview: Children learning from one another 213

Extract 26 Learner interview: Children retrieving a chunk of language 214

Extract 27 Learner interview: Children using analytic thought for retrieval 214

Extract 28 Teacher interview: Learner participation and popular activities 216

Extract 29 Teacher interview: Learners’ engagement \& aesthetic qualities 217

Extract 30 Teacher interview: Sophie on children's verbal participation 219

Extract 31 Teacher interview: Children's response to the Weather Song 221

Extract 32 Teacher interview: Repeated encounters with stories 222

Extract 33 Teacher interview: Repeated encounters with graded readers 223

Extract 34 Teacher interview: Repetition through decontextualized practice 224

Extract 35 Teacher interview: Sophie on visual clues as part of storytelling 225 
Extract 36 Teacher interview: Ruth on rhythmic language and actions

Extract 37 Teacher interview: Ruth on learners’ ability to reproduce songs 227 


\section{Abbreviations}

CDS Child Directed Speech

CLIL Content and Language Integrated Learning

EFL English as a Foreign Language

ESL English as a Second Language

EYLP Early Years Literacy Programme

FL Foreign Language

FLL Foreign Language Learning

FLT Foreign Language Teaching

IRF Initiation - Response - Feedback cycle in classroom discourse

LAD Language Acquisition Device

L1 first language, mother tongue

L2 second language

MFL Modern Foreign Language

NNS non-native speaker

NS native speaker

SLA Second Language Acquisition

SSIMH the 'song stuck in my head' phenomenon

STM Short-term memory

TD Triadic Discourse, three-part structure of classroom discourse

TPR Total Physical Response

UG Universal Grammar

YL young learner 


\section{Transcription Conventions}

Adapted version (Dalton-Puffer, 2007)

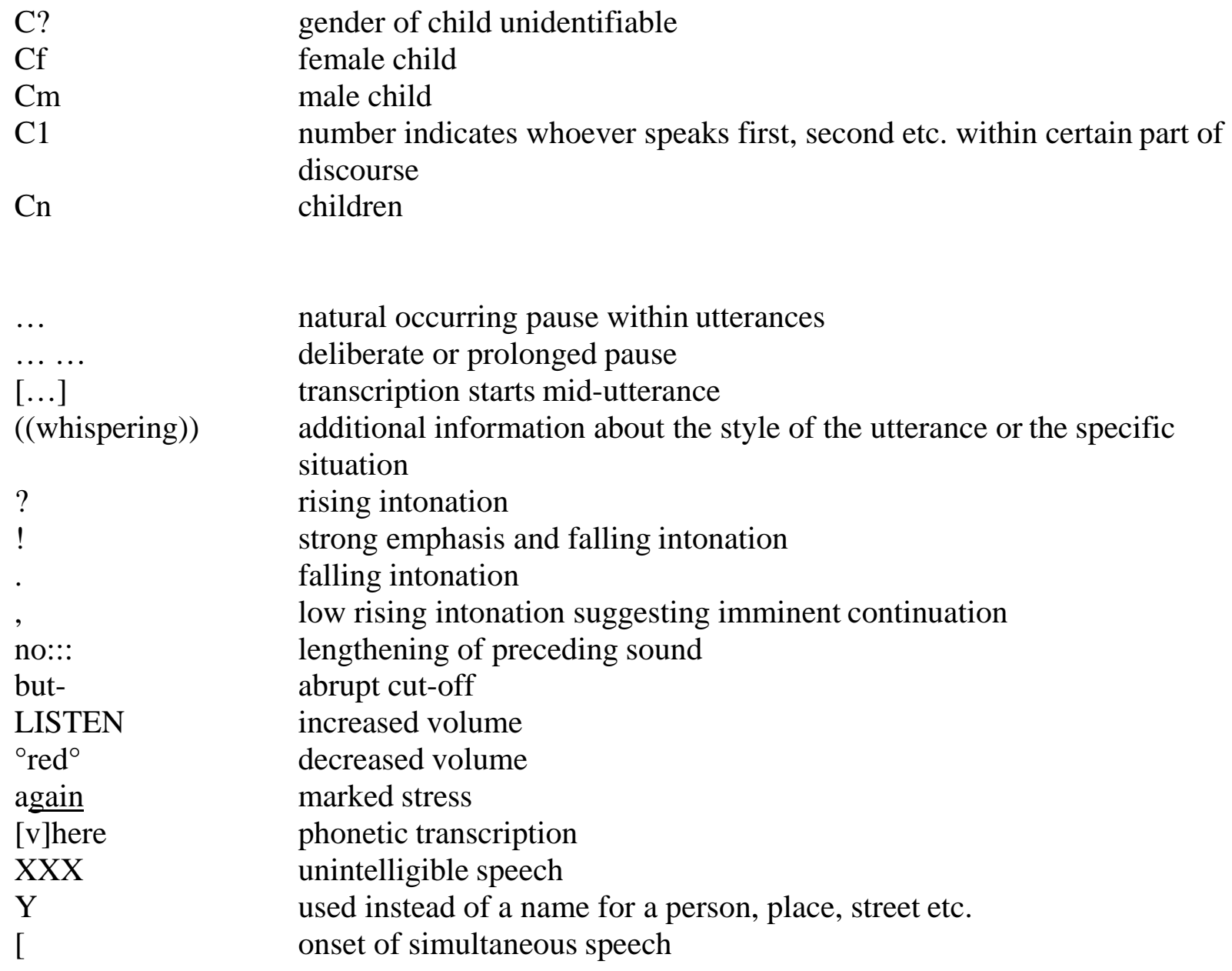

Notes:

Capital letters are used for individual words that need to be capitalized according to English or German spelling rules. Capitalization is not used at the beginning of sentences, since the transcription regards speakers' contributions as utterances rather than grammatical sentences. Italics are used for translated speech. 


\section{Chapter 1}

\section{Introduction}

\subsection{The Problem}

The idea for this project on songs, chants and stories in the primary English classroom was born in 2005 when I started to work as a teacher trainer in RhinelandPalatinate in Germany. At the time, foreign language teaching (FLT) was being newly implemented in primary schools in Germany, which had an impact on teacher education. FLT policies varied in the different federal states. In Rhineland-Palatinate, which is situated in the southwest of the country, it had been decided that classroom teachers should provide 50 minutes per week of English or French teaching to all of their primary schoolchildren in Years 1 to 4 (Ministerium für Bildung, Frauen und Jugend, 2004a). Consequently, English and French modules became compulsory components of the primary teacher degree programme at university, and I was asked to develop classes on children's literature as part of the EFL module. I realized that I needed to gain some first-hand experience in primary-school classrooms in order to make informed decisions about course design.

It has been asserted that children are naturally drawn to narratives (Ghosn, 2004), and that they enjoy singing and rhyming (Brewster, Ellis and Girard, 2002). It is no surprise then to find recommendations to use stories, songs and rhymes in the primary foreign language (FL) classroom. Most publications on teaching young learners include chapters on the use of these genres (Reilly and Ward, 1997; Klippel, 2000; L. Cameron, 2001; Brewster, Ellis and Girard, 2002; Pinter, 2006; Christiani and Cwik, 2008). Stories are also listed under the heading 'key insights' in the document on good practice and main principles for teaching young learners written for the European Commission (Edelenbos, Johnstone and Kubanek, 2006). Moreover, recent empirical studies have investigated how far stories and songs can contribute to young learners’ FL acquisition (Drew, 2009; Mourão, 2013; Coyle and Gomez Gracia, 2014).

Stories are also mentioned numerous times in the official brochure on the teaching of English and French at primary school in Rhineland-Palatinate (Ministerium für Bildung, Frauen und Jugend, 2007). Stories in the FL are seen as appropriate stimuli for creative writing tasks in German lessons (p. 6), authentic or real stories in the FL are recommended as suitable materials to support self-study 
activities (p. 7) and stories, songs and rhymes are thought to facilitate both cultural understanding and provide experience with 'real' language:

Children do not only learn the foreign language as authentically as possible through songs, rhymes, stories, children's books and real objects of the country or culture in question, they also encounter a different world. (Ministerium für Bildung, Frauen und Jugend, 2007: 11, my translation)

Moreover, parents are encouraged to express interest in the stories, songs and rhymes that their children might have learnt at school, to listen to their children reproduce these in the FL and to search actively for stories, CDs, films, and even for pen pals (Ministerium für Bildung, Frauen und Jugend, 2007).

With stories, songs and rhymes taking such a prominent position in official documents, we should expect them to be used regularly in primary classrooms up and down the federal state. However, at the beginning stages of this project there had not been a study with particular focus on the use of stories, songs and rhymes in primary English foreign language (EFL) classrooms in Rhineland-Palatinate. Yet there were many questions which needed answering. Were stories, songs and rhymes really used as often as one might expect judging from theoretical and official writings? How and why were they used, and what impact did they have on the children's learning of English? The study reported on in this PhD set out to explore these questions in order to arrive at evidence-based recommendations for teacher training.

Apart from this, one has to note that there has been a sense of uncertainty about the usefulness of primary FLT within the general public and even among researchers and groups of decision-makers. At the time of writing, researchers still voice their doubt about the usefulness of an early start to FLT (Copland and Enever, 2015), and the concern was even more prominent at the beginning of this project. For example, classroom data from Rhineland-Palatinate suggested a lack of 'real' or meaningful communication in primary classrooms, which questioned the concept of the integrated foreign language programme (IFA), as practised in Rhineland-Palatinate (Roos, 2006).

At the same time, early MFL teaching that was successful has not always triggered the necessary support from politicians. This was especially evident in the early stages of primary FLT when numerous pilot studies were being conducted in 
different federal states of Germany. For example, projects on primary EFL that had yielded positive results supporting the notion of an early start in FL learning in the 1970s and that had led to the development of curricular guidelines in Lower Saxony and in North-Rhine Westphalia did not lead to the implementation of FLT in primary schools at the time (Beckmann, 2006).

One glance at the history of primary languages in the UK will be sufficient to highlight how notoriously unpredictable the course of events within that particular domain has been over the last few decades. First attempts to introduce FLs in primary schools date back to the 1960s and 70s when a pilot scheme was carried out involving schools in England and Wales. An evaluation of the project was published by the National Foundation for Educational Research (NFER), in which the scheme did not receive positive feedback (Burstall, 1974). The report did not attest primary FL learning a 'significant advantage' (Boyd, 2001: 7) over FL programmes that started at secondary school. The lack of success was mainly attributed to the inadequate training of teachers (Woodgate-Jones, 2005). It took almost three decades for another effort to establish primary FLT in the UK. It was only in 2002 that the Department of Education and Skills (DfES) announced that all primary schoolchildren aged between 7 and 11 years of age would be entitled to learn a MFL by the year 2010 (Woodgate-Jones, 2005). In 2010, however, the scheme was scrapped before it could be properly implemented. This decision does not seem surprising if we look at some texts that researchers produced at the time. Enever (2009: 25), for example, states in her report on FL learning at English primary schools that the data she collected do not 'reflect a pattern of overwhelming enthusiasm' for the scheme, especially among boys. This complements the overall tone that Myles uses to describe her project with co-researcher Mitchell (Myles, 2012). According to the researchers, the data collected do not provide evidence for the effectiveness of MFL in primary schools. In fact, older learners outperformed younger learners of French when it came to acquiring grammatical structures and they used a wide range of cognitive strategies.

With so much controversy and uncertainty both in Germany and countries such as the UK, we can hardly perceive the case for primary FLT as clear-cut. Rather, it is an area that has seen unprecedented instability and change, so much so that the discussions about the usefulness of early FLT have distracted from the fact that we still know very little about what goes on in actual primary FL classrooms (Edelenbos, 
Johnstone \& Kubanek, 2006; Garton, Copland and Burns, 2011).

\subsection{The Purpose of this Study}

Recent studies such as the collections of articles on primary EFL practice in Europe edited by Nikolov (2009) and by Bland (2015), the ELLiE project (Enever, 2011a) and research on global practices in primary EFL by Carton, Copland and Burns (2011) have contributed to a better understanding of the the teaching of English to young learners, which is something that this $\mathrm{PhD}$ also strives to do.

At the beginning of this project, however, little was known about how teachers put guidelines into practice, how English lessons are taught in real-life classrooms, what children really learn and how lessons are experienced by those most closely involved, namely teachers and young learners:

There is still only little research in to what really goes on in classrooms, and what English classes are actually like. Many of the numerous publications on foreign language teaching that have appeared in recent years are based rather on practical teaching experience, or on views of how foreign language teaching should be than on empirical research findings.

(Roos, 2006: 220, my translation)

This study addresses this lack of knowledge by investigating actual classrooms and studying teachers and learners in a natural setting. I had to take the lack of empirical studies into account and did so by opting for an exploratory research design that started with open research questions that were also fairly general in nature. For example, it could not be determined if teachers followed recommendations and if and how often they made use of songs, stories, rhymes and chants in their primary EFL classrooms. Therefore, the following pair of general umbrella questions guided my research at the beginning, but were meant to be refined, as the project evolved:

1. How do primary teachers teach English to young learners in Rhineland-Palatinate?

2. How do learners respond to being taught English in these classrooms? 


\subsection{Outline of Chapters}

This thesis comprises two parts, of which the first is dedicated to a discussion of existing research on primary EFL practice in Germany and abroad (Chapter 2), the use of songs, stories, rhymes and chants in language teaching (Chapter 3) and methodology used in this study (Chapter 4).

The second part is devoted to the analysis of data collected. As part of the analysis, questionnaire, observational and interview data are presented (Chapters 5, 6 and 7). Relevant procedures are explained in detail and limitations of each research instrument are highlighted.

Findings from all of these different research instruments are discussed in Chapter 8. Overall, three issues lie at the heart of this research: the role of imitation, the importance of visualization for the language learning process, and the role of memorized language chunks for fluency in FL production. 


\section{PART ONE}

\section{Literature Review}

\section{Chapter 2}

\section{History and Current Trends of Primary FL Teaching Practice}

The following chapter gives an overview of the beginnings of primary-level FL teaching. In particular, I will focus on the implementation process of primary FLs in Germany and describe the current situation of EFL in the German Länder. This information will then be extended to include policies on primary FL teaching in other European countries. Results from recent studies on primary FL classrooms both in Germany and beyond will be analysed in order to identify aspects that can inform the analysis of data that I collected as part of my project.

\subsection{The Introduction of Primary FL Teaching in Germany}

The teaching of foreign languages to children as young as 6 or 7 years is not such a new idea, as Kubanek-German has pointed out, referring to historical accounts from the $16^{\text {th }}$ through to the $19^{\text {th }}$ centuries (Kubanek-German, 2001). Nevertheless, we should remember that FLT of that sort was mostly limited to children from the upper classes who concentrated on reading and usually also writing ancient languages. At the beginning of the $19^{\text {th }}$ century, for example, children who were supposed to attend a traditional grammar school in Germany, a humanistisches Gymnasium, normally started Latin lessons at the age of 6 or 7 in so-called Lateinschulen, but there was no Modern Foreign Language (MFL) teaching for all young children at school. There were, however, regional exceptions, such as a reformed grammar school in Frankfurt that, from the 1890s onwards, started to offer French as first FL to pupils as young as 9 (Kubanek-German, 2001). Then, there was English tuition at private Waldorf-Schulen that developed on the basis of Rudolph Steiner's ideas from 1919 onwards (Schmid-Schönbein, 2008). Yet first attempts to introduce MFLs on a large scale in the public sector in Germany only date back to the time after World War II. 


\subsubsection{Primary FL teaching in East and West Germany (1945-1990)}

Post-war Germany was divided, and until its reunification in 1990, education policies followed different pathways which were at the beginning greatly shaped by the different Allied Forces. In former East Germany, the GDR, allegiance to the Soviet Union meant that in terms of FLs, Russian was attributed highest priority. As early as the school year 1952/53, Russian was introduced as first FL in primary and secondary education (Huschner, 1997). Special classes were created, so-called $R$-Klassen, where Russian was taught from Year 3 onwards. Pupils who attended these classes took their Abitur, the German equivalent of A-levels, for Russian at the end of Year 10. These learners continued with their Russian language programme and took another exam after Year 12, the so-called Sprachkundigenabschluss (Huschner, 1997). It must be said that the number of these special classes was always intended to be limited, and attendance was reserved for high-performing and talented learners (Baske, 1979). For everybody else, FL learning started in Year 5 at the beginning of secondary school. There was no intention to extend FL tuition to include all primary schoolchildren.

In West Germany, on the other hand, ideas on early FL learning seem to have been influenced by the American FLES initiative, Foreign Languages in Elementary Schools, that had started at the beginning of the $20^{\text {th }}$ century in the US and gained momentum since (Beckmann, 2006). The interest in primary FL learning in West Germany was probably also spurred on by two international UNESCO conferences on the subject in Hamburg in 1962 and 1966 (Beckmann, 2006; Schmid-Schönbein, 2008). However, the federal structure of West Germany and the principle of Kulturhoheit der Länder according to which every federal state decides its own education policies has had an impact on the implementation process of primary MFL teaching. Different models of early FL programmes developed.

One of the pioneers of post-war FLT at primary school in West Germany was Gompf, who started to teach English to her Year 3 learners in a non-pressurized atmosphere without homework, tests or marks in the state of Hesse in 1966 (Gompf, 1971 and 2008). Another example of early FLT at primary level is a study involving twelve primary schools as well as ten secondary schools in Lower Saxony between 1970 and 1975 (Doyé and Lüttge, 1977). The researchers found that those learners who had started learning the FL at primary level outperformed learners who had only started EFL in Year 5 at the beginning of secondary school. 
In the 1970s, pilot studies on primary EFL were carried out in almost all federal states in Germany, with the exception of Rhineland-Palatinate and the Saarland (Gompf, 1975). It seems that in these early stages of primary EFL, the main purpose of teaching very young learners was seen in the long-term improvement of linguistic competence. It was hoped that by starting early, learners would later be able to master the FL better (Sauer, 1993).

\subsubsection{Primary FLT as part of the European initiative}

Still, it took about 30 years for the first federal states to introduce MFL teaching at primary school, and when MFLs finally did enter all primary classrooms in Germany, it was mainly due to an external stimulus.

The signing of the Maastricht Treaty in 1992 marked a new era for Europe. From 1993 onwards, when the Treaty came into force, European citizens were allowed to live and work in any country of the European Union. The knowledge of European languages became more important as a result. Proficient use of several languages spoken within the EU was quickly seen as essential by key EU agencies to ensure that all European citizens were able to participate fully in the democratic and social life of multilingual Europe. In fact, the White Paper on Education and Training published in 1995 already set the objective for Member States to take actions for proficiency in three languages (European Commission, 1995), and the Presidency Conclusions of the Barcelona European Council on 15-16 March 2002 stated that at least two FLs should be taught from a very early age (European Council, 2002). The responsibility to create conditions for the development of language competence lies with governments in Member States, which have been tasked with implementing

sets of measures to promote the acquisition of language skills by encouraging the use of foreign languages for the teaching of certain subjects, to facilitate lifelong language learning, and make linguistic diversification the priority in language education policies (Council of Europe, 2007: 35).

Hightened awareness that foreign language learning (FLL) is needed in a functioning European society in connection with the Maastricht Treaty and subsequent developments prepared the ground for intensified efforts to introduce early MFL teaching in Germany. Different pilot projects were carried out and 
different approaches to primary FLT experimented with in the 1990s.

In fact, Kubanek-German (2000), who looked at current trends in FL provision in primary schools across different federal states at the turn of the millennium, distinguished five different approaches ranging from the playful, but relatively systematic, which included the use of a child-oriented coursebook, as practised in Hesse and Hamburg at the time, to that which based MFL teaching on authentic materials and refrained from systematic progression, as exemplified by Bavaria. Alongside this variety of approaches, there were schemes that focused on different languages found in a multicultural society, for example in North Rhine-Westphalia with its richly diverse population, and Border Programmes in Saarland, Bavaria and Saxony that focused on the language of neighbouring countries, such as French, Czech and Polish (Kubanek-German, 2000).

What is striking about these projects before the nation-wide introduction of MFL teaching at primary schools is the diversity and disagreement on some of the central questions in MFL teaching. It is not only the question of progression and the use of a coursebook that was answered very differently; there were even different views on which language or languages should be learnt. However, there seemed to be one area of common ground, as Kubanek-German points out:

When the new primary programmes started in the early 90s, there was a marked unwillingness among teachers and curriculum planners to administer tests or describe progress in a systematic fashion. The principle of child-orientation (holistic approach, integrative approach, use of stories, avoidance of anxiety, fostering motivation and intercultural openness) seemed to exclude formal testing. (Kubanek-German, 2000: 65)

Primary MFL teaching in the 1990s emphasized the notion of a holistic learning experience in a non-pressurized atmosphere and of 'natural' language presented to children through authentic texts, such as stories, songs and games. Yet one could already detect changing attitudes, namely that the 'trend towards accountability seems to be growing' (Kubanek-German, 2000: 65).

A few years later, summative assessment had become part of FLT in primary schools in most federal states (Gompf, 2006). Once MFLs had been introduced in the primary curriculum all over Germany, formal assessment followed suit, which has been criticized by some founders of early FLT programmes. For example, Gompf and Helfrich (2005) have argued that graded assessment may have a negative 
impact on the amount of speech produced and practised by children as they may feel intimidated by the prospect of being assessed.

However, there are still some federal states today that refrain from the use of tests and use verbal comments and portfolios instead to document children's progress. Among these is also Rhineland-Palatinate where a pilot study on primary FLT was carried out in the early 1990s.

\subsubsection{The integrated FL programme (IFA) in Rhinleand-Palatinate}

Central to the researchers' pedagogical thinking was the notion of integration (Geibert, 1995; Helfrich, 1995). The FL, either French or English, was supposed to be integrated into many different subject areas, such as music, art, science, German or sports (PE). Class teachers were evidently thought able to meet this requirement of integrating the FL into as many subject areas as possible since they teach most of the primary syllabus and spend most of the time with the children. But the idea of integration did not stop there. French or English were to be integrated at different stages of the lessons and with different teaching methods, whether they be teacher-centred joint speaking or self-study activities. The FL was also seen to play its part within extra-curricular activities, such as school fêtes, field trips or assemblies. Integration also meant that all children attended the FL classes and that no children were excluded because of their weak performance in other subjects.

Other criteria that had to be followed by participating teachers during the project were the time frame of 90 minutes of teaching per week and no use of assessment or coursebook. Between 1990 and 1995, the pilot study was carried out in nine schools, comprising a total of 26 Year 3 and Year 4 groups. French was taught in three of these nine schools and English in the remaining six. Data were collected and analysed on the basis of questionnaires for teachers and parents, non-standardised talks with teachers, lesson observations as well as interviews with children (Geibert, 1995; Helfrich, 1995; Rück, 1995; Petillon, 1995). The results showed overwhelming support for the programme by all participants. This model of 'integrated foreign language teaching’ (or Integrierte Fremdsprachenarbeit, shortened IFA) was later used as a basis for the implementation of FLs at primary level in Rhineland-Palatinate.

In 1998, MFL provision started for children in Years 3 and 4 of primary school in Rhineland-Palatinate (Martin, 2006). However, between 2004 and 2005, 
when all primary schoolchildren started to receive FLT in Rhineland-Palatinate, some of the main aspects of the pilot study conducted by Geibert, Hegele, Helfrich, Rück and Petillon were changed. English or French was now taught from Year 1 instead of Year 3. Rhineland-Palatinate became one of the first federal states in Germany to provide FLT to 6 year-olds (i.e. Year 1). This may seem impressive, but one has to remember that the amount of teaching time was amended as well. Instead of 90 minutes per week as in the pilot study, teachers were now supposed to teach only 50 minutes (Ministerium für Bildung, Frauen und Jugend, 2004a). It is also important to note here that the introduction of FLs at primary level in Rhineland-Palatinate was first and foremost politically motivated. It was a promise put forward by the federal state's Prime Minister Kurt Beck from the SPD that appealed to many parents during the election campaign in 2001. Once the election was won, the implementation process began. The first university courses for future primary teachers were attended on a voluntary basis from the summer term in 2001 before they became compulsory for all students enrolled on primary teacher training programmes in 2002 (Martin, 2006). University courses first comprised 10 modules, but were soon reduced due to the 'sharp increase in student numbers' (Martin, 2006: 89). Since 2004, further training has also been offered to practising teachers by a scheme called PFIFF (Projekt Fort- und Weiterbildung im frühen

Fremdsprachenlernen) that consists of an intensive programme of 90 hours on FLT methodology (Ministerium für Bildung, Wissenschaft, Jugend und Kultur, 2009).

However, there was still a shortage of primary school teachers qualified to teach either French or English when primary-level FL was rolled out across all schools between 2004 and 2005. Schools dealt with this shortage in different ways. In some schools, all class teachers were asked to teach some English or French even if they had not yet been properly trained. Other schools put FLT only in the hands of qualified staff, who then taught the FL as specialist teachers in a 50-minute session once a week.

Federal states such as Baden-Wuerttemberg and North-Rhine Westphalia also developed FLT programmes, which seem more ambitious due to the fact that more time is allocated to MFL teaching from Year 1 onwards, namely two sessions of 45 minutes per week (Gompf, 2009). These two states, however, are also among those that favour summative assessment and that provide their teachers with a structured curriculum. The overall trend seems to be to ensure accountability, which often 
implies greater uniformity and a departure from other core values of progressive primary teaching, such as free choice of materials, new methods of documenting learning progress and a non-pressurized learning environment.

The tendency to support standardization is evident now in official materials produced in Rhineland-Palatinate. In a leaflet written for parents and published in February 2005, oral communication is clearly stated as central aspect of primary FLT, and writing and reading, although mentioned as well, seem to be of secondary importance:

Oral communication must be seen as a central aspect of foreign language teaching. However, reading and writing have been included in an extended curriculum due to the fact that children experience foreign languages through listening, speaking, reading and writing as a whole. Therefore, reading and writing are to be integrated appropriately in MFL tuition. (Ministerium für Bildung, Frauen und Jugend, 2005, my translation)

Yet, in a more comprehensive brochure published in November 2011, parents are presented with a precise list of learning objectives that not only incorporates the four skills but also introduces the notion of acquiring grammatical knowledge and its proper use:

At the end of primary school, children are supposed to be able to understand utterances in the foreign language, to name objects, to ask questions, to give answers, to converse with their communication partners, to read and write individual words and sentences etc. They will also gain insights into aspects of grammar and the correct use of grammatical structures. (Ministerium für Bildung, Wissenschaft, Jugend und Kultur, 2011: 12, my translation)

Such a list of learning objectives seems to be in line with the principles of standardization and accountability. Apart from that, however, parents might be reminded of their own experience with learning a FL at secondary school.

Cameron's critical remark comes to mind, namely that primary FL programmes all too often risk being nothing more than a 'watered-down' secondary syllabus, which presents 'children with just a few of the structures typically found early on at secondary level' (L. Cameron, 2001: xiii).

If we compare early ideas on FLT with the language of official guidelines 
today, we notice that there is a tension that seems to arise from a mismatch of original ideas on good primary FLT and expectations of what sort of outcomes these FLT programmes for young learners should and can yield. The question arises if data from learners and teachers would in fact confirm a rift between great expectations as set out in curricula and actual classroom practice.

\subsection{The Situation of Primary FLT in other European Countries}

As with Germany, growing interest in primary-level FL teaching in other European countries can also be traced back to the time after WW2. Apart from a pilot study in Sweden that focused on teaching English through the use of audiovisual material in the late 1950s, there were also projects on primary MFL teaching in the UK and France in the 1960s and 70s (Beckmann, 2006). However, pilot studies such as these did not always lead to the nationwide implementation of primary-level FLT as the example of the UK illustrates where the pilot project 'French from Eight' had started in selected primary schools in England and Wales in 1963 but was not extended to all primary schools in the country (Boyd, 2001).

Primary EFL most quickly developed in Sweden, Finland and Norway, which were first to make English or French compulsory subjects from Year 3 onwards in the 1970s (Beckmann, 2006). English also entered Hungarian primary school as a compulsory subject from Year 3 in 1978 (Beckmann, 2006). In most European countries, however, large-scale primary MFL is still a recent feature of the educational system and was implemented between the 1990s and 2010.

\subsubsection{Variation and trends}

According to the Eurydice report (2012) that provides an overview of FLT at school in 32 European countries, including all Member States at the time as well as Iceland, Liechtenstein, Norway, Croatia (which joined the EU in 2013) and Turkey, 78.2\% of primary schoolchildren were learning a FL in 2009/10. Germany’s efforts to implement primary FLT can therefore be seen as part of a European trend. However, there are great variations within Europe. For example, in Belgium, children in the German-speaking community start learning a FL as part of their pre-school education from the age of three, in Cyprus and in Malta at the age of five and in Luxembourg pupils start learning their first FL at the age of six and their second FL at the age of seven (Eurydice, 2012). At the same time, Dutch schoolchildren start 
learning their first FL at ten years of age and Irish as well as most British schoolchildren may only start learning their first MFL in secondary school, since MFL teaching is not compulsory at primary level (Eurydice, 2012). It must be noted that Welsh and Irish Gaelic are part of the primary curricula in Wales and Ireland respectively, but they are not commonly referred to as MFL. About one quarter of primary schools in England, Wales and Northern Ireland offered MFL teaching at the turn of the millenium, according to one survey (Boyd, 2001).

Of course, variations in primary FL provision can partly be explained by the fact that countries such as Belgium, Cyprus, Malta and Luxembourg are bilingual or multilingual societies. Governments of multilingual societies need to ensure that their citizens receive a minimum of language education in more than one official language, even if certain regions remain monolingual and individuals may not feel that they need to communicate in another official language in order to take an active part in social and public life. Furthermore, the status of a language also plays an important role. Citizens whose mother tongue is not spoken by many people outside their own country have a greater need to learn a FL that is widely spoken around the world, such as English. Not only has English become the language of science and commerce, it has also conquered other domains such as the arts, music and fashion. It is no surprise then that English is the FL most widely taught in all but 4 of the 34 European countries (Eurydice, 2012).

The Eurydice Report, Key Data on Teaching Languages at School 2012, reveals a few trends in primary EFL teaching in Europe. One that is relevant for primary FLT is that FL learners are becoming younger. Several countries have moved the starting age of FL tuition forward, with the most radical changes being introduced in Cyprus, Poland and the German-speaking part of Belgium, where learners start learning their first FL between three to five years earlier than in 2007.

\subsubsection{Problematic issues}

The Eurydice Report (2012) also highlights problematic issues in the provision of FLs at European schools. Although more primary schoolchildren learn FLs, the proportion of time allocated to teaching them is rather low in most countries. Only few countries or regions, namely German-speaking Belgium, Estonia, Greece, Luxembourg, Malta and Croatia, have regulations in place that ensure that $10 \%$ of teaching time or more is allocated to FL teaching in primary school. Luxembourg, 
where more than $40 \%$ of teaching time is dedicated to FLL, stands out. This, to some extent, reflects the situation in Germany where great variation can be found in terms of FL teaching time and where in some federal states, such as Rhineland-Palatinate, the time allocated to FL teaching is the equivalent of only one lesson per week (Ministerium für Bildung, Frauen und Jugend, 2004a).

Another problematic area is the lack of qualified staff. According to Eurydice, 'it seems that a lack of qualified staff is a matter of concern in primary education' (Eurydice, 2012: 85). For example, the report lists five countries where specialist or semi-specialist teachers take over FL provision although official recommendations state that FLs should be taught by generalist teachers, who teach all or almost all subjects of the curriculum (Eurydice, 2012). It is suggested that this is due to a lack of generalist teachers with appropriate FL competence or training. Likewise, generalist teachers sometimes have to cover for specialist teachers (Eurydice, 2012). It may well be that it is this perceived lack of qualified staff that leads to a situation where states in Europe either do not provide recommendations on the kind of qualification that primary FL teachers must bring to the classroom, or provide very flexible guidelines that allow schools more room for maneuver. Again, this is reminiscent of staff shortages as mentioned in connection with the implementation of primary-level FL teaching in Rineland-Palatinate in Germany (see Chapter 2.1, p.11).

Another problematic issue is a lack of exposure to the FL in connection with school life. According to students in almost all countries, teachers do not normally speak in the target language during lessons and fewer than one third of learners have taken part in extracurricular activities organised by their schools, such as 'projects with schools abroad' or 'excursions and field trips' (Eurydice, 2012). However, learners do seem to be exposed to English more often than to other FLs through different types of media, and this is especially the case in Bulgaria, Estonia, the Netherlands, Sweden and Flemish as well German-speaking Belgium (Eurydice, 2012). These data only refer to learners at the end of their secondary education, and thus the question arises if exposure inside and outside primary FL classrooms shows similar characteristics. Recent empirical studies on primary EFL practice can shed some light on this issue, and on other problematic aspects raised by the Eurydice Report. 


\subsection{Empirical Studies on Primary FL TeachingPractice}

With the Eurydice Report (2012) mainly focusing on policies and recommendations in connection with primary-level FL education, the picture that emerges is by no means complete. What is missing is data from actual primary FL classrooms as gathered through observation, questionnaires or interviews with learners and teachers. In that respect, empirical studies are of particular interest, such as research by Pienemann, Kessler and Roos (2006), or Engel, Groot-Wilken and Thürmann’s (2009) as well as Nikolov’s (2009) collections of reports on different research projects. More recent publications include the ELLiE book edited by Enever (2011a) and research undertaken by Garton, Copland and Burns on global practices in EFL teaching to young learners (2011).

\subsubsection{Timetabling and qualified staff}

With reference to time constraints, which have been identified as one critical issue (Eurydice, 2012), one can note that there is indeed some confirming evidence in other studies. Enever (2009), for example, reporting on data collected as part of the ELLiE project during 2006 and 2007 in England, refers to a time frame of 30-minute FL lessons once a week, 'supported by five to ten minute further inputs two or three times a week' (Enever, 2009: 25), which would suggest a weekly FL provision of 40 to 60 minutes. This is a time allocation at the lower end of the scale if compared to other European countries (Eurydice, 2012). The fact that children were asked to indicate if they would prefer more frequent FL lessons highlights that timetabling had been perceived as a potentially critical issue.

On the other hand, Harris and O’Leary (2009) report that the implementation of 1.5 hours of MFL provision each week in the final two years in Irish primary schools was also problematic. Over one third of teachers (37\%) did not manage to teach their class in French, German, Spanish or Italian for 90 minutes a week, and mostly opted for 60 minutes instead. Interestingly, it was more often permanent staff members who failed to provide the suggested 1.5 hours of FL tuition. Visiting teachers were more likely to reach the target time allocation. It seems that FLL competed with other subjects. Most often teachers named 'an overcrowded curriculum and timetabling problems' as reasons for not teaching the FL for 90 minutes each week (Harris and O’Leary, 2009: 6).

The fact that visiting teachers have to support staff members in order to meet 
the requirements for FL provision also indicates that staffing can be problematic in primary-level FL teaching. In fact, staffing problems at primary level are not a new phenomenon. The numbers that Nikolov (2000) provided for some Eastern European countries at the beginning of the new millennium were discouraging. In Hungary, for example, 64\% of primary EFL teachers were retrained Russian teachers. In the Czech Republic 76\% of teachers did not hold teaching qualifications for English. A lack of sufficiently trained primary EFL teachers is still mentioned in more recent studies. For example, Oostdam and van Toorenburg (2009) point out that the position of English in teacher training programmes in the Netherlands was weak at the time, with only $10 \%$ of the teacher training courses adhering to the suggested 'minimum variant of two modules of 40 hours each' and with the dicscontinuation of large-scale in-service training courses that had been organised shortly after the introduction of primary MFL in 1986 (Oostdam and van Toorenburg, 2009: 77). Their questionnaire data collected between 2001 and 2002 reveal that 38\% of 158 responding primary teachers had not received any formal training in teaching English.

Even more worryingly, in Ireland where 400 schools participated in the above-mentioned project on primary MFL, only 38\% of class teachers felt confident that they were able to teach a MFL at primary level, with more than two thirds of class teachers (68\%) reporting that their highest level of qualification in a MFL was their Leaving Certificate from school (Harris and O’Leary, 2009). Consequently, Harris and O’Leary (2009) regarded teacher training as the greatest challenge if MFL provision was to be introduced on a national scale in Ireland. Varying degrees of language competence in teachers were also found by the ELLiE team in their sample of seven classrooms from seven European countries. Primary-level teachers' competence in English ranged from B1 to C2, with most of the teachers falling below the C2 level that the authors, maybe a little too idealistically, regard as 'preferable' for reasons of fluency (Enever, 2011a).

Data that Garton, Copland and Burns (2011) collected on the basis of a survey among teachers from 144 countries, show that one third had not received pre-service training and about one quarter had not been given any in-service training. At the same time, $18 \%$ of teachers reported to be native speakers of English or to have 'native speaker competence', and 39\% regarded their level of English as 'advanced'. About one third reported to be at upper-intermediate or intermediate 
level, while almost one tenth of the total population of responding teachers saw themselves at pre-intermediate, elementary or even at beginner level (Garton, Copland and Burns, 2011). This means that in this global sample, almost half of the teachers did not meet the $\mathrm{C} 1$ benchmark. The $\mathrm{C} 2$ level, as recommended by the ELLiE team, was achieved by a minority of teachers only (Enever, 2011a).

\subsubsection{Exposure to FL inside and outside the classroom}

However, high levels of language competence do not seem to guarantee that teachers use the target language exclusively and ensure that learners receive the highest possible amount of exposure to the FL. While the only teacher who used the FL exclusively in the ELLiE sample had native-like competence in the FL, another teacher at C2 level only used the FL $40-60 \%$ of the time and was in that respect outperformed, if one can call it that, by two teachers at C1 level who spoke the FL between 70 and $90 \%$ of the lesson time during the second phase of the project (Tragant Mestres and Lundberg, 2011). On the other hand, teachers with lower levels of language competence tended to use the FL less according to the data collected by the ELLiE team. The two teachers who were reported to be at B1 or B2 decreased their use of the FL towards the end of the project, when they were reported to use the target language between 20 and $40 \%$ of the lesson time.

Low rates for the use of the target language in primary MFL classrooms, however, do not seem that unusual as Harris and O’Leary’s findings from Ireland suggest. More than one third of class teachers reported that they used the target language less than 50\% of their lesson time (Harris and O'Leary, 2009). On the basis of a Dutch sample, a similar picture emerges although direct comparison of data is problematic due to the fact that the researchers used different phrasing for question items and answer options in their survey. The majority of Dutch FL teachers (60.0\%) reported that they used 'mainly English' and more than one third of teachers (34.2\%) said they used 'mainly Dutch', with the remaining teachers stating that they either used ‘just English’ (4.5\%) or ‘just Dutch’(1.3\%) during lessons (Oostdam and van Toorenburg, 2009). In a global sample (Garton, Copland and Burns, 2011), considerably fewer teachers reported using ‘mostly English’ namely 39.8\%. Most teachers (51.4\%) used a mix of L1 and FL, but fewer teachers (8.8\%) reported using mainly their learners' L1 in the classroom.

All these data suggest that the 'ordinary' primary-level FL classroom tends to 
be an environment where learners are not likely to be exposed to the target language all of the time and quite often not even most of the time. Learners are most likely to be exposed to a mix of both languages during FL lessons, which is similar to the findings reported for secondary FL classrooms (Eurydice, 2012). This is important in so far as this means that the amount of exposure to the FL in the classroom will in many cases be considerably less than suggested by the time allocated to FLs according to curricular guidelines. Less exposure, however, means less input in the FL, which is likely to impact negatively on FLL.

In terms of exposure to the FL through extracurricular activities, the ELLiE team found 'some' use of projects such as teacher exchanges, pen-pal communication via post or email as well as visits from foreign students, but these initiatives do not seem to allow for systematic out-of-school FL exposure (Enever 2011b). It is interesting to note though that children do find access to the FL on their own outside school. On average more than half of the children (56\%) in the ELLiE project listened to the FL online and almost one quarter of them (24\%) used the internet to watch films or series in the FL (Enever, 2001b). These numbers hide great differences. While Swedish and Croatian children seemed to be exposed to the FL most, namely on average eight hours per week, children in England only came into contact with the FL for less than three hours every week (Muñoz and Lindgren, 2011). Swedish and Dutch children also seemed to use the FL on the internet more flexibly. They went online and used the FL for games, for communication on Facebook and on YouTube. In contrast, English children seemed to access websites but did not go online for playing games or listening to songs (Muñoz and Lindgren, 2011).

Varied out-of-school use of media did have an impact on children's performance in the FL according to the researchers. Not only were children found singing English pop songs and quoting lines from advertisements, the analyses also showed that

in the case of the listening task, watching movies in the FL (possibly subtitled) was the activity with the strongest explanatory power of the pupils listening skills, followed at a distance by listening to music in the FL, reading and playing games, in this order; speaking with someone did not have a significant impact on listening (Muñoz and Lindgren, 2011: 114).

Digital media, then, especially when used for watching films, listening to songs and 
playing games seems to hold a great potential for YLs’ progress in the FL. In fact, there is evidence from other empirical data that confirms that singing and playing games are favourite activities with children in primary EFL (Harris and O’Leary, 2009), and therefore it is not surprising that children spend time enjoying music, movies and games online if they are left to decide how to use the FL outside their classroom.

\subsubsection{Popular activities in primary FL classrooms}

In Harris and O’Leary’s study (2009), most teachers reported that their pupils seemed to enjoy activities such as 'wordgames', 'raps/songs', 'language awareness activities', 'action games/sports' and 'drama' in their primary MFL programme. Interestingly, however, these were not the activities that the teachers themselves used most frequently. In fact, these 'most enjoyable' activities only came in sixth, eighth, nineth, 11th and 16th place on teachers' 18-item list of most frequently used activities. At the same time, 'whole-class repetition of sentences/phrases', which was named as the most frequently used activity by teachers, was considered the activity least popular with children according to their teachers.

Confirming evidence is also provided by Roos (2006) who describes the learning environment of EFL classes in Year 3 groups in Rhineland-Palatinate in Germany. He also observed whole-class repetition as a common activity, and describes other activities such as storytelling, TPR activities, action songs, chants and games as 'particularly popular'. However, he does not explicitly identify a mismatch between teachers' agendas and pupils' favourite activities. Yet it is interesting to ask if and why teachers' choices of activities divert from their learners' preference, especially since recent research seems to suggest that learners do actually make progress in the FL by doing what they enjoy most (Muñoz and Lindgren, 2011).

The analysis of data from the global sample (Garton, Copland and Burns, 2011) also revealed whole-class repetition as the activity reported by most teachers to be used in every lesson or often (74.0\%). Games (69.9\%) and songs (66.9\%) ranked in fourth and fifth place after 'listening to tape-recorder/CD' and 'children reading out loud', but before 'filling gaps/blanks in exercises', 'role-play’ and 'grammar exercises', which suggests a preference for listening and reproducing language over exercises that involve spontaneous use of the FL or grammatical and 
metalinguistic knowledge. Storytelling, however, did not appear among the ten most frequently activities mentioned by teachers, although $42 \%$ of teachers reported using it every lesson or often. It seems that the proportion of teachers who used storytelling frequently was counterbalanced by the share of $17 \%$ of teachers who answered that they never or rarely used stories in the classroom.

All empirical studies reveal great variety in the way primary-level FL teaching is organised in terms of numbers of lessons, course materials and class sizes (Pienemann, Keßler and Roos, 2006; Engel, Groot-Wilken and Thürmann, 2009, Nikolov, 2009; Enever, 2011a; Garton, Copland and Burns, 2011). This diversity reflects the variation in national guidelines and recommendations for teachers as described in the Eurydice Report (2012). For example, whereas in some contexts course books are used and have to be used, in others, teachers use materials from different sources (Enever, 2011b; Garton, Copland and Burns, 2011). In terms of class sizes, one can note that in the ELLiE sample they were found to vary from 15 to 30 (Lopriore and Krikhaar, 2011).

\subsubsection{Learners' FL output}

Several empirical studies highlight that young children acquire mostly nouns and are very likely to use ready-made chunks of language. Roos (2006) studied the language of 16 primary schoolchildren from Rhineland-Palatinate at the end of their Year 4 and compared their performance in interviews with those of 11 learners from a bilingual primary school in Schleswig-Holstein as part of the MILES project (Multimodale Interaktive Lernmodule für Englischlehrkräfte und Sprachstudierende). He found that learners from Rhineland-Palatinate who had started learning English at the beginning of Year 3 and had been provided with 50-minute EFL tuition per week before the actual implementation of MFLs in all primary schools, mostly produced individual words, especially nouns. If they used multi-item sequences, these were usually formulaic phrases that had not been broken up yet so that individual parts could not be combined for new statements (Roos, 2006). The majority of these learners had reached Levels 1 and 2 of Pienemann's model of Spracherwerbsstufen that he had postulated on the basis of developmental features, such as the use of words and formulae at Level 1, and the use of possessive-s, plural-s, the morphemes -ing and -ed in verbs, subject-verb-object word order in statements and questions as well as negation in statements at Level 2 (Pienemann, 
1998). In contrast, the majority of learners from the bilingual programme had already reached Level 3 at the end of their first year of learning English, and Level 4 at the end of their third year (Roos, 2006). While this may be disappointing news with reference to the integrated FL programme (IFA) as practised in schools in Rhineland-Palatinate, it also highlights the importance of exposure to the FL. Learners on the bilingual programme had received more lessons in the FL. Their FL programme was supported by English-medium tuition in maths, science, RE, PE and music. All other subjects but German were conducted through the medium of English, which amounts to 70\% of all classroom time (Burmeister, 2006).

Data from the WiBe pilot project of primary MFL in Baden-Wuerttemberg also suggest that children first rely on reproducing individual words and chunks that are presented to them (Weskamp, 2009). In this project, FLL started in Year 1 and children received two FL lessons per week. Data were collected over the period of 4 years and reveal that children progressed from reproduction to more flexible use of the FL. They started to change language and to produce their own multi-item statements or questions (Weskamp, 2009). Weskamp concludes that although verbal interaction in the classroom was initially dominated by the teacher's language, learners' participation increased over time until teachers and learners conversed in a way that entailed spontaneous language use (Weskamp, 2009).

In the ELLiE sub-sample of six learners from each participating class, learners too demonstrated a predominant use of single nouns in individual interviews conducted twice, once in year 1 and once in year 2 of the study. Learners also used stretches of speech, which were 'mostly represented by fixed phrases' (Enever, 2011b). Although learners still produced more nouns in the second interview, the numbers of adjectives, verbs and phrases were more than twice as high than in the previous year (Enever, 2011b). This suggests that learners were beginning to develop a more varied lexical repertoire. It is noteworthy that 'learners with more out-of-school exposure to FL tend to produce more words and phrases than learners with less out-of-school exposure' (Enever, 2011b). Listening scores were also higher in contexts where English was used widely in social life (Enever, 2011b). High listening scores, however, were found to be linked to high performance in reading and lexical diversity as well (Szpotowicz and Lindgren, 2011). Those learners who learnt English as a FL in an environment where most of the population spoke a Germanic language as L1 but could converse in English at a basic level and where 
cinema and television (including children's programmes for children aged 3 years and above) were undubbed, reached highest competence in the FL (Szpotowicz and Lindgren, 2011). They were able to 'produce longer and more complex responses and questions' than other learners in the ELLiE sample (Szpotowicz and Lindgren, 2011: 138). While this uncovers that primary FLL holds great potential if supported by out-of-school exposure to the FL and by the use of authentic audiovisual material, such as children's TV programmes and films, it also highlights the limitations of primary FL programmes that take place in a setting that only offers minimal exposure to the FL.

\subsection{Concluding Remarks}

The overview of implementation processes of primary-level FL in Germany as well as in other European countries, and the review of empirical data have shown the diverse nature of FL programmes at primary school. Great variation could be detected in aspects such as age of learners at the start of FLL, class sizes, the frequency and number of weekly FL provision, recommendations on teachers' degree of specialization in the subject and on the use of course books.

At the same time, a number of problematic issues of primary FL schemes have been reported on repeatedly. First, the time allocated to FLL in primary curricula tends to be minimal and timetabling can be an issue where the FL has to compete with other subjects. Second, pre-service and in-service teacher training is not always easily available, which creates staff shortages. Third, learners do not normally experience exclusive use of the FL in their classrooms.

In terms of linguistic development, research evidence suggests that learners favour activities that involve a playful use of language, such as playing games, singing, chanting or storytelling, which, however, may not be among the activities that teachers use most often. Moreover, YLs’ progress in English seems to involve the reproduction of individual lexical items, especially nouns and fixed phrases before learners develop more varied lexical repertoires and produce genuine utterances. Learners tend to thrive on self-directed out-of-school encounters with the FL, which mostly involve media such as television and internet.

This raises questions for the data collected in primary EFL classrooms in this project. For example, can similar timetabling and staffing issues be identified? In how far is exposure to the FL limited by teachers' use of German? Which skills do 
teachers focus on in their teaching, and which exercises do they use frequently? Do learners in this project demonstrate a similar preference for singing, storytelling, or chants and less enthusiasm for whole-class repetition of chunks of language? What is the nature of learners' FL output and are there any traces of out-of-school exposure to English in learners' use of English? 


\section{Chapter 3}

\section{Songs, Chants, Rhymes and Stories in Primary FL Teaching}

Recent empirical studies on primary FL teaching practice have shown that songs, in particular, are very popular among young learners of English. Learners not only seem to enjoy singing in the classroom (Roos, 2006; Harris and O’Leary, 2009; Garton, Copland and Burns, 2011), they also make use of digital media to listen to songs in their free time (Muñoz and Lindgren, 2011). There is also some indication that storytelling is popular in the classroom (Roos, 2006), and as with songs, young FL learners in some countries spend time outside school with narratives in the form of watching films (Muñoz and Lindgren, 2011). It seems there is less evidence for the popularity of chant and rhyme, but this may simply be due to the fact that questionnaires in empirical studies did not include these genres. However, with chant and rhyme being related to song and regular features of stories, there are at least some grounds for assuming a similar degree of popularity among young FL learners.

The fact that especially listening skills were found to be positively influenced by children's out-of-school encounters with narrative and song (Muñoz and Lindgren, 2011) highlights the potential of these genres for FL learning. It is no surprise then that these genres are mentioned as part of good practice in primary FL classrooms (Edelenbos, Johnstone and Kubanek, 2006). At the same time, teachers do not always use these genres as frequently in their classrooms as their popularity would suggest that they should do (Harris and O’Leary, 2009; Garton, Copland and Burns, 2011), which may indicate that teachers feel uncertain if and how songs, chants, rhymes and stories should be used in primary FL classrooms.

This chapter is devoted to a literature review on the use of these genres in L2 learning. I will refer to contradicting views on the use of literature in EFL classrooms and analyse in how far musical and literary texts can contribute to both general cognitive and emotional development as well as linguistic competence in the FL. I will explore arguments that refer to general FL learning before focusing on primary-level FLL in particular. In the second part of this chapter, empirical research on the use of musical and literary texts in primary EFL classrooms will be discussed. 


\subsection{Theoretical Positions}

Song, chant, rhyme and story may be different genres of texts, but they all share at least one characteristic, and that is their aesthetic quality. Unlike other text genres, such as newspaper articles, academic writing, or commercials that serve their assigned purposes, musical and literary texts defy (purely) utilitarian functions. They are artistic texts and as such they may entertain, enchant, inspire, calm, stir or provoke, educate or enlighten their audience but they are not defined by their functionality. Through their versatile, non-conformist, playful nature, works of art engage their audience and they do so on more than a purely cognitive level. They address us as a whole person with our memories, fears, dreams, values, and sense of beauty.

Literary texts have always had a place in traditional FL learning. Individual scholars who learnt Latin or Ancient Greek, and later MFLs, studied texts of politicians, philosophers, playwrights and poets. The teaching of Latin and Ancient Greek in school also centred on texts of classical thinkers and included literature. Since the learning of Latin and Ancient Greek was part of an upper-class upbringing, the study of literature as part of FL learning has become associated with an elite education. With the introduction of MFLs in German secondary education at the end of the $19^{\text {th }}$ century, however, the Grammar-Translation Method was used and 'exemplificatory sentences' introduced instead of the traditional literary texts in order to make the learning of MFLs manageable in a school setting (Howatt and Widdowson, 2004). Subsequently, the Reform Movement criticised the special status that was attributed to the individual sentence stripped of its wider context and no longer embedded in discourse as part of the Grammar-Translation Method (Howatt and Widdowson, 2004). In fact, Wilhelm Viëtor, a German Realschulgymnasium teacher, who first published his critique of the traditional FL classroom Der Sprachunterricht muss umkehren / Language Teaching Must Change in 1882, suggested that language should be studied on the basis of whole texts, 'zusammenhängender Lektüre' as he called it (Viëtor, 1905: 30). Yet the importance placed on the spoken word and on developing listening as well speaking skills as part of the Direct Method developed by the Reform Movement also meant that less time was available for the reading of texts, and also of literary texts of any sort.

It is the Reform Movement's pragmatic view of language teaching (that is focusing on what is needed for communication) that, to some extent, prepared the 
ground for educationalists who question the usefulness of literature in FL classrooms. Our modern FL classroom today is not that much different to the FL classroom that the Reform Movement envisaged. The Audiolingual Method, Communicative Language Teaching (CLT), the Natural Approach or Task-Based Learning are all founded on key principles of the Direct Method, which emphasizes the use of the target language, a focus on spoken communication that regards the mastery of pronunciation as important, and presenting language in context, in a meaningful way so to say (Viëtor, 1905). These principles are closely linked to the observation of what FL learners need to be able to do in face-to-face communication with native speakers. The main focus is no longer on developing learners' ability to read literary texts in the FL. In that respect, it is not surprising that some educationalists, such as Edmondson (1997), have voiced some doubt about the 'special status' of literary texts in FL programmes.

Edmondson (1997) argues that 'it is certainly not essential to handle literature in the interests of developing adequate L2 proficiency' and that literary texts are not superior to other types of text (Edmondson, 1997: 45). Within this line of argumentation, literature, if used at all, should complement other material used in the FL classroom. The idea that a variety of texts should be used in the FL classroom, not only literary texts, is a notion that is not necessarily disputed by supporters of literature in language education. Texts, other than literary texts, can also engage learners and support their personal development. Bredella (1996) acknowledges that 'aesthetic reading is not limited to literary texts, but that literary texts are organized in such a way that the reader will greatly profit from reading them aesthetically' (Bredella, 1996: 1). Criticism about literature in FL programmes not only stems from scepticism about the value of literature in the FL learning process, but also from the observation that learners do not always experience the study of literary texts as motivating within an FL setting (Edmondson, 1997). Literature does not always seem to be handled successfully in FLT.

Hall (2005 and 2015), who provides a comprehensive overview of literary texts in education, suspects that literature is sometimes used 'in ways that fail to coordinate the literary and the linguistic' (G. Hall, 2005: 47). While the teaching of literature in tertiary FL programmes seems to overemphasize 'literariness' and neglect linguistic aspects of literary texts, the use of literature as part of a communicative curriculum at lower secondary level tends to focus on linguistic 
aspects but to avoid the engagement with literary features (Hall, 2005). Apart from that, both of the above approaches to literature all too often fail to address the impact that a literary text, or any piece of art, has on the individual.

Teaching often focuses on 'efferent reading' of a text when it should also allow for 'aesthetic reading' (Rosenblatt, 1978). Learners should not only talk about the text, they should also be given the opportunity to interact with it in order to make sense of the emotions and thoughts that it triggers in them. This notion of 'aesthetic reading' became central to Reader Response Theory, also associated with Iser(1978) and Holland (1968), for example. Reader Response Theory developed in opposition to 'historical readings' of the New Criticism in the 1950s and 60s. Learners were asked to blank out their own reactions to and impressions of the text, since these were seen to interfere with an objective analysis of the literary work. However, 'aesthetic reading' does not exclude thoughtful consideration. On the contrary, 'aesthetic experience contains a reflective element' (Bredella, 1996: 3). We become aware of a literary text having an impact on us and we attend to the thoughts and associations that the text evoked in us. Although Reader Response Theory has had an influence on educational practice, there is still a strong focus on 'efferent reading' in classrooms that is manifest in comprehension checks, for example, and seems to be partly caused by a wash-back effect of exam practice.

As Paran (2010) has highlighted in his reflections on the dilemmas of testing language and literature, there is a discrepancy between the nature and purpose of assessment that serves 'external goals', such as access to higher education, and the teaching of literature that aims at 'internal goals', such as fostering personal growth. Traditional assessment needs to be reconsidered in order to address the tension caused by an imbalance between the 'values of teaching' and the 'values of testing' (Paran, 2010). Notably, potential problems with the teaching of literature as part of FL programmes most often seem to be linked to organisational aspects that can be changed and improved through adequate curriculum design as well as appropriate teacher training so that learners actually do enjoy the study of literary texts.

\subsubsection{General cognitive and emotional development}

With reference to some modern FL programmes that refrain from incorporating literature in their curriculum in order to concentrate on the transfer of knowledge 
and skills relevant to learners' future career, one has to admit that if our learners study a FL in order to use it at work, in an office or shop, for example, then they will need to be prepared to handle language normally used in these contexts, of course. However, if we designed our FL programmes to include only materials and activities that cover our FL learners' future work life, we would reduce our teaching to being a vehicle for the development of professional skills alone. This kind of teaching reduces learners to their future role as working citizens when they are more than that. They are human beings, who, by learning a FL not only acquire new language skills, but also continue to learn about life and grow as personalities through the materials and activities we offer as well as the challenges we set them. This is true for learners of all ages but it is an even more compelling argument in the discussion on FL teaching at primary or secondary school where learners are younger and spend a larger proportion of their life time in a FL classroom.

Paran (2008), who discusses the divide on the question of literature in FLT among educationalists, points out that language learning 'is not only about language - it is about learning as well; it is not only about training, but also about education' (Paran, 2008: 468). In this way, the decision to incorporate literature or other artistic texts that address the learner as a whole person reflects a holistic and humanistic approach to teaching. Within the tradition of humanistic teaching, learning involves the whole person, mind as well as body (Rinvolucri, 1999), and learning not only utilizes the left hemisphere of the brain that is associated with logical thinking, but also the right hemisphere that is linked to intuition as well as creativity (Rogers, 1983). Language, as produced by the learner in humanistic exercises, stems from a personal or group experience so that 'students speak to the teacher because they have something to express, something that has welled up from their emotions' (Rinvolucri, 1999: 199). FL learners, then, make genuine use of the FL as they also discover something new about themselves or others, while teachers may find it easier to respond in a genuine way (Rinvolucri, 1999). Literary texts, including song, can, in a similar way, create personal as well as group experiences and lend themselves to humanistic teaching practices.

In particular, it is the opportunity to enter a world that is different from our own, and to live through the high and low points of the literary figures that makes the engagement with a text a very personal matter. Literature allows us to experience an 'alternative world' (G. Cook, 2000). According to Paran and Watts(2003), 
literature addresses two human needs:

[...] firstly, the need to tell stories, to express through creative means our thoughts about the world around us and ways of interpreting experience; secondly the need to hear stories, to experience what Auden has called 'secondary worlds', through which we interpret our primary world. (Paran and Watts, 2003: 4)

In this way, literature not only offers opportunities for understanding the world we live in, it is also a means for human beings to express themselves. It includes both receptive as well as productive dimensions of language use. Thus, literature provides ample opportunity to learn more about our inner life and to grow as human beings, or, as Wright (2003) has put it: 'in using stories in language teaching we are using something bigger and more important than language teaching itself' (Wright, 2003: 7).

And yet this positive view of literature in language education should not prevent us from acknowledging that literature has also been used and abused in language classrooms for the assertion of political power in the past. Hall (2005 and 2015) reminds us that the teaching of literature in English language classrooms during colonial times is associated with suppression and the assumption that the cultural achievements of one community, that of the ruling colonial power, are superior to others, the colonized communities. This aspect is, to some extent, still of relevance today when English-speaking countries dominate world politics, and needs to be considered in the discussion of literary texts in EFL classrooms in order to raise awareness among teachers about the vulnerability of literature for the misuse in political conflicts.

Of course the example of literature in English language education in former British colonies highlights another aspect as well. Culture is conveyed through literature, and so is language. Therefore, the teaching of language always entails the teaching of culture, which includes the teaching of literature. It has been noted that language and culture are inseparable (Byram, 1989), and it has also been pointed out that culture can be 'viewed as a set of stories we tell about our selves and others in search of understanding and fulfilment' (G. Hall, 2005: 67). In fact, literature in education is often regarded and treated as part of cultural studies nowadays (G. Hall, 2005). On the other hand, literature is often perceived as a means to come to terms with one's cultural identities that are shaped by the experience of learning another 
language and living in another culture (Kramsch, 1993). Within this understanding of language learning, the individual has multiple cultural identities and lives in a society that is made up of people with different multiple identities. Literature in a language classroom, then, provides a platform for discussions. Different cultural backgrounds make for different readings of the same text. These can be shared and reflected upon so that learners reach a deeper understanding and appreciation of their cultural identities without having to deny their diverse cultural heritage. In this way, literature offers a pathway to language learning that goes beyond the acquisition of linguistic skills or cultural knowledge, but aims at intercultural understanding as part of peace education (Ghosn, 2004). It is, thus, of utmost relevance to multicultural primary EFL classrooms as well, even if the texts that children are reading or listening to are much simpler.

With respect to literature in primary EFL, Garvie (1991) has postulated that 'story in its widest sense' offers 'meaning potential without which the learning of language is rigid' and is the 'carrier of life's messages' (Garvie, 1991: 56). This argument highlights the fact that has been made by supporters of CLT, namely that language use in the FL classroom needs to be embedded in meaningful, or authentic, discourse (Brumfit and Johnson, 1979). The language that learners use while they are learning needs to refer to something 'real' that learners and teachers want to talk about. It needs to refer to information, thoughts and feelings that they want to share and get across, without which language use in the FL classroom can be assumed to be shallow, verging on the meaningless.

It has been stressed that 'stories offer a whole imaginary world, created by language, that children can enter and enjoy’ (L. Cameron, 2001: 159). Stories not only create their own alternative reality, they also create a link to the outer world, life outside the classroom (L. Cameron, 2001). This provides opportunities to speak about real life problems, which helps young children to understand the world around them. At the same time, teachers should not indulge in an uncritical attitude towards stories and overestimate the impact that stories have in today's multimodal world. Children may equally be drawn to other text types that use text and visuals creatively (L. Cameron, 2001). Moreover, not all stories used in language classrooms are 'poetic, meaningful stories that will instantly capture children’s imagination’ (L. Cameron, 2001: 160). Therefore, teachers have to select literary texts carefully, and design storytelling sessions and accompanying activities well to allow for a holistic 
learning experience.

Ghosn (2004), who argues the case for incorporating fiction written for children in primary EFL teaching, highlights several areas of personal growth through literature. One aspect is the development of 'academic literacy' and 'thinking skills' that can pave the way for English-medium instruction, for example, at a later stage. Through talking about literature, children can be introduced to analysing texts, e.g. 'looking for main points and supporting details; comparing and contrasting; looking for cause-effect relationships; evaluating evidence’ (Ghosn, 2004: 60). In this way, literature in primary EFL can encourage the development of abstract thinking skills that students will need to rely on in secondary school whether they go on to attend bilingual classes or not.

Apart from that, literature can also 'contribute to the emotional development of the child' (Ghosn, 2004: 57). Through engaging in stories, for example, the child is presented with aspects that are part of human life, such as friendship, solidarity and kindness, but also illness, loss and feelings of loneliness (Ghosn, 2004). If the child identifies with the literary figures, the problems that they face become his or hers, and through the actions that the literary figures take to solve a conflict, the child lives through and learns from this experience. The fostering of empathy is central in that respect, which is also the case for an understanding of 'otherness' that literary texts help to address and raise awareness of (Lütge, 2013).

The fantasy worlds of literature that children enter when they listen and read stories, for example, challenge the concepts of 'self' and 'other', thus 'providing an enormous educational potential' (Lütge, 2013: 97). The 'otherness' found in literary texts confronts children with stereotypes that they might have. In identifying with the literary figures, learners may be led by the teacher to question these preconceptions. Lütge (2013), referring to Almond’s Skellig (2009) and Rowling’s Harry Potter series published from 1997, identifies 'superhuman, 'magic', 'evil', 'nonhuman', 'exotic' and 'cultural' otherness that children are introduced to. However, the list could be extended for primary EFL classrooms to include otherness in physical appearance, for instance, as is addressed in books for a younger audience, such as McKee’s Elmer (1968), a story about an elephant in patchwork-coloured style who has to come to terms with his different, out-of-place appearance, and Cave and Riddell's Winner of UNESCO Prize Something Else (1994) that tells the story of a blue-grey furry creature that is excluded from play 
until he gets to know another strange-looking creature that confronts him with his own stereotypes of otherness. The encounter with literary figures that feel uncertain about where they belong acts as a metaphor to real-life encounters with otherness that can be talked about in classrooms in order to encourage children to respond with openness and tolerance to otherness in their environment.

Mourão (2012) provides some suggestions as to how artistic texts, such as rhyme, song and picture book, alongside action games, can help very young children develop their 'emotional intelligence’ (Salovey and Mayer, 1990; Goleman, 1995), which includes a range of competencies, such as 'empathy, intuition, creativity, flexibility, resilience, stress management, coping, leadership, integrity, intra-personal and interpersonal skills’ (Mourão, 2012: 8). With emotional intelligence involving so many personality traits, it cannot be attended to appropriately within one particular lesson once or twice a week. Rather, it has to be worked on continually across different subject areas, including MFL learning (Mourão, 2012). For example, the singing of a song in the FL or the reading of a picture book can teach children how to show and handle emotions (Mourão, 2012).

More recently, two other aspects of personal development have been associated with the teaching of literature, namely the teaching of 'visual' as well as 'literary literacy’ (Bland, 2013a; Burwitz-Melzer, 2013). In a digital world where information is not only transported through the use of language but also increasingly through the use of images in the form of pictures as well as video, children need to be enabled to understand multiple modes of communication. What seems to be needed is a 'pedagogy of multiliteracies' (New London Group, 1996), which has to be practised in teacher training as well as in primary and secondary schools (Burwitz-Melzer, 2013). The teaching of literature in EFL should therefore include 'visual art forms', or multimodal literary texts, such as picture books, comics, graphic novels or films (Burwitz-Melzer, 2013). The reading of multimodal literary texts is seen as a contribution to the promotion of literary literacy, which entails much more than the teaching of reading 'as a merely informative skill' (Burwitz-Melzer, 2013: 56). Literary literacy involves a deep appreciation for the relevance of literature in our daily lives. Through the teaching of literary literacy, then, our learners become lifelong readers in their first as well as their second language, something that is easily threatened by a focus on 'everyday and business-related communication' as well as ‘out-put oriented' approaches that 
dominate European and national guidelines (Burwitz-Melzer, 2013: 55).

Bland (2013a and 2013b) has argued that it is especially 'open, ambiguous literary texts' (2013a: 32), such as postmodern picture books, that lend themselves to the teaching of multiliteracy in an EFL classroom. According to Bland (2013a), it is the 'juxtapositions of meanings created through pictures, words, layout and gaps' that encourage learners to search for meaning (Bland, 2013a: 32). Because the picture book can only be fully understood if both, pictures and verbal text, are read, children learn to make sense of images and relate them to the verbal text that accompanies them. They are challenged to look for meaning, make assumptions and formulate hypotheses (Bland, 2013a). They will, therefore, develop visual literacy alongside literary literacy.

All of the above mentioned considerations for the use of literary texts, and stories in particular, support a humanistic line of argumentation. However, it has been stressed that a decision to use literature that is based on purely non-linguistic aspects cannot sufficiently justify the use of literature in the FL classroom. After all, for literature to be a valuable contribution to a FL programme, it has to serve its objective, namely to teach and foster language learning. One might also suspect that a humanistic approach to literature in the FL classroom may hastily focus on 'content and response' with 'insufficient attention' to the language of the literary text that affected the reader and produced the response in the first place (G. Hall, 2005: 57). Therefore, the question cannot be avoided as to what exactly, in terms of linguistic competence, literary texts, including songs, can bring to the endeavour of second or FL learning.

\subsubsection{Linguistic development}

One argument that has already transpired in the discussion of humanistic approaches to language teaching is the issue of meaningful communication. Literature in language classrooms, if handled adequately, can provide young learners with genuine language in meaningful contexts (Garvie, 1991; L. Cameron, 2001; Ghosn, 2004). This, of course, is in line with preconditions for FL learning as suggested by CLT theory (Brumfit and Johnson, 1979) as well as the concept of 'comprehensible input' formulated and further developed by Krashen since the 1970s (Krashen, 1977, 1981 and 2003). The latter states that we acquire language when we are presented with language that we can just about decode with the focus being on understanding 
the message it contains rather than the language itself. This argumentation for language acquisition draws on situations where the learner is confronted with the FL as in natural spoken communication as well as in reading for pleasure. The voluntary engagement with literary texts creates opportunities for the learner to receive comprehensible input.

Since literary texts address us as a whole person and may touch and move us, they can also fill learners with the desire to express their thoughts and feelings triggered by the text, and in sharing their ideas and trying to make themselves understood, learners are challenged to use the FL for genuine statements. In doing so, they may encounter difficulties in expressing themselves and may be forced to rephrase their verbal contributions. According to the 'output hypothesis' (Swain and Lapkin, 1995), this should foster productive FL use and be beneficial for FL proficiency. Apart from these very general assumptions about the positive influence of literature on progress in the FL, the question arises as to how different genres of literary texts can contribute to the development of specific language skills.

It seems sensible to get to terms with the nature of these genres, to identify their characteristics in order to understand in which ways these texts can facilitate language acquisition. In the following, I will first look at song, chant and rhyme, since they share a number of features, and then turn my attention to stories.

\subsubsection{Song, rhyme and chant}

Song, rhyme and chant are all genres of poetry, whose most striking feature is its inherent rhythm, which makes it a relative of music. Song is regarded the most simple form of poetry that can be sung (von Wilpert, 1989). In fact, most early poetry seems to have been songs ranging from Chinese folk songs from about 1500 BC to Egyptian hymns and Hebrew songs (von Wilpert, 1989). Chants are often performed by more than one speaker, which emphasizes rhythmical patterns and makes them appear musical. Chants have had their place in traditional as well as modern drama (van Wilpert, 1989). Rhyme refers to both, a feature of poetry, namely the 'sameness of sound between words or syllables' as defined in theOxford Advanced Learner's Dictionary (1989), as well as a genre that exhibits this feature. It is this sound correspondence that creates a musical impression. Rhyme, which seems to have occurred in Europe between 3rd to 5th century AD, was first used in beginning syllables before it also appeared in end syllables (Arndt, 1989). It is the 
latter that has become a characteristic feature of song lyrics and nursery rhyme, and it is also used in some chants.

Rather than a stream of continuous speech as in prose, lyrical texts are bound by the restrictions of the length of a line, or a verse. However, the written form of a verse is a purely external feature. The true nature of verse is uncovered through its sound patterns (Arndt, 1989). Lyrical poetry, in this view, is a musical piece of art that reveals its beauty through the act of performance (Arndt, 1989). In the English language, the musical dimension of poetry is rooted in the patterns of stressed and unstressed syllables that evoke a sense of rhythm; whereas in Ancient Greek, for example, patterns of shorter and longer syllables were used (G. Cook, 2000). Unlike prose, verse is ruled by a rhythmic pattern, the metre, that provides a certain type of frame for the language to be used (Arndt, 1989). This brings with it highly condensed language that is used to express the speaker's feelings and inner thoughts without any objectification as can be found in narrative or dramatic texts (von Wilpert, 1989). Its immediacy of expression makes lyrical poetry appear to be the prototype of all literature (von Wilpert, 1989).

Indeed, the first European narratives in Ancient Greek were written up in verse, such as Homer's Iliad and Odyssey around 700 BC (von Wilpert, 1989). Until the High Middle Ages it was regarded obligatory to write up sophisticated literary texts in verse (Arndt, 1989). In a German context, for example, it was only from the 15th century onwards, that lyrical narratives were begun to be rewritten in prose, and it took another century for the first novels to be written (Arndt, 1989). Verse seemed to dominate both dramatic and narrative literary texts at a time when literature was mainly passed on orally. The oral tradition of literature requires accurate recall of extended samples of speech. The nature of verse with its rhythmic language, on the other hand, provides a support frame for recitation from memory. It has therefore been suggested that 'verse is a remnant of a mnemonic device, now partly superseded by literacy’ (G. Cook, 2000: 27). In this sense, verse supports the recall of stretches of speech that would otherwise more easily be lost, which is relevant for language learning.

It has also been argued that verse, in nursery rhymes for example, can foster L1 learning in various ways. Even if young children do not understand verses that their caregivers recite for them, such as nursery rhymes, they are introduced to 'instances of paralanguage', such as rhythm, intonation as well as 'interpersonal 
interaction as expressed by eye contact, facial expression, and touch’ (G. Cook, 2000: 14). Importantly, rhythmic breaks in some verses 'not only coincide with linguistic boundaries' but also emphasize them to a much higher degree than in everyday speech drawing the child's attention to linguistic aspects of the rhymes that at the beginning may be no more than 'rhythm and intonation, without a semantic meaning' (G. Cook, 2000: 15). In this way, rhythmic language in verse, sometimes accompanied by repeated actions, aids comprehension. With every encounter, the rhyme will slowly transform into language and can be understood. Moreover, the 'regularity and predictability of the verse' also seems to provide a support structure for the memory that has to deal with unfamiliar language and meanings (G. Cook, 2000: 27). Thus, children may be able to recite verses by heart mastering pronunciation perfectly before they also fully understand the meaning behind the sounds.

This is of relevance in so far as native speakers as well as learners of a second language have been found to focus on prosodic and phonetic features at the beginning stages of the language learning process. Cooing as well as babbling, also called 'vocal play', precede talking in the L1 and facilitate L1 acquisition through the practice of motor skills necessary to produce speech sounds typical to the child's L1. Young native speakers have mastered the basics of pronunciation in their first language by the age of three (Crystal, 2005), long before most word learning occurs, which is during the years they spent at school (Bloom, 2002), or before they master word order and tenses (Lightbown and Spada, 2006). Ellis (1996), for example, has postulated that 'at the early stages of learning words, it is their phonological structure that is salient' (Ellis, 1996: 93). This assumption is based on research undertaken by Entwisle (1966), who analysed word associations among participants of different age groups and found that 'clang associates', words evoked by their similarity in sound to another word, were most frequently given by first-grade children. Other researchers have pointed out that Anglo-American white middle-class children 'first utilize prosody to signal different social identities and roles' before they make use of other linguistic elements (Schieffelin and Ochs, 1986: 177) .

If prosodic features take such a leading role in L1 development, one might ask if this could also be the starting point for L2 learning, and if that was the case, then song, chants and rhymes, which seem to highlight prosodic features in speech, 
may have to be regarded as a worthwhile contribution to the L2 learning process. In fact, results obtained in L2 research support this assumption. Henning (1973), for example, found that beginners' mistakes in a vocabulary recognition task were mainly attributed to acoustic clustering whereas more advanced learners or native speakers tended to make mistakes that indicated semantic clustering. Beginners seem to be attracted by prosodic features of the L2 and they seem busy trying to come to terms with these phonological qualities of language. Ellis (1996) has suggested that 'in both the L1 and L2, lexical items are first represented as ordered phonological strings' (Ellis, 1996: 94). Beginners' inclination to attend to acoustic cues needs to be addressed in instructed language learning. They can be expected to benefit from teaching that encourages them to imitate and play with the sounds of the FL.

It is not surprising then that song and rhyme have been recommended as mnemonic learning devices in FL learning (Boers and Lindstromberg, 2008). However, it has to be noted that these suggestions have mainly addressed the cognitive element in language learning, namely the correct recall of language items. However, as I have argued, literary genres, such as song, chant and rhyme cannot be reduced to their 'usefulness'. It is precisely their aesthetic qualities, their musical nature that appeals to learners and that affords instances of joyful repetition of language that reconcile what has often been conceived as opposing sides, namely cognitive versus emotional aspects of learning. One could argue that in the same way as rhythmic language in song, chant and rhyme, appeals to young L1 learners and aids their language acquisition, it can also engage and support young FL learners. It is noteworthy that verses in the form of songs, chants and rhymes have to be performed and that this experience is normally part of the intimate and affectionate interaction between caregiver and child. This fuels the child's continued interest in repeated encounters with the verse, which supports retrieval and recall of language. It is the highly emotional aspect of the passing down of verses from one generation to the next that, according to Hunt (2001), has ensured the survival of nursery rhymes over many centuries.

While song, chant and rhyme share the feature of rhythmic language, the degree of their musical character varies. Rhyme makes a text appear more melodic, yet not all songs or chants exhibit this feature. Rhymes have been found to help sensitize children for similar sounding words, which supports the development of 
literacy (Bradley and Bryant, 1983; Bryant et al. 1989). Thus, they normally feature in pre-school education in the English-speaking world and rhymes, including nursery rhymes, can be regarded a worthwhile contribution in the EFL classroom as well. Another aspect that increases the musical character of a genre is melody. Whereas chants are normally spoken, rhymes, in the form of traditional nursery rhymes, can also often be sung. Songs are always tonal. They are the one genre where music and language merge with one another. The positive influence of music and especially singing on FL learning has been argued for by practitioners and educationalists for quite some time.

For example, Jolly (1975) who taught beginners and intermediate Japanese courses for which she used songs as supplements, found that songs not only provided some variation that made work on language appear less tedious, but also helped to teach certain aspects of language. In 'class evaluations' at the end of term, students themselves thought that the songs created a 'relaxed and enjoyable atmosphere' and contributed to vocabulary learning as well as to a better understanding of Japanese culture (Jolly, 1975). From the teacher's perspective, songs supported the development of pronunciation, grammatical structures, vocabulary and idiomatic expression, which led her to conclude that 'there is an innate receptiveness in us to respond to the rhythmic patterns of language' that 'we are merely capitalizing on' by using songs in the FL classroom (Jolly, 1975: 14).

Murphey (1990), who brought up 'the song stuck in my head phenomenon’ (SSIMH), suggested that music or song may activate the language acquisition device (LAD) or be a 'strategy of the LAD'. In his discussion, he argues that SSIMH may be linked to other phenomena that have been reported in connection with language learning, such as 'involuntary rehearsal of a FL' or 'Din in the head' (Barber, 1980) during intense exposure to the FL, 'egocentric language' as observed in children (Piaget, 1923 and 1959) and the 'inner speech’ that evolves from egocentric speech and has also been called 'verbal thought' (Vygotsky, 1962). According to Murphey, song can trigger similar rehearsal of language and aid FL acquisition, because if 'involuntary rehearsal is the humming of the efficient LAD, music and song may initially play an associative facilitating role in engaging and stimulating it' (Murphey, 1990: 61). While SSIMH is mostly involuntary, there have been accounts of voluntary playback of others' speech as in the example of a Japanese lady who had learnt to master English by replaying any instances of exposures to the target language 
(Murphey, 1995). Findings from the ELLiE project (Enever, 2011a) suggest that songs and commercials are also used by young learners for voluntary replay outside school, which has a positive effect on their overall competence in the FL.

Fonseca Mora (2000) argues that sounds are fundamental of both music and speech and that therefore, language teaching should emphasize the melodic character of language. Referring to L1 research that suggests that the typical melodic contour or musical patterns of a language are mastered and attended to first by children (Mehler and Dupoux, 1992; Feu and Piñero, 1996), Fonseca Mora (2000) argues that FL teachers should exaggerate the rhythmic articulation of an utterance so that their intonation is more musical, in the same way as caregivers modify their speech to young L1 children when they use Child Directed Speech (CDS). The use of tunes is also recommended. Songs are seen to be 'an effective way of providing students with lexical patterns that are stored in their minds and that can be effortlessly retrieved' (Fonseca Mora, 2000: 151). Apart from the memorization of language chunks, song lyrics can also provide example language that can be used 'to deduce grammatical information', according to Fonseca Mora (2000: 151).

Despite voices from practitioners and their efforts to provide materials for teachers (Murphey, 1992; Paterson and Willis, 2008), one has to acknowledge that in many EFL contexts, whether they are secondary schools, tertiary education, or vocational training, the use of songs and music has not become a regular and frequent feature in EFL classrooms. Even in primary schools where teachers are aware of the popularity of songs among their learners, they are not necessarily used frequently by teachers (Harris and O’Leary, 2009; Garton, Copland and Burns, 2011). This may be a consequence of traditional research that tends to regard music as an 'ancillary ability - one dependent on or derivative of language' (Brandt, Gebrian and Slevc, 2012: 1). This view, supported for example by Pinker (1997) and Wilson (2012), has increasingly been challenged by researchers from across different disciplines. Reviewing a body of studies by psychologists, linguists, anthropologists and musicologists, Brandt, Gebrian and Slevc (2012) argue that musical ability is an essential ingredient in the language acquisition process. After all, infants do not understand the meaning of the language spoken to them during most of their first year. Speech, for them, is not referential yet, but rather some sort of 'vocal performance', and in this way very much like music (Brandt, Gebrian and Slevc, 2012). It is this interrelatedness of music and emerging language acquisition that suggests that the use 
of music and song might also be beneficial in the FL classroom. Song highlights prosodic features of speech and can therefore pave the way for mastering intonation and pronunciation, which seem to be the stepping stones for L1 and L2 acquisition. Song, and other musical texts, such as chants and rhymes probably too, encourage 'creative play with sound' (Brandt, Gebrian and Slevc, 2012), which precedes and paves the way for language production.

\subsubsection{Stories}

As for stories in language education, it has been pointed out that they provide a meaningful context for communication in the classroom. If a story captures the children's interest, then they develop the desire to understand what is going on, and in this way the communicative situation can be regarded genuine. The information that children receive is also meaningful in the way that a story tells about events that unfold over time (L. Cameron, 2001), and language is always presented in the context of a storyline and very often accompanied with illustrations as in picture books or with actions as in storytelling. At the heart of a narrative, there is a conflict that has to be solved, a problem that has to be overcome, a fight that has to be won (von Wilpert, 1989; L. Cameron, 2001). The history of narratives is diverse and comprises legends about gods and heroes, fables and folk tales as well as the modern picture book or the novel. However different these genres might be, there are characteristics that traditional stories normally share, so-called 'prototypical features of stories' (Propp, 1958; Labov, 1972; L. Cameron, 2001), and these are also put to use in many modern stories. For example, there is an opening, then the characters and the setting are described, a problem or conflict is introduced followed by a number of events that resolve the problem. The story ends with a closing that can be a formulaic phrase as in fairy tales and a moral that may or may not be directly stated (L. Cameron, 2001).

Since children grow up with stories in their first language, they have learnt how stories are structured. This helps them when they listen to a story in the FL as well. The typical structure of a story acts as a scaffolding device for comprehension, and so do illustrations or accompanying actions. There are other literary devices that support the meaning-making process, such as parallelism (L. Cameron, 2001). This refers to similar events that are repeated and varied, such as the three pigs building each a house but of different material and the wolf trying to blow each house down in the folk tale The Three Little Pigs. Cameron (2001) calls these structuring elements 
patterns of 'predictability + surprise' or 'repetition + change', and argues that they present children with 'a way into the story' (L. Cameron, 2001). Moreover, each time an event is repeated, the same language recurs, which provides children with repeated encounters of lexical items and opportunities for retrieval of meaning and maybe also reproduction of some items if children are encouraged to join in. It is interesting to note that it is these aesthetic features of a story that foster understanding and language acquisition. In fact, Cameron warns that narratives that do not exhibit some of the prototypical features, such as a plot or a conflict, will not 'capture children's imagination in the same way that stories do’ (L. Cameron, 2001: 162). Stripped of their aesthetic qualities, these 'non-stories' lack some of the features that support language learning.

Ghosn (2004) explicitly argues for the use of 'authentic children's stories' written for native speakers as opposed to didactic texts written for learners of English, such as 'basal readers'. She regards authentic stories as a source for 'predictable yet natural language which promotes word recognition' and which 'offers opportunities for authentic reading and writing tasks' (Ghosn, 2004: 58). Literary texts, unlike EFL coursebooks, she suggests, offer different examples of authentic communicative situations with the relevant language, and are more likely to elicit a greater proportion of pupil talk than 'artificial' texts for language learners (Ghosn, 2004). If a story can spark the learner's interest, then they will want to respond to it and this creates affordances for language learning. Some of the pupil talk, at least, will be in the FL, and this provides 'opportunities for receiving feedback and for negotiating meaning' (Ghosn, 2004: 59). There also seems to be great potential for learners to become familiar with past tense forms through storytelling, which allows for teaching that follows natural language acquisition theory (Ghosn, 2004). In this sense, stories are seen to create an environment that affords language learning as a natural environment does, and by doing so overcomes some of the 'artificiality' of FL classrooms.

While there seem to be many arguments that suggest that songs, chants, rhymes and stories should be of great value in primary English FL classrooms for both, general educational as well as linguistic reasons, the question remains if empirical studies of actual classroom practice can confirm these assumptions. 


\subsection{Empirical Research}

Empirical research on the role of songs, chants and stories in language learning can inform this project on primary EFL and provide a valuable basis for analysis of questionnaire and classroom data. While there seems to be a bulk of studies that have examined the impact of rhythmic language, as in song or rhyme, and of story on L1 acquisition, there seems to be less research with respect to L2 learning (Nation, 2001; Fonseca Mora et al. 2015), and even less regarding young learners in FL classrooms. Findings of studies that looked at primary FL classroom practice, such as the ELLiE project (Enever, 2011a; Muñoz and Lindgren, 2011), havealready suggested a positive influence of children's repeated exposure to song and narrative in the FL on their language competence. With their focus being on general aspects of classroom management, such as the choice of material and activities in the primary FL classroom, these studies do not allow for a detailed understanding of how songs or stories contribute to linguistic development in the FL. In the following, I will discuss empirical studies that have focused on the use of musical or literary texts in young learners’ instructed L2 and FL learning.

\subsubsection{Musical texts and young learners' progress in formal FL learning}

Songs have been found to further vocabulary growth. In an Austrian context, teenagers learnt vocabulary incidentally from oral input in the form of English pop songs that they listened to in their free time (Schwarz, 2012). Similar results have been obtained with preschool children in a Spanish EFL context. Coyle and Gómez Gracia (2014) report that using song in the teaching of new language items can facilitate the development of receptive knowledge of vocabulary in learners. Five-year-old children, who had had two years of EFL instruction prior to the study, were presented with the song The wheels on the bus in three 30-minute sessions on consecutive days. Key vocabulary of the song was taught explicitly and repeated through the use of gestures and images in all three sessions. The song was sung or listened to seven times in total with accompanying actions. Children either joined in the actions or, if they wanted to, joined in the singing as well. Vocabulary picture tests were given to each individual child on three occasions, namely once before and twice (immediately and five weeks) after the teaching sessions. Results showed significant gains of learners' receptive vocabulary, but productive vocabulary did not grow significantly. Only four children out of a total of 25 were able to reproduce any 
of the five target words. The authors report that the children had seemed more focused on repeating onomatopoeic phrases and on copying actions than on saying the target words during listening to the song. They conclude that 'some caution should be taken not to over-emphasize gestures and amusing sounds' if that distracts children’s attention away from target vocabulary (Coyle and Gómez Gracia, 2014: 283). They suggest that 'younger learners should be encouraged to actively reproduce L2 songs to improve their retention of L2 vocabulary’ (Coyle and Gómez Gracia, 2014: 284). It seems that preschool children may need more opportunities to listen to and join in the song in order to be able to reproduce words.

It would be interesting to see, for example, how children's productive test scores were to change if instead of the explicit teaching of the target words they had listened to and joined in the song more often. It is worthwhile considering that for these very young children, the imitation of onomatopoeic phrases and gestures might be more helpful in learning about a word's meaning than direct teaching of vocabulary. Rather than drawing less attention to these features, it may actually be a good idea to let these very young learners enjoy imitating sounds and actions, and in doing so addressing their need for contextualized learning (Piaget, 1923 and 1959). There is another aspect that deserves some reflection with regard to testing. Apart from the fact that children will also have learnt the target words through the repeated exposure to the test situation, which means that their performance cannot be traced back to the teaching of the song alone, one should also remember that individual testing can be problematic with very young children. Although common practice in psychological studies, it has been pointed out by educational researchers that one-to-one interviews can be intimidating for very young EFL learners and should therefore be avoided (Moon, 2000). If we agree with the notion of a friendly and relaxed atmosphere being an important ingredient in the primary EFL classroom, then we have to acknowledge that a testing situation that may easily trigger feelings of insecurity in participants is inconsistent with our normal teaching routine. This is very likely to confuse learners, especially if they are very young. We cannot expect a testing situation that causes nervousness and inhibition to provide a true picture of a learner's competence in the FL. It has been noted that negative emotions can prevent our memory from working properly (Stevick, 1999). Research on native speakers' language production in interview situations (Höweler, 1972) and in the face of audience feedback (Blubaugh, 1969) as well as neurobiological research (Damasio, 
1994) suggest that native speakers' language production is negatively influenced by negative emotions. This can also be anticipated for FL learners. Therefore, settings that the researcher creates to elicit learner talk need to be perceived as non-threatening and informal in order to ensure that learners can demonstrate their true language abilities.

In another study on the use of music in EFL classrooms, it has been reported that the introduction of 'musical stimuli' in the form of songs as part of the FL programme in Year 6, the final year of primary school in Spain, had a positive impact on listening, reading and speaking skills in particular (Toscano-Fuentes, 2010). This has also been documented for reading skill in particular in a study conducted with 7- to 8-year old Spanish EFL learners (Fonseca Mora et al, 2015). Drawing on research that has linked difficulties in the learning-to-read process to poor phonological language skills (Brady, 1991; Jongejan et al, 2007; Melby-Lervåg et al, 2012; Hulme and Snowling, 2014) and referring to studies that have suggested that musical training may counteract poor phonological skills in L2 learning (Chobert and Besson, 2013), the authors tested a phonological training programme with 63 Spanish EFL learners. The two experimental groups were taught 'early reading skills such as the alphabetic principle, phonological awareness and phonics' through video clips (Fonseca Mora et al, 2015: 3). Whereas one group worked with video clips that included melodies, the other received the same training but without the musical support. Tests on 'musical abilities', 'early reading skills', 'working memory' and 'socio-cultural level' were conducted before the eleven-week training programme and immediately afterwards (Fonseca Mora et al, 2015). Test results showed that children in both experimental groups outperformed children in the control group in the 'Correct letters read in English' as well as the 'Initial sound identification' and the 'Correct words read in an English dialogue' tasks. However, 'a further impact of the music support was not demonstrated' (Fonseca Mora et al, 2015). The researchers note, however, that pre-tests revealed significant differences between groups with regard to learners' musical aptitude, with the non-musical experimental group reaching the highest mean scores, which might explain why no difference could be detected between musical and non-musical experimental groups in the post-tests. The authors suggest that 'learners with higher musical aptitude may tend to benefit more from the phonological training program than children with lower musical aptitude’ (Fonseca Mora et al, 2015: 10). The researchers stress that 
the children in the musical experimental group did achieve better results in the reading tasks than their peers who did not receive phonological training. Fonseca Mora et al (2015) argue that the repeated encounters with melodies and their 'memorable lyrics' helped children to remember words and speech sounds.

While the above study highlights the importance of phonological training, it does not provide evidence of musical training being superior to other non-musical training. And yet, the results of this study are interesting because they indicate that musical intervention in the FL classroom is twofold. On the one hand, learners may benefit from singing, because words and speech sounds that occur in song lyrics are more easily acquired. On the other hand, singing itself may refine their musical expertise and their phonological skill in the long term, which helps them in the acquisition of any new words as well as speech sounds, and improves their reading performance. Indeed, singing ability has been linked to speech imitation ability, although it has to be pointed out that these experiments were conducted with adults (Christiner and Reiterer, 2013). In the study, working memory as well as the participants' sense of rhythm and their 'vocal flexibility' accounted for $66 \%$ of the variation in speech imitation of a sample of Hindi which was unfamiliar and unintelligible to participants. It is likely that children with musical training in singing show similar ability when it comes to imitating speech. Therefore, it has been suggested that singing training might be used for the teaching of pronunciation in L2 and FL classrooms (Christiner and Reiterer, 2013).

The study that Fonseca Mora and her colleagues (2015) conducted also raises new questions, for example how learners respond to the phonological material presented to them. Since the researchers focused on data collection involving tests and questionnaires, the data cannot inform us about what exactly happened in the classroom. However, this information could be of great value. It might provide us with additional insights on children's behaviour at the time of exposure. Did children show any signs of understanding the video clip, or did they seem confused? Did they ask questions, and if so, what kind of questions were they? Were there any other verbal responses, and of what kind? Did they respond non-verbally to the material, and if so, how? Answers to these questions could shed some light on the FL learning process, and therefore classroom as well as interview discourse from my investigation of a primary EFL setting will be screened for children’s responses. 


\subsubsection{Stories and young learners' progress in formal L2 or FL learning}

With regard to storytelling and language learning in children, Elley's research (e.g. 1989, 1983) provides valuable insights. Importantly, Elley has not only studied L1 classrooms (1989) but also the effect of reading on children for whom English is the L2. In his paper 'The Impact of Reading on Second Language Learning', co-written with Mangubhai (1983), Elley and his colleague reported on a project that involved 614 nine- to eleven-year-old pupils in Fijian schools over nine months, including testing. The starting point for the study was the idea that differences between first and second language learning could be outbalanced through a flood of 250 high-interest illustrated story books supplied to each class that would encourage children to read in English, thereby improving their command of their L2. While 380 pupils participated in the reading programme, either in the Shared Book Experience or in the Sustained Silent Reading Group, the remaining 234 pupils followed the traditional English teaching programme that consisted mainly of oral drill exercises taught by non-native English speakers with limited and delayed exposure to printed texts.

In the Shared Book Group, the graded texts of the traditional programme were replaced with high-interest books containing suitable language and illustrations. Following a procedure that was developed by Holdaway (1979) in primary schools in New Zealand, teachers introduced the book by inviting children to speak about the pictures and about their predictions on the plot, thereby drawing the children's attention to some new words as well. After this pre-reading activity, the children listened to the teacher reading the whole story or parts of it. Reading was repeated twice on the following day or on two days, during which children were 'encouraged to join in and read easier sections with the teacher' (Elley and Mangubhai, 1983: 58). The teaching objective was for the children to pick up some new L2 items incidentally in a non-pressurized environment, because if 'children enjoy the experience, they will want to read it often', which maximizes exposure to the same verbal material until learners 'master the language of the book' (Elley and Mangubhai, 1983: 58). During the storytelling sessions, the focus was on meaning-making through predicting and confirming events that occurred in the story. Reading was later followed by whichever activities seemed appropriate in connection with a particular story such as role-plays, artwork, vocabulary exercises or writing tasks. 
In the Silent Reading Group, reading was completely in the hands of the children. Although teachers would read books aloud every day, there would also be 20 to 30 minutes during which children would choose a book and read on their own without interference by the teacher according to a method developed by McCracken (1971). The main idea was that children read for enjoyment and pleasure alone, so the learners were not set any additional tasks (Elley and Mangubhai, 1983).

The results of the post-tests on reading comprehension, grammatical structures, word recognition, listening comprehension as well as composition, all indicated that both Book Flood groups outperformed the control group, with the Shared Book Group receiving even better scores than the Sustained Silent Reading Group. In fact, further tests in General Studies, which covered science and social studies, in Mathematics as well as in Fijian, suggested that 'there was a transfer effect apparent in the second year' (Elley and Mangubhai, 1983: 65). Better L2 skills had led to improvements of related skills needed in other subject areas.

A follow-up study by Ricketts (1982) in Fijian primary schools confirmed these results. Elley and Mangubhai concluded that

time spent on reading in school has been regarded largely as entertaining, as relaxing. However, it must also be seen now as educationally beneficial. Furthermore, strict controls over the vocabulary and structures of L2 pupils' reading materials seem unnecessary and counterproductive. Children can learn new structures from relatively uncontrolled materials, provided there is the support of cues from pictures, absorbing context, and teacher guidance. (Elley and Mangubhai, 1983: 66)

Elley continued to carry out research on the effects of book reading on L2 acquisition. A study conducted with six- to nine-year old learners in Singapore rendered similar results (Elley, 1991), and so did programmes in South Africa and Sri Lanka (Elley, 1998). Those children who started to have access to high-interest books and were offered read-alouds, shared and silent reading learnt the target language more quickly and reached better results in literacy tests in the L2 than their peers in classes that did not follow the reading programme.

The results of the above study by Elley and Mangubhai (1983) are intriguing for more than one reason. First of all, they highlight the fact that reading a story that children find interesting but that does not necessarily serve any short-term didactic purpose, such as revising certain grammatical structures or new vocabulary, can 
actually have many more benefits than simply to create a relaxed atmosphere. What Elley and Mangubhai's study has shown is that encouraging children to read for pleasure can have a positive effect on their long-term performance not only in the target language but also in other subject areas.

Furthermore, the study shows that success in L2 learning is not just about reading, it is also about reading something that sparks the learners' interest and engages them. It seems that we have to differentiate much more between different kinds of texts used in classrooms. Here, it was the real book created for native speakers, for their entertainment and their education that had a much bigger impact than the graded reader tailored to L2 learners' needs. It is almost as if these illustrated story books filled the classroom with real-life situations creating a fictitious L2 environment that learners could enter and try to understand. We may be reminded of Cook's idea of literary texts creating an alternative world for learners (G. Cook, 2000). These stories, in a way, created an alternative naturalistic environment, which may seem paradoxical, since stories are rooted in fiction and may be anything but realistic. Very much like L1 learners trying to make sense of their natural environment, the L2 learners find themselves transported into the world of the story that they want to understand and be a part of. The focus shifts from doing a language exercise to making sense of a situation that happens to be portrayed in a language other than the L1. In a way, L2 learners then experience the same type of situational learning as they did when they learnt their L1. Of course, this high level of engagement in a story can only be achieved if the text appeals to the learner and is approved of as being a genuine story, which always entails an artistic quality that many didactic texts lack.

It is this creation of a learning environment that resembles a real-life encounter with natural language that might be especially valuable if we look at language learning from a neurobiological perspective. Neurobiologists argue that there is a sensitive period for language learning, and that 'evolution has designed the brain to acquire grammar and phonology by about four years of age through natural interaction with others' (Schumann, 1999). Within this line of argumentation, language instruction before the 'close of the sensitive period' at about 15 years of age is regarded as 'equivalent to learning under conditions of environmental deprivation' (Schumann, 1999: 40). In other words, we need to feed our young learners with encounters of natural language. Developmental psychology supports 
this view in so far as it suggests that learners have reached the 'formal operational stage' at about 11 years (Piaget, 1923 and 1959) and can think adult-like. That is the time when learners have abstract thinking skills that are necessary to make the most of language instruction in the form of direct teaching of vocabulary items or grammatical features. Learners who are younger, however, should benefit more from any material that affords exposure to natural language, such as 'real' stories, according to this view.

Critics may argue that although the Shared Book Experience seems to have worked well in a context where English is a second language, results may be entirely different in a setting where English is taught as a FL. It may be worthwhile to mention a study carried out by Drew (2009) in primary EFL Norwegian classrooms. In this project, the Australian Early Years Literacy Programme (EYLP) was introduced in grades 3 to 7 . The EYLP features substantial amounts of reading, namely 290 well-illustrated graded readers at 26 levels. The idea is that children should read as many readers from one level as possible and read other books as well. In the Norwegian project, the children were organised in homogeneous groups, and the classroom was divided into different learning centres, or 'stations'. The study, which was carried out between spring 2006 and autumn 2007, comprised three classes of 57 pupils in total from one school and two classes of 58 pupils in total from two control schools. Data were collected through teacher interviews, observations and tests (Cambridge Young Learners Starters). At the beginning of the study, children had had about 50 lessons of English in total. EYLP was not used every week. A typical EYLP lesson would start with a plenary of about 5 to 10 minutes that involved some singing and information on activities, and would be followed by group work at different stations (such as silent reading, writing, vocabulary practice on computers, role-play, games, vocabulary activities, time at teacher's centre) before the session would end with another plenary. At a teacher centre, every child was asked to read the book they had read at home aloud, and then they would choose a new book. While the teacher would read the unfamiliar book to the children, she would also ask questions about it. The pupils who were part of the reading programme outperformed their peers from the two control schools especially in the listening and oral tests (Drew, 2009).

Even if this study differs from the study by Elley and Mangubhai (1983) not only in the number of participants but also in the choice of graded readers rather 
than original children's books, the example of Drew's study suggests that extended reading programmes can have a similar positive effect on learners' L2 acquisition in an EFL setting. However, in the same way as studies on the use of musical texts by Fonseca Mora et al. (2015) do not provide a detailed picture of how children responded verbally and non-verbally to the texts, this information is also lacking in these studies on the use of stories in instructed L2 and FL learning environments.

In this respect, Mourão’s study (2013) conducted in a preschool EFL context in Portugal is of special interest. Mourão observed how children aged between 56 and 79 months responded to English picture books during teacher-led read alouds, which were repeated seven times during consecutive lessons, and how children managed retelling the picture books in small groups after these repeated encounters with it. The sample of participants comprised 64 children in total from three different schools. On the basis of audio and video recordings, Mourão was able to analyse children’s verbal and non-verbal behaviour during read alouds as well as small group retells. She found that 'children pay particular attention to the peritextual elements of a picturebook' in order to make predictions in their L1 about the evolving narrative and to produce any English words that they know already (Mourão, 2013: 73). It is the picture books' peritextual features that frame the text, such as covers, dedications, titles or illustrations, and that create opportunities for learners to negotiate meaning and share different understandings of a text, thereby supporting the development of 'inferential thinking', 'interpretation skills’ as well as ‘visual literacy’ (Mourão, 2013). At the same time, these shared picture book readings create a platform for language use that may at first be mostly in the L1 but gradually also include L2 items from the picture book and the discussions about it (Mourão, 2013). Mourão’s data show that very young learners rely on the L1 in their verbal response to the stories, and that this can be the starting point for FL learning. As the children strive for meaning and express their thoughts in their L1, the teacher can gently provide the equivalent words and strings of words in the FL that the children can then take up and reproduce. In that way, learners are encouraged to express something in the FL that is of real interest to them, and that is embedded in a context, namely the illustration, layout and narrative of the picture book. Mourão’s data also indicate that many encounters with a text are necessary before these very young FL learners appropriate language of the picture book. This raises the question if primary school children, who are a few years older, respond to picture books in a similar way, and if this genre could also aid their FL 
learning.

Indeed, classroom data from a story-based primary EFL programme that Chen-Ying (2004) analysed indicate that stories can engage ten-year-old FL learners to search for meaning using visual clues provided by pictures. They identify details in the pictures and try to construct meaning from them initiating discussions among each other and with the teacher. Learners also express their thoughts and feelings spontaneously by responding nonverbally, such as laughter for example, or by responding verbally using mostly their native language or individual words in the FL, such as 'yes', 'prince', 'princess'. When multi-item sequences appear, such as 'this is a mouse', they normally occur after the teacher used the same or very similar language repeatedly beforehand. Children seem to imitate their teacher's language. The teacher, on the other hand, used various strategies to scaffold language learning, among others pointing to characters and objects in the pictures, using gestures, repeating or rephrasing language items. Chen-Ying concludes that longitudinal studies need to be conducted and discourse from different classrooms compared. This stresses the importance of data collection over a longer period of time in order to identify any evidence of long-term effect of listening to stories or of progress in language output during repeated encounters with a story. In this way, data from consecutive lessons and from different classrooms need to be analysed for evidence of children's reliance on visual clues for meaning-making, of children's imitation of language as well as their recall of multi-item sequences.

A study carried out by Kolb (2013) in German primary EFL classrooms already provides some positive evidence with regard to the reading of picture books. However, it mainly refers to motivational aspects of FL learning. Kolb let 23 children aged between 9 to 10 years choose between nine picture books. Over a period of three weeks, learners 'had the opportunity to explore the books in pairs or small groups' (Kolb, 2013: 35). Different types of data, namely video recordings, student self-assessment questionnaires as well as interviews with nine children and the teacher, were collected and analysed. On the basis of these data, Kolb argues that 'children are able to work with English picture books on their own' and they 'use a variety of comprehension strategies' (Kolb, 2013: 41). Kolb stresses that learners reported to be more motivated to read, more confident and competent. This study suggests that picture books can engage and motivate and therefore be of great benefit with slightly older children in primary EFL classrooms. However, it does not offer 
any explanation as to how exactly primary schoolchildren respond verbally to the picture book, how they try to make sense of the narrative and if or how they use the FL. These are questions that are of relevance if we want to gain a deeper understanding of how illustrated stories can facilitate FL learning in the classroom.

\subsection{Concluding Remarks}

In this chapter, I have reflected on theoretical positions as well as empirical research on the use of songs, chants, rhymes and stories in FL and L2 learning in general and primary EFL classrooms in particular.

While it has been shown that there are also critical voices with regard to the status of literature in FL education, the review of relevant literature has revealed great support for the use of literary and musical texts in instructed FL learning. Positive effects on cognitive and emotional development have been identified, such as the fostering of abstract thinking skills, intercultural competence, visual and literary literacy as well as emotional intelligence. At the same time, song, chant, rhyme and story have also been regarded as beneficial for linguistic development, since they afford meaningful and genuine communication, contextualized learning as well as repeated exposure due to their aesthetic qualities. While song, chant and rhyme seem to highlight prosodic features of speech and to aid memory, stories can create a make-believe atmosphere that simulates a naturalistic environment reminiscent of L1 acquisition.

The review of empirical studies seems to confirm this line of argumentation. However, research findings are still patchy. While there has been some research on the use of songs and stories in classrooms, there seems to be a general lack of research that analyses children's verbal and non-verbal response to songs, chants, rhymes and stories in a primary EFL setting at the moment of exposure and over a longer period of time. 


\section{Chapter 4}

Methodology

In the past few years, numerous studies have been published on primary-level FL teaching that report on teaching practice (Eurydice, 2012) and analyse data from real classrooms (Nikolov, 2009; Enever, 2011a; Garton, Copland and Burns, 2011). Recently, there has also been an increased interest in the use of stories and songs in young learners’ EFL classrooms (Drew, 2009; Bland, 2013 a and b; Lütge, 2013; Burwitz-Melzer, 2013; Mourão 2012 and 2013). However, during the first stages of data collection for this project between 2007 and 2008, none of these studies were available. In fact, most of these studies were only published after data collection for this project was completed in 2010. At the time, research that informed on actual teaching practice in primary EFL classrooms was scarce and mostly reflected primary-level FL teaching before large-scale implementation (e.g. Geibert 1995; Helfrich 1995; Petillon, 1995; Pienemann, Kessler and Roos, 2006). There was also a lack of studies that analysed primary-level FL classroom data on the use of songs, chants, rhymes and stories, although these text genres were recommended for the teaching of young learners (Cameron, 2001; Paran and Watts, 2003; Ghosn, 2004; Edelenbos, Johnstone and Kubanek, 2006).

This lack of research was not surprising since primary EFL was still relatively new at the time. However, it meant that this research project on songs, chants, rhymes or stories in primary EFL was a step into new territory and could not rely on a well-tested research design for data collection and analysis. Instead, a framework for research had to be conceptualized and this entailed a reflection on more general questions of research design, such as which research methods of data collection and analysis were available and appropriate for the purpose of this study.

This chapter is devoted to a review of both traditional and modern approaches to classroom research that guided my decisions for the methodology of the research project. Decisions on specific procedures of data collection and analysis as part of various research methods, such as questionnaire, classroom observation and interviews with teachers and groups of learners, will be reported on in the relevant chapters in the second part of this thesis. 


\subsection{Traditions and New Trends in Classroom Research}

An early example of classroom research is a study by Stevens (1912) that analysed one hundred random observations of lessons. The data showed that teachers talked for about $64 \%$ of the time. Stevens also looked at the kind of questions that teachers asked pupils, drawing up question categories and counting the question types per minute. This study is very characteristic for early classroom research in its focus on quantitative analysis (Wragg, 1999).

\subsubsection{Quantitative studies on FL teaching methods and classroom interaction}

When classroom research was finally adopted by researchers in FL acquisition in the 1960s, it was this kind of quantitative analysis that was given the most attention. Research questions evolved around the impact that different teaching methods or activities had on language achievement (Chaudron, 1988). For example, Scherer and Wertheimer (1964) compared 'audiolingual' and 'traditional' teaching methods under real classroom conditions of tertiary German as a FL, and Politzer and Weiss (1969) analysed videotaped segments of secondary French FL classrooms for teacher behaviour that had a positive impact on student performance. However, it was soon found that teaching is such a complex process that it is difficult to identify 'good' and 'bad' teaching devices (Politzer, 1970). It seemed that the quantitative analysis of one aspect in the classroom had its limitations. It could not provide the answer to the question of how to create the perfect L2 classroom.

Researchers therefore turned away from the idea that one teaching method could be prescribed, and rather focused on the description of classroom processes (Allwright and Bailey, 1991). Classroom interaction was now analysed (e.g. Wragg, 1970; Moskowitz, 1967, 1971 and 1976). Researchers counted the frequency with which some of the teachers' and students' behaviour occurred in order to gain a better understanding of how the learning atmosphere and interaction created by the teacher influenced student behaviour (Chaudron, 1988). The focus started to shift to the linguistic dimension of classroom interaction and analysis began to concentrate on communication. The strong focus on the linguistic aspect of interaction can be seen in the researchers' use of 'transcriptions of recorded classroom events as their prime data base' (Allwright and Bailey, 1991: 12). What was actually said in the classroom became more important. In line with that, Sinclair and Coulthard (1975), notably, developed a hierarchical system of analysis that defined a lesson as a 
number of 'transactions' that could be further broken up into 'moves' and 'acts', which allowed a thorough linguistic description of classroom events (Allwright and Bailey, 1991).

\subsubsection{Questioning the suitability of quantitative research instruments}

However, L2 research has not continued to refine this system of analysis any further, which can partly be explained by a growing uneasiness about 'closed' techniques in traditional classroom research:

The problem with observation schedules and with surveys is [...] that someone has to decide in advance what to look for, or what to ask questions about, and that someone is most often a researcher who is not typically directly involved in the classroom being investigated. (Allwright and Bailey, 1991: 4)

This leads to a situation where aspects that would be worthwhile investigating are missed because the researcher lacks insider knowledge. Another reason why researchers paid less attention to developing systems for classroom interaction might have been the interest in a new approach that originated in sociology and anthropology, namely ethnographic research.

Ethnographic research is essentially different in its aim 'not to prejudge the importance of the events observed' (Allwright and Bailey, 1991: 5), which means that the researcher refrains from generating hypotheses before data collection. Rooted in anthropology, ethnographic methods were first used to collect a record of behaviour observed in people of different cultures. Rather than deciding which aspects to focus on during observation beforehand, an ethnographer will concentrate on collecting as much data from the research site as possible by meticulous record keeping and participating in the life of the community under investigation. In the case of classrooms, the research site will include both the inside and the outside of a classroom, since what happens in a classroom is understood to be shaped by the wider context of the whole school within a wider community. Only on completion of the extensive data collection will interpretation begin. This does not mean that researchers do not 'apply some preconceived perspectives and suppositions' (Chaudron, 1988: 47), but they should be aware of these in order not to attend to their data selectively.

Among the researchers who have supported the use of ethnographic methods 
in classroom research are, for example, Wilson (1977), Erickson (1981) and van Lier (1988). The interest in ethnography as a possible source for new research procedures in classroom research was spurred on by growing doubt regarding the suitability of traditional classroom research that typically applied quantitative research instruments.

The key problem was seen in the impossibility 'to control the number of different variables' in real classrooms, which in turn means that results are easily biased and therefore make it impossible to 'test a theory-driven prediction' (Allwright and Bailey, 1991: 37). Criticism of quantitative research tools also came from van Lier (2004), for example, who voiced his concern about the reduction of context, data and complexity in quantitative classroom research. His argument runs as follows:

In order to conduct coherent investigations it is necessary to simplify and select from the infinite variety of the real world. This means that potentially significant aspects of the environment or setting may simply be ignored, or that contextual variables are eliminated by setting up experiments in controlled settings. (van Lier, 2004: 9-10)

According to van Lier then, quantitative research may produce distorted data, which consequently lead to research findings that do not really refer to the situation one set out to investigate. He argued that quantitative research lacked 'ecological validity', which is a concept that had been used and refined by researchers since the 1940s (e.g. Lewin, 1943; Neisser, 1976; Bronfenbrenner, 1979). Studies that use an experimental design will provide us with information about how people act in a controlled experiment, but they will not inform us about learning and teaching in classrooms, because learners may behave differently in natural environments (van Lier, 2004). Therefore, these research findings are not transferable to classroom settings, since classrooms work differently from laboratories. What classroom researchers, trying to gain a better understanding of learning and teaching, need is 'real data' gathered in real classrooms (Maybin, 1994). This is important insofar as it highlights the importance of classroom data for this project that investigates the use of songs, chants and stories in the primary-level EFL classroom. 


\subsubsection{The paradigm shift in language learning and research}

The heightened awareness of the value of qualitative research and the interest in academic disciplines such as anthropology and also neurosciences paved the way for a paradigm shift in second language acquisition (SLA) and educational research (Watson-Gegeo, 2004). A new understanding of language learning, teaching and researching has been emerging since, which needed to be considered for the design of this project. One of the central ideas fuelled by research findings from the neurosciences is that cognition does not ride 'in a detached fashion above the body', but that 'all cognitive processes are embodied’ (Watson-Gegeo, 2004: 332).

In addition to that, there seems to be an awareness that not one method, one approach or even one discipline is the one to uncover scientific truth (van Lier, 2004). With regard to the study of language use, applied linguistics 'has become far more interdisciplinary’ (J.K. Hall, 2011). Ellis and Larsen-Freeman (2006), referring to the complexity of different variables impacting on language learning, conclude that language and learners are complex and that therefore 'no single discipline of inquiry has the monopoly on language’ (Ellis and Larsen-Freeman, 2006: 561).

It is the concept of 'emergence' that has become a central part of a new understanding of language learning, teaching and researching. The notion of emergence is linked to the idea that learning is non-linear, and not gradual, and that learning is accompanied by re-organization, or restructuring (McLaughlin, 1990). It has been defined as a kind of transformation process during which 'relatively simple elements combine together to form a higher-order system' so much so that the 'whole is not only more than the sum of its parts, it is of a different nature than its parts’ (van Lier, 2004: 5).

\subsubsection{Implications for this research project}

The review of traditional approaches and recent trends in classroom research has revealed that the complexity of the classroom setting and the learning process cannot be done justice to with traditional quantitative research methods alone. Any project on language learning in classrooms has to take this insight on board. Moreover, if there is not one discipline, approach or research method that holds the key to the truth, then one has to consider borrowing ideas and instruments from different research traditions in order to gain a better understanding of FL classrooms.

Thus, one consideration for the research project reported on here was that 
one should view the primary English classroom, of which very little was known, as a place foreign to the researcher where a group of people interact with each other establishing their own rules and norms, very much like members of a community of practice. It seemed logical that the only way to understand what was going on was by experiencing this environment in its complexity, which meant that the researcher, who was the outsider, had to submerge herself into the everyday life of this primary English classroom in order to gain insider knowledge (see also Green, Skukauskaite and Baker, 2012). This, of course, pointed towards an ethnographic approach, which would involve participant observation, interviews and fieldnotes (Maybin, 2007). Furthermore, such a consideration also implied longitudinal research that would provide the researcher with enough time to become fully acquainted with the 'cultural' group under study, but that would also give participants enough time to welcome the researcher into their community, to establish trust and to share their knowledge.

The main aim, therefore, was to establish a rich and variegated data source collected using different methods. Diverse data allow the researcher to triangulate findings in order to evaluate their reliability. Moreover, with a multi-method research design the weaknesses of one research method can be counterbalanced by the strength of another. For example, a questionnaire provided information on different teachers' teaching materials and the use of songs, rhymes and stories in primary EFL, but this information was found to be too general and raised new questions that could best be studied through participant observation or discussed in face-to-face interviews with teachers and students. In this way, the research design developed organically as the project went on, but it must be said that, from the start, it had been anticipated that a multi-method approach would be recommendable and necessary.

Another consideration was the fact that a small-scale research project, such as a $\mathrm{PhD}$ thesis, is restricted in terms of time and resources that can be allocated to data collection and analysis. While it may have been fascinating to find out more about as many teachers and children as possible and to investigate how all of them experience English as a foreign language in a primary school setting, this would have entailed much more time and effort than one person could invest. Thus, as the project progressed, I had to narrow the focus and concentrate on one particular school and its EFL classrooms. Insights from case study projects were therefore 
referred to so as to arrive at informed decisions in the planning of extended visits to primary EFL classrooms.

With a multi-method approach and the accumulation of a rich data source, it could have been easy to lose sight of the bigger picture, which was to gain a better understanding of the workings in a primary EFL classroom. It was important to find a way to organise research procedures in a framework that ensured that even with different research methods being used, these would not be applied under different perceptions of learning and teaching. The research design needed a sort of compass for assistance in navigation. The ecological worldview (e.g. van Lier, 2004) was considered to be such a navigational tool since it demonstrates how such a perspective can address many of the issues pointed out in the discussion on a new understanding of learning languages. Aspects such as context, quality versus quantity or the concept of emergence can all be accommodated within it. Making use of an ecological perspective for our purposes does not mean that it is seen as the only true answer. It is rather the case that ecology provided a setting that allowed me to take into account the above-mentioned current trends in language research.

I am now going to discuss each of the above mentioned qualitative research concepts (Figure 1), namely the ecological perspective, insights of ethnographic research, case-study design and discourse analysis of observational and interview data, in more detail in order to clarify the main principles that shaped my research.

\title{
Figure 1: Research perspective, approach, design \& method of analysis
}

\author{
Ecological perspective \\ used as a framework for research project
}

Ethnographic approach

in order to get insider knowledge over an extended period of time and to

understand the workings of a primary EFL classroom 


\subsection{The Ecological Perspective}

Within the concept of ecology as a worldview, teaching and learning are understood as complex processes. The learner or the classroom, just like any individual organism, cannot be studied without taking all conditions into account that create the environment in which learning takes place (Bronfenbrenner, 1979). The study of language, however, is linked to the study of teaching (van Lier, 2004). Education cannot take place without language, which is why the study of a classroom entails the study of the language being used in it. If we agree with the argument that language and education are inseparable, then the principle of context within an ecological perspective is also relevant for any project investigating classrooms. Context, on the other hand, occurs on all levels of investigation, whether it is the analysis of an individual utterance that needs to be interpreted within the communicative situation in which it appears, or whether it is an observational period with one particular teacher at one particular school that has to be understood within the context of official guidelines and curricula. It follows that at every stage of analysis, a description and an evaluation of context and its impact are necessary.

The study of the learning and teaching environment entails an analysis of situations that either encourage learning or make it more difficult. In ecological terms, this is an 'affordance' (e.g. Gibson, 1979). With regard to classrooms, affordance 'means a relationship between organism (a learner, in our case) and the environment that signals an opportunity for or inhibition of action' (van Lier, 2004: 4). Affordance is closely linked to the above-mentioned micro and macro levels of context. An official guideline such as the brochure on FL learning at primary school can be an affordance, and so can be the rules or routines established in the community of a school, or materials, or seating arrangements as chosen by a teacher or by learners.

The appreciation of the context of teaching and learning within an ecological worldview comes also with a heightened awareness of responsibility for the environment one is studying. For researchers, this means that they are aware that their work is influenced and spurred on by the values they believe in, they adhere to these values while they are conducting their research and they regard their research findings as being of value to the outer world (van Lier, 2004: 6). For ecological research this involves the adherence to ethical principles that ensure that the environment under investigation stays intact. Therefore classroom research had to be 
carried out in a way that did not hinder the teaching or learning processes, and did not have any negative implications for future teaching and learning (see Appendix 1 for Statement of Ethics).

For the project reported on here, this meant for example that applying tests in primary EFL classrooms had to be avoided since official guidelines for primary EFL in Rhineland-Palatinate specifically state that children's progress is to be documented in the form of a language portfolio and that a positive and non-pressurized learning atmosphere is paramount (Ministerium für Bildung, Frauen und Jugend, 2004). A research design that relied on a series of tests would not only have confronted children with tasks unfamiliar to them in the FL and would have disrupted the day-to-day learning in the classrooms under study, it would also have been against expectations set by the community which these schools were a part of. One might feel inclined to say that tests could have been designed in the form of a game, and while it is true that one could easily produce a test that creates the impression of being a playful enterprise, this view ignores the fact that children are inquisitive and may have asked about the purpose for the game and what the researcher was going to do with the recording or the notes. It would not have been ethical to withhold or disguise information on testing procedures, and thus children would have perceived the 'game' as what it is - a test. All specific procedures undertaken to ensure adherence to ethical principles are laid out in the chapters on questionnaire, observation and interview data.

Apart from the ethical dimension in ecological research, there is another principle to be considered, namely a critical attitude (van Lier, 2004). Critical thought in research implies that the researcher constantly observes and articulates how far the chosen research instruments are appropriate, or if the research design needs to be re-evaluated and adapted during the course of a project. The research design of this study slowly evolved as each stage of the project not only provided new insights but also raised new questions. Thus, research questions were constantly refined, and the process of data collection re-evaluated.

\subsection{The Ethnographic Approach}

It has already been suggested that, in terms of research design, the best way forward is to borrow ideas from different disciplines for classroom research. Among these different sources of academic expertise, the ethnographic approach is especially 
promising, since it addresses many of the concerns about traditional classroom research and follows main principles of an ecological worldview. What the ethnographic approach shares with an ecological perspective is a holistic and ethical attitude towards mainly qualitative data collection, analysis and presentation.

Watson-Gegeo (1988) was one of the first classroom researchers who advocated the use of ethnographic methods and who applied key principles of ethnographic research to the study of language classrooms. Importantly, mere description of a culture-sharing group, such as a school, is not enough. Description needs to be followed by an explanation of the described behaviour (Watson-Gegeo, 1988: 2). Another key principle is a holistic procedure. The ethnographic researcher needs to study behaviour as well as the context in which it occurs. Two levels of context can be distinguished, namely 'horizontal' and 'vertical'. Horizontal refers to 'behavior, interactions, and events as they unfold in time, together with the immediate circumstances affecting them', while the vertical level of contexts includes 'institutional constraints and influences from the larger culture and society' (Watson-Gegeo, 1988: 2-3). By describing as well as interpreting behaviour and the impact of different layers of context, the ethnographer will fulfil the key principle of providing ‘thick explanation’ (Watson-Gegeo, 1988).

The concept of thick explanation is also supported by Davis (1995), who argues that qualitative studies in the area of language learning must do more than describing the process as observed within a community. They should further our understanding of how language is learnt and which role sociocultural and mental processes play. In order to uncover the workings of all these different layers of context, I had to refer to a variety of different data. For example, different interview data had to be collected, such as informal as well as formal interview data with teachers as well as learners, and different official documents, such as guidelines and curricula published by the Ministry of Education, had to be studied.

Apart from these theoretical considerations, Creswell (2007) provides some practical guidelines for ethnographic research that were useful for this research project. Among the recommendations that seemed especially important is the notion of a 'key informant' (Creswell, 2007). Unless a university teacher or researcher who wants to conduct a qualitative and ethnographic study in a school setting also works at school, s/he may lack insider knowledge. It was vital to establish contacts with primary school teachers who would also welcome me into their classrooms and 
share their views with me. A questionnaire, distributed to as many teachers as possible within one area could not only provide some first insights into primary EFL and more research questions to follow up, it could also be seen as a means to identify possible key informants so as to be able to spend an extended period of time in a primary EFL classroom and gather observational as well interview data from real classrooms.

With data ranging from observational data in form of questionnaires, audio-recorded classroom discourse, audio-taped interviews with teachers and learners as well as learners' portfolios and official guidelines and curricula, a very extensive data base had to be anticipated with at least one crucial question lurking in the background, namely the question of how much data is needed in order to create a 'holistic cultural portrait of the group' under study (Creswell, 207: 72). Data collection is considered complete when 'no additional levels are found that substantially contribute to the explanation' (Watson-Gegeo, 1992: 54). Needless to say, in terms of primary EFL teaching in one federal state of Germany, this could easily render an unmanageable amount of data for one researcher with a time limit of a $\mathrm{PhD}$ thesis to keep. It is the extent of potentially relevant data that has been identified as a challenging characteristic of ethnographic research (Creswell, 2007). It is also a feature that has often been underestimated, which in turn has led to unsatisfying quality in some research projects. Cameron (2001), for example, criticizes the fact that ethnography and participant observation have been 'overused in social science', and admits that 'some of what is called 'ethnographic' research does not meet the standards set by 'classical' anthropology' (D. Cameron, 2001: 54). Hence, it may be more appropriate to say that my research strove to adopt an ethnographic approach (Green and Bloome, 1997) and to follow some of the principles of original ethnographic research, which are 'ongoing regular contact and some degree of participation', 'naturalistic setting', and a research objective that wants 'to understand that way of life as group members understand it themselves' (D. Cameron, 2001: 54).

It also seemed obvious that in order to reach the amount of detail necessary that allows for thick description, I needed to reduce the amount of ground I could cover. Rather than aiming at producing a portrait of primary EFL classrooms in one federal state of Germany, I had to consider a small-scale study, and finally opted for studying the environment of one school and explaining the workings of its primary 
EFL classrooms. This, of course, pointed towards a case study design for my research project.

\subsection{The Case Study Design}

There is an overlap between ethnographic and case studies in their use of a rich and varied data base, their preference for longitudinal research designs and their holistic approach:
Case study research is a qualitative approach in which the investigator explores a bounded system (a case) or multiple bounded systems (cases) over time, through detailed, in-depth data collection involving multiple sources of information (e.g. observations, interviews, audiovisual material, and documents and reports) [...].(Creswell, 2007: 73)

Whereas an ethnographic project aims at understanding the workings of a culture-sharing group, case studies typically aim at exploring an issue, a developmental aspect on the basis of one or several cases (Creswell, 2007). However, not all researchers regard case studies as a methodology. Case study design can also be a consequence of the decision-making process and the question of what to study (Creswell, 2007). Case study, then, becomes a question of narrowing focus, for example, from primary EFL classrooms in general to the study of EFL classrooms at one particular school, as in this study. It is this view of case study I will adopt, since within the project reported on here, the case study design was a consequence of organisational decisions within the framework of a generally ethnographic-oriented approach.

Furthermore, the choice of cases may not always follow a purposeful sampling strategy. Sometimes cases have to be selected on the basis of accessibility and availability (Creswell, 2007). Since there were no established contacts to primary schools at the beginning of this project, it could not be predicted how many and which primary classrooms would be available for research. This depended entirely on the kind of response the researcher would get when distributing and collecting the questionnaire. A certain degree of uncertainty is by no means unusual in case study research, since 'we have little or no control over how the form or content of the data will appear' (Brown and Rodgers, 2009: 47).

A glimpse at the history of case study design highlights its versatile character. Apart from psychology, case studies have also been used in anthropology, sociology, 
political science, law and medicine (Brown and Rodgers, 2009). It is notable that, in human sciences, the description of a particular case or several cases normally centres on the progress that the individual(s) make over a period of time. Case study design, therefore, is by nature longitudinal, which meant for my project that a short period of observations would not be sufficient. Regular visits stretching over several weeks were needed, which of course is in line with principles of an ethnographic approach. And so is the demand for collecting a rich data source that can include both qualitative as well as quantitative data (Creswell, 2007). This is by no means a contradiction to earlier critical remarks on the nature of quantitative research in classroom research, but rather an extension of the argumentation that not one kind of research can hold the key to uncover the truth. In the same way, as quantitative research alone cannot answer all our questions on learning FLs, neither can research that focuses entirely on qualitative methods.

As with any research tool, design, or approach, there are also limitations that have to be considered in connection with case studies. Apart from an element of uncontrollability as discussed before, there is the issue of generalizability. Given the fact that the number of cases is always very limited even with a multiple case study, generalizability is, not surprisingly, regarded as 'problematic' in case study design (Brown and Rodgers, 2009). In other words, having studied a small number of primary EFL classrooms, one has to acknowledge that research findings of this project may not apply to other primary EFL settings, since the size of the sample is not representative to allow for generalization. Moreover, case study research is not about eliciting findings that could be generalized. It is about examining the particular in order to gain a deeper understanding of one issue, such as FL learning through songs, chants and stories in primary classrooms at one particular school.

\subsection{Discourse Analysis}

One more research tradition that is relevant to this project and needs further examination is discourse analysis. The link between education and language has already been highlighted. I have argued that a study in education entails the study of language. There is, however, also an overlap of ethnographic approach and language use:

A researcher undertaking ethnographic work in any community must try to understand that community's culture - its ways of 
acting in the world and making sense of the world - in the way community members understand it themselves. Speaking is both a way of acting in the world and a means for making sense of it, and language has thus been one of the aspects of culture that anthropologists have paid attention to. (D. Cameron, 2001: 47)

Within this theoretical concept, language is not only a means through which a culture-sharing group establishes its identity. It is also a means for members of a particular community to reflect on this identity. Language communicates the values and conflicts of a community, which is why an ethnographic study has to take into account how people use language.

The study of 'language in use' (D. Cameron, 2001), or 'language at use in the world, not just to say things, but to do things' (Gee, 2011: IX) can be referred to as discourse analysis. Studying the language as it is used by teachers and learners in the classroom can help to gain a deeper understanding of the learning environment and the language learning process. For this project, insights and tools of discourse analysis were used to study how teachers and learners interacted.

There are a number of features that discourse analysis shares with an ethnographic approach, and indeed also with an ecological worldview. In this respect, the preference for an explorative attitude towards research can be mentioned. One of the pioneers in analysing people’s everyday language use, Sacks (1984), stressed the need for an open attitude towards data, an attitude that is not biased by hypotheses. This idea can still be found in more recent publications, such as when the discourse analyst is recommended to approach a piece of data as if it was entirely strange, that is new (Gee, 2011). This is in line with qualitative research traditions. Theresearcher should approach a piece of data without any expectations or assumptions, since these would make it impossible to study a text objectively. If researchers try to find evidence for or against hypotheses, they will attend to data selectively and miss other patterns of communication in their data.

Another common feature that discourse analysis shares with the ecological perspective and ethnographic approach is the awareness that context is important and has to be accounted for by the researcher. With regard to what people say and how they answer questions, it has been argued that people always do so by 'first making some assessment of who is asking and why' (D. Cameron, 2001: 14). If one ignores the fact that participants in a study assess the situation, whether it is informal or formal interviews, or even a classroom setting when teachers are not directly 
talking to the researcher but to their learners, then one might easily take their statements at face-value when they are in fact a product of what participants think might be anticipated of them and how they feel about these expectations. One good example of this mechanism at work was provided by Wolfson (1976), who reported on her attempt to conduct unstructured interviews. Interviewees refused them on the grounds that they did not meet their expectations of a 'proper' interview. Therefore, the notion that 'talk is always designed by those who produce it for the context in which it occurs' (D. Cameron, 2001: 145) is valuable advice and needed to be considered for the analysis and interpretation of fieldnotes gathered through participant observation, and recorded classroom discourse as well as interviews.

One very important motivation that guides participants and that should not be underestimated is their effort to avoid losing face. Researchers who keep meticulous fieldnotes and even record everything that is said in the classroom may easily be perceived as intimidating and threatening, which is why participants may respond differently to the pressure of such a situation, which is asymmetrical, as all research encounters are (D. Cameron, 2001). Researchers must therefore study the discourse pattern for evidence of a struggle for power, which includes 'evidence of resistance to power' (D. Cameron, 2001: 178). Thus, data from this study was studied for underlying tensions between researcher and participants. Whereas primary children are less likely to have felt the pressure of their actions being scrutinized, teachers may have felt entirely different during observation and in interviews. This was taken into account in the analysis of teacher interviews as well as teachers' verbal behaviour in the classroom.

In line with minute attention to contextual information, discourse analysis demands thorough data collecting and processing procedures. First of all, oral discourse has to be transcribed, which involves audio-recording it. Once recordings are available for research, the question remains as to how much of these should be transcribed. In this project, every intelligible recording was also transcribed for the simple reason that it is the nature of speech to be 'evanescent' (D. Cameron, 2001). Un-transcribed utterances may carry important details which are easily lost to the researcher or his/her audience if not on paper. It seemed evident that transcribing classroom discourse as well as interviews would easily yield a very rich data source in a project such as this. In collecting data, I had to consider that too many recordings mean unmanageable amounts of data, while too few recordings may not provide 
sufficient data. A key question seemed to be to find out when enough data had been collected, such as when 'analysis is not turning up anything new, but only additional examples of patterns' that have already been identified (D. Cameron, 2001: 29). This is in line with the principle of 'saturation' mentioned by Davis (1995). There are still more practical questions concerning the accuracy and layout of transcriptions as well as the procedures for audio-recordings that need to be answered. These will be discussed in more detail in the chapters on participant observation and interviews.

\subsection{Concluding Remarks}

In this chapter, I have discussed various research traditions within the field of educational and classroom research in order to establish which methodology may be suited best to this project on primary EFL classrooms. With a study that explores new terrain, it seemed sensible to decide for an explorative as well as qualitative research approach, since closed-ended methods would have demanded hypotheses about the primary EFL classroom that could not be established without the risk of missing important issues (Chaudron, 1988). This study needed to explore English primary classrooms using open-ended methods that bring to light insights of teachers and learners and that reveal phenomena of this particular environment that can inform us and pave the way for future qualitative as well as quantitative analyses.

It has been argued that for this research project to be comprehensive, a multi-method design needed to be applied that entails qualitative as well as quantitative research instruments. It has also been suggested that for classroom research, various research traditions can inform on appropriate principles for research procedures and research instruments. Figure 1 (p. 60) demonstrates how insights from ecological, ethnographic, case study and discourse analysis research traditions have been applied in this project.

An ecological perspective was used as an overarching framework for this research project so as to ensure that research methods, instruments and procedures borrowed from different disciplines followed some common principles and were brought in line for a coherent methodology. An ethnographic approach was applied for an understanding of classrooms as culture-sharing communities. Insights from the ethnographic research tradition informed on how to gain insider knowledge through extended exposure to and participation in the life of a culture-sharing group, namely primary EFL classrooms. Case study design was used as a way of narrowing 
focus onto one particular school. Discourse analysis, the study of language used by teachers and learners, was referred to for collecting and analysing classroom and interview data.

It has been shown that all of these research traditions share some key characteristics, such as the demand for a rich data base and the use of different research instruments. Details of data collection procedures and principles for analysis will be reported on in the following second part of this thesis.

On the basis of the literature review that included studies on primary FLT practice and on the use of songs, rhymes, chants and stories in language education, the umbrella questions formulated at the end of Chapter 1 (p. 4) can be refined as follows:

1. How do primary teachers teach English to young learners in and around a medium-sized town in Rhineland-Palatinate?

- In how far is exposure to the FL influenced by timetabling and staffing issues and teachers' use of German?

- What role does singing, rhyming, chanting and storytelling play in teacher's lesson organisation in comparison to other activities and with reference to the teaching objectives they set themselves?

2. How do learners respond to being taught English in these classrooms?

- Is there any evidence of children's enthusiasm for singing, rhyming, chanting and storytelling and how does that compare to or compete with teachers' agendas?

- What is the nature of learners' FL output, such as individual words, especially nouns, or multi-item sequences, and are there any traces of out-of-school exposure to English in learners' use of English? 


\section{Chapter 5}

\section{Questionnaire}

For this project, data were collected over the period of three years between May 2007 and October 2010 (see Appendix 1 for Statement of Ethics). This chapter is devoted to the presentation of questionnaire data. I will report on the design, administration and analysis of a questionnaire distributed to local primary school teachers in a small area covering about $22 \mathrm{~km}$ from west to east and $20 \mathrm{~km}$ from north to south.

At the time when preparation for data collection started, the teaching of English at primary schools was still a new concept in Rhineland-Palatinate. The subject had only been introduced to all learners a year before. However, the conditions that teachers found themselves in on the introduction of the scheme were different to those in the pilot study conducted from 1990 to 1995 (Geibert, 1995; Helfrich, 1995). All learners were now supposed to be taught from Year 1 onwards instead of Year 3 and for 50 minutes per week instead of 90. The data gathered during the pilot study could therefore only be a rough indication of what teachers and learners were experiencing once the integrated EFL scheme was introduced.

It seemed appropriate to start a project on primary EFL with a questionnaire that would allow for a relatively swift return of quantifiable data, which would provide a sound basis for more in-depth research in classrooms. It was hoped that questionnaire data would not only answer some of the initial research questions but also highlight issues that should be explored further.

I will refer to the research questions formulated at the end of the literature review (p. 70) and discuss to what extent questionnaire data can contribute to answering these. Limitations of this research instrument will be commented on, as will any unusual or unexpected findings that made it necessary to refine my initial research questions.

\subsection{Methodology and Data Collection}

A questionnaire was seen as a suitable tool in the developing research design, since it lends itself to a more structured approach to participant selection (Dörnyei, 2003). Overall a two-phase design, consisting of a quantitative phase in the form of a questionnaire and a qualitative phase in the form of observations and interviews, 
seemed suitable for this project, since potential informants had to be identified first. Rather than approaching any small number of primary schools at random, a questionnaire could be used as a filtering device and allow for informed decisions in the selection process.

\subsubsection{Questionnaire construction}

The idea was that local primary teachers would receive a written collection of questions that they would be asked to complete themselves (Dörnyei, 2003). In the following, the process of questionnaire construction that was informed by Dörnyei (2003), Foddy (1993) and Peterson (2000) will be described in detail.

\subsubsection{Cover letter}

The introduction to a questionnaire can either be integrated in the questionnaire itself or provided separately in form of a cover letter (Peterson, 2000). In this project, the latter was chosen. Although I had established contact with headteachers of each primary school beforehand and explained the nature of the project to them on the telephone, I had not had the opportunity to speak to each teacher before the administration of the questionnaire. It was felt that some form of personal contact needed to be established to each individual teacher, and a cover letter provided the necessary platform to do so (Appendix 1).

The introductory section has to fulfil two functions, namely to encourage participation through rapport and to 'legitimize a research project' (Peterson, 2000: 103). Rapport was built by introducing myself as a teacher trainer and writing my personal signature under each cover letter. As for legitimization, the nature of the research project was clearly described. It was stressed that teachers' insights were highly valued and regarded as essential in the process of creating appropriate courses for future generations of teachers, thereby explaining to the participants why information was being collected (Foddy, 1993). In the second part of the cover letter, the practicalities of completing the questionnaire were explained, such as anonymity and the nature of the questions to be answered. It was emphasized that the questionnaire had been designed so that it could be filled in relatively easily and quickly. A note assuring that all answers would be dealt with in strictest confidence was incorporated and put in bold print so as to clearly stand out. The main body of the letter ended with a thank-you note for potential participants. 
Below the personal signature of the researcher, there was an additional note printed in a lighter shade of grey that could be cut off by participants and returned via fax. Participants were given the opportunity to express the wish to be informed about the results of the survey and to volunteer for further co-operation.

With brevity being another essential feature of a good cover letter so as not to lose the interest of potential participants (Peterson, 2000), the main body of the letter was no longer than about a third of a page, and the whole letter with addresses, signature and extra note fitted on one A4 page.

\subsubsection{Questions on aspects of primary-level EFL teaching}

This part of the questionnaire started with three lines of instructions followed by two sets of questions, the first consisting of general questions about the teaching of English at primary school and the second consisting of questions about the use of songs, stories and rhymes (Appendices 2 and 3).

While questions have to be placed in a logical order so as to avoid confusion and to reduce ‘the time of administering a questionnaire’ (Peterson, 2000: 108), questions also have to be ordered so as not to 'allow the questions or their answers to influence answers to subsequent questions' (Peterson, 2000: 108). In the first part of the questionnaire, for example, questions about how to integrate English into different subject areas (1a - 1d) were grouped together, and so were questions about teaching materials (2 - 3) and popular activities (4 - 5). In order to avoid participants being biased in their answers by the order in which questions appeared, the question about learning objectives in primary EFL (5) was placed at the end of this set of questions. It was felt that putting this question at the beginning or middle of the set would have impacted on teachers' answers about when and how to integrate the FL as well as what kind of material and activities to use, since teachers are trained to plan their teaching on the basis of teaching objectives. A similar structure was used for the second set of questions concerning the use of literary texts and songs in the primary EFL classrooms.

In terms of ordering, there is another aspect that needed to be considered, namely that questions that are 'less complex, less difficult to answer, less threatening, or less personal' should appear before 'more complex, difficult, threatening, or personal questions' (Peterson, 2000: 109). In this questionnaire, general questions about the teaching of English at primary level were considered less complex than 
questions on literary texts and songs in the classroom, which might have been perceived as very specific, more difficult and even more personal. However, also within each section, easier questions were put before more complex questions. For example, the closed-ended question asking teachers to select the accessible and favourite teaching materials from a list ( 2 and $3 a$ ) demanded less cognitive effort from participants than the open-ended question that asked teachers why certain materials were more suitable than others in the learning of foreign languages (3b).

Open-ended questions are generally considered to 'take more time and effort to answer' (Peterson, 2000: 32) since the participant is not provided with ready-made answers, which explains why non-completion rates are higher than with closed-ended questions. However, if answered, they hold the potential to provide the researcher with valuable insights and insider knowledge that the researcher could not have anticipated and thus not have given as an answer option in a closed-ended question format (Dörnyei, 2003). Questionnaire items 12 and 13, the last questions in this question section, are also good examples of open-ended questions that can 'provide a far greater “richness” than fully quantitative data’ (Dörnyei, 2003: 47). Question 13, for example, is a probe question and nondirective, inviting participants to give any further comments on primary EFL. If answered with enthusiasm, this question was the one most likely to yield surprising new issues for future research. Because of its nondirective nature, and the effort that was involved in answering it, this last question may have been regarded as especially 'tricky' or difficult. At the same time, this question may have also been experienced as motivating, since a questionnaire consisting only of closed-ended question items or open-ended questions that are too directive creates the impression that respondents' views have to match preconceived answer options (Gillham, 2000).

Question 12, on the other hand, may have been perceived as the most sensitive question. A question asking participants to report on any problems that can occur when using literary texts or songs in primary EFL can easily be interpreted as a very personal, or even threatening question. Teachers might have been worried that any problems they mention are interpreted as a lack of competence. However, this question held the potential to uncover issues that the researcher without hands-on experience of primary EFL classrooms may not have considered and easily missed. Thus, in order to avoid teachers feeling intimidated, the wording that was chosen incorporated the modal verb können, which means 'can', and the phrase aus Ihrer 
Sicht, which translates as 'in your view'. This implied a sense of variability, namely that not everyone was expected to have the same opinion, or rather that there was no 'right' answer to this question.

Two of the closed-ended items were multi-scale items following the design of Likert scales. The original set of responses of 'strongly agree' to 'strongly disagree' was modified as suggested by Dörnyei (2003). In this questionnaire, respondents had to indicate the importance they attach to different teaching objectives (Question 6) and to the reasons why they use literary texts and songs (Question 9). In each case, an odd number of steps was chosen ranging from 1 (sehr hoch/ very important) to 5 (sehr gering/ not very important at all). In order to accommodate answers that were not listed as items in the questions, an extra option called 'other' was added to each list. In this way, an attempt was made to outbalance any incompleteness of this closed-ended question format.

\subsubsection{Demographic questions}

Demographic questions about the participants were placed at the very end of the questionnaire where they are least likely to meet rejection because of their sensitive nature or because they evoke a sense of bureaucracy (Peterson, 2000; Dörnyei, 2003). While placing demographic questions at the end is one strategy to keep refusal rates low, it was not the only measure to be considered. Care also had to be taken not to overstretch participants' patience by asking too many personal questions. For that reason, questions that were not relevant for this study or could easily compromise anonymity were not included, such as questions about the teachers' marital status or gender. With only a small minority of male primary school teachers in schools, a question item on gender would have exposed male participants unnecessarily, while the small number of anticipated questionnaires from male teachers also meant that the data would not be sufficient to draw any conclusions from. However, teaching qualifications, experience and personal interests seemed crucial to understand and categorize teachers' responses appropriately. Teachers' responses on teaching material and activities, for example, were expected to be influenced by teachers' level of English and their interests in literature and music, so the questionnaire had to include questions on these aspects.

In order to avoid any intimidation that might be caused by questions on qualifications and experience, all answer options were carefully listed so that the 
lowest possible type of qualification was always mentioned first, and the highest last (as in Questions 18 and 19), whereas with regard to teaching experience the shortest time span was always mentioned first, and the longest last (as in Questions 14 and 16). This procedure ensured that teachers saw the answer option most suited to describe their status before they noticed answer options beyond their current level of knowledge and experience, which might have caused participants to feel incompetent. Participants might have been reluctant to answer these questions truthfully or they might have felt inclined not to answer them at all.

Another measure that was taken to reassure participants and to encourage them to give honest answers was the repeated confirmation of ensuring anonymity at the beginning of this section. Moreover, participants were informed that they could leave any questions unanswered by putting an abbreviation for 'no comment' next to the question if they did not wish to provide an answer.

The last two questions in this section concern the learners. Information about their previous knowledge of English or their first and second languages was hoped to help interpret data gathered about their learning progress and also about teachers' decisions on appropriate learning material or activities. Therefore, teachers were asked to indicate how many of their pupils learnt English as their first or second FL, how many spoke German as their second language and how many had already had some English tuition at kindergarten.

The demographic question section was designed to be no longer than one A4 page so as not to overwhelm participants, and the slightly smaller print was used to underline the fact that these questions carried less importance than the questions on primary-level EFL teaching. All in all, the questionnaire comprised four pages that were printed onto A3 paper and folded into booklet format for convenient handling. The questionnaire ended on a note expressing the researcher's gratitude to the participant.

\subsubsection{Piloting}

Before the questionnaire was distributed to teachers in local primary schools, a first version of the questionnaire was given to six volunteers who provided valuable feedback on the structure and wording of the questionnaire. This piloting phase took place between March and April 2007. Among the volunteers to test the 
questionnaire were three academics, all lecturers of applied linguistics, and three primary school teachers employed in Rhineland-Palatinate.

Suggestions that were made during the piloting phase mostly concerned the wording of the questions or answer options. Language that was perceived as too vague or too technical was changed to improve readability (Foddy, 1993). Only once did extra answer options need to be added. One teacher felt that there should be a number of answer options for Question 1b that asks if English is offered as a separate session. I had expected schools to either opt for integrating English into other subject areas or to offer English in separate sessions. The teacher's comment to add answer options such as 'often', 'sometimes', 'rarely' and 'never' suggested that there was much more flexibility in the organisation of EFL provision. This was taken seriously in an attempt to ensure that response options were both complete and well-balanced (Foddy, 1993).

One issue unfortunately became obvious only after the piloting phase. Question 19 asks how participants learnt English. In the original version the first answer option was phrased as 'I attended further training courses', which had been anticipated as the most basic answer type. Since other types of learning English other than the ones provided could still be written down next to the answer box 'other', it was felt that any irregularities would still be catered for. One teacher during the piloting phase indicated that she had only learnt English at school, but it was regarded an exception for a teacher not to have had any further training, and the set of answer options was not changed before the first batch of questionnaires was distributed. However, during the course of questionnaire administration, I was able to hold informal talks with teachers and headteachers, and it soon became obvious that by no means had all teachers been given extra training to teach English at school due to organisational constraints, and therefore the only FLT that they might have received was during their time at secondary school. All these teachers would not have been able to tick any ready-made answer option and they would have had to explain next to the box 'other' that their only EFL training was at school, which might have made them feel uncomfortable and out of place. In order to avoid feelings of intimidation, it was considered best to introduce this answer option for the second batch of questionnaires distributed in local primary schools.

Unfortunately, it must be noted that the lack of this answer option might have had a negative impact on return rates for the first batch of questionnaires. 


\subsubsection{Administration of questionnaire}

One of the first questions with regard to questionnaire administration concerned the size and type of sample. With recommendations ranging from $0.1 \%$ to $10 \%$ (Dörnyei, 2003), deciding on the correct sample size is a complicated matter. In this project, the main purpose of the questionnaire was not to collect as much data as possible but to collect enough data to make informed decisions for follow-up qualitative research. Thus, it was decided best to follow the practical advice given by Dörnyei (2003) to use a sample of about 50 participants. This is a relatively small sample, but it must be noted that the focus during this preparatory stage of the whole project was on identifying potential issues for in-depth research and for establishing contact with potential participants.

With regard to sampling type, it was important to strive for a sample that would reflect the characteristic structure of that particular professional group and be 'very similar to the target population in its most important general characteristics', such as age, gender, ethnicity or educational background (Dörnyei, 2003: 71). In order to achieve this mix in the sample, it was decided that the questionnaire should be distributed to all primary teachers in one region including village schools as well as schools in a more urban setting. In this way, responses from as many teachers as possible from this small community could provide a miniature image of primarylevel EFL practice in one region of the federal state. From the start, the focus was on achieving complete coverage of one small area and a high return rate. This, it must be noted, is very different to an approach that addresses a big community of teachers, as practiced in online surveys for example. In the latter approach, the number of questionnaires distributed is much higher, and the number of returned questionnaires available for data analysis can easily exceed a sample of 50. However, the percentage of teachers who respond as compared to the number of teachers targeted is normally quite low, because participants can easily refuse to take part in an online survey by just deleting the email message. It is also more difficult to establish rapport through an email that can be deleted before it has even been read. Rapport, however, is a key ingredient for high return rates. The lower the return rate, the less likely it is that the sample is representative of the community that was addressed. Such a sample may provide data that stems from individual teachers from many different schools in very different areas. Their responses must be regarded as isolated voices from an otherwise silent crowd. In this way, a bigger sample does not 
equal better data, on the contrary. Therefore, the most suitable approach seemed to be to ensure high return rates by concentrating on a small community.

Since universities work alongside schools and not from a superior position in the educational hierarchy, completion of questionnaires is always on a voluntary basis. Apart from the fact that compulsory participation in research projects is not very likely to yield honest answers and extensive data from participants, it is the only way to ensure a $100 \%$ return rate. Voluntary participation, which equals participant self-selection, on the other hand, always carries the risk of lower return rates, although it holds the potential of richer and more insightful data (Dörnyei, 2003). It is not difficult to envisage that primary school teachers who might not be motivated to teach English in their classrooms would be potential dropouts in this study. With their concerns not being voiced, the data would provide a distorted picture of real primary EFL classrooms. It was therefore important to identify ways in which high levels of participation could be encouraged.

One strategy was to establish personal contact in order to stimulate interest. Rather than sending out pre-survey letters (Dörnyei, 2003) that can go unnoticed, especially at busy times, headteachers were contacted via telephone. The telephone call was not meant to take up too much time so as not to be perceived as an intrusion. In the telephone calls, the researcher introduced herself, explained the objectives of the research undertaken, provided some information about the content and length of the questionnaire as well as the procedures for administration. An offer was made to headteachers to inform them about the results of the survey (BAAL, 2006).

Apart from getting the immediate attention from decision-makers at school, the first contact via telephone was also a good opportunity to respond to any questions that headteachers had. This helped to reassure headteachers and to create a sense of transparency, which was more likely to win their support than a letter that by nature has a more formal effect and does not allow for any spontaneous interaction. Headteachers did, indeed, respond positively to this approach and expressed their support throughout. While headteachers of all bigger primary schools warned against low return rates, explaining that they received great numbers of queries from researchers and students to fill in questionnaires, headteachers of small schools often expressed their surprise and their delight at being invited to take part in a research project. 
The first batch of 87 questionnaires was distributed in May/June 2007 in close proximity of approx. $7 \mathrm{~km}$ west, north, east and south of a medium-sized town. The second batch of 48 questionnaires was given to schools in small towns and villages further away, up to approx. 10km south and north of town and $15 \mathrm{~km}$ west after the summer break. A total of 21 schools were given questionnaires, which equaled a hundred percent coverage of all state primary schools that offered English in that area. Only two schools did not take part in the study, one of which was an independent school, and the other only offered French at primary level. All in all, 135 questionnaires were distributed, out of which 60 were returned and could be used for analysis, producing a return rate of $44.4 \%$.

Most questionnaires of the first batch were delivered by myself, and I used this opportunity to speak to headteachers, heads of departments or teachers in person in order to establish some personal connection with participants, who were more likely to develop a sense of commitment if they knew the person who was carrying out the project. However, some headteachers stated explicitly that they preferred to receive the questionnaires by post. This request was respected in order not to cause unnecessary conflict, which could have had a negative impact on participation. The idea was to allow schools a choice of questionnaire administration so as to avoid any inconvenience or intimidation that could have led to biased results.

\subsubsection{Questionnaire return}

The return rate (51.7\%) was highest in the town during the first period of questionnaire distribution. The lowest return rates were achieved during the second period of questionnaire distribution in September/October 2007, namely 35.4\% (see Appendix 4). As expected, the degree of personal involvement in the project had an impact on return rates. Whereas I had visited 6 out of the nine town schools during questionnaire distribution, all the other schools had received the questionnaires in the post. Return rates were higher where personal contact had been established not only via a telephone call but also through distributing questionnaires in person.

The three schools that produced a return rate of $100 \%$ were all smaller schools or schools where fewer staff taught English, whereas lower return rates can at least be linked to two schools with a higher number of staff. This is in line with the remarks by headteachers of smaller schools who expressed enthusiasm about the project and heads of larger schools who pointed out that there was a certain 'survey 
fatigue’ factor among staff. There was one school that did not return any questionnaires due to organisational constraints, according to the headteacher.

It must be noted that a few headteachers, especially those at larger schools, did not exactly know how many teachers were teaching English, and how many questionnaires were needed. To be on the safe side, headteachers' highest estimates were used during questionnaire administration. Therefore, the overall return rate of $44.4 \%$ represents an estimate at the lower end of the scale. The real return rate may well have been slightly higher.

\subsection{Procedures for Data Analysis}

Data was going to be analysed qualitatively as well as quantitatively. Data processing started with each questionnaire being allocated a unique identification code. Data were initially entered into an Excel file and later uploaded to SPSS for the reliability analysis of scales.

\subsubsection{Data entry and coding procedures}

Answers had to be simplified for open-ended questions, such as Question 4 on most favourite activities in the primary English classroom. Teachers' answers that consisted of anything from individual words to sentences had to be numerically coded. If a teacher's response was seen as identical to responses from other teachers, such as 'singing' and 'singing songs', then it was coded in the same way. If, however, a teacher introduced a new thought and her answer did not exactly match any answers given before, then a new category had to be opened up. In this way 'artwork' was not seen as identical to 'work with material that they made themselves' in Question 4. Open-ended questions like this produced between 10 to 30 different codes. A balance had to be struck between keeping clearly distinct answer categories and keeping answers separate that really referred to different concepts. The process of turning words into numbers involves interpretation and must be seen as simplification. Although greatest care was taken to be true to original answers, it is acknowledged that there is a risk of misinterpretation.

In order to ensure transparency during data entry, a logbook was created in the form of comments within the Excel file. The researcher used this tool to ensure that coding was consistent during data entry, which stretched over several weeks, and that coding procedures could be looked up again during data analysis. 


\subsubsection{Problematic issues}

All in all, it has to be said that data entry revealed some problematic aspects with question items that had not been anticipated, although the questionnaire had been piloted and checked carefully. Some of these were clearly linked to questionnaire design and could have been avoided, such as a missing negative answer option (Question 1c), a lack of space in a table (no. 6) and confusion about follow-up questions (nos. 8a-d). As anticipated, Question 19 about the teachers’ English language background proved problematic. Although it was answered by more participants than the other questionnaire items mentioned above, 8 of 60 teachers still left it unanswered. Interestingly, 7 of these were part of the first batch of questionnaires to be sent out, at a time when the answer option 'I learnt English at school' had not yet been added. The decision to extend the set of answer options in order to include the lowest possible qualification proved worthwhile, with only one teacher of the second batch of 29 teachers avoiding this question.

In some cases, however, a change of questionnaire design would not have prevented problems. In Question 2 about material that was available to them for primary EFL, for example, some teachers did not report using a textbook but they ticked the box for 'listening material accompanying the textbook'. It was decided that the respondent probably meant that although they did not have a textbook, they would still use CDs or tapes, and therefore these answers were coded as option answer 'extra listening material for songs, stories and poems'. Then, there was another problem with Question 6 on the importance of different teaching objectives. Some teachers put crosses on the lines separating two columns, signalling that they could not make up their mind if it was 'very important' or just 'important'. In that case, the higher figure of the scale was always entered. This meant that the data had to be changed slightly in order to fit into the numerical system.

For two questionnaires coming from the same school, most answers were identical, which means that these questionnaires may not be entirely genuine. Differences in answers were only found in five demographic questions. One should not assume indifference to the questionnaire too readily. This behaviour of answering questions in the same way may also stem from a considerable amount of insecurity, indicating that at least one of the two teachers did not want to 'make any mistakes' by providing answers that could be perceived as 'wrong'. Apart from these two questionnaires, all others seemed genuine. 
The enthusiasm with which teachers answered questions varied enormously. On the low end of the scale, there was one questionnaire that was very sparsely completed, and on the opposite end of the scale there were questionnaires that were completed elaborately with long lists of up to 30 titles of stories, songs and rhymes used in the primary EFL classroom. If extensive answers in questionnaires can be an indicator for the enthusiasm with which teachers approach primary EFL, then it is interesting to note that this enthusiasm could not be linked in any way to teachers' qualifications or the amount of teaching experience in primary EFL. Elaborate answers came from teachers with varying degrees of qualification and experience. However, some of the teachers who reported using a great variety of different material in the classroom also reported having had more than average language training or general teaching experience.

\subsection{Questionnaire Results}

The demographic question section consisted of questions 14 to 22 and provided information on the participating teachers. In the following, I will report on participants' teaching experience, qualifications and personal interests before presenting main findings on teaching practice and the use of songs, rhymes and stories.

\subsubsection{Demographic information}

One can note that all different age groups of teachers were represented in the sample (Figure 2). Answers to questions therefore reflect views from teachers with varying degrees of experience.

The data also suggest that teaching English was a new experience for most teachers in this sample, with almost three quarters of teachers having taught English for less than 5 years (Figure 3). However, the remaining teachers had taught English for longer than 5 years or even 10 years. If some of the latter had been teaching in Rhineland-Palatinate at the time, these teachers would know about the pilot project, and would be conscious of the changes to the concept that were undertaken after its introduction to all primary schools. 
Figure 2: Working experience as a primary school teacher (Question 14)

No. of responding teachers: 60

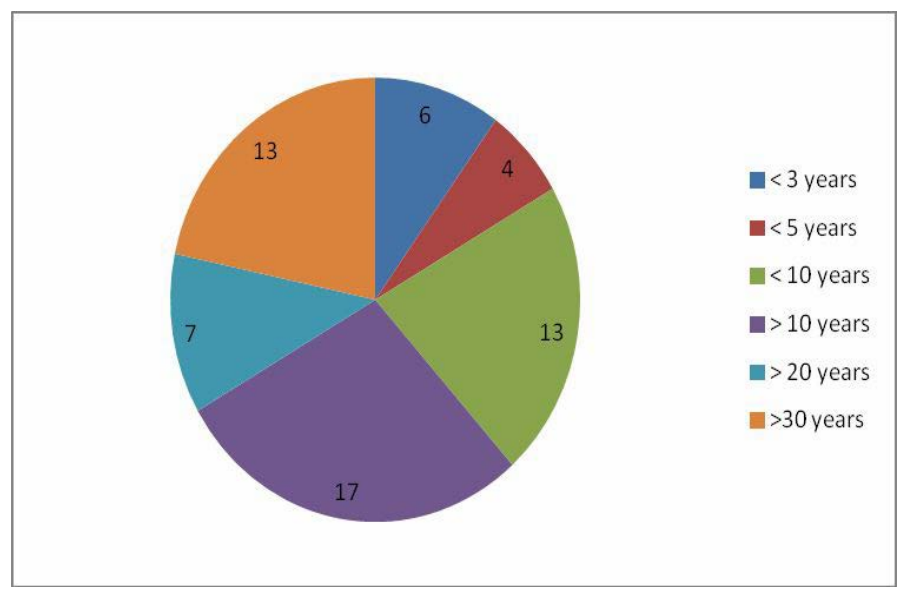

Figure 3: EFL teaching experience at primary school (Question 16) No. of responding teachers: 60

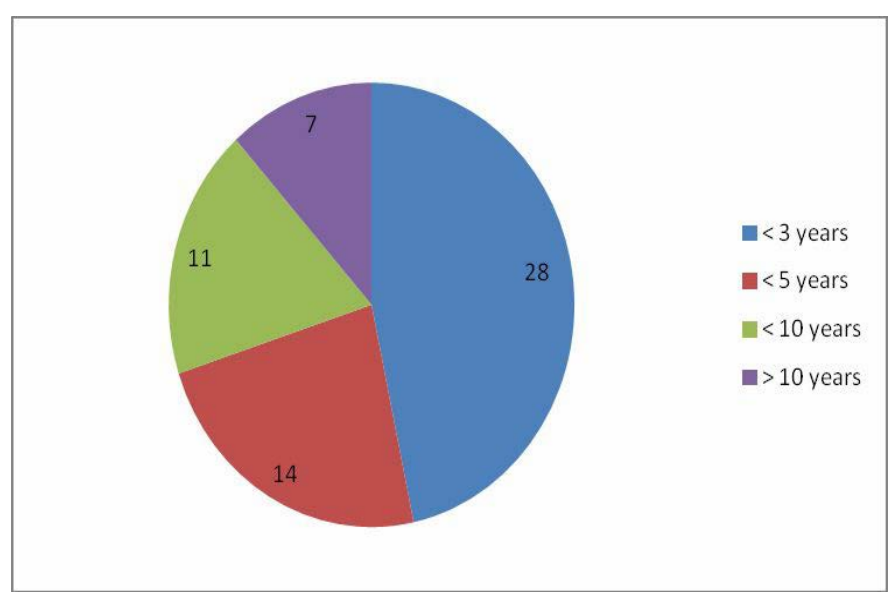

Answers to Question 18 provide valuable information on teachers' related teaching experience. 18 percent of responding teachers (11/60) had also taught English at other institutions, of whom all but two worked at the Hauptschule, the German equivalent to the former secondary modern school in the UK. These teachers would have taught teenage learners in the FL, which might have had an impact on their teaching style. These teachers most likely would also have studied English as a main subject at university during the first phase of teacher training. Indeed, 8 teachers, which equals 15 percent of all responding teachers, reported having studied English at college or university (Table 1). It means that 85 percent of the remaining teachers who responded to this question had to receive their EFL training that enabled them to teach English in a primary classroom elsewhere or that they did not receive any 
training at all. Since 8 teachers left this questions unanswered, results have to be treated with caution. However, there is reason to believe that those teachers who did not answer this question, did so because they did not feel that their training was adequate.

Table 1: Teachers' EFL training (Question 19)

(teachers could choose more than one option)

No. of responding teachers (non-responding teachers): 52 (8)

\begin{tabular}{|l|l|l|}
\hline Answer options & No. of teachers & $\begin{array}{l}\text { Percentage } \\
100 \%=52\end{array}$ \\
\hline I learnt English at school. & $21^{*}$ & $40 \% *$ \\
\hline $\begin{array}{l}\text { I attended additional professional training } \\
\text { courses alongside my work. }\end{array}$ & 34 & $65 \%$ \\
\hline $\begin{array}{l}\text { I studied English as a subject when I did my } \\
\text { academic training at college/ university. }\end{array}$ & 8 & $15 \%$ \\
\hline $\begin{array}{l}\text { I lived in an English-speaking country. } \\
\text { I worked in an English-speaking environment. }\end{array}$ & 0 & $0 \%$ \\
\hline I am a native speaker of English. & 0 & $0 \%$ \\
\hline
\end{tabular}

*It is likely that not all teachers ticked all the answer options that applied to them. More teachers might have learnt English at school and attended further training, but only indicated the highest qualification, namely additional professional courses.

If one analyses teachers' answers to Question 19 in more detail (Table 2), one finds in fact that 21 percent of responding teachers reported only having been taught English at school. One fifth of responding teachers then have to teach EFL even though they reported never having attended any training for it. This is quite a remarkable proportion of teachers without appropriate teaching qualifications, and confirms findings of various European studies that have revealed teacher training as a problematic issue in primary EFL (Nikolov, 2000; Oostdam and van Toorenburg, 2009; Enever, 2011a; Eurydice, 2012). 
Table 2: Analysis of different types of teachers' EFL training (Question 19)

No. of responding teachers (non-responding teachers): 52 (8)

\begin{tabular}{|c|c|c|}
\hline Type of EFL training & No. of teachers & $\begin{array}{l}\text { Percentage } \\
100 \%=52\end{array}$ \\
\hline Additional professional training courses only & 24 & $46 \%$ \\
\hline EFL classes at school only & 11 & $21 \%$ \\
\hline $\begin{array}{l}\text { EFL classes at school and additional } \\
\text { professional training courses }\end{array}$ & 9 & $17.5 \%$ \\
\hline English as subject at college/university & 7 & $13.5 \%$ \\
\hline $\begin{array}{l}\text { EFL classes at school, English as subject at } \\
\text { college/university and additional professional } \\
\text { training courses }\end{array}$ & 1 & $2 \%$ \\
\hline
\end{tabular}

A lack of training is likely to impact on the quality of input that teachers can provide in the FL. One would not expect teachers without intensive training in the FL to use it as confidently as someone who has been exposed to the FL over long periods of time during academic training or stays abroad. The exposure to the FL that learners receive through the teachers' use of English may be limited.

As for the range of subjects teachers cover, one can note that almost all of the responding teachers teach all the main subjects, such as German, maths and science. Over two thirds of them also reported teaching each of the specialist areas art, music as well as PE, and even over one third mention teaching RE/ethics (Figure 4). Traditional teacher training normally covers all the main subjects, but not all the specialist areas. Therefore, one should expect much lower figures for the specialist areas. These high figures suggest that teachers have to teach more subject areas than they received training for at university. Informal talks with teachers at school have confirmed this. While some of them were able to gain extra teaching qualifications for some of the additional subject areas, there are also cases where teachers have to teach subject areas that they have not received any training for. There are also teachers who have had to teach all subjects of the primary curriculum during some school years of their career. 
Figure 4: Teacher's subjects (Question 15)

No. of responding teachers (non-responding teachers): 59 (1)

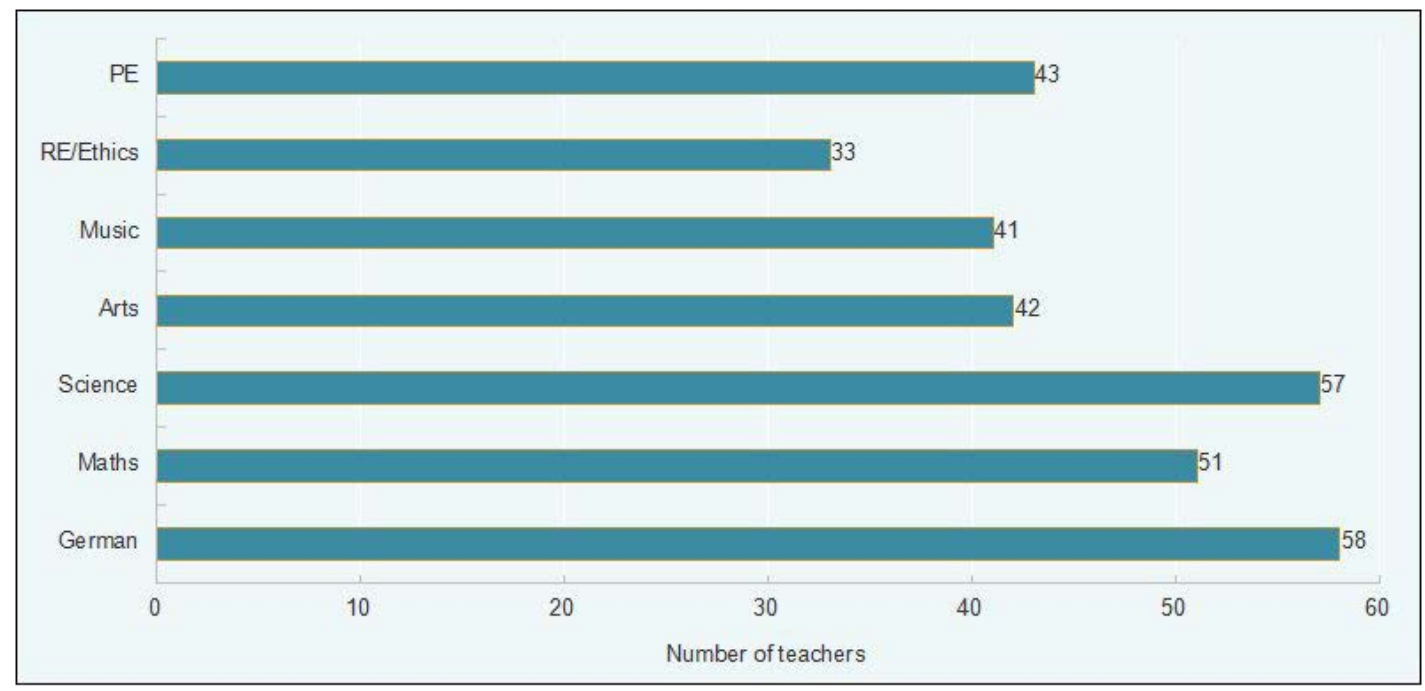

Most teachers of this sample were working with Year 3 at the time of the survey (Figure 5). All year groups were represented and almost as many teachers were teaching Years 1 and 2 (32) as Years 3 and 4 (38). Since some teachers not only teach their own class in English but also have to go into other classes as specialist teachers of English, the total figure of teachers is above 60 .

Figure 5: Teachers' year groups (Question 17)

No. of responding teachers (non-responding teachers): 59 (1)

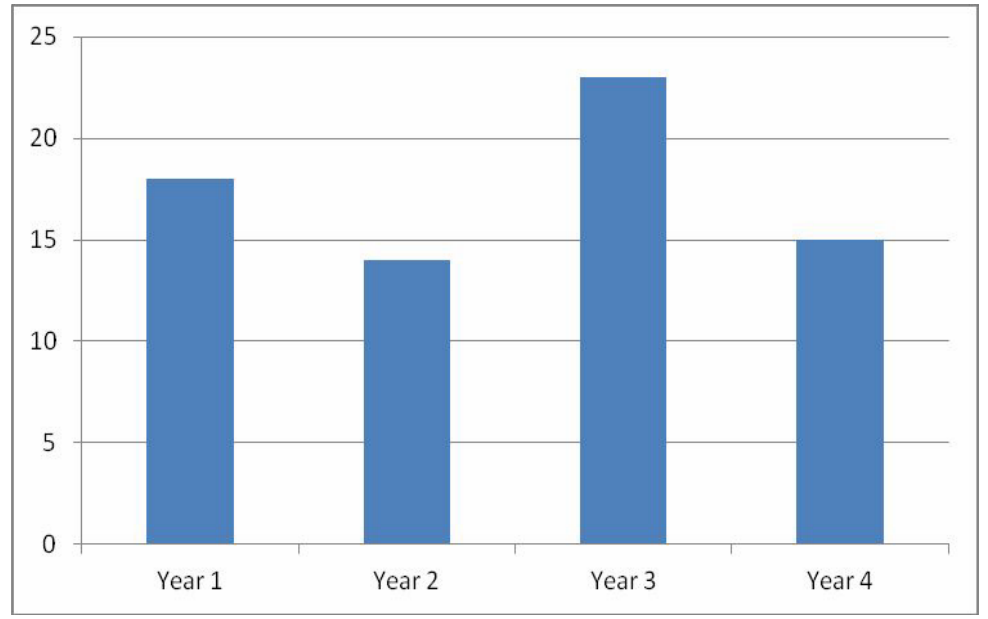

Answers to Question 27 on interests and hobbies of teachers were supposed to provide some context for the interpretation of data on songs, stories and poems (Figure 6). With the majority of responding teachers indicating that they did or do a 
lot of reading and with at least half of them reporting having sung in a choir at some point and more than half of the teachers mentioning that they play one or more than one instrument, this sample consists of a majority of teachers who are in favour of literary texts and music.

Figure 6: Teachers' experience with music and literature (Question 20) No. of responding teachers (non-responding teachers): 59 (1)

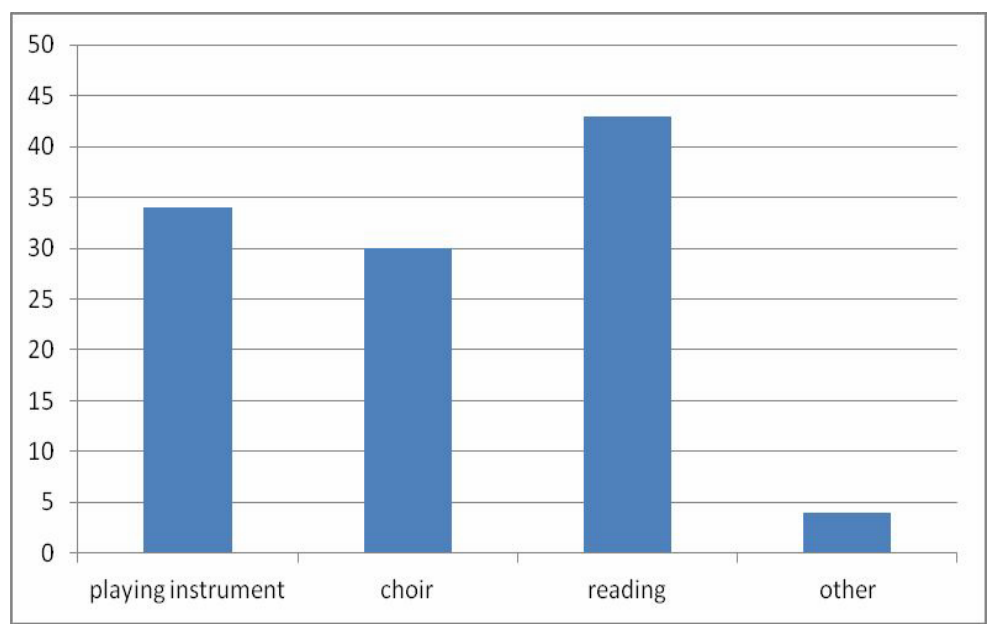

Teachers' generally positive attitude towards literature and music is likely to have impacted on their answer behaviour. This suggests that teachers who completed the questionnaire did so because of their positive attitude to music and literature. While this might be true, we also have to acknowledge that reading and playing an instrument are generally regarded as worthwhile past-times by the educated, and even teachers who did not complete the questionnaire may still attend to these hobbies. Indeed, considering the fact that music and literature are commonly associated with an elitist and sophisticated group, it is astonishing that about one quarter of responding teachers admits to not reading in their spare time, and more than one third does not seem to play a musical instrument. Neither should we assume that a preference for music and literature always leads to a preference for singing and storytelling in the classroom, since these could still be perceived as too challenging with a group of FL learners. On closer inspection, this sample proves to be more varied than suspected. It is certainly not only made up of teachers who report to be literature and music enthusiasts. Less than one third of teachers (19/60), reported to be devoted to all three activities in their free time, namely playing an instrument, singing in a choir and reading. 


\subsubsection{Integrating EFL into other subject areas and using it in various contexts}

Table 3 presents teachers' responses to the question in which subject areas English is integrated. One can note that English is most often integrated into the teaching of music, closely followed by science and German. High scores for integrating English into German and science may seem surprising, but one has to remember that these two subjects are considered the main subjects in the primary curriculum, alongside maths. It is possible that teachers use English, because they see this as an opportunity to practise new topics in a different way repeatedly. For example, when talking about the autumn in science class, one can teach children a poem about autumn in English. However, maths, which would lend itself to this strategy of varied and repeated practice in the FL, if we think of counting games for example, does not seem to be popular with teachers when it comes to integrating English. One possible explanation is that teachers who did not study English as their main subject at university, lack the English terms that are needed for describing mathematical calculations that go beyond basic counting, and may therefore feel less confident. 17 teachers reported integrating English into PE, which is a higher result than for maths.

By comparing the numbers of teachers who reported teaching each subject area with the subject areas they indicated to be using for EFL teaching, the extent to which some subject areas are favoured for integrating English becomes even more obvious (see Appendix 5). This is especially true for music. While 41 out of 59 responding teachers reported to teach music (Question 15, Figure 4); 42 out of 60 responding teachers indicated that they used English when teaching music (Question 1a, Table 3). Thus, every teacher who taught music reported to also integrate English into their music lessons. Music is the only subject area that received unanimous support with regard to EFL teaching.

When analysed in more detail (Table 4), one can see that a minority of teachers (7/60) manage to incorporate English into five or six subject areas and about one quarter of them still uses English in four subject areas, which is astonishing for various reasons. Again, it highlights the fact that some teachers cover almost all of the primary-level curriculum and are therefore able to incorporate EFL into many other subject areas. Moreover, it is surprising to see that some teachers invest in the planning of cross-curricular activities, which is likely to be more timeconsuming, when EFL only holds a very limited time slot of 50 minutes per week. 
Music, PE or RE, for example, have been allocated two to three weekly lessons each, and one would expect teachers to plan their preparation time accordingly.

One might have expected to find a great majority of teachers who use English in two or three subject areas, but only one third reported integrating English into two to three subject areas. At the same time, almost quite as many admit to integrating English into only one subject area or not at all. This is also remarkable given the fact that integration into other subject areas is a key element in the FLT concept developed in Rhineland-Palatinate (e.g. Geibert, 1995; Helfrich, 1995). It suggests that integrating English into a few subject areas poses a problem to a substantial number of primary teachers, namely 28.3 percent in this sample.

Table 3: Integrating EFL into other subject areas (Question 1a)

No. of responding teachers: 60

\begin{tabular}{|l|l|}
\hline Subject areas & No. of teachers \\
\hline Music & 42 \\
\hline German & 36 \\
\hline Science & 36 \\
\hline PE & 17 \\
\hline Maths & 16 \\
\hline Arts & 13 \\
\hline RE & 1 \\
\hline
\end{tabular}

Table 4: Integrating EFL into other subject areas (Question 1a)

No. of responding teachers: 60

\begin{tabular}{|l|l|}
\hline No. of subject areas & No. of teachers \\
\hline 6 & 3 \\
\hline 5 & 4 \\
\hline 4 & 16 \\
\hline 3 & 10 \\
\hline 2 & 10 \\
\hline 1 & 11 \\
\hline 0 & 6 \\
\hline
\end{tabular}

Teachers' answers to Question $1 \mathrm{~b}$ also indicate that, in practice, there are some problems with the concept of integrating FL learning into regular teaching time. Official recommendations can only be followed in rare cases (Table 5). Not even $10 \%$ of the responding teachers reported that English was completely integrated into regular teaching, while 25\% stated that English was always offered as a separate session. It must be noted that English is more often offered as a separate session than it is fully integrated into everyday teaching. However, the majority of teachers, namely $66 \%$, seem to opt for neither extremes but prefer a flexible approach of both, integrating the EFL into normal teaching and teaching it separately, to varying degrees. 
Table 5: EFL provision in form of a separate session (Question 1b)

Number of responding teachers (non-responding teachers): 56 (4)

\begin{tabular}{|l|l|l|l|l|}
\hline Answer option & always & often & sometimes & never \\
\hline No. of teachers & 14 & 19 & 18 & 5 \\
\hline Percentage & $25 \%$ & $34 \%$ & $32 \%$ & $9 \%$ \\
\hline
\end{tabular}

Percentage calculated on the basis of no. of responding teachers

Here, one might suspect that teachers have an established routine of when and how to integrate the FL into everyday teaching. Indeed, an overwhelming majority of teachers, in fact 62 percent, reported using English at the beginning and at the end of a class (Table 6). This suggests that English is mostly used for rituals in the classroom, such as greetings, saying how you feel, counting how many children are there and who is missing. This also indicates that, although teachers might be using English at the beginning of a PE or maths class, the kind of communication will be very similar and the extent to which the FL is used to communicate about the topics that are going to be at the centre of a lesson must be quite low.

Almost one third of teachers (30\%) reported using English with children sitting in a circle, which is a seating arrangement frequently used in primary school classrooms whenever the focus is on oral communication, as for starting a new subject, presenting students’ work and storytelling for example. Since self-study activities, projects as well as pair work, involve children taking the initiative and therefore need a higher percentage of verbal responses coming from the learners themselves, this means that these situations are linguistically more challenging for learners of English. It is not surprising then that only few teachers reported using English in these contexts (Table 6). Four to five teachers stated that they used English when their learners work in groups and pairs, during self-study activities, and during projects, but it is important to note that these are not the same teachers but for one case. Only one of these teachers indicated to be using English both for group and pair work as well as during self-study activities. Teachers' comments on Questions 1a, b, c and d suggest that although attempts are made to integrate English in different ways, the level of variety and flexibility is limited. The focus seems to be on oral communication that is guided by teachers' intervention. 
Table 6: Using English in different teaching contexts (Question 1d)

Number of responding teachers: 60 (teachers could choose more than one option)

\begin{tabular}{|l|c|c|}
\hline Answer option & $\begin{array}{l}\text { No. of } \\
\text { teachers }\end{array}$ & $\begin{array}{l}\text { Percentage } \\
(60=100 \%)\end{array}$ \\
\hline At the beginning or end of class & 37 & $62 \%$ \\
\hline When children are sitting in a circle & 18 & $30 \%$ \\
\hline When children work in groups and pairs & 5 & $8 \%$ \\
\hline During self-study activities & 5 & $8 \%$ \\
\hline During projects & 4 & $7 \%$ \\
\hline
\end{tabular}

\subsubsection{Teaching material}

Questions 2 and 3 concerned the use of teaching materials (Figure 7). Among the top four materials that more than 30 out of 60 teachers reported having access to were 'extra copies for games, songs, stories and rhymes' (50/60), 'flashcards' (43/60), 'extra listening materials for stories, songs and rhymes' (38/60) and 'children's books' (33/60). Textbooks are of much less importance, being only mentioned by slightly more than one third of teachers. Although 23 teachers reported having a textbook available to them, two of them explicitly stated that they only used them for themselves to select suitable material that could then be copied for all children. The high number of teachers referring to copies suggests that there might be more teachers among these 21 who only use the textbooks for themselves, but that their learners do not have access to these textbooks.

It has to be noted that there was an astonishing degree of variation in the responses that had come from the same school, which could be detected in all those cases where questionnaires from one school were returned together in the same envelope. Apart from two schools, great differences could be identified as to teaching methods, materials and the integration of English into other subject areas. For example, some teachers, although working at the same school, reported using different textbooks as a resource for their teaching. This suggests that there is not necessarily a common approach to primary EFL that all teachers at one particular school follow. 
Figure 7: Availability of different teaching materials (Question 2)

Number of responding teachers: 60

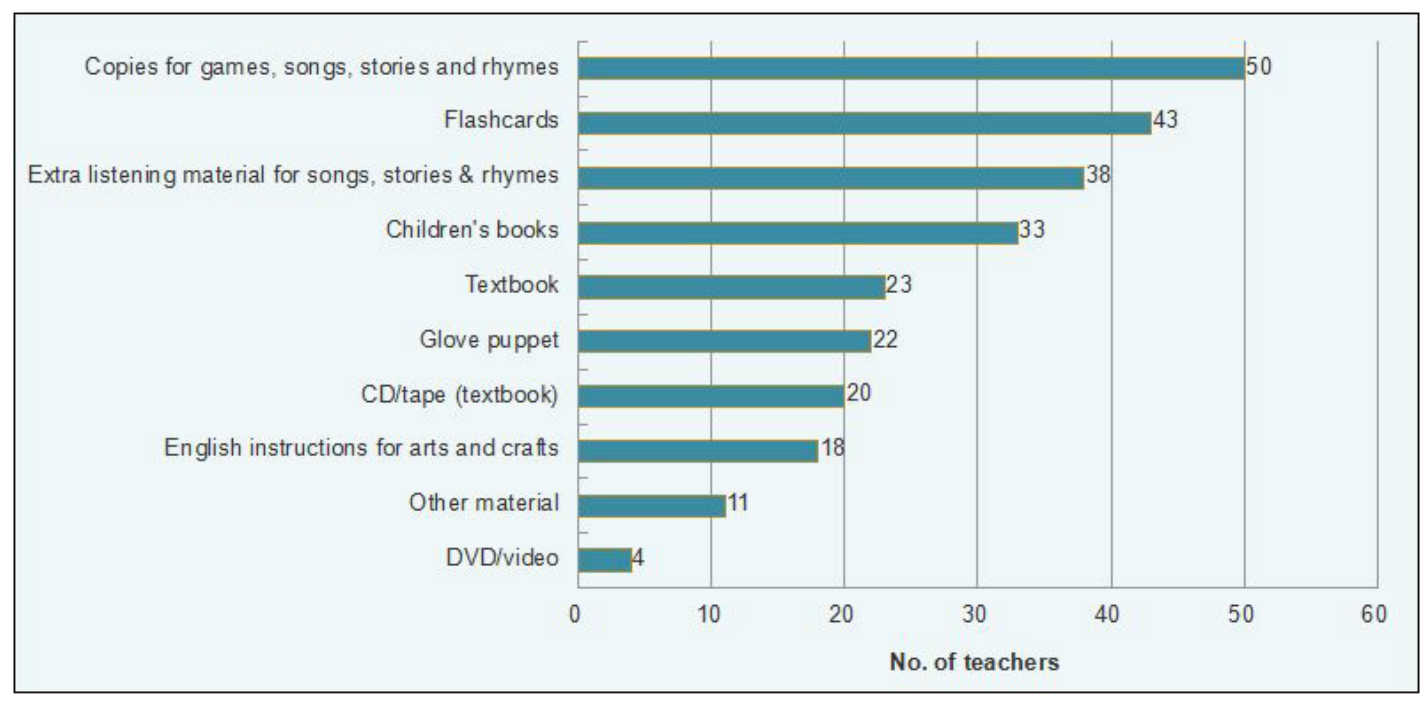

With regard to textbooks (Table 7), it has to be pointed out that teachers addressed during the first questionnaire distribution period that targeted schools within the town borders reported having access to textbooks less often, which might indicate fewer financial resources in urban primary schools. Whereas only seven teachers (23\%) from the first batch of questionnaires reported that a textbook was available to them, sixteen teachers (55\%) from the second batch of questionnaires reported access to a textbook. An overwhelming majority of the teachers had access to a textbook named IKURU (Fröhlich-Ward, Lehnart-Adler \& Wessel-Schmidt, 2001).

The title of this textbook refers to a baby chimpanzee that was found in the jungle in Congo in 1998 and raised in a shelter by the Jane Goodall Institute. Ikuru is the main character in the textbook and features in stories, exercises and games throughout the coursebook. This provides the coursebook with some authenticity and a proper link to the real world, which probably appeals to teachers and learners alike. Having a main character that exists in the real world is a feature that also distinguishes it from the other two textbooks that were available to more than one teacher. Both of these use fictitious characters. Green Keystones (Börner, 2007) was only mentioned by three teachers of the first administration period within the town borders and Supermouse (Harrison, Prochazka \& Rychli, 2005) was only mentioned twice in the second batch of questionnaires distributed in surrounding villages. 


\section{Table 7: Availability of textbook (Question 2)}

Number of responding teachers: 60

Number of teachers reporting availability of textbook: 23

Number of teachers providing title(s) of textbook(s): 22 (some teachers provided more than one title)

\begin{tabular}{|c|c|c|c|c|}
\hline Title of textbook & Publishing House & $\begin{array}{l}\text { Total no. of } \\
\text { teachers }\end{array}$ & Batch I & Batch II \\
\hline Ikuru & Cornelsen & 13 & 1 & 12 \\
\hline Green Keystones & Diesterweg & 3 & 3 & \\
\hline Supermouse & Hueber & 2 & & 2 \\
\hline Abenteuer Englisch & Mildenberger & 1 & 1 & \\
\hline Englisch mit Köpfchen & Mildenberger & 1 & 1 & \\
\hline Green Colour & Not known* & 1 & 1 & \\
\hline Kooky & Cornelsen & 1 & & 1 \\
\hline Playtime & Oxford University & 1 & & 1 \\
\hline Magicland & Langenscheidt & 1 & & 1 \\
\hline Playway & Klett & 1 & & 1 \\
\hline Storytime & Westermann & 1 & & 1 \\
\hline
\end{tabular}

* A textbook with this title could not be found. The participant was possibly referring to another textbook with a similar title, such as Green Keystones.

Videos and DVDs were the materials least often mentioned being available to teachers, which is remarkable if one considers that schools normally have access to one or two TV sets per school and use them for other subject areas as well. Classrooms are also more often equipped with computers, and most DVDs nowadays can be run in various languages.

More than one third of teachers (36\%) reported having access to three or four different materials and almost as many teachers (34\%) mentioned that five to six different materials were available to them (Table 8 and Figure 8). 
Table 8: Number of different materials available to teachers (Question 2) Number of responding teachers: 60

\begin{tabular}{|l|l|l|}
\hline No. of teachers & $\begin{array}{l}\text { Percentage } \\
(100 \%=60)\end{array}$ & $\begin{array}{l}\text { No. of materials } \\
\text { available }\end{array}$ \\
\hline 11 & $18 \%$ & 3 \\
\hline 11 & $18 \%$ & 4 \\
\hline 10 & $17 \%$ & 5 \\
\hline 10 & $17 \%$ & 6 \\
\hline 7 & $12 \%$ & 2 \\
\hline 6 & $10 \%$ & 7 \\
\hline 3 & $5 \%$ & 1 \\
\hline 2 & $3 \%$ & 8 \\
\hline
\end{tabular}

Figure 8: Number of different materials available to teachers (Question 2) Number of responding teachers: 60

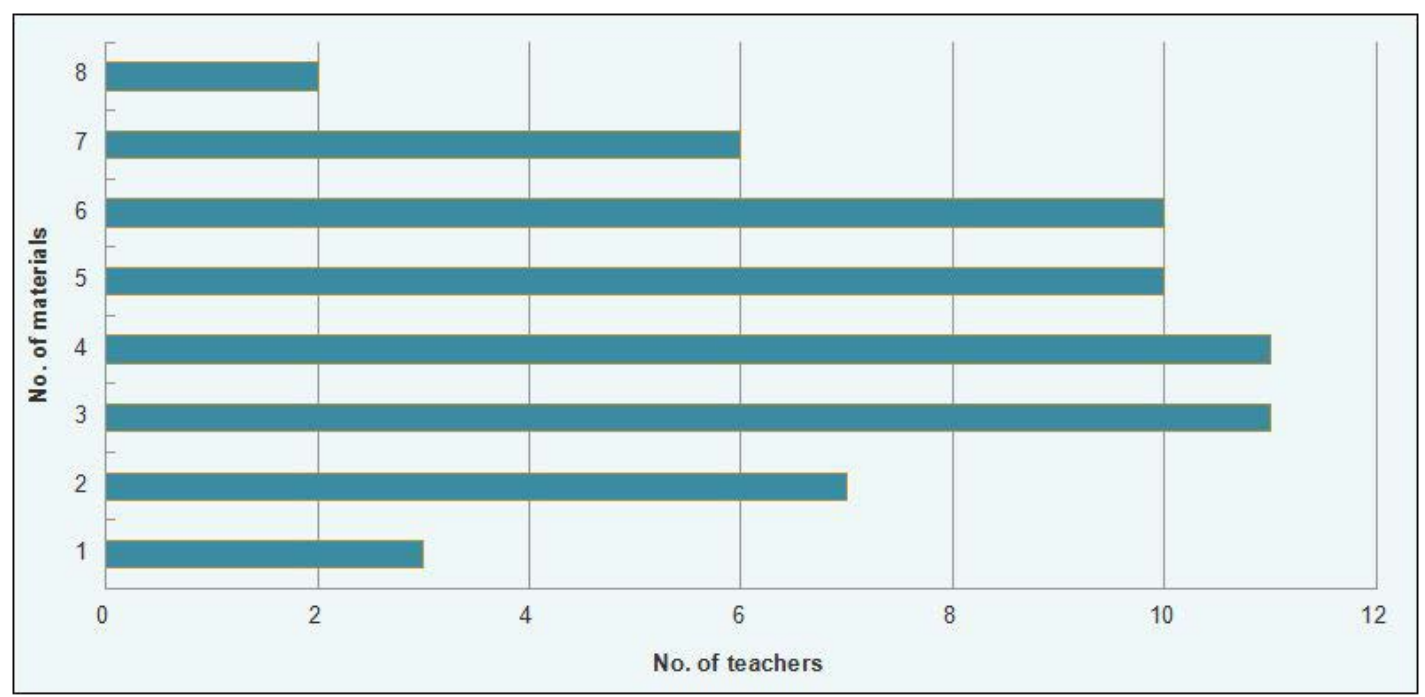

The higher the number of different materials that are available, the more varied a FL environment one can expect. With over two thirds of this sample having access to three to six different teaching materials and with 'extra copies for songs, stories and rhymes' from various sources being mentioned by most teachers (50/60) as most accessible teaching material, one can envisage a situation where teachers have got copies for their EFL classroom and on top of that a choice of two to four more materials from a reservoir of flashcards, extra listening material, children's books 
and textbooks, all of which were among the five most frequently named available teaching materials.

Responses to the follow-up Question 3 confirm this assumption. When asked which teaching materials were among their most favourite (Table 9), extra copies for games, songs, stories and rhymes were mentioned by 63 percent of teachers, flashcards by 52 percent, extra listening material for songs, stories and rhymes by 37 percent and children's books by 32 percent. Interestingly, the teaching materials that are most often reported to be available to teachers are also the teaching materials that are most often referred to as favourite material. However, the case is different for textbook use. 23 teachers reported having access to a textbook, of which two explicitly stated that they only used it for themselves. However, not even half of these 23 teachers regarded it as one of their favourite materials.

Table 9: Teaching materials that teachers favour (Question 3a)

Responding teachers: 60 (teachers could choose more than one answer option)

\begin{tabular}{|l|l|l|}
\hline No. of teachers & $\begin{array}{l}\text { Percentage } \\
(100 \%=60)\end{array}$ & Favoured material \\
\hline 38 & $63 \%$ & Copies for games, songs, stories and rhymes \\
\hline 31 & $52 \%$ & Flashcards \\
\hline 22 & $37 \%$ & Extra listening for songs, stories and rhymes \\
\hline 19 & $32 \%$ & Children's books \\
\hline 10 & $17 \%$ & Textbook \\
\hline 9 & $15 \%$ & CD/tape accompanying textbook \\
\hline 5 & $8 \%$ & Glove puppet \\
\hline 3 & $5 \%$ & English instructions for arts and crafts \\
\hline 3 & $5 \%$ & Other material \\
\hline 0 & $0 \%$ & DVD/video \\
\hline
\end{tabular}

Responses to question items referring to availability and preference of teaching material suggest a focus on games, singing, storytelling and rhyming and an emphasis of oral communication, especially listening. This is supported and extended to include speaking by answers to Question 3b. This was a follow-up, open-ended question and asked for the reason why teachers preferred the materials they had mentioned in 3a. Sixteen teachers (27\%) left this question blank, which 
was to be expected since fewer responses are typical for open-ended questions that are more time-consuming. Most teachers provided one or two reasons. In total, 21 different reasons were categorized. Among the top five arguments that teachers gave for their choice (Table 10), the idea that the material encouraged learners to speak the FL ranked highest. 30 percent of responding teachers provided that as a reason, which confirms that teachers place great importance on oral skills. This is further strengthened by the fact that 20 percent of them also prefer a certain kind of teaching material because it provides native speaker input. This is likely to refer to 'perfect' pronunciation and intonation, as well as fluency in spoken communication. Interestingly, however, the second strongest argument given by 23 percent of responding teachers was that the material allowed for effective learning with pictures and sound, which suggests that teachers regard visual aid as essential in the FL classroom. This raises new questions as to how teachers use pictures for the teaching of the FL that could best be answered through classroom observation.

Table 10: Reasons for preference of teaching materials (Question $3 \mathbf{b}$ ) Responding teachers: 44 (teachers could name more than one reason) Non-responding teachers: 16

\begin{tabular}{|l|l|l|}
\hline No. of teachers & $\begin{array}{l}\text { Percentage } \\
(100 \%=44)\end{array}$ & Reasons for preference of teaching materials \\
\hline 13 & $30 \%$ & Material encourages children to speak the FL \\
\hline 10 & $23 \%$ & $\begin{array}{l}\text { Material allows effective learning with pictures and } \\
\text { sound. }\end{array}$ \\
\hline 9 & $20 \%$ & Material provides native speaker input \\
\hline 9 & $20 \%$ & Material can be used flexibly and easily \\
\hline 5 & $11 \%$ & Material is appropriate for age group \\
\hline
\end{tabular}

\subsubsection{Favourite activities in the primary FL classroom}

Question 4 asked teachers about activities that were most popular with children in their experience. Most responding teachers (93\%) wrote down at least two activities. If one looks at the total number of references to most favourite activities, the following picture develops (Table 11). 
Table 11: Top five popular activities (Question 4)

Number of responding teachers: 59

Number of non-responding teachers: 1

\begin{tabular}{|l|l|l|}
\hline No. of teachers & $\begin{array}{l}\text { Percentage } \\
(100 \%=44)\end{array}$ & Popular activities for children according to teachers \\
\hline 52 & $41 \%$ & Singing \\
\hline 38 & $30 \%$ & Games \\
\hline 15 & $12 \%$ & Dancing \\
\hline 14 & $11 \%$ & Rhymes and poems \\
\hline 9 & $6 \%$ & Artwork \\
\hline
\end{tabular}

41 percent of responding teachers mentioned singing as one of the most popular activities, which makes it the most popular activity among children according to their teachers. If we consider that 12 percent of teachers also thought that dancing was one of their learners' favourite activities, then we can conclude that music in the form of singing or dancing together take up more than 50\% of responses. Games were mentioned by $30 \%$ of responding teachers and they were therefore seen as more popular than rhymes and poems. Stories, remarkably do not appear among the top five favourite activities.

Question 4 did not ask teachers to rank activities according to their popularity with children, and yet we can assume that the order in which teachers mention popular activities may reflect their perceived popularity. More popular activities can be assumed to come to teachers' mind first. Thus, it is interesting to find out which activity was mentioned first most often. Indeed, most responding teachers, 59 percent, mentioned singing first, which strengthens its status of most popular activity for children, according to the teachers who participated in this project.

Questionnaire item no. 5 asked teachers to indicate which activities they found most effective regarding their learners' linguistic development, since activities that children find popular may still not be used very often in classrooms if teachers do not regard them as beneficial for the learning process. This was another openended question and response rates were lower. 43 out of 60 teachers (72\%) answered this question. This question was deliberately formulated in a way that did not require teachers to mention a certain number of activities. However, the layout provided 
three bullet points suggesting that teachers were invited to offer up to three activities. Most teachers only mentioned one or two activities, and only 33\% of responding teachers did write down three activities. If one looks at the activities that were mentioned first and second, one can note that singing was again mentioned most often, that is 19 times, which highlights the fact that teachers do not only seem to regard singing as popular with children but also as a useful activity that facilitates and furthers FL learning. Role plays and conversations were mentioned 15 times, which indicates that teachers do seem to place great importance on developing oral skills.

\subsubsection{Musical and literary texts in the primary EFL classroom}

The second set of questions within the main question section all concerned the use of musical and literary texts, such as songs, stories or picture books and rhymes or poems. Question 7, which asked if teachers used any stories, poems or songs, was only answered negatively by one teacher. On being asked how often these different genres were being used in their primary school classroom, the remaining 59 teachers of this sample gave the following response (Table 12).

Songs seem to be the most popular genre, with an overwhelming majority of 86 percent of responding teachers reporting to use them 'in every session' or 'in every $3^{\text {rd }}$ to $5^{\text {th }}$ session'. It is the only genre that none of the respondents reported to use 'never' or only 'once or twice every school year'. The second most popular genre are nursery rhymes, which in the German translation Kinderreime is a general term referring to any rhyme consisting of at least two lines, not only traditional nursery rhymes. 86 percent of responding teachers reported using them 'in every $3^{\text {rd }}$ to $5^{\text {th }}$ session' or 'a few times every school year'. These answer options were also chosen by a majority of responding teachers with the regard to poems (76\%) and picture stories (70\%), though not by quite as many teachers. If we consider that there are a number of poems written to be recited at special times of the year, such as Halloween, Christmas and Easter, then this response pattern is not surprising. However, it is unlikely that teachers refer to longer poems here, and the distinction between a rhyme that can be two to four lines long and a poem that might not be much longer than four lines might have been blurred with different teachers interpreting these terms in slightly different ways. 
Table 12: Frequency of using musical and literary texts (Question 8a)

Number of responding teachers: 52-59 (varies across different genres)

Number of non-responding teachers: 1-7 (varies across different genres)

\begin{tabular}{|c|c|c|c|c|c|c|c|c|c|c|}
\hline & \multicolumn{2}{|c|}{$\begin{array}{l}\text { Song } \\
(\mathrm{N}=59)\end{array}$} & \multicolumn{2}{|c|}{$\begin{array}{l}\text { Nursery } \\
\text { rhymes } \\
(\mathrm{N}=56)\end{array}$} & \multicolumn{2}{|c|}{$\begin{array}{l}\text { Poems } \\
(\mathrm{N}=54)\end{array}$} & \multicolumn{2}{|c|}{$\begin{array}{l}\text { Picture } \\
\text { stories } \\
(\mathrm{N}=54)\end{array}$} & \multicolumn{2}{|c|}{$\begin{array}{l}\text { Stories } \\
(\mathrm{N}=52)\end{array}$} \\
\hline & No & $\%$ & No & $\%$ & No & $\%$ & No & $\%$ & No & $\%$ \\
\hline In every lesson & 25 & 42 & 5 & 9 & 4 & 7.5 & 4 & 7.5 & 0 & 0 \\
\hline $\begin{array}{l}\text { In every } 3^{\text {rd }} \text { to } 5^{\text {th }} \\
\text { lesson }\end{array}$ & 26 & 44 & 24 & 43 & 18 & 33 & 20 & 37 & 11 & 21 \\
\hline $\begin{array}{l}\text { Not regularly, but } \\
\text { a few times every } \\
\text { school year }\end{array}$ & 8 & 14 & 24 & 43 & 23 & 43 & 18 & 33 & 11 & 21 \\
\hline $\begin{array}{l}\text { Once or twice } \\
\text { every school year }\end{array}$ & 0 & 0 & 1 & 1.5 & 7 & 13 & 8 & 15 & 17 & 33 \\
\hline Never & 0 & 0 & 2 & 3.5 & 2 & 3.5 & 4 & 7.5 & 13 & 25 \\
\hline
\end{tabular}

There seems to be a tendency towards the use of very short texts. Rhymes are mentioned as being used more often than poems, and 'picture stories', referring to illustrated stories as well as picture books, more often than 'stories' that consist mainly of verbal text. 58 percent of responding teachers reported using stories either never or rarely, which was defined as 'once or twice during the school year'.

The responses to Question 8a are confirmed by teachers’ answer behaviour to follow-up question 8b. When it comes to the suitability of a certain genre for the teaching of English to young learners (Figure 9), it is again songs that were mentioned by most teachers. 46 participants (85\%) of responding teachers indicated that they found songs suitable for primary-level FLT. Nursery rhymes, as before, took second place, being mentioned by 34 of the responding teachers (63\%), and in third place again picture stories. They were seen as appropriate by 26 teachers (48\%) of the 54 teachers who responded. Poems and stories were mentioned least often, by 33 and 13 percent respectively. The response to Question 8b then mirrors the teachers' answer behaviour to Question 8a. The genres that teachers reported to be 
using most frequently were also those they found most suitable for primary-level EFL teaching.

Figure 9: Suitability of different genres for primary-level FLT (Question 8b) Number of responding teachers (non-responding teachers): 54(5) (more than one answer option could be chosen)

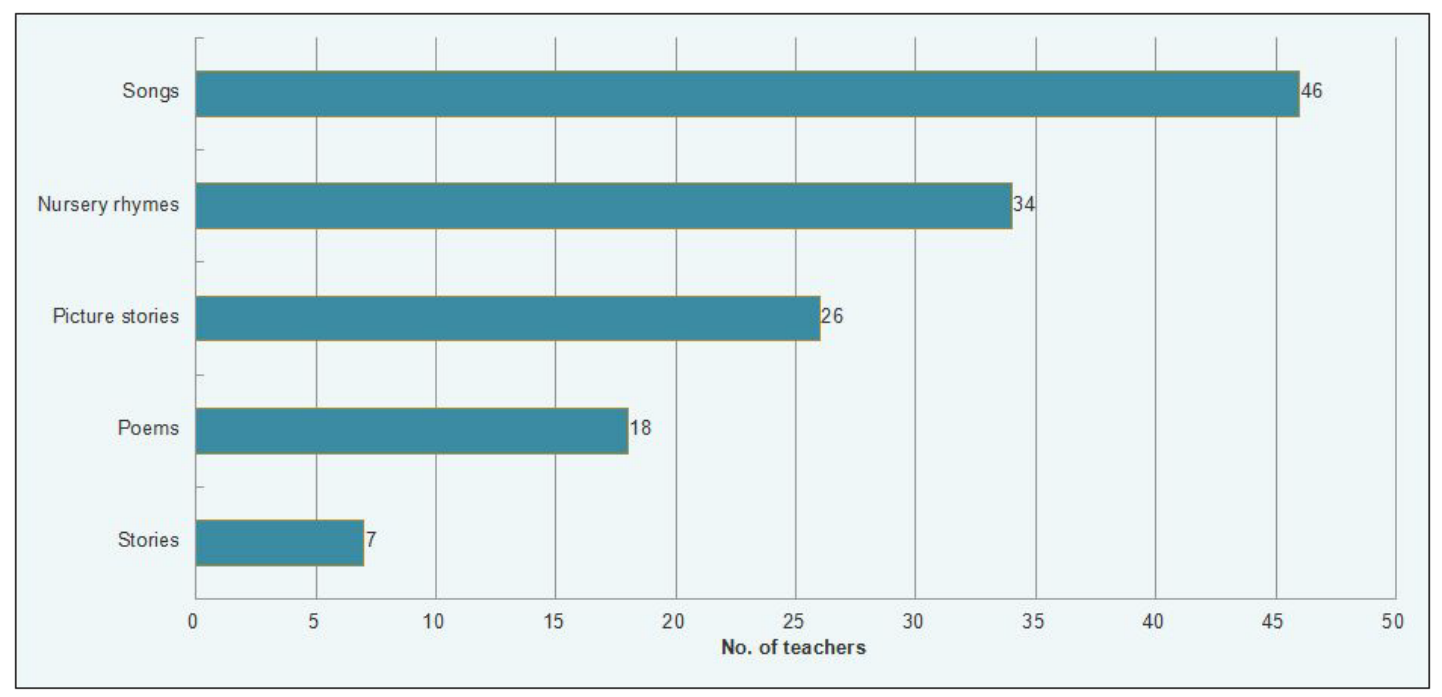

The follow-up open-ended question as part of $8 \mathrm{~b}$ asked teachers to provide reasons for their views expressed in 8b (Table 13). Considerably fewer teachers replied to this open-ended question, which was to be expected. Among the 40 teachers who provided reasons for the suitability of certain genres, motivation was mentioned most often. 50 percent of responding teachers explained their choice of a particular genre by saying that it increased and sustained motivation in their learners. The second most frequently mentioned reason referred to the memorability of genres. 33 percent of the responding teachers gave the 'memorable' nature of a genre as criterion for its suitability in the primary EFL classroom and pointed out that 'words seem to be remembered more easily'. The fact that one third of the responding teachers remarked on a genre being memorable was surprising and indicates that musical and literary texts are not only used for purely motivational reasons but also because teachers believe that learners will actually learn more. The third most frequently named reason for the use of one of these musical or literary genres referred to speaking. 20 percent of responding teachers explained their choice for a particular genre by saying for example that it was 'encouraging speaking, because it was not intimidating' or that 'even shy kids start speaking'. This reveals teachers' 
strong focus on the development of oral skills again, which is further confirmed by the fact that almost as many teachers (18\%) chose any of these genres because they supported the development of listening comprehension. These results, therefore, partly reflect answers given before to question 3b where teachers' responses also implied a focus on listening and speaking.

Table 13: Reasons for suitability of genre (Question 8b)

Number of responding teachers (non-responding teachers): 40 (20) (more than one reason could be named)

\begin{tabular}{|l|l|l|}
\hline No. of teachers & $\begin{array}{l}\text { Percentage } \\
(40=100 \%)\end{array}$ & Reasons for suitability of genre \\
\hline 20 & $50 \%$ & Genre is beneficial for motivation levels. \\
\hline 13 & $33 \%$ & $\begin{array}{l}\text { Genre is memorable and supports the memory of } \\
\text { words. }\end{array}$ \\
\hline 8 & $20 \%$ & $\begin{array}{l}\text { Genre encourages speaking because it is not } \\
\text { intimidating. }\end{array}$ \\
\hline 7 & $18 \%$ & Genre supports the development of listening skills. \\
\hline 5 & $13 \%$ & Genre is appropriate for age group. \\
\hline
\end{tabular}

Question 8c, an open-ended follow-up question, asked teachers to write down titles of stories, rhymes, poems and songs that have worked well in their primary EFL classroom. The astonishing fact about these replies is the diversity of answers. For example, 66 stories were mentioned, of which 52 were only mentioned once. A similar picture emerged for rhymes, poems and songs (Table 14). This variety in the teachers' answers is astonishing and shows that teachers are able to locate a vast number of appropriate materials. However, the diversity of teachers' responses also suggests that teachers do not seem to be able to refer to one common source of suitable materials that is accessible to every primary school teacher, such as publications by education authorities. Furthermore, it could indicate a lack of communication and co-operation between teachers working at one school or at different schools concerning material as well as teaching ideas that work well and can be shared. This confirms earlier responses to Question 2 that revealed a lack of common teaching strategies with regard to teaching materials within some schools. For a complete list of all texts mentioned, see Appendix 6. 
Table 14: Number of stories, rhymes/poems and songs that teachers have used and found useful (Question 8c)

Number of responding teachers (non-responding teachers): 43 (17)

\begin{tabular}{|l|l|l|l|}
\hline & $\begin{array}{l}\text { Total no. of } \\
\text { texts }\end{array}$ & $\begin{array}{l}\text { No. of texts } \\
\text { mentioned once }\end{array}$ & $\begin{array}{l}\text { No. of texts } \\
\text { mentioned more } \\
\text { than once }\end{array}$ \\
\hline Picture stories/stories & 66 & 52 & 14 \\
\hline Nursery rhymes/poems & 52 & 47 & 5 \\
\hline Songs & 64 & 40 & 24 \\
\hline
\end{tabular}

There are, however, individual texts that seem to be used widely, among them the picture book The Very Hungry Caterpillar by Carle that was mentioned by 19 teachers as well as two songs, namely Head, Shoulders, Knees and Toes, mentioned 23 times and Old MacDonald Had a Farm, referred to 13 times. Another song, titled Good Morning, was mentioned by 11 teachers, but it is not entirely clear if all teachers referred to the same song. All other texts that were mentioned numerous times were referred to by fewer than 10 teachers, which does not indicate widespread use. Table 15 below provides an overview of texts that were most frequently mentioned.

Table 15: Titles of stories, rhymes/poems and songs that teachers have used and found useful (Question 8c)

Number of responding teachers (non-responding teachers): 43 (17)

\begin{tabular}{|l|l|l|}
\hline Genre & Titles & $\begin{array}{l}\text { No of times } \\
\text { mentioned }\end{array}$ \\
\hline Picture stories & $\begin{array}{l}\text { The Very Hungry Caterpillar (Carle, 1969) } \\
\text { Elmer (McKee, 1968) } \\
\text { Brown Bear, Brown Bear, What Do You See? (Carle } \\
\text { \& Martin, 1967) } \\
\text { Froggy Gets Dressed (London \& Remkiewicz, 1994) }\end{array}$ & 4 \\
\hline Nursery & $\begin{array}{l}\text { Incy Wincy Spider } \\
\text { rhymes/poems }\end{array}$ & $\begin{array}{l}19 \\
\text { One, Two, Buckle My Shoe }\end{array}$ \\
\hline Songs & $\begin{array}{l}\text { Head, Shoulders, Knees and Toes } \\
\text { Old MacDonald }\end{array}$ & 3 \\
\hline
\end{tabular}




\begin{tabular}{|l|l|l|}
\hline & Good Morning & 11 \\
If You Are Happy & 9 \\
Ten Little Indians & 8 \\
\hline
\end{tabular}

Most overlap occurred in teachers' answers to songs. This supports earlier results for Questions 8a and 8b where songs were reported to be used more frequently than other genres and regarded as the most suitable genre by most teachers as well. As for stories, one can observe that the titles provided by teachers cover different categories of texts, such as modern picture books (Elmer, Froggy Gets Dressed), fables and fairy tales that are also known in German (The Wind and the Sun, The Lion and the Mouse, Little Red Riding Hood), stories linked to seasons (featuring keywords Rudolph and Halloween in the title) and stories that have been explicitly created for learners of English, sometimes by German authors, such as Englisch keine Hexerei by Guderian \& Guhe (Appendix 6).

What is striking about the list of titles (Appendix 6) is that there are very few texts that are traditional stories in primary classrooms or nurseries in the Englishspeaking world, such as Goldilocks (only named twice) and The Three Little Pigs (named three times). Other traditional tales are missing altogether, such as Jack and the Beanstalk, The Ugly Duckling or Cinderella. There is also a lack of frequent references to very popular picture books, such as The Gruffalo (Donaldson and Scheffler, 1999), which has even been turned into a film by Max Lang and Jakob Schuh. The Gruffalo was only mentioned by one teacher in this questionnaire, which is also true for The Pig in the Pond (Waddell and Barton, 1992), Ten in the Bed (Dale, 1988) and Paddington Bear stories (e.g. Bond, 1958). Another very successful book, both in the English-speaking world and in primary EFL classrooms, We Are Going on a Bear Hunt (Rosen and Oxenbury, 1989), which has also been published in various versions (e.g. 1997, 2007 and 2009), and is recommended by various online providers of EFL materials such as Primary colours and Teflnet, was only mentioned by two teachers. In a way, this is not all too surprising considering that the curricular guidelines for primary-level FLT in Rhineland-Palatinate only list very few titles of stories, songs and rhymes (Ministerium für Bildung, Frauen und Jugend, 2004b). Teachers are only provided with one example of a picture book, namely Brown Bear, Brown Bear, What Do You See?, two titles of traditional tales, The Gingerbread Man and The Three Little Pigs, two traditional nursery rhymes, 
Incy, Wincy Spider and Hickory, Dickory, Dock as well as a few songs, namely Happy Birthday, For He's a Jolly Good Fellow and Head, Shoulder, Knees and Toes. While this is a rather short list that does not encourage widespread use of musical and literary texts, teachers do seem to use some of the recommended texts, and they also seem to be able to locate and identify others. However, the lack of other well-known texts in teachers' lists of titles indicates that teachers may not benefit from regular and on-going guidance or training. Primary-school EFL classrooms then do not always provide young learners with some of the texts that are generally considered contemporary classics read or sung to anglophone children in their home and in child care. In this way, young FL learners miss the opportunity to experience real or authentic texts that are part of native speakers' repertoire and their contemporary culture.

In response to Question 10, only about half of the responding teachers (32/54) reported using follow-up activities for songs, rhymes and stories in class (Table 16), which is surprising given the fact that follow-up activities are generally considered as an integral part of a three-step process involving any listening or storytelling activity (L. Cameron, 2001; Read, 2007).

Table 16: Top five follow-up activities (Question 10)

Number of responding teachers (non-responding teachers): 54 (6)

Number of teachers who reported using follow-up activities: 32 (teachers could provide more than one)

\begin{tabular}{|l|l|l|}
\hline $\begin{array}{l}\text { Number of } \\
\text { teachers }\end{array}$ & $\begin{array}{l}\text { Percentage } \\
(32=100 \%)\end{array}$ & Follow-up activity \\
\hline 11 & $34 \%$ & Artwork \\
\hline 11 & $34 \%$ & Role play and conversation \\
\hline 8 & $25 \%$ & Working with words \\
\hline 6 & $19 \%$ & Games \\
\hline 5 & $16 \%$ & Dancing/moving about \\
\hline
\end{tabular}

The most favourite follow-up activities as mentioned by teachers confirm responses to earlier questions in so far as a strong emphasis on oral skills is evident, with about one third of responding teachers mentioning role plays and conversation as a followup activity that they use after working on literary and musical texts. As with replies to Question 8b, teachers' answers also reveal a tendency to focus on memory, as one 
quarter of them reported to work on vocabulary as part of follow-up activities. The reference to games and dancing, on the other hand, is reminiscent of teachers' earlier remarks on children's preference for games and music (Question 4, Table 11). Yet, teachers' focus on artwork during follow-up activities, as reported by one third of responding teachers, seems unprecedented. Artwork was not perceived as popular as dancing or games (Question 4, Table 11) nor did it appear in teachers' choice of activities that improve language command (Question 5). However, the preference for artwork during follow-up activities can still be explained. It seems to be linked to teachers' response to Question 3b where 23\% of responding teachers stated that they preferred a certain material because it allowed 'effective learning with pictures and sound'. Visualization of what is being talked about is obviously seen as important in the primary-level FL classroom, which is something that artwork can provide. It will be interesting to see if and how this can be linked to another priority that teachers mentioned, namely memory of words, which is a question that cannot be answered by the questionnaire data.

\subsubsection{Likert scales}

Likert scales were used in two question items of the main question section, once in Question 6 on teachers' objectives for primary-level FLT and another time in Question 9 on teachers' objectives for using songs, rhymes, poems or stories in their primary EFL classrooms.

Data for both questionnaire items were uploaded onto SPSS to carry out a reliability analysis (Table 17) to check for internal consistency of the scale. A number of cases, 11 for Question 6 and 15 for Question 9, had to be excluded from the analysis since respondents had left a box blank. As mentioned before, the size of the table might have been problematic.

Internal consistency checks of scales of both question items produced Cronbach’s Alpha values between 0.632 for Question 9 and 0.738 for Question 6 . While both are above the critical value of 0.6 , they are not entirely satisfactory, since 'internal consistency estimates for well-developed attitude scales containing as few as 10 items ought to approach 0.80’ (Dörnyei, 2003: 112). Questions 6 and 9 both consisted of between 10 and 16 items. Thus, results for both questions have to be treated with caution. 
Table 17: Reliability analysis (teaching objectives, Question 6 \& 9)

\begin{tabular}{|c|c|l|c|c|}
\hline Question & Valid Cases & Excluded Cases & Cronbach's Alpha & No of items \\
\hline 6 & 49 & 11 & 0.738 & 16 \\
\hline 9 & 45 & 15 & 0.632 & 10 \\
\hline
\end{tabular}

For each given teaching objective in primary FLT, answer options on Question 6 ranged from score 1 for 'very important' to score 5 for 'not very important at all'. If one analyses responses on the basis of average scores (Table 18), the five most important teaching objectives in primary FLT focus on pronunciation, listening comprehension, positive attitudes towards the FL and foreign cultures as well as responding to questions. The five teaching objectives that attracted the highest average scores and were therefore considered of less importance all concern reading, writing and grammar. Written communication and metalinguistic knowledge in the form of grammatical understanding seem of much less relevance to responding teachers than oral communication.

Table 18: Teaching objectives in primary-level FLT (Question 6)

Number of responding teachers: 56-60 for individual learning objectives Number of non-responding teachers: 0-4 for individual learning objectives

\begin{tabular}{|l|l|l|}
\hline Teaching objective & Average score & $\begin{array}{l}\text { Ranking } \\
\text { according to } \\
\text { average score }\end{array}$ \\
\hline Pronounce words correctly & 1.33 & 1 \\
\hline Understanding what has been said & 1.50 & 2 \\
\hline Being enthusiastic about learning a FL & 1.55 & 3 \\
\hline Being open-minded towards different cultures & 1.66 & 4 \\
\hline Answering questions & 1.76 & 5 \\
\hline Studying the meaning of words & 2.07 & 6 \\
\hline Getting to know about the culture & 2.25 & 7 \\
\hline Speaking freely & 2.35 & 8 \\
\hline Reading short simple texts & 2.98 & 9 \\
\hline Reading out loud single words/sentences & 3.05 & 10 \\
\hline Reading out loud short texts & 3.21 & 11 \\
\hline Writing words/sentences & 3.76 & 12 \\
\hline
\end{tabular}




\begin{tabular}{|l|l|l|}
\hline Using grammatical rules & 4.07 & 13 \\
\hline Writing short texts & 4.09 & 14 \\
\hline Understanding grammatical rules & 4.25 & 15 \\
\hline
\end{tabular}

If one analyses teachers' responses in more detail, the following observations can be made for receptive language use, productive language use and metalinguistic awareness, cultural knowledge as well as attitudes.

With regard to receptive language skills (Figure 10), most teachers, namely almost 60 percent, regarded listening, the understanding of what had been said, as most important. It was also the only item that did not attract a single 'not very important at all' answer option by any of the responding teachers. In fact, almost 100 percent of teachers attributed some importance to it by choosing one of the first answer options, either 'very important', 'important' or 'somehow important'. In terms of reading, the item that attracted most positive responses was 'reading out single words or sentences'. However, only 10 percent of the responding teachers thought that it was 'very important'. The trend here seems to be towards reading individual items rather than texts, which was only considered as 'very important' by 5 percent of responding teachers. In fact, when it came to reading out short texts, almost 40 percent of responding teachers opted for 'not very important' or 'not very important at all'.

This is slightly puzzling if one considers teachers' responses to all those items that referred to productive oral language use (Figure 11). 'Pronouncing words correctly' was thought to be 'very important' or 'important' by 85 percent of teachers, and the item 'answering questions' attracted even more such positive responses, namely by almost 90 percent of responding teachers. 'Speaking freely' was not perceived as quite as important, with just over 55 percent of responding teachers calling it 'very important' or 'important', but about 30 percent on top of that still thought it was 'somehow important'. Speaking then, received many positive responses, which is why one would anticipate more teachers to regard reading out aloud as important. 
Figure 10: Teaching objectives with regard to receptive language use in primary-level FLT (Question 6)

Number of responding teachers: 56-60 for individual learning objectives Number of non-responding teachers: 0-4 for individual learning objectives

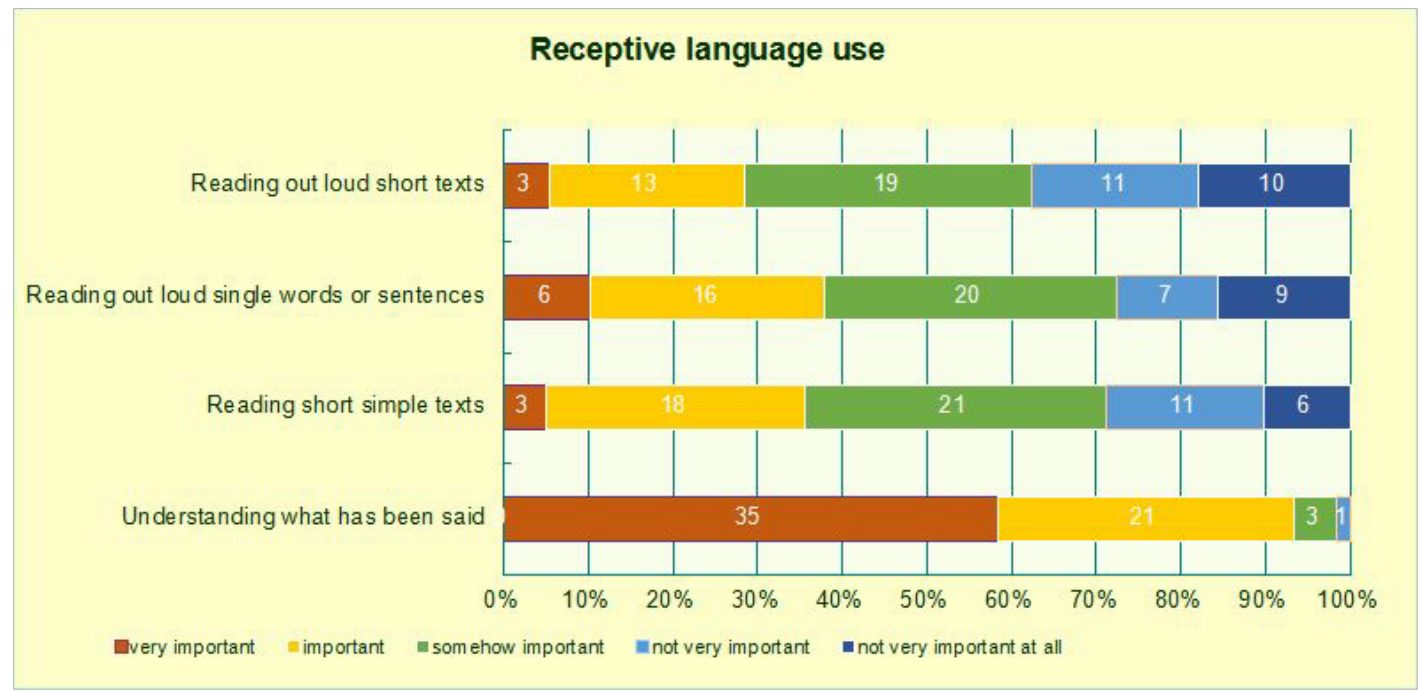

Figure 11: Teaching objectives with regard to productive language use in primary-level FLT (Question 6)

Number of responding teachers: 58-60 for individual learning objectives Number of non-responding teachers: 0-2 for individual learning objectives

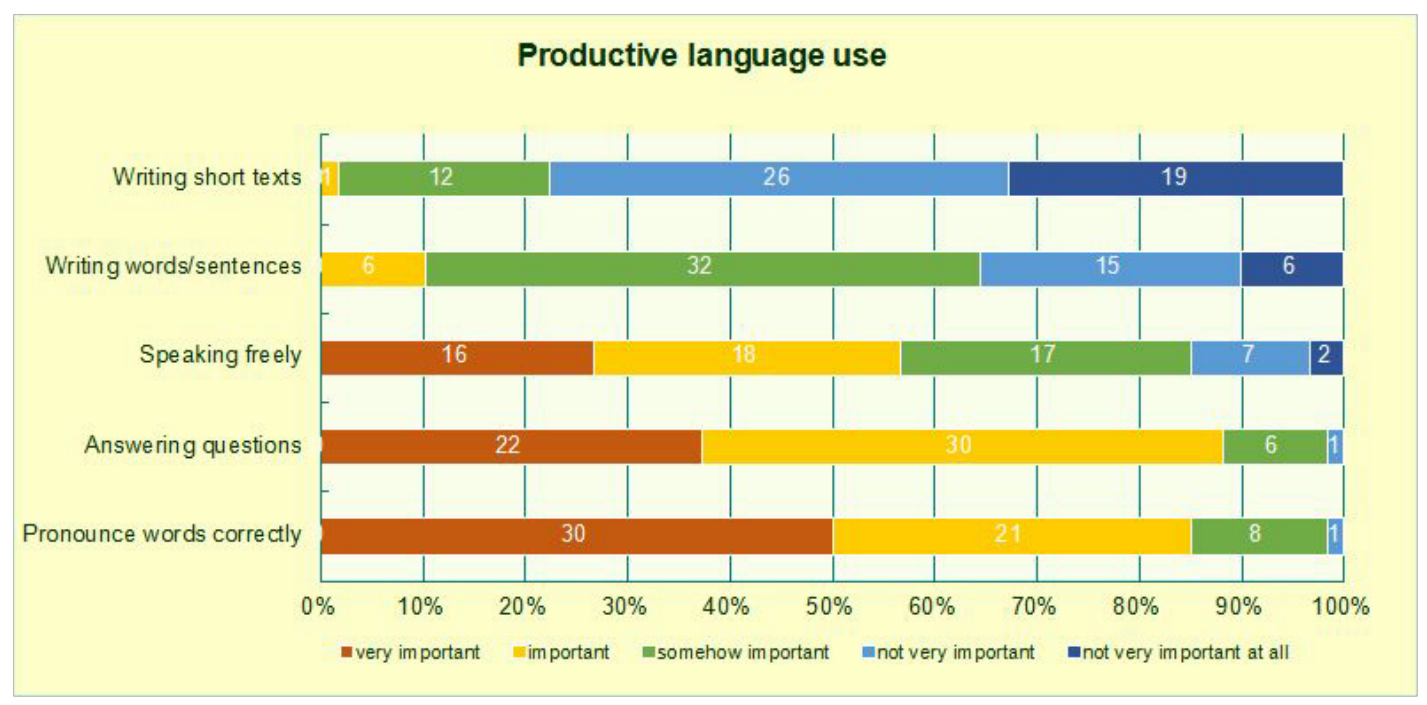

Writing seems to be of much lower priority if one considers that none of the responding teachers thought it was 'very important'. However, at least about 65 percent regarded the writing of individual words or sentences as either 'important' or 'somehow important'. This is not the case for writing short texts. A great majority of teachers, namely almost 80 percent, perceived that as of little or no importance. 
With regard to attitudes, cultural knowledge and metalinguistic awareness, one can say that teachers placed most importance to developing and sustaining motivation and an open-mind towards other cultures (Figure 12). About 90 percent of responding teachers thought these aspects of FLT to be either 'important' or 'very important'. The teaching of cultural facts, on the other hand, appears to be of considerably less importance. However, the least priority is attributed to understanding grammatical rules, with almost 85 percent of teachers regarding this as either 'not very important' or 'not very important at all'. Although 'using grammatical rules' also attracted many negative responses, the picture is slightly different. More teachers seem to admit some sort of importance to applying grammatical rules, namely 25 percent. In contrast to this, understanding the meaning of words was perceived as much more important. Almost 75 percent of responding teachers saw that as either 'important' or 'very important'. Thus, there seems to be a tendency among teachers of this sample towards focusing on vocabulary, which confirms results to previous question items.

Figure 12: Teaching objectives with regard to metalinguistic awareness, cultural knowledge and attitudes (Question 6)

Number of responding teachers: 54-60 for individual learning objectives Number of non-responding teachers: 0-6 for individual learning objectives

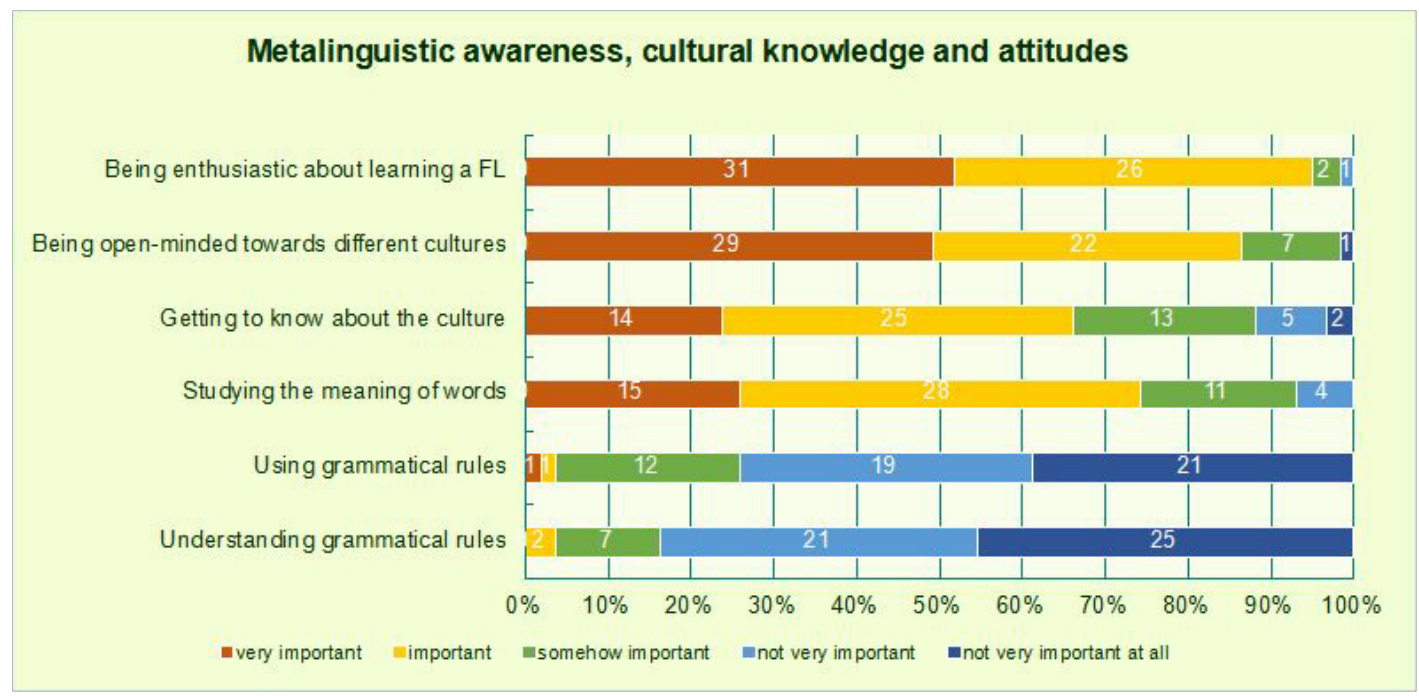

The relative lack of interest in grammar might be explained by the fact that basic linguistic terms such as 'verb' and 'noun' as well as 'past' and 'present' are only slowly introduced in Year 2, and most of this more abstract knowledge is taught more intensely in Year 3 and especially Year 4 before children leave for secondary 
school. A glimpse at teachers' responses in the demographic question section (Table 19) shows that only 15 teachers reported working with Year 4, which explains why most teachers regard the knowledge of grammar rules as less important. Most emphasis is therefore put on oral communication and an open attitude towards the FL and other cultures in general. This is in line with many official recommendations for primary MFL such as produced by the Ministry of Education in RhinelandPalatinate at the time (Ministerium für Bildung, Frauen und Jugend, 2005).

\section{Table 19: Teachers' year groups (Question 17)}

No. of responding teachers (non-responding teachers): 59 (1)

(some teachers teach more than one year group)

\begin{tabular}{|l|l|l|l|l|}
\hline Year & I & II & III & IV \\
\hline $\begin{array}{l}\text { No. of teachers working } \\
\text { with particular Year }\end{array}$ & 18 & 14 & 23 & 15 \\
\hline
\end{tabular}

Question 9 asked teachers to indicate why they used stories, poems and songs in their primary EFL classroom. Teachers' responses confirm results on the importance of learning objectives in primary EFL classrooms in general and also on criteria for suitable materials.

The analysis of average scores shows that among the aspects given highest priority are improving motivation, encouraging language play and word learning, ensuring variety in the classroom and listening comprehension (Table 20). The least priority is given to cultural knowledge and grammar. Notably, there is a great gap in average scores between items that refer to oral skills, vocabulary and attitudes and those that refer to cultural knowledge and grammar. Although pronunciation was not regarded as important for the use of songs, rhymes and stories in the primary FL classroom, its average score is nonetheless below 2.0 and much closer to the score for motivation, which ranks in place one, than to the one for cultural knowledge, which ranks in next place behind pronunciation. 
Table 20: Reasons for using stories, rhymes/poems and songs (Question 9)

Number of responding teachers: 53-57 for individual learning objectives Number of non-responding teachers: 3-7 for individual learning objectives

\begin{tabular}{|l|l|l|}
\hline Teaching objective & Average score & $\begin{array}{l}\text { Ranking } \\
\text { according to } \\
\text { average score }\end{array}$ \\
\hline To motivate my pupils & 1.32 & 1 \\
\hline To let my pupils enjoy playing with words & 1.54 & 2 \\
\hline To support vocabulary acquisition & 1.60 & 3 \\
\hline To bring variety into the classroom & 1.60 & 3 \\
\hline To train listening comprehension & 1.88 & 4 \\
\hline To let my pupils enjoy music and literature & 1.89 & 5 \\
\hline To improve pronunciation & 1.96 & 6 \\
\hline To present cultural facts & 3.14 & 7 \\
\hline To train grammatical structures & 3.48 & 8 \\
\hline
\end{tabular}

If teachers' responses are analysed in more detail, one finds that, with regard to language use (Figure 13), most teachers seem to use songs, rhymes and stories for improving vocabulary and listening comprehension. Between 85 and 90 percent of responding teachers regarded these aspects as 'very important' or 'important'. Working on pronunciation was also important for many teachers during instances of singing, rhyming and storytelling. Over 75 percent of responding teachers perceived that as 'important' or 'very important'. It is again grammar that was given much less attention. Half of the responding teachers did not attribute any importance to the training of grammatical structures when using songs, rhymes and stories in the primary EFL classroom. This is in line with recommendations made by Lynne Cameron (2001) who does not see the teaching of a particular grammatical structure as a criterion for choosing a literary text for young learners’ EFL classrooms.

In terms of cultural knowledge and attitudes, three aspects seem especially relevant for teachers of this sample (Figure 14). First of all, it is motivation that most teachers reported to have in mind when they decide to use songs, rhymes and stories in their classrooms. Over 70 percent gave highest priority to motivation, with almost all the remaining teachers regarding it as 'important'. The aspect that received nearly as many positive responses was language play. 95 percent of responding 
teachers chose either answer option 'very important' or 'important'. The third aspect that attracted many positive responses was variation. Songs, rhymes and stories are seen to provide a welcome change to classroom routine.

Figure 13: Reasons for using stories, rhymes/poems and songs with regard to language use (Question 9)

Number of responding teachers: 53-57 (varies for different items)

Number of non-responding teachers: 3-7 (varies for different items)

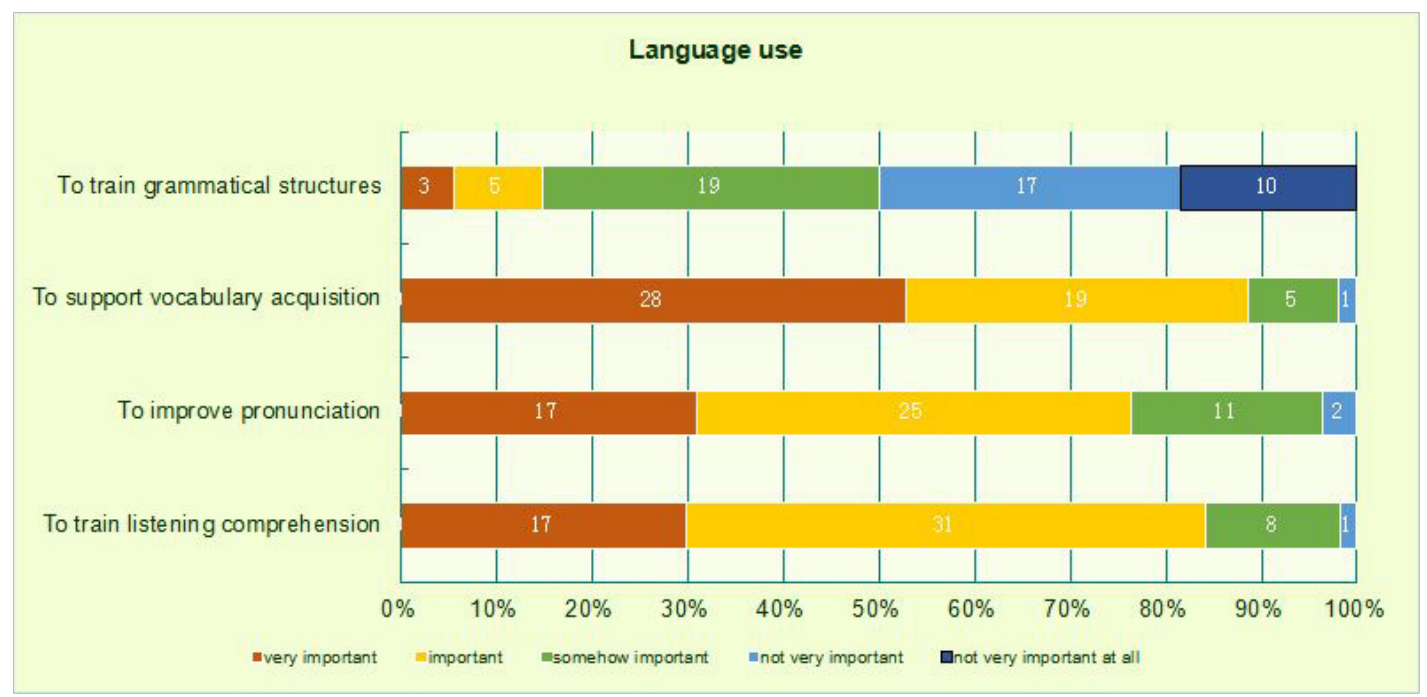

Figure 14: Reasons for using stories, rhymes/poems and songs with regard to cultural knowledge and attitudes (Question 9)

Number of responding teachers: 53-56 (varies for different items)

Number of non-responding teachers: 4-7 (varies for different items)

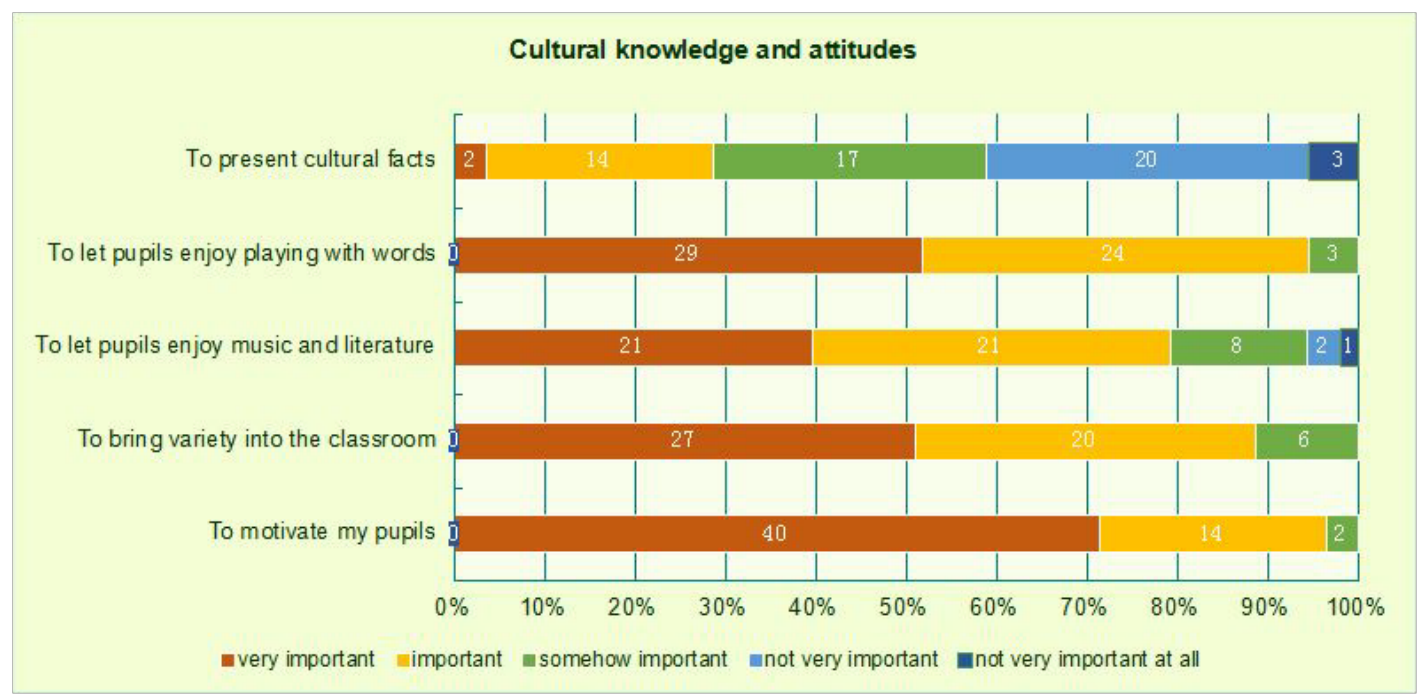

The lack of interest in teaching cultural facts through songs, rhymes and stories confirms teachers' responses to Question 6 and is a logical consequence of teachers' 
objectives. A teacher who does not regard cultural knowledge as important in EFL, will not use songs, rhymes and stories in order to get learners acquainted with cultural details.

The responses to the Likert scale question items seem to be consistent and support results of other question items, such as a strong focus on spoken communication, listening, speaking and pronunciation especially, on vocabulary as well as on the development of a positive attitude towards learning a FL and other cultures. At the same time, teachers' answers again show a tendency to avoid an emphasis on writing, grammar and cultural information.

\subsubsection{Problematic issues in primary EFL}

Open-ended Question 12 asked teachers to report on any problems that they think can occur when literary texts or songs are used in the primary EFL classroom. 54 out of 60 teachers answered this question. The majority of responding teachers (34/53), did not mention any problems. The remaining twenty teachers pointed out 17 different problems. However, at a closer look, these comments refer to issues that are related and could be regarded as different aspects of the same problem (Table 21).

Table 21: Problematic issues with regard to using songs, rhymes and stories (Question 12)

Number of responding teachers (non-responding teachers): 54 (6)

Number of teachers mentioning problems: 20

\begin{tabular}{|l|l|l|}
\hline $\begin{array}{l}\text { Problematic issues when using songs, } \\
\text { rhymes/poems and stories }\end{array}$ & No. of teachers & $\begin{array}{l}\text { Percentage } \\
(100 \%=20)\end{array}$ \\
\hline Texts are overwhelming/ too difficult. & 6 & 30 \\
\hline Pronunciation can be difficult. & 3 & 15 \\
\hline Young learners do not know enough words. & 3 & 15 \\
\hline $\begin{array}{l}\text { Texts should be appropriate and not contain } \\
\text { difficult words. }\end{array}$ & 2 & 10 \\
\hline Translation is difficult. & 2 & 10 \\
\hline Difficult words occur occasionally. & 1 & 5 \\
\hline
\end{tabular}

30 percent of teachers who named problems referred to the complexity of literary and musical texts. Six teachers noted that stories, poems and songs were 
overwhelming for young learners or too complicated, with two of these teachers stating that therefore texts had to be simplified.

Another cluster of problems seems to relate to vocabulary knowledge, with again 30 percent of comments on problematic issues referring to this aspect. Three teachers thought that young learners did not know enough words, with one of these teachers remarking that this lack of vocabulary caused children to lose interest. Three more teachers referred to vocabulary being an issue, but expressed more optimism. One of these teachers commented that difficult vocabulary appeared 'occasionally'. The other two teachers stressed that texts have to be appropriate and should not contain difficult vocabulary or should be explained through the use of pictures and sound.

Other problems that were mentioned by more than one teacher concerned pronunciation, which was remarked upon by three teachers, although in two cases it is not quite clear whose pronunciation was meant, teachers' or pupils', and in which context, namely while presenting a text or understanding it. The third teacher referred to children's pronunciation and the problem that it could not be checked.

One more problem area mentioned by two teachers was translation, although comments did not indicate what exactly was meant. Do teachers ask children to translate parts of stories or songs? Or do they think that they might have a problem with comprehension because there is no translation?

All in all, one can note that if problems are identified, then these refer to the complex nature of literary and musical texts, which most of the teachers here associate with vocabulary. If we consider that pronunciation is also an aspect of vocabulary knowledge, and translation touches the issue of word meanings, then all of the problems mentioned lead back to a lack of vocabulary knowledge in one way or another. It is not only young learners' vocabulary that might be an issue here, although most teachers who mentioned problems stress that the vocabulary found in stories was sometimes too difficult for their learners. Vocabulary of literary texts and songs can also be challenging for teachers because the words one finds in children's stories are not necessarily the words that one finds in textbooks or language classes that teachers will have attended at school and in further training. The language of children's stories can be very archaic and often contains infrequent and poetic words, such as in one of the traditional and well-known nursery rhymes Jack and Jill. On the other hand, some children's stories, especially picture books, 
very often refer to everyday situations, and the language that is used can be very informal, and contain words that are not often used in the written language of textbooks (e.g. sink, the mat by the door, to hug, a cuddle etc.). It is therefore not surprising that many teachers would identify vocabulary as the main problem area when using stories, poems and songs in the primary EFL classroom.

The last question of the main question section, Question 13, invited teachers to make additional comments on the concept of integrated FLT at primary school in Rhineland-Palatinate. Almost one quarter of respondents (14/60) took the opportunity do so, with 10 of these teachers referring to problems with teaching English at primary school. There are four problem clusters that can be identified among these ten critical comments (Table 22).

Table 22: Problematic issues with regard to primary EFL in RhinelandPalatinate (Question 13)

Number of responding teachers (non-responding teachers): 14 (36)

Number of teachers mentioning problems: 10 (more than one problem could be mentioned)

\begin{tabular}{|l|l|l|}
\hline Problematic issues in primary EFL & No. of teachers & $\begin{array}{l}\text { Percentage } \\
(100 \%=10)\end{array}$ \\
\hline Time allocation to FLT & 4 & 40 \\
\hline Teacher training & 3 & 30 \\
\hline Availability of suitable teaching material & 3 & 30 \\
\hline Integrating FL into everyday teaching & 2 & 20 \\
\hline
\end{tabular}

First of all, four out of ten teachers commented negatively on the time allocated for FLT. According to them, the 50 minutes per week that the Ministry of Education in Rhineland-Palatinate reserve for primary EFL within the curriculum were not considered sufficient. Another issue that was raised was the training of teachers that three teachers found problematic. Incorrect pronunciation of non-native speakers of English was seen as one problem, and it was pointed out that teachers without any qualifications and further training should not be teaching. It was criticized that training courses do not take place in schools and are time-consuming. Three teachers touched on the issue of organising suitable material, arguing that material in textbooks was sometimes old-fashioned and not suited for an integrated approach to primary EFL teaching, and picture books were difficult to get hold of. One more 
problem cluster that was referred to was that the concept of integrating the FL into the normal teaching of other subjects does not always seem to work. It was described as difficult to find relevant situations in which the use of the FL would make sense.

Only one sixth of this sample of primary teachers took the opportunity to raise criticism of the FL concept as practised in Rhineland-Palatinate, and it must be noted that it is difficult to draw any conclusions from this small number of critical voices. However, it is interesting that all of the critical remarks refer to organisational constraints. The majority does in fact refer to staffing and timetabling problems, namely a lack of training and a lack of time and opportunity for the teaching of the FL.

\subsection{Discussion of Questionnaire Results}

It was the aim of this questionnaire to render some data from teachers that would provide first insights on the workings of primary school EFL classrooms in one small area so that informed decisions could be made for follow-up research, such as selection of participants and aspects that needed further investigation. In the following, I will discuss in how far questionnaire results contributed to answering initial research questions on how primary teachers teach English to young learners in and around a medium-sized town in Rhineland-Palatinate.

\subsubsection{Lesson organisation, choice of materials, activities and teaching objectives}

The questionnaire yielded information on some general aspects of primary EFL, such as the integration of the FL into other subject areas, the availability of teaching material, activities that teachers regarded as suitable and teachers' objectives. The questionnaire also elicited some response on teachers' experience with songs, rhymes, poems and stories.

The analysis of teachers' answers suggests that English is more often offered as a separate session than it is fully integrated into everyday teaching in primary EFL classrooms in the region under study in Rhineland-Palatinate. This indicates that organisational constraints make it difficult for classroom teachers to fullyembed the teaching of the FL. This is especially evident since the data have shown that most teachers not only teach the main subjects German, maths and science but also specialist areas, such as arts, music and PE, which would make it easier to link the 
FL to other subject areas. However, only 38 percent of teachers manage to integrate English into more than 3 subject areas.

The fact that English is mostly offered as a separate session may be due to either staffing or timetabling issues. A lack of qualified staff normally leads to expert teachers taking over the teaching of English rather than the class teacher. The allocation of a certain time slot for the FL is a consequence. Another reason for the separate teaching of the FL may also be the awareness that other subject areas compete with the FL and that FLT has to be timetabled in order to ensure that it actually takes place in an overcrowded curriculum.

One sixth of this sample of primary teachers took the opportunity to raise criticism. All of the critical comments referred to organisational constraints, namely staffing and timetabling problems, such as a lack of training and a lack of time and opportunity for the teaching of the FL. Staffing problems, in particular, confirm findings from other research on primary EFL in Europe (Nikolov, 2000; Oostdam and van Toorenburg, 2009; Enever, 2011a; Eurydice, 2012).

According to teachers' answers, the teaching of English is mostly integrated into music, science and German lessons and is most often part of rituals at the beginning or end of a lesson by this sample of teachers. This has implications for exposure to the FL. It means that exposure to the FL is restricted to certain routines that may not allow for rich and varied input. Although the FL may be used in a meaningful way, the link to other subject areas cannot be regarded very strong if one considers that, for example, the singing of the song Head, Shoulders, Knees and Toes at the beginning of a sports session does not involve a great amount of vocabulary and content that refers to sports. This suggests a weak form of integrating content and language (Paran, 2013).

It must be noted that there are great differences not only from one school to another but also within teams of teachers regarding the number of different materials and the extent to which English is integrated into other subject areas, which means that one must expect great differences as to the quality and quantity of input that learners receive in different primary EFL classrooms in the region. Most favourite teaching materials seem to be extra copies for stories, games and similar activities, flashcards, as well as extra listening materials. With regard to teaching objectives, most emphasis is put on oral communication over written language and an open 
attitude towards the FL and other cultures over cultural facts and vocabulary over grammar.

It remains to be seen if actual classroom practice can confirm these questionnaire findings. Questionnaire data can only insufficiently explain how the FL is used in actual classrooms. It seems that classroom observation could provide more valuable insights into that aspect.

\subsubsection{The role of songs, chants, rhymes and stories in teacher's lesson organisation in comparison to other activities and with reference to their teaching objectives}

Almost all teachers reported using stories, poems and songs in their classroom. Songs seemed most popular, followed by rhymes and picture stories. Questionnaire data repeatedly showed the popularity of songs in the primary EFL classrooms. All teachers who reported teaching music also reported to integrate English. It was the genre reported to be used most often by teachers and also regarded to be the most suitable genre for the teaching of a FL in primary classrooms.

According to the participating teachers, singing was also regarded as children's most popular activity before games, dancing, rhymes and artwork. The popularity of songs is maybe not surprising given the fact that other studies yielded similar results. In a study by Harris and O’Leary on primary MFL teaching in Ireland, teachers named word games, raps/songs, language awareness activities, action games/sports and drama as the five most enjoyed activities by children (Harris and O’Leary, 2009). However, questionnaire data could only provide limited information on the question of how learners respond to the teaching of a FL in the classroom, since it is teachers' observations that were analysed not learners' own views.

Many different titles of songs, stories and rhymes were provided by participants, but only very few mentioned by many teachers, and some well-known traditional tales and modern picture books were missing from the lists that teachers offered in this study. This again points towards great differences between classrooms and a lack of common resources that teachers share in this area.

There seemed to be a tendency towards very short texts and illustrated texts, with rhymes being regarded as more suitable than poems and picture stories as more appropriate than stories. In general, the genres that teachers reported to be using 
most frequently were also those they found most suitable for primary-level EFL teaching, namely songs, nursery rhymes and picture stories - in that order.

The focus on singing and short, or illustrated literary texts seems to complement teachers’ objectives for primary EFL. Teachers' answers suggested a strong emphasis on oral communication, especially listening comprehension, pronunciation and responding to questions alongside the development of positive attitudes, such as motivation for the learning of a FL and an open-mind towards the foreign culture. Since songs and rhymes highlight prosodic features and were also considered to be popular with children, they lend themselves to these teaching objectives. There was a general disinterest in the teaching of cultural facts, written communication and grammar. Accordingly, stories that entail more text and would involve more focus on the written word as well as more demanding content and language structures, were considered less suitable and reported to be used less often. The focus on listening and reproduction of spoken language is in line with other research findings on primary EFL (Garton, Copland and Burns, 2011).

Artwork was the most favourite follow-up activity according to teachers. Visualization of vocabulary seems to be regarded as important in the primary-level FL classroom, and, of course, a piece of drawing can visualize objects, for which new words were introduced in the FL. Questionnaire data cannot answer the question if and how visualization can be linked to another priority that teachers mentioned, namely memory of words. Data from actual EFL lessons would be needed to examine the interplay of these two aspects.

The issue of vocabulary was, in fact, raised by numerous teachers. It was referred to as being problematic when dealing with songs, stories or rhymes in the primary EFL classroom. At the same time, some teachers referred to the memorable character of a particular genre to justify their choice indicating that the learning of words could be fostered by choosing musical or literary texts. The role of vocabulary, including visualization, was therefore identified as an aspect of the language learning process that needed further investigation. In order to understand how visualization and language play might be used by teachers and learners, one would have to study actual FL lessons in progress. 


\subsection{Concluding Remarks}

The questionnaire findings provided some basic understanding of the use of songs, rhymes and stories, and therefore answered some aspects of the initial research questions as laid out at the end of the Literature Review chapters. For example, insights on teaching objectives, available material and favourite activities in the classroom could be drawn from the data. It was also evident that musical and literary texts, especially songs, seemed to play a central role in many primary EFL classrooms in the area under investigation, and that their use helped to reach some of the objectives that teachers set themselves, such as developing listening and basic speaking skills.

However, not all questions could be answered. For example, results from the survey did not provide information on how exactly singing, learning rhymes and storytelling were organised, structured and integrated into primary EFL during lessons, and more importantly how learners responded. New questions were raised as well. The questionnaire findings did not offer any information on how teachers and learners dealt with unknown words and how far visualization contributed to the learning of new words. At this stage of the project, it seemed necessary to refine and extend the initial research questions to include 1.3 and 2.2:

1. How do primary teachers teach English to young learners in and around a medium-sized town in Rhineland-Palatinate?

1. 1 How do teachers organise their lessons, which materials and activities do they use and which teaching objectives do they follow?

1. 2 Which role does singing, rhyming, chanting and storytelling play in teachers' lesson organisation in comparison to other activities and with reference to the teaching objectives they set themselves?

1. 3 How do teachers teach unknown vocabulary, and what is the role of visualization in that process?

2. How do learners respond to being taught English in these classrooms?

2.1 Is there any evidence of children's enthusiasm for singing, rhyming, chanting and storytelling and how does that compare to or compete with teachers' agendas? 
2.2 What do children's non-verbal or verbal responses tell us about how they manage FL input in the form of songs, rhymes, chants and stories, construct meaning and learn to use the FL?

2.3 What is the nature of learners' FL output, such as individual words, especially nouns, or multi-item sequences, and are there any traces of out-of-school exposure to English in learners' use of English? 


\section{Chapter 6 \\ Participant Observation in Primary EFL Classrooms}

As explained in the previous chapter, questionnaire data could not provide answers to more specific questions on teaching practice. This is not surprising, because experiments and surveys 'are not designed to explore the complexities and conundrums of the immensely complicated social world that we inhabit' (Richards, 2003: 8). Therefore, examples of classroom interaction were collected during periods of participant observation.

\subsection{Methodology and Data Collection}

In the following, I will report on the choice of research tools and procedures of data collection. I will argue that participant observation that aims at immersing into everyday life was seen as the most promising method to understand the workings of real classrooms in this project, and that audio recordings that could be transcribed and analysed alongside fieldnotes were regarded as most suitable, due to the fact that they ensure a minimum of intrusion and distortion of data.

\subsubsection{Choice of research tools}

In this study, 'observing' meant being in the classroom, and joining in with all the activities. I felt that a researcher continually writing down notes in the back of the classroom would alienate herself from the group she was studying, and would therefore be unable to gain a profound understanding of the teaching and learning situation. It was regarded as good practice for the researcher to get involved in the teaching process itself, and to act as an assistant to teachers, supporting them in every way possible, whether that included sharing teaching ideas and materials or even working with children during busy periods of group or desk work. In this way, it was possible to gain an insider perspective and to address teachers' wish for a mutual working relationship and by doing so to adhere to ethical principles of research in Applied Linguistics (BAAL, 2006).

However, this procedure meant that without the observer taking notes during the lesson, valuable information could easily be lost. Two measures were taken to counterbalance this possible negative effect of participant observation. One of these was the use of recordings. Visual and sound recordings provide the most comprehensive account of classroom interaction. The presence of a video camera, 
however, has a more profound impact on teachers and learners and may amplify the effect known as observer's paradox (Labov, 1970). The video camera highlights the fact that observation is taking place and that something unusual is going on, which in turn causes participants to act differently than they would normally do.

However, a sound recording device is much more unobtrusive. It can be placed in the classroom without drawing too much attention to itself. Thus, learners are more likely to behave as they normally do, especially if the visitor spends so much time in the classroom that she becomes almost a part of it. Teachers also have to worry less about a possible negative effect on discipline caused by the excitement of a video camera on display. Therefore, the teachers were expected to agree more readily to a sound recording than to a camera being placed in their classroom.

On the other hand, if a sound recording is the only instrument being applied, other important information may be lost, such as the use of different seating arrangements, pictures and the children's behaviour. A written account that could accompany the sound recording was seen as essential. While it would be impossible for the participant observer to take notes during class, a detailed written account was therefore produced immediately after returning from each observation.

There are limitations to participant observation that had to be acknowledged. An observer who becomes part of the community that he or she studies is more at risk of 'going native', especially if this researcher is a teacher herself, as in this study (Richards, 2003). In order to minimize this risk more than one research instrument was used so that data could be triangulated (Allwright and Bailey, 1991). In this way, interviews with participants were conducted for member validation (Richards, 2003).

Even with the risk of over-identification and lack of precise in-class notetaking in mind, participant observation still seemed to be the most promising method. After all, by engaging in the environment under study, I was more likely to see the world of teachers' and learners' classrooms as they see it themselves, which in turn would contribute to a deeper understanding of the ongoing interaction.

\subsubsection{Procedures for data collection}

Observational data for this research project needed to be gathered over a longer period of time to ensure that teachers and learners became familiar with the visitor in the school and behaved as they normally did, reducing the effect caused by the observer’s paradox (Labov, 1970, see also Samph, 1976). However, spending 
prolonged periods of time in one particular learning environment is more than a mere necessity for a sound data base; it is also the only strategy that ensures that a deeper understanding of a community can develop, as suggested by ethnographic research traditions, and that the research undertaken adheres to ethical principles (Richards, 2003).

Extensive contact with teachers and learners could be ensured by concentrating on one learning environment, that is one primary school. The school was chosen because teachers there had expressed an interest in follow-up research during questionnaire administration. Observations were scheduled during two observational periods between February and June in the school years 2007/8 and 2008/9 after access had been granted. At the school, three teachers and one student teacher were providing English sessions to all primary school children at the time (Table 23). In total, 38 lessons were observed during the weeks spent at the school.

Table 23: Observation Matrix

\begin{tabular}{|l|l|l|l|}
\hline $\begin{array}{l}\text { No. of } \\
\text { lessons }\end{array}$ & $\begin{array}{l}\text { No. of teachers } \\
\text { involved }\end{array}$ & $\begin{array}{l}\text { No. of classes } \\
\text { involved }\end{array}$ & $\begin{array}{l}\text { No. of lessons } \\
\text { recorded }\end{array}$ \\
\hline 38 & 4 & 9 & 15 \\
\hline
\end{tabular}

Before observations commenced, a letter for learners' parents was handed out in all classes (Appendix no. 1). Parents were informed about the researcher being in the classroom, working with their children and recording English sessions. Parents were asked to indicate on a slip of paper if they agreed for their child to take part in the project. The project was only carried out in classes where none of the parents had voiced disagreement.

Not all classes could be recorded. For example, teachers were always given time to get used to the researcher being in the classroom before recording started. In general, the idea was to refrain from recording if the researcher could detect a degree of tension and unwillingness from teachers even if they had all agreed to take part in the project. It was crucial for the success of the project, to balance the researcher's interest for a rich database with possible concerns of participants and to respect participants’ apprehension. Recordings were also stopped if the circumstances were not favourable, such as during noisy workshop sessions that produced incomprehensible accounts of lessons. In the end, classroom discourse was recorded during 15 lessons. 


\subsubsection{The participating school, children and teachers}

The school where observations were conducted is situated on the edge of a mediumsized town, in walking distance of the town centre. The school is a medium-sized primary school. At the time of the study, there were two classes of up to 28 children for each of the four different year groups.

Classes in the school were of mixed nationality, with approximately $50 \%$ of the children coming from a non-German speaking family background. A good number of children spoke Russian as their first language, but there were also children with Italian, Brazilian and Indonesian backgrounds. Many of the children went to a local kindergarten and were fluent German speakers, but some still needed extra help, which was provided in separate classes during the school day. The children who needed tuition in German left their classroom at regular times during the week and received instruction in small groups.

The school operated a policy whereby only teachers who had obtained their teaching qualification in EFL were allowed to teach the language. With the majority of teachers not having received training yet, most English lessons in the school were held by two teachers, in the following called Sophie and Ruth. This is why the great majority of observations were carried out in the classrooms of these two teachers. There was one more English teacher, in the following referred to as Julia, who only taught the FL in her own class at the time of the project, and one student teacher, who was encouraged to teach a few EFL lessons during her internship.

Sophie was a young teacher who had started her teacher degree programme at university straight after school and had finished her teacher training four years prior to this study. She had not studied English as a subject at university, but received her qualification in one of the further training courses offered in RhinelandPalatinate. Sophie had worked as a cover primary-school teacher elsewhere for a year, before coming to this school.

Ruth joined the school six years prior to this project, and was the longest serving EFL teacher among participants. She had studied English as one of her main subjects at university and started working at the school after she had finished her training. Ruth is the only teacher observed at this school who had taught EFL for more than five years.

Julia had not studied English as her main subject, but had attended extra EFL training alongside her studies during her time at university. She had been teaching as a primary-school teacher for five years. 
The student teacher was still studying at university, with one of her main subjects being English. Her teaching experience at the time consisted of internships that took place in between teaching blocks during the academic year.

\subsection{Procedures for Data Analysis}

Classroom observations resulted in a total of 38 written accounts of EFL sessions in the form of fieldnotes and 15 recordings of classroom discourse (Table 24).

Table 24: Observation data

\begin{tabular}{|l|l|l|l|l|}
\hline Fieldnotes & $\begin{array}{l}\text { Classroom } \\
\text { recordings }\end{array}$ & $\begin{array}{l}\text { Teachers } \\
\text { recorded }\end{array}$ & $\begin{array}{l}\text { Learner groups } \\
\text { recorded }\end{array}$ & $\begin{array}{l}\text { Total recording } \\
\text { time (mins.) }\end{array}$ \\
\hline 38 & 15 & 4 & 7 & $586: 55$ \\
\hline
\end{tabular}

For reasons of transparency, all comprehensible EFL classroom discourse was transcribed. This produced a total of 15 transcripts and yielded a data base of more than 59,000 words (Table 25). In the following, I will explain different aspects of data analysis, including transcription procedures and criteria for the screening of data.

Table 25: Transcription data

\begin{tabular}{|l|l|l|l|l|l|}
\hline Transcript & $\begin{array}{l}\text { Observed } \\
\text { lesson }\end{array}$ & Year* & Teacher & $\begin{array}{l}\text { Length of } \\
\text { recording ** } \\
\text { (mins.) }\end{array}$ & $\begin{array}{l}\text { Word count } \\
\text { of transcript }\end{array}$ \\
\hline 1 & 3 & 4 & Sophie & $37: 53$ & 3,500 \\
\hline 2 & 4 & 3 A & Sophie & $45: 28$ & 5,183 \\
\hline 3 & 5 & $3 \mathrm{~B}$ & Sophie & $35: 02$ & 4,684 \\
\hline 4 & 6 & 4 & Sophie & $43: 35$ & 4,674 \\
\hline 5 & 7 & $3 \mathrm{~A}$ & Sophie & $47: 41$ & 5,373 \\
\hline 6 & 8 & $3 \mathrm{~B}$ & Sophie & $44: 15$ & 3,904 \\
\hline 7 & 9 & 1 & Sophie & $27: 35$ & 4,164 \\
\hline 8 & 10 & 1 & Julia & $42: 29$ & 3,410 \\
\hline 9 & 11 & 4 & Sophie & $47: 23$ & 3,825 \\
\hline 10 & 25 & 3 & Ruth & $37: 58$ & 4,364 \\
\hline 11 & 26 & 4 & Student Teacher & $41: 50$ & 3,295 \\
\hline 12 & 29 & 3 & Ruth \& Researcher & $40: 54$ & 4,146 \\
\hline
\end{tabular}




\begin{tabular}{|l|l|l|l|l|c|}
\hline 13 & 31 & 3 & Ruth & $44: 32$ & 5,165 \\
\hline 14 & 32 & 3 & Ruth & $44: 42$ & 2,750 \\
\hline 15 & 38 & 3 & Ruth & $05: 38$ & 716 \\
\hline
\end{tabular}

TOTAL: $\quad 586: 55$

59,153

* There were two parallel sessions, that is identical lessons taught in different groups of the same year, therefore 3A \& 3B.

** The varying length of recording time is a result of either organisational constraints, such as a lesson starting late and changing seating arrangements, or the level of background noise during busy periods of pair, group and project work, which made it impossible to record intelligible speech.

\subsubsection{Transcription procedures}

Wherever possible, lessons were transcribed from beginning to end. As for the process of transcribing, every effort was made to write up an as accurate a record as possible of what could be heard in the recordings. Stretches of speech were listened to numerous times and transcripts checked for accuracy so as to avoid utterances being omitted due to the observer's tendency to hear what she might expect to hear rather than what is really there. This is a potential threat for observational data even if it has been recorded, since the problem of selective observation is not solved by the use of a recording device, but only delayed until the time when the recording has to be analysed (Ochs, 1979). At the same time, every attempt was made to create uncluttered transcripts, since too much detail can impact negatively on clarity and readability (D. Cameron, 2001; Gee 2011).

With this project focusing on the learning of a foreign language, any aspect that could be evidence for learning language had to be transcribed. Words, even half-spoken, cut-off words or syllables were of importance, just as any kind of repetition or pause that could indicate hesitation and possibly lack of confidence in the correct use of language. At the same time, decisions had to be made as to how detailed the transcription should be. For example, since this was not a study on pauses in learners' or teachers' speech, it was felt that the distinction between what seemed a naturally occurring pause within an utterance and a pause that seemed prolonged or deliberate was sufficient and no further analysis of pauses was necessary. In the same way, this study does not specifically focus on a certain aspect of pronunciation, and data was therefore transcribed in standard orthography with occasional ‘comic-book orthography’ for dialectal native language use (Jefferson, 
1983 and 2004) as well as exact phonetic transcription for incorrect FL use wherever appropriate.

Another issue to mention is overlap and latching. With the majority of data coming from a classroom where there are distinct rules for turn-taking, overlap and latching are less common than in naturally occurring speech. Since teachers and learners alike are expected to speak in proper sentences, there is less fragmentary language use and non-standard syntax.

All discourse data in the main text of this thesis are presented in a table with two columns for two participant groups, the teacher and the children. This layout reduces top to bottom bias to a minimum so that potential differences in adult and child communication patterns and cognitive behaviour can be identified (Ochs, 1979). There is another reason why such a layout seems preferable for analysis of classroom discourse. The separation of teacher and learner talk produces a visually accurate representation of the amount of teacher talk in relation to learners' contributions. Since the teacher sets stimuli for learners, and therefore initiates discourse, it is seen as appropriate to present the teacher's talk in the left column.

\subsubsection{Criteria for the analysis of classroom data}

Fieldnotes and transcripts were screened to triangulate findings from the questionnaire and to supplement insights on primary EFL practice that the questionnaire had failed to produce. Data analysis entailed both quantitative and qualitative aspects and followed the research questions as refined after the analysis of questionnaire data and laid out at the end of Chapter 5 (p. 121).

As part of the quantitative analysis of the classroom observation data, the proportion of teaching allocated to literary and musical texts was calculated. Fieldnotes were examined to establish in how many of the observed sessions the different genres that occurred, that is story, chant and song, were actually used. Transcripts were screened to evaluate how much of classroom discourse was devoted to stories, songs and chants. In the same way, the amount of FL input that children received during instances of storytelling, singing and chanting was determined.

As part of the qualitative analysis, transcripts were read numerous times. Each transcript was studied on its own to understand how the lesson was organised as a whole and which parts of the lesson focused on the teaching of stories, songs and chants. These stretches of classroom discourse were then analysed in greater 
detail to examine how exactly teachers introduced children to songs, stories and chants and how children responded to them.

Care was taken to avoid reading the data selectively, that is with particular hypotheses of anticipated learner and teacher behaviour in mind, since this bears the risk of missing potentially enlightening details in teacher-learner communication (Ochs, 1979; Sacks, 1984; D. Cameron, 2001). I tried to take an unbiased view that enables the discourse analyst to identify interaction that is out of the ordinary and worth investigating further (Gee, 2011). At the same time, it cannot be ignored that researchers normally approach a piece of data with certain questions in mind, which is also true for this project.

With reference to the teachers, I was interested in their use of the FL and mother tongue, how they ensured that learners understood and how they responded to learners' verbal and non-verbal contributions. With regard to the learners, I wanted to find out if their responses revealed any rejection or enthusiasm for the songs, chants and stories, if they tolerated unknown vocabulary or felt overwhelmed by expressing confusion for example, and if there was any sign of them understanding language or reproducing language from these texts.

Apart from the analysis of what teachers and learners actually said, it was also examined how teachers and learners said something. The transcripts were screened for changes in the speed of the communication flow, for increases of latching and overlap for example, that is speakers taking turns very quickly or interrupting each other, but also for prolonged or deliberate pauses or an increase of noise level or disruptive behaviour. Since observable changes of behaviour can have different causes, such as a prolonged silence can be the consequence of either confusion or amazement, these stretches of classroom discourse were then examined more closely with regard to the context in which they occurred so as to understand what exactly caused the change in communication.

Having been analysed individually, the transcripts were then compared to reveal if there were any recurrent patterns of teacher and learners behaviour in classroom discourse during the teaching of songs, chants and stories.

\subsection{Results of Classroom Observation Data}

In the following, results of quantitative and qualitative analysis of classroom data will be presented. I will report on the extent to which classroom discourse was dedicated to songs, chants and stories. I will analyse the characteristics of the texts 
that were used, how these texts were presented by teachers and how learners responded to them.

With regard to teaching, the structure of example lessons will be analysed to demonstrate how teachers organised instances of storytelling, chanting and singing. Then, I will turn my attention to the learners and focus on example extracts from different lessons that featured songs, chants and stories in order to discuss how learners responded to these texts, both verbally and non-verbally. There will also be a separate section on a picture book session that was part of my teaching experience as participant observer in the school, and that provides more insights into how learners managed the first encounter with a picture book.

\subsubsection{Quantitative aspects of the lessons}

On the basis of the fieldnotes, an overview was produced of how often musical and literary texts were used during classroom observation (Appendix 7). The analysis shows that the genres applied in the primary EFL classrooms were songs, chants and stories. They were presented, performed and experienced in 29 of the 38 primary EFL lessons that were observed in the school, which equals $76 \%$ of observed sessions (Table 26). This comes down to $74 \%$ if one deducts the three sessions that were parallel lessons in groups of learners of the same year group (Table 26).

\section{Table 26: Frequency of songs, chants and stories}

\begin{tabular}{|l|r|}
\hline No. of lessons (incl. parallel sessions) & 29 \\
\hline Percentage of lessons (incl. parallel sessions), $100 \%=38$ & 76 \\
\hline No. of lessons (excl. parallel sessions) & 26 \\
\hline Percentage of lessons (excl. parallel sessions), $100 \%=35$ & 74 \\
\hline
\end{tabular}

According to the above calculation, about three quarters of classroom time were devoted to the teaching of songs, chants and stories. In the remaining lessons, teachers focused on form-focused language practice in the form of question-answer activities, on playing games, on the development of cultural knowledge and on the completion of self-assessment forms as part of the portfolio that learners are required to produce (Appendix 7).

The frequency with which each genre was used is illustrated in Table 27. Stories were most often used by teachers, that is in 50\% of all lessons observed, followed by songs, which featured in almost a quarter of all lessons. Chants were only used in three of these lessons, that is in $8 \%$ of 38 observed lessons. These 
numbers only change slightly if one deducts parallel sessions (Table 27). In three lessons, two different genres were used in the same session (Appendix 7).

Table 27: Use of different genres

\begin{tabular}{|l|l|l|l|l|}
\hline Genre & $\begin{array}{l}\text { No. of lessons } \\
\text { (incl. parallel } \\
\text { sessions) }\end{array}$ & $\begin{array}{l}\text { Percentage } \\
(100 \%=38)\end{array}$ & $\begin{array}{l}\text { No. of lessons } \\
\text { (excl. parallel } \\
\text { sessions) }\end{array}$ & $\begin{array}{l}\text { Percentage } \\
(100 \%=35)\end{array}$ \\
\hline Story & 19 & 50 & 17 & 49 \\
\hline Song & 9 & 24 & 7 & 20 \\
\hline Chant & $3 *$ & 8 & $3^{*}$ & 9 \\
\hline
\end{tabular}

* In one lesson, Lesson 11, two chants were used.

Within the 29 lessons during which work on songs, stories and chants could be observed, 23 different texts were being used by teachers and learners, that is 11 different stories, 9 different songs and three different chants (Table 28).

Table 28: Number of different texts according to genre

\begin{tabular}{|l|r|r|r|}
\hline & Story & Song & Chant \\
\hline Total no. of different texts & 11 & 9 & 3 \\
\hline of which teacher-initiated & 11 & 3 & 3 \\
\hline of which learner-initiated & 0 & 6 & 0 \\
\hline
\end{tabular}

It has to be noted that although all instances of storytelling and chanting were initiated by the teacher, this is not the case for singing. In two lessons, 21 and 25, the singing of songs was initiated by learners. As they were asked to name titles of songs that they knew so that they could be written down for their portfolio, learners started singing. The teacher, Ruth in this case, changed her lesson plan to let her learners perform some songs and they sang six different songs during these two portfolio lessons.

While fieldnotes can provide some rough indication of how often songs, chants and stories were used, they cannot give exact information on how much classroom discourse of each of the lessons was devoted to these texts. Therefore, all 15 recordings and transcriptions of EFL classroom discourse were analysed for more details (Appendix 7). Two measures were taken.

Firstly, recordings were examined to establish how much time was spent by teachers and learners on performing, presenting and reflecting on songs, chants and 
stories. Recording time, naturally, includes stretches of slower and faster paces of discourse. It also includes pauses and silences, such as teachers waiting for their class to settle down or to answer them and stretches of unintelligible speech that cannot be transcribed. Secondly, transcripts were studied for the word count associated with instances of singing, chanting and storytelling. Transcripts offer information on how much of the comprehensible verbal interaction was linked to songs, chants and stories. Naturally, they do not reflect passages of verbal classroom interaction that was unintelligible and they also include details on non-verbal interaction. Both measures, therefore, have their limitations, but it is hoped that by using two different measures, the effects of these can partly be outbalanced.

The analyses of recording time and word count suggest that $49 \%$ of classroom time and $62 \%$ of classroom interaction can be associated with the teaching and learning of songs, chants and stories in the primary EFL classrooms under observation (Table 29). Results for both types of analysis vary by 1 to $7 \%$ for different genres. Nonetheless, both measures indicate that approximately a quarter of classroom time and interaction was devoted to stories, followed by song and chant.

Table 29: Proportion of time and word count for song, chant and story

\begin{tabular}{|l|r|l|r|l|}
\hline & Recording time & $\begin{array}{l}\text { Percentage } \\
(100 \%=586: 55)\end{array}$ & $\begin{array}{l}\text { Pord count } \\
(100 \%=59,153)\end{array}$ \\
\hline Story & $132: 22$ & 23 & 16,466 & 28 \\
\hline Song & $78: 28$ & 13 & 11,737 & 20 \\
\hline Chant & $78: 37$ & 13 & 8,065 & 14 \\
\hline
\end{tabular}

If one looks at the amount of classroom time and interaction for individual lessons, one can find great variation (Appendix 7). In terms of time devoted to the genres, proportions range from 15 to $70 \%$ for story, 12 to $76 \%$ for song and 8 to $77 \%$ for chant (Table 30). Maximum rates were achieved at times when texts were presented and worked on for the first time, as in the case of the Weather Song in Lesson 5, the football chant in Lesson 4 and the April Weather story in Lesson 7 (Appendix 7). Minimum rates were mostly reached in episodes of learners revising or presenting, as in the case of the Weather Song in Lesson 8, of the Football Warm-up in Lesson 11, of songs sung as part of portfolio work in Lesson 25 and graded readers read out aloud in front of the class in Lesson 32, but also in the case of the Easter Chant in Lesson 10 which was used as motivation booster (Appendix 7). 
Table 30: Minimum \& maximum proportions of recorded classroom time related to song, chant and story

\begin{tabular}{|l|l|l|l|l|l|l|}
\hline & $\begin{array}{l}\text { Min. } \\
\%\end{array}$ & $\begin{array}{l}\text { Lesson/ } \\
\text { Transcript/ } \\
\text { Teacher }\end{array}$ & Text & $\begin{array}{l}\text { Max } \\
\%\end{array}$ & $\begin{array}{l}\text { Lesson/ } \\
\text { Transcript/ } \\
\text { Teacher }\end{array}$ & Text \\
\hline Story & 15 & $32 / 13 /$ Ruth & $\begin{array}{l}\text { Look At Me } \\
\text { Go Away Floppy } \\
\text { Big Feet } \\
\text { Kipper's Diary }\end{array}$ & 70 & $7 / 5 /$ Sophie & April Weather \\
\hline Song & 12 & $\begin{array}{l}8 / 6 / \text { Sophie } \\
25 / 9 / \text { Ruth }\end{array}$ & $\begin{array}{l}\text { Weather Song } \\
\text { London Is A } \\
\text { Very Big Town } \\
\text { Head, Shoulders } \\
\text { Rudolph the Red- } \\
\text { Nosed Reindeer } \\
\text { Mosquito Song }\end{array}$ & 76 & $5 / 3 /$ Sophie & $\begin{array}{l}\text { The Weather } \\
\text { Song }\end{array}$ \\
\hline Chant & 8 & $10 / 8 /$ Julia & $\begin{array}{l}\text { Easter Chant } \\
77\end{array}$ & $11 / 9 /$ Sophie & $\begin{array}{l}\text { Easter Bunny } \\
\text { Chant }\end{array}$ \\
\hline
\end{tabular}

In terms of how much classroom interaction was devoted to song, chant and story, a similar picture evolves. Minimum and maximum rates of word count vary considerably from $10 \%$ to $90 \%$ for one text (Table 31). If one compares proportions of classroom time and word count, one finds that in all but two cases (max. rate for story and min. rate for song), the same texts can be associated with low and high rates. However, there are also differences. For example, according to the analysis of word count, both the lowest and the highest proportions are linked to songs, not to chants, as the analysis of recording time suggests.

The highest maximum percentage of classroom time and interaction for an individual session is reached in Lesson 5 for the teaching and learning of The Weather Song (Table 30 and Table 31), which indicates that although the rate for the frequency of songs was lower than for story (Table 27, p. 132), song was at times the more dominant genre in the primary EFL classrooms observed as part of this study. 
Table 31: Minimum \& maximum proportions of recorded classroom interaction related to song, chant and story

\begin{tabular}{|l|l|l|l|l|l|l|}
\hline & $\begin{array}{l}\text { Min. } \\
\%\end{array}$ & $\begin{array}{l}\text { Lesson/ } \\
\text { Transcript/ } \\
\text { Teacher }\end{array}$ & Text & $\begin{array}{l}\text { Max. } \\
\%\end{array}$ & $\begin{array}{l}\text { Lesson/ } \\
\text { Transcript/ } \\
\text { Teacher }\end{array}$ & Text \\
\hline Story & 32 & $32 / 13 /$ Ruth & $\begin{array}{l}\text { Look At Me } \\
\text { Go Away Floppy } \\
\text { Big Feet } \\
\text { Kipper's Diary }\end{array}$ & 79 & $10 / 8 /$ Julia & $\begin{array}{l}\text { Easter Bunny } \\
\text { Book }\end{array}$ \\
\hline Song & 10 & $25 / 9 /$ Ruth & $\begin{array}{l}\text { London Is A Very } \\
\text { Big Town } \\
\text { Head, Shoulders } \\
\text { Rudolph the Red- } \\
\text { Nosed Reindeer } \\
\text { Mosquito Song }\end{array}$ & 90 & $5 / 3 /$ Sophie & $\begin{array}{l}\text { The Weather } \\
\text { Song }\end{array}$ \\
\hline Chant & 18 & $10 / 8 /$ Julia & $\begin{array}{l}\text { Easter Chant } \\
79\end{array}$ & $11 / 9 /$ Sophie & $\begin{array}{l}\text { Easter Bunny } \\
\text { Chant }\end{array}$ \\
\hline
\end{tabular}

\subsubsection{Analysis of songs, chants and stories used in the primary EFL classrooms}

All texts that were used in primary EFL classrooms were analysed for their content and form, that is their structure, linguistic features and modes of presentation in order to understand how they function in the context of a young learners’ FL classroom.

Aspects that influence FL learning are of special interest, such as the length of the text and its lexical and syntactical richness. The two latter aspects are reflected in the degree of repetition of language. For the understanding and memorization of FL input, more aspects are of relevance, such as visualization through pictures (Nation, 2001) and accompanying actions (Asher, 1969), sound through the use of literary devices such as onomatopoeia, rhyme and rhythm (Henning 1973; Boers and Lindstromberg 2008), and the degree of repetition of both content and language (L. Cameron, 2001), which increases opportunities for noticing new words (Nation, 2001), for example. All texts were analysed for these aspects. In the following, I will summarize results of this analysis. 


\subsubsection{Songs}

During observations, nine songs were performed as part of EFL sessions (for full texts see Appendix 8), of which two were traditional songs, four were favourite children songs in the English-speaking world and three were songs that are less well-known.

Jingle Bells and One, Two, Three, Four, Five are both songs that are part of British and American heritage. While the former is a well-known Christmas carol composed by the American James Lord Pierpont and published in 1857, the latter is a famous nursery rhyme that is also used in pre-school education in the Englishspeaking world ever since it first appeared as a one-verse poem about a hare in the collection Mother Goose’s Melody (1780).

Among the more modern children's classics that were used are Head, Shoulders, Knees and Toes, I Can Sing a Rainbow, If You're Happy and You Know It and Rudolph the Red-Nosed Reindeer. The former two have also entered the world of modern music, that is hip hop and pop, since cover versions have been produced by various artists. These versions are easily accessible through the new media, such as You Tube. The Christmas song about Father Christmas' helper Rudolph has achieved similar status. Although the song has not yet become part of the world of pop, there are many cover versions of the song that was written by Johnny Marks and sung by Gene Autry on the first recording in 1949. Ever since then, it has become part of the repertoire of songs played and performed at Christmas, not just in English-speaking countries but also abroad. If You're Happy and You Know It has also become very successful in Germany, because of the German version by Gerhard Schöne, one of East Germany’s well-known Liedermacher, songwriter and performer, whose songs for children entered kindergartens in the East and the West and are still widely sung as part of preschool education.

Among the less-well known songs are London Is a Very Big Town, The Mosquito Song and The Weather Song. The first of these was published in the O!Kay! magazine with accompanying tape for primary EFL learners in 1999. The Mosquito Song, as part of a package of song lyrics all featuring insects, is available at the Wee Sing website (Penguin Group, USA) that advocates 'learning through music'. As the other two songs, the Every Kind of Weather Song, which I will simply refer to as The Weather Song, is closely linked to educational purposes. It is part of the Boogie Beebies series (2005) produced for pre-school children by the 
$\mathrm{BBC}$. The programme that combines dance and song targets a young native-speaker audience who are still learning their first language.

Tonal repetition and variation as well as metric units, called bar, are the natural ingredients of song. All of these create patterns of repetitions that are reflected in and complemented by repetition in language, that is patterns of stressed and unstressed syllables, rhyming patterns of similar sounding words and repetition of lexical items. The latter is of special interest for our purposes, since any repetition of vocabulary decreases the amount of processing and memorizing that learners have to manage when they are getting to know and use a new song in the FL. In order to establish the degree of repetition of lexical items, the total word count of each song has been compared to the proportion of lexical items that only occur once in the text (Appendix 8). Table 32 provides a summary of this analysis.

Table 32: Proportion of repetition of lexical items in songs

\begin{tabular}{|c|c|c|c|c|}
\hline Title & Word count & $\begin{array}{l}\text { No. of items } \\
\text { occurring } \\
\text { once }\end{array}$ & $\begin{array}{l}\text { Proportion } \\
\text { of single } \\
\text { occurrences }\end{array}$ & $\begin{array}{l}\text { Proportion } \\
\text { of repetition }\end{array}$ \\
\hline $\begin{array}{l}\text { If You're Happy and You } \\
\text { Know It }\end{array}$ & 132 & 0 & $0 \%$ & $100 \%$ \\
\hline I Can Sing a Rainbow & 73 & 4 & $5 \%$ & $95 \%$ \\
\hline $\begin{array}{l}\text { Head, Shoulders, } \\
\text { Knees and Toes }\end{array}$ & 32 & 4 & $13 \%$ & $87 \%$ \\
\hline The Mosquito Song & 43 & 8 & $19 \%$ & $81 \%$ \\
\hline London Is a Very Big Town & 26 & 8 & $31 \%$ & $69 \%$ \\
\hline Jingle Bells & 20 & 15 & $75 \%$ & $25 \%$ \\
\hline The Weather Song & 24 & 19 & $79 \%$ & $21 \%$ \\
\hline One, Two, Three, Four, Five & 45 & 38 & $84 \%$ & $16 \%$ \\
\hline $\begin{array}{l}\text { Rudolph the Red-Nosed } \\
\text { Reindeer }\end{array}$ & 43 & 40 & $93 \%$ & $7 \%$ \\
\hline
\end{tabular}

The calculations are based on the texts as they were sung in the classroom. If only one verse was sung, for example, then only this one verse was used for the analysis.

The song with the highest proportion of repetition is If You're Happy and You Know It. Not even one lexical item occurs only once in this text, all the language is repeated on the basis of three chunks which form the building blocks of this song. These are 'if you're happy and you know it' (repeated four times in every verse), 'and you really want to show it' (repeated three times on the whole) and 'clap your 
hands' (repeated three times in one verse). The latter phrase is a an example of prefabricated language with open slots that can be filled with different lexical items of the same sort, that is 'verb+your+body part' (Weinert, 1995). This chunk of language, the only one that shows some variation from one verse to the next, is supported by actions, that is the actual clapping of one's hands, for example, which functions as a kind of scaffolding device for understanding what is being sung about (Table 33).

Table 33: Visualization, sound and literary devices in songs

\begin{tabular}{|c|c|c|}
\hline Title & Visualization & Sound \& language \\
\hline If You're Happy and You Know It & actions & \\
\hline I Can Sing a Rainbow & & $\begin{array}{l}\text { word play } \\
\text { rhyme }\end{array}$ \\
\hline Head, Shoulders, Knees and Toes & actions & \\
\hline The Mosquito Song & actions & onomatopoeia \\
\hline \multicolumn{3}{|l|}{ London Is a Very Big Town } \\
\hline Jingle Bells & & $\begin{array}{l}\text { onomatopoeia } \\
\text { rhyme }\end{array}$ \\
\hline The Weather Song & $\begin{array}{l}\text { video clip } \\
\text { actions }\end{array}$ & \\
\hline One, Two, Three, Four, Five & & rhyme \\
\hline Rudolph the Red-Nosed Reindeer & & rhyme \\
\hline
\end{tabular}

Other songs that exhibit a very high degree of repetition of language are I Can Sing a Rainbow (95\%), Head, Shoulders, Knees and Toes (87\%) and The Mosquito Song (81\%). The first of these, I Can Sing a Rainbow, consists of one chorus that is sung twice and one verse. While the chorus shows one slight variation, that is the change from 'I can sing' to 'you can sing', the only verse features the repetition of a whole line, that is 'listen with your eyes'. It is noteworthy that the repetition of this piece of language coincides with the fact that it does not seem to make any sense. We do not listen with our eyes, and yet we do use our eyes to understand the world around us. Repetition, in this case, functions like a signal. It draws our attention to this play on words, and at the same time it gives the listener more time to process it. In the verse, there is also the repetition of chunks consisting of several items, such as 'sing a 
rainbow', and the repetition of individual items. The only two lines that contain lexical items that only occur once end on rhyming words, 'see' and 'me'. The rhyme highlights these new lexical items and draws the listener's attention to them, increasing the chance of noticing them.

Head, Shoulders, Knees and Toes also consists of a repetition of chunks of language. These are 'head, shoulders', 'knees and toes', 'and eyes/ears/mouth/nose'. The latter again is a prefabricated phrase with an open slot, 'and+body part'. During observations, only this verse was sung once, as the teacher let the children quickly sing a few songs during portfolio work. Normally, however, this one verse would be repeated, and each time one more body part is left out while the actions are still performed. Through the repeated singing, the meaning of the lyrics is retrieved through the actions (Table 31). There is another feature here that leads to focused attention. The song is normally performed as a game, during which anybody who sings when they are supposed to be silent or anybody who gets actions mixed up is out.

The Mosquito Song is also accompanied by actions. There is clapping at the beginning and end of the song. This action coincides with the use of onomatopoeia. The sound 'zzzt' is supposed to represent the noise that mosquitoes make, whereas the clapping represents the common human reaction to mosquitoes. The same is true for the miming of scratching that is used when the words 'itch' and 'scratch' appear. The latter word is reminiscent of the sound that is produced when something sharp rubs against a surface. Actions and onomatopoeia highlight lexical items and make it easier for the learner to notice and understand them.

The remaining songs show a lower degree of repetition, and they are all short songs, between 20 to 45 words of length. Apart from London Is a Very Big Town, which features the repetition of a whole line, a six-item string, the other songs only feature the repetition of short chunks of three or two words, or of individual words. However, they are accompanied by visualization, sound or literary devices. In Jingle Bells, onomatopoeia is a prominent feature, with the word 'jingle' representing the sound of the bells. It is repeated three times. The Weather Song is presented as part of a video clip that features a native speaker doing actions with appropriate film sequences of sun, windy weather conditions and rain pouring down in the background. One, Two, Three, Four, Five and Rudolph the Red-Nosed Reindeer, on the other hand, feature regular use of rhyming words. In the nursery rhyme, the eight 
lines are organised in four sets of pair rhymes, and in the Christmas carol every second line of the four-line chorus and verse rhyme.

\subsubsection{Chants}

During observations, three chants were used, one associated to the topic football and the other two to the topic Easter. The proportion of repetition in terms of lexical items for all of these is between 68 and 87 percent (Table 34). The Football WarmUp (Boogie Beebies, 2005), which features the highest percentage of repetition is basically a list of instructions, such as 'head and chest' and 'save the goal' with occasional remarks of encouragement thrown in, such as 'that's it' and 'okay'. However, these instructions and remarks are repeated and spoken rhythmically in time with modern techno dance music playing in the background as in a music video clip (Table 35). This is underlined by the presenter doing the moves at the same time, which gives the impression of a dance routine.

Table 34: Proportion of repetition of lexical items in chants

\begin{tabular}{|l|r|l|l|l|}
\hline Title & $\begin{array}{l}\text { Word } \\
\text { count }\end{array}$ & $\begin{array}{l}\text { No. of items } \\
\text { occurring } \\
\text { once }\end{array}$ & $\begin{array}{l}\text { Proportion of } \\
\text { single } \\
\text { occurrences }\end{array}$ & $\begin{array}{l}\text { Proportion of } \\
\text { repetition }\end{array}$ \\
\hline Football Warm-up & 179 & 23 & $13 \%$ & $87 \%$ \\
\hline Easter Chant & 14 & 3 & $21 \%$ & $79 \%$ \\
\hline Easter Bunny Chant & 51 & 16 & $32 \%$ & $68 \%$ \\
\hline
\end{tabular}

Table 35: Visualization, sound and literary devices in chants

\begin{tabular}{|l|l|l|}
\hline Title & Visualization & Sound \& language \\
\hline Football Warm-up & $\begin{array}{l}\text { video clip } \\
\text { actions }\end{array}$ & $\begin{array}{l}\text { instrumental background } \\
\text { music }\end{array}$ \\
\hline Easter Chant & actions & rhyme \\
\hline Easter Bunny Chant & actions & $\begin{array}{l}\text { onomatopoeia } \\
\text { rhyme }\end{array}$ \\
\hline
\end{tabular}

Movement is also a central feature of the other two chants. In the Easter Chant, in which 79 percent of lexical items were repeated, the chanting of 'hop, hop, hop' is accompanied by actual hopping. The only words that are not repeated is the threeitem chunk 'Please don't stop', which forms a rhyming pair with the verb 'hop'. In the more elaborate Easter Bunny Chant (Diekmann, 2008a), the same rhyming 
words, that is 'hop' and 'stop', are used in the first two lines, and the regular rhyme pattern continues and is only interrupted once. The Easter Bunny Chant is much more demanding in terms of lexical complexity, with the proportion of repeated lexical items being 68 percent. It seems like an extension of the Easter Chant that was used in Year 1. Lexical items appear again and are surrounded by more complex phrases. Again, there are actions that are also more elaborate (Figure 15).

There is also the use of onomatopoeia at the end of the chant that expresses contentedness with the chocolate eggs mentioned before. In this way, onomatopoeia functions as an additional explanation and supports comprehension of the previous line, which contains five words that only occur once.

\section{Figure 15: Actions in the Easter Chant and Easter Bunny Chant}

Easter Chant
Easter Bunny,
Easter Bunny,
Hop, hop hop
(hopping around in a
circle)
Easter Bunny,
Easter Bunny,
Please don't stop.

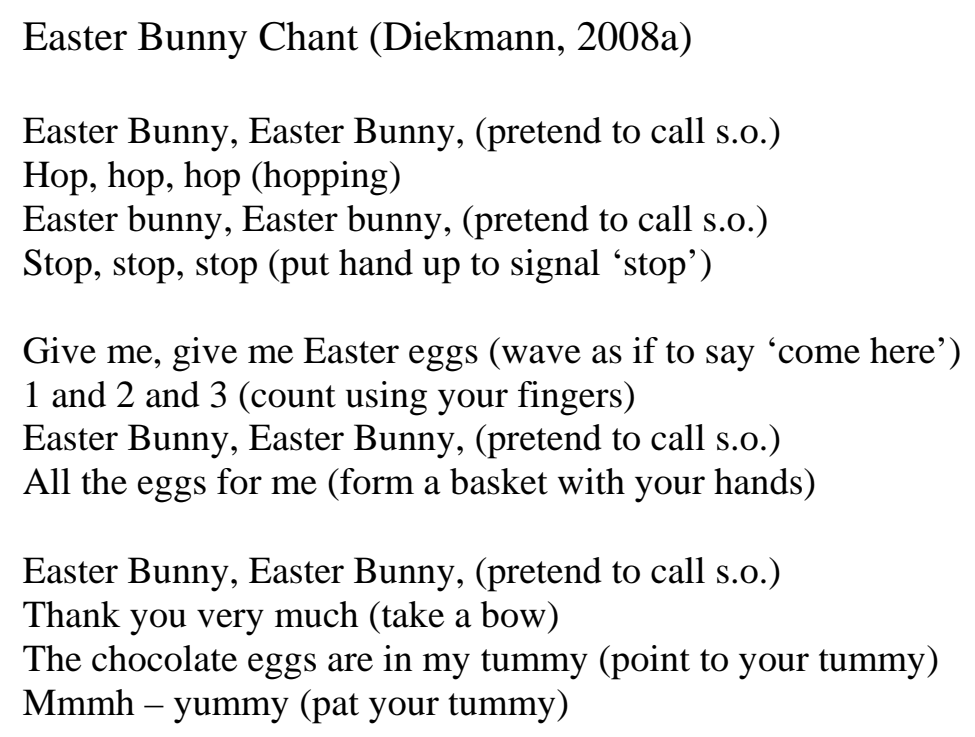

\subsubsection{Stories}

Stories that were used in the primary EFL classrooms have been studied for recurring chunks and patterns (Appendix 8), for the use of visualization and sound but also for their adherence to the structure of prototypical stories, such as 'an opening [...], introduction of characters, description of the setting, introduction of a problem, a series of events that lead to the resolution of the problem, a closing [...] and a moral', without which a story is not experienced as such by the learner (L. Cameron, 2001: 161f., referring to Propp, 1958; Labov, 1972).

With regard to recurring language, I will use the term 'pattern' to refer to prefabricated phrases with open slots, such as 'The house is black', with noun and adjective representing the open slots here (Elllis, Brewster and Girard, 2001; 
Weinert, 1995). These patterns allow for a degree of variation, because parts of them can be substituted, which is why they have to be distinguished from 'recurring chunks' that appear again in exactly the same way.

The overview of word count and degree of repetition (Table 36) shows that there is great diversity in this genre, with the shortest text, a graded reader, being only 24 words long, and the longest text, a picture book, consisting of 1,065 words. While all texts exhibit some kind of repetition, the overall proportion of which ranges from 36 percent in the April Weather story (Diekmann, 2008b) to 93 percent in the Easter Bunny's Book (Englisch begegnen 16). There are stories in which exact repetition of chunks does not occur at all, and on the other end of the spectrum, there are texts in which exact repetition accounts for 85 percent of the language. Although there are different degrees and kinds of repetition, all of these stories have in common that more than one third of lexical items are in some way or another 'recycled'.

Table 36: Proportion of repetition of lexical items in stories

\begin{tabular}{|l|r|r|r|r|}
\hline Title & Word count & \multicolumn{2}{l|}{$\begin{array}{l}\text { Proportion of } \\
\text { recurring chunks }\end{array}$} & \multicolumn{2}{l}{ Proportion of } & \\
\hline Easter Bunny Book & 207 & $83 \%$ & $10 \%$ & $93 \%$ \\
\hline Big Feet & 39 & $51 \%$ & $38 \%$ & $89 \%$ \\
\hline Kipper's Diary & 45 & - & $89 \%$ & $89 \%$ \\
\hline Go Away Floppy & 24 & $38 \%$ & $50 \%$ & $88 \%$ \\
\hline Look At Me & 33 & $85 \%$ & - & $85 \%$ \\
\hline Rudy's Fall & 67 & $15 \%$ & $45 \%$ & $60 \%$ \\
\hline The Three Little Pigs & 676 & $27 \%$ & $30 \%$ & $57 \%$ \\
\hline The Smartest Giant & 1,065 & $23 \%$ & $28 \%$ & $51 \%$ \\
\hline Froggy Gets Dressed & 459 & $31 \%$ & $18 \%$ & $49 \%$ \\
\hline Milly the Mouse & 204 & - & $46 \%$ & $46 \%$ \\
\hline Winnie the Witch & 508 & $20 \%$ & $19 \%$ & $39 \%$ \\
\hline April Weather & 71 & $25 \%$ & $11 \%$ & $36 \%$ \\
\hline
\end{tabular}

The stories can broadly be put into two categories, these are didactic texts that were especially created for the purpose of teaching, and stories that were written for the entertainment of young English native-speakers, which I will refer to as 'authentic' stories. Among the 'didactic' stories are those that were created for EFL teaching 
situations and those that are aimed at young children learning English as their mother tongue.

Among the latter group are the graded readers Big Feet, Kipper's Diary, Go Away Floppy and Look At Me (Hunt and Brychta, 2000). All of these readers consist of 8 pages, that is three double spreads and two individual pages at the beginning and end of the story. Each page features a picture and a sentence underneath (Figure 16). In order to understand the story, the reader must consider text as well as pictures. With the text being simple and repetitive, it is the pictures that provide context, elaboration and highlight the surprise event, an important ingredient in prototypical stories (L. Cameron, 2001). In this way, these graded readers work very much like authentic picture books.

Figure 16: Look At Me (Hunt and Brychta, 2000)

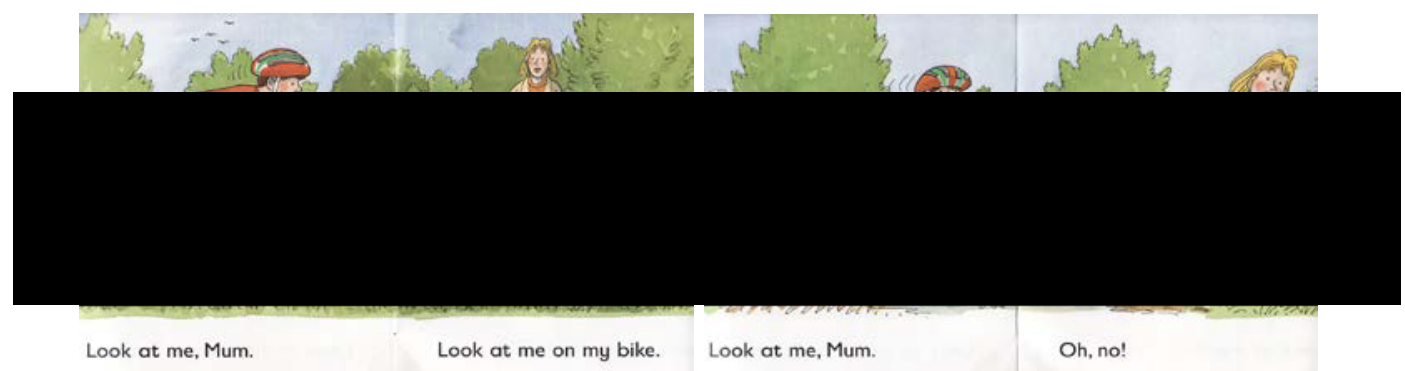

Among the other group of didactic texts, those for EFL learners, are The Easter Bunny's Book, Rudy's Fall, Milly the Mouse and April Weather. All of these either make use of pictures or actions or both (Appendix 8), but not the written text. The Easter Bunny's Book looks like a colour-in book without any text (Figure 17).

Figure 17: The use of pictures in the Easter Bunny's Book (Englisch begegnen 16)

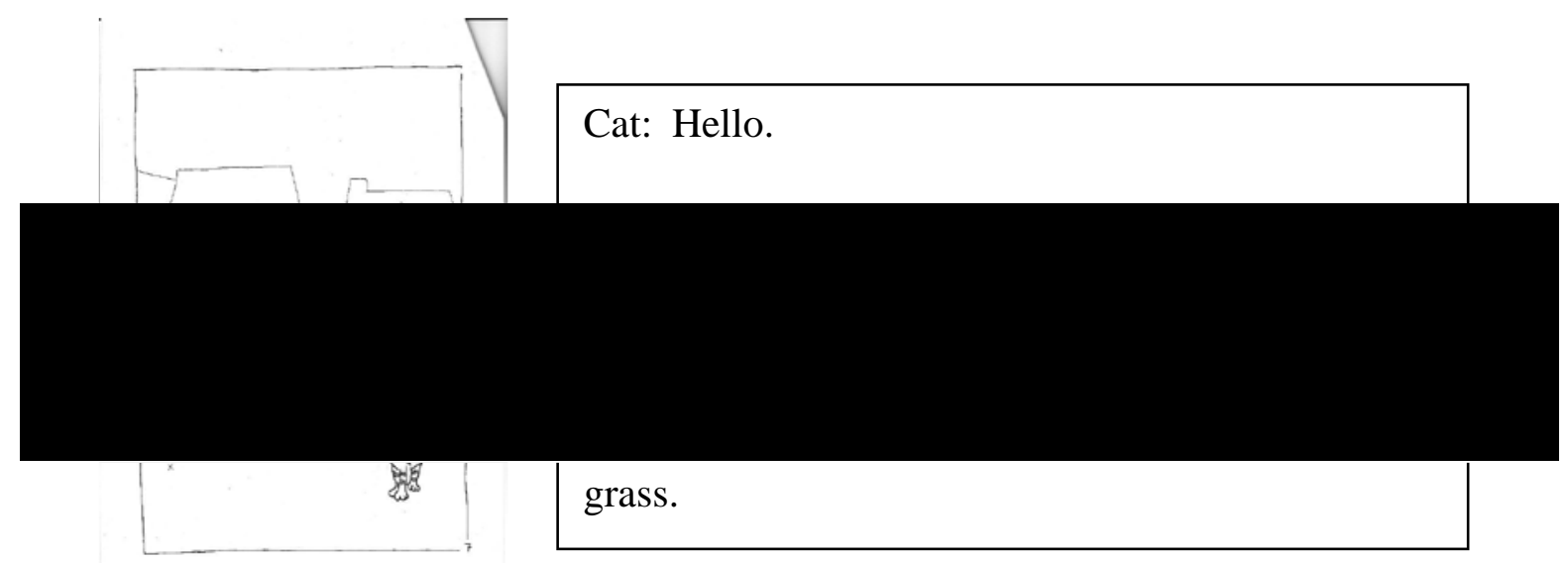


The text is only read out by the teacher and consists of a short dialogue that is repeated for each animal that Easter Bunny meets. There is an illustration for each dialogue, so all the different animals and hiding places are shown. There is no conflict, no surprise event and no conclusion, which means that this text lacks some prototypical features of stories (L. Cameron, 2001) and is not likely to be enjoyed as a 'proper' story. Here, the in-built parallelism of repeated action and language, as expressed by the recurring dialogue, creates the impression of mechanic repetition.

The text of April Weather (Diekmann, 2008b) consists of a string of instructions with descriptions about the setting or weather conditions thrown in, such as 'what a nice day' or 'it's cold'. Apart from the narrator, there are no other characters and the story is told in present tense. However, there is some sort of storyline about someone who wants to go out and experiences all sorts of different weather conditions. The sheer number of weather changes in this text give it a humorous side, which is further highlighted by the accompanying actions. The pictures that are provided as an extra for the April Weather story only consist of black lines and seem to invite colouring (Figure 18). They were used for this purpose after the actual storytelling that involved actions (Figure 19).

\section{Figure 18: The use of pictures in April Weather (Diekmann, 2008b)}

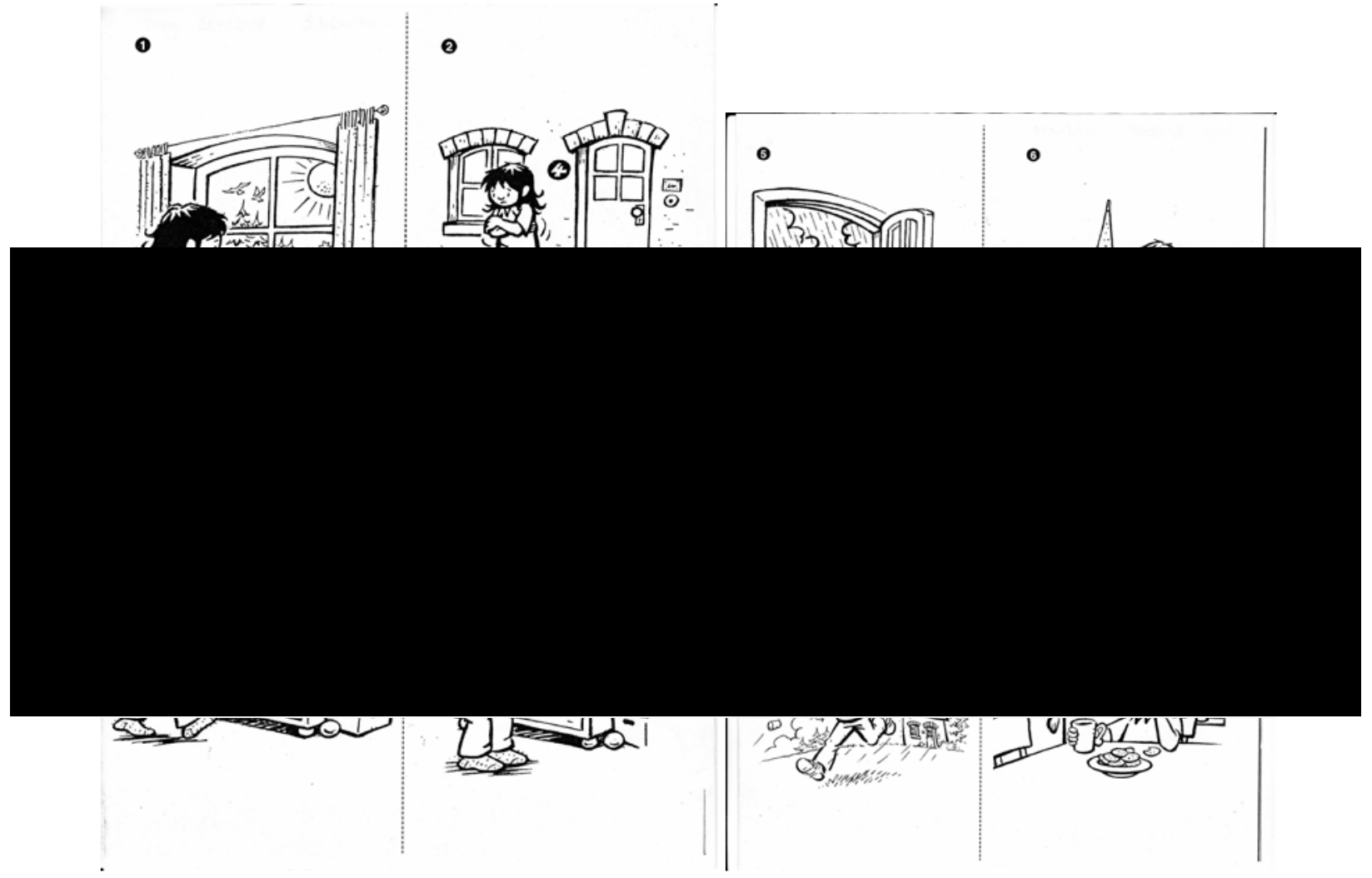


Figure 19: Actions in the April Weather story (Diekmann, 2008b)

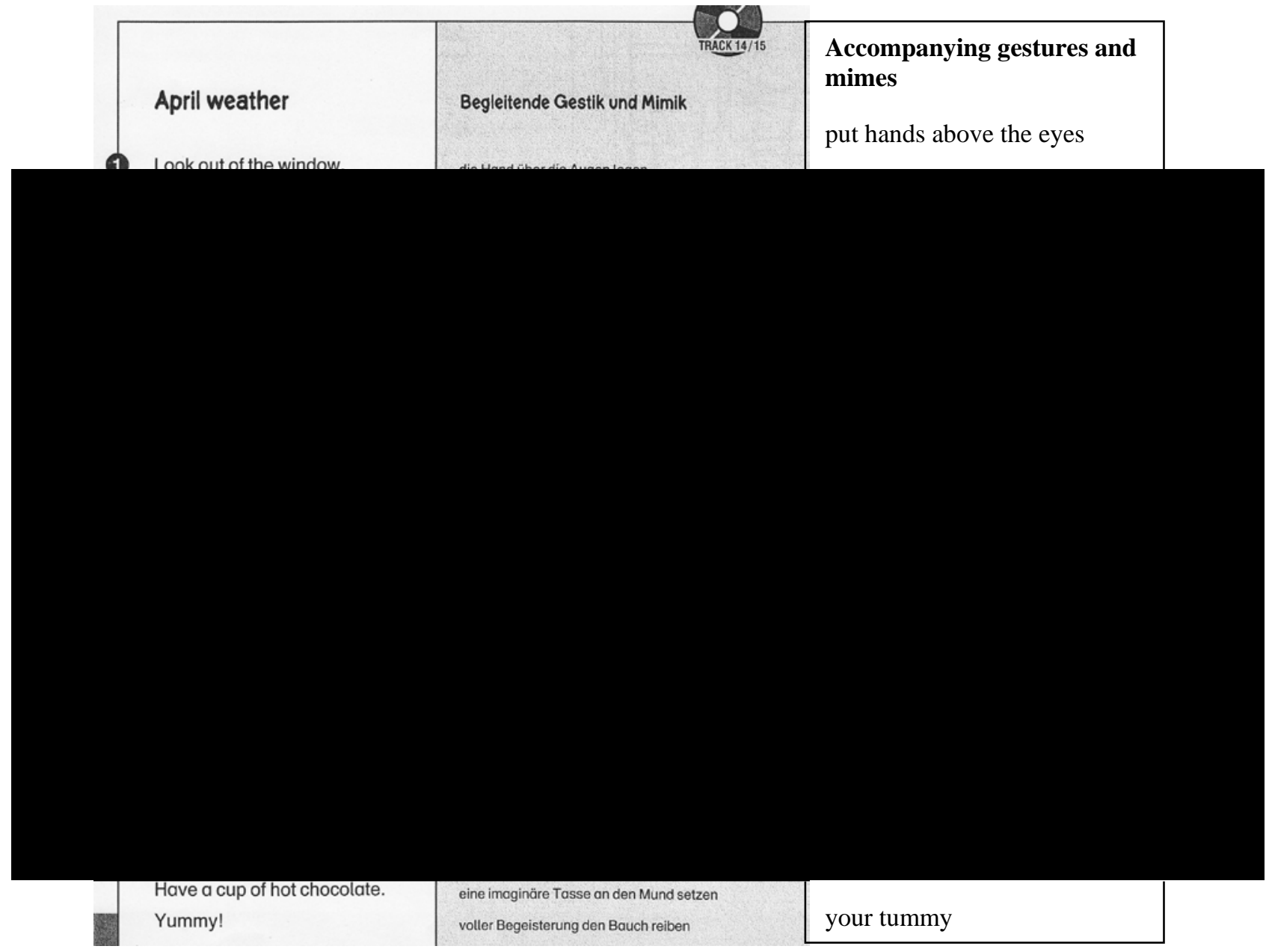

For the story of Milly the Mouse, pictures of a house and a mouse were used and put on the blackboard and details were added by hand. Pictures and drawings on the blackboard were also used for Rudy's Fall, but there were also actions that Ruth did herself, such as pretending to run and hurting herself, the latter accompanied by onomatopoeia.

In all of the above stories, pictures, drawings, actions and onomatopoeic expressions worked individually or together to support the narrative. They provided the learners with visual or acoustic clues that facilitated some basic understanding of the text.

Among the group of authentic stories, there was one traditional story, The Three Little Pigs, and three picture books, Froggy Gets Dressed (London and Remkiewicz, 1992), The Smartest Giant in Town (Donaldson and Scheffler, 2002) and Winnie the Witch (Thomas and Paul, 1987). The folk tale The Three Little Pigs comes in various different versions. The version used during observations was one 
of the less elaborate ones, taken from a magazine for primary EFL teachers. The plot features the three pigs, their mother and the wolf. There are no other characters, such as a merchant who sells the building material, for example. The story centres on the well-known dialogue and song 'Who's afraid of the big bad wolf' which appears twice, once at the beginning and once at the end of the story. Pictures are used to illustrate various scenes of the story, such as the wolf trying to blow down one of the houses (Figure 20).

Figure 20: Pictures in The Three Little Pigs (Grundschule Englisch 23, 2008)

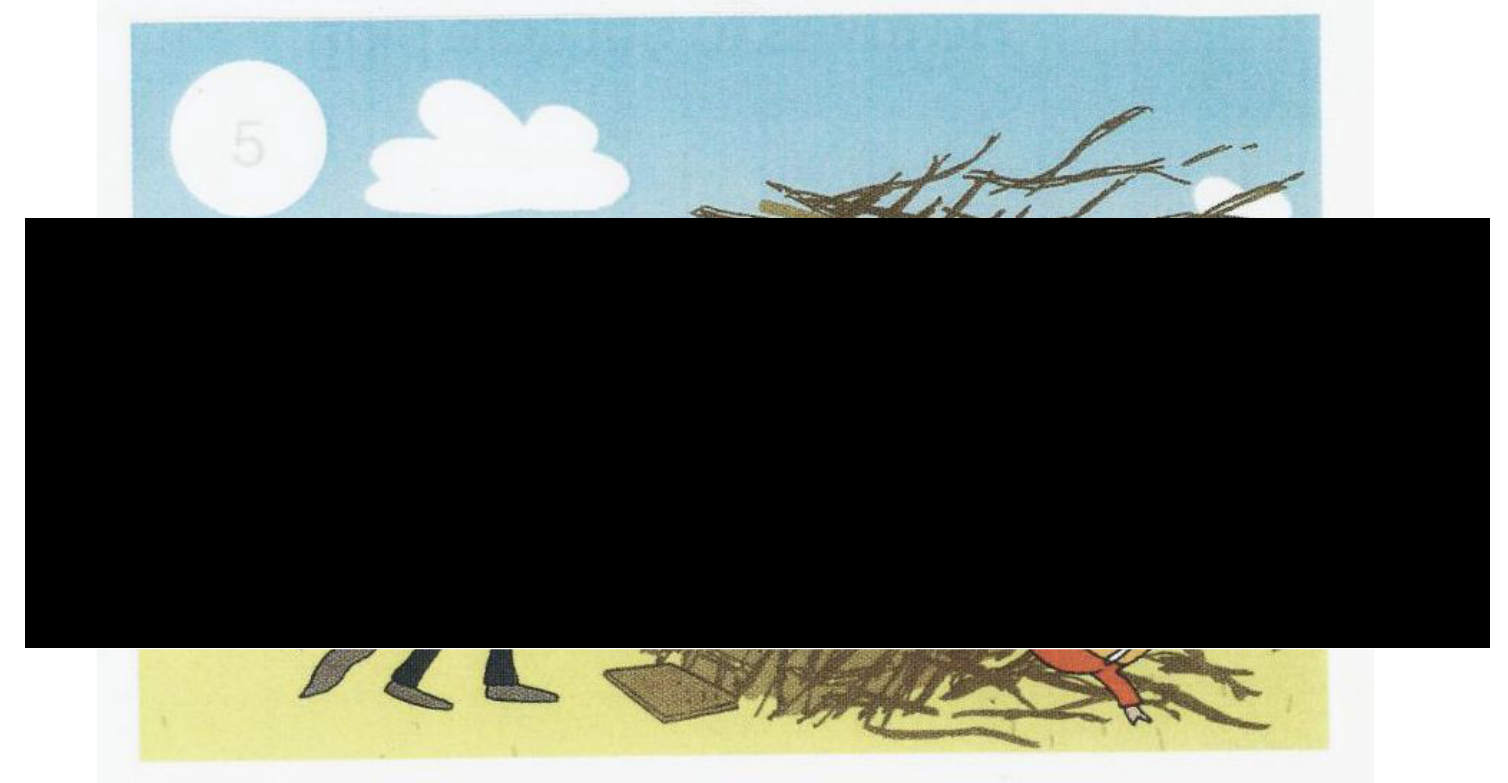

The only stories that were not only authentic but also came in the format of a real book with English writing in it, were three picture books. The picture book Froggy Gets Dressed (London and Remkiewicz, 1992) is about a young frog who, having woken up in the middle of winter, wants to go out and enjoy the snow. He ignores his mum's advice. Instead, he starts dressing up. He then runs outside, but is reminded by his mother that a piece of clothing is missing. He has to undress, put the missing piece of clothing on and dress again. Three times his mother calls him back in, but then Froggy gets tired and goes back to sleep. Froggy Gets Dressed features many lexical items associated with clothing, such as 'socks', 'boots', 'hat' and 'scarf', for example. There are also many synonyms for 'putting on' and 'taking off'. In fact, almost every single piece of clothing is accompanied by a different lexical item, such as 'pull on/off', ‘tie on' or 'tug on'. Moreover, there are onomatopoeic expressions with all the different pieces of clothing that need putting 
on and with the running out into the snow, e.g. 'zoop', 'zwit' and 'flop', to name but a few.

Froggy Gets Dressed is an authentic picture book written to entertain and capture children's attention. It therefore features many of the characteristics of stories (L. Cameron, 2001). Descriptions of characters and setting are provided by the illustrations. The verbal text then reveals the problem (frogs are supposed to sleep in winter), unfolds the events (the dressing and undressing), offers a resolution (frog goes back to sleep) and a formulaic closing ('Good night, Froggy'), which may point to the moral that frogs should indeed be asleep in winter. The story is told in past tense.

Froggy Gets Dressed also features other literary devices, such as dramatic irony, a built-in predictability, a surprise event and parallelism. By looking at the illustrations, the children can see that Froggy is missing his trousers, before his mother has even started calling him (Figure 21). The children therefore know more than the main character in the story. It can also be anticipated that children use their knowledge of how stories work to predict what might happen next.

With actions being repeated, so is language, such as the dialogue between mother frog and Froggy and all the phrases for dressing and undressing. The literary devices of repetition and parallelism not only provide the text with artistic qualities, they also make it more accessible for FL learners (L. Cameron, 2001). Thus, while Froggy Gets Dressed with its lexical richness may appear too complicated for English beginners, its structure and composition seem to support understanding and counterbalance the difficulties caused by unfamiliar vocabulary or unfamiliar past tense forms of verbs.

Figure 21: Froggy Gets Dressed (London and Remkiewicz, 1992)

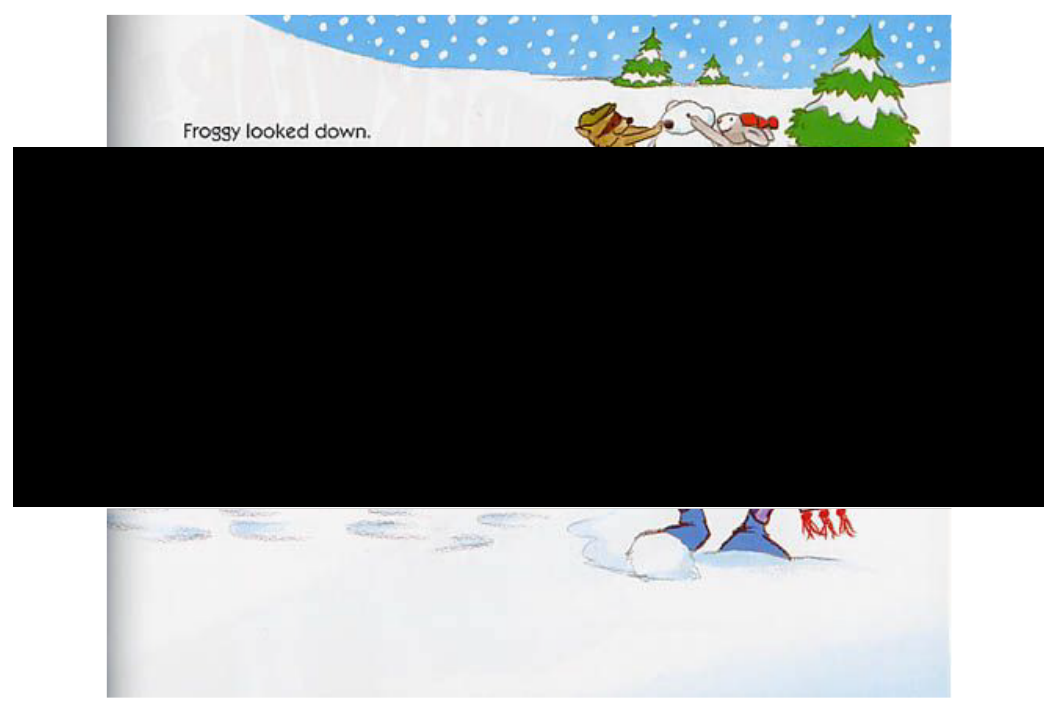


In The Smartest Giant in Town (Donaldson and Scheffler, 2002), George, the main character, is introduced as a giant whose scruffiness impairs his self-confidence and leaves him with the desire to change his appearance. On noticing a new shop, he decides to buy new clothes. However, soon he meets various animals all in dire need of some help. As he walks home, he gives away parts of his clothing to help a cold giraffe and a homeless mice family, for example. George thus turns from smartest giant into kindest giant and is crowned as such on his return home wearing his old clothes again.

The narrative exhibits prototypical features as found in traditional folk tales. There is not only a fairy town full of giants and other fairy characters; there is also the pattern of repetition. Just like the knight or prince who must solve several riddles or fight against a certain number of beasts, each bigger and stronger than the one before, George faces a number of situations in which he has to help, and the sacrifices he makes become bigger each time. It is one thing to give away one's tie, it is entirely another to give away a shoe and a sock and continue one's journey barefoot. This repetitive structure of the narrative is mirrored in the way language is used. There are recurrent lexical items and syntactic patterns in the dialogue between George and the animals, such as 'What's the matter?', 'Cheer up' and 'I wish I had' (Figure 22).

Figure 22: The Smartest Giant in Town (Donaldson and Scheffler, 2002)

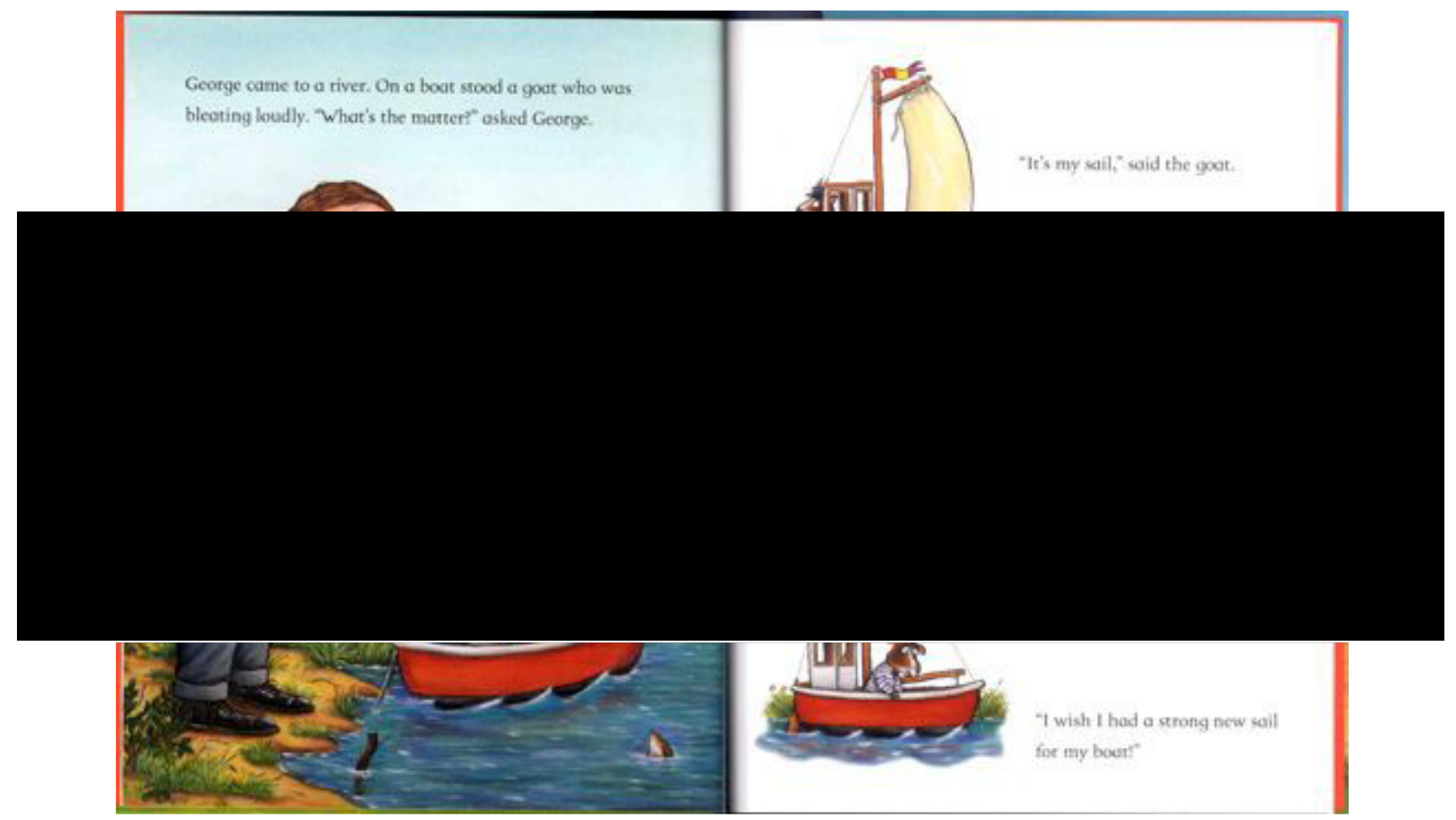


Moreover, there is the repetition of the song that George sings and that becomes longer each time he has helped an animal. The song represents a summary of the plot, and highlights the irony of George's situation:

My tie is a scarf for a cold giraffe, My shirt's on a boat as a sail for a goat, My shoe is a house for a little white mouse, One of my socks is a bed for a fox, My belt helped a dog who was crossing a bog (Donaldson and Scheffler, 2002: 24)

Dialogue and song may both act as ‘a way into the story’ (L. Cameron, 2001: 163), both for understanding the story and for productive language use. Singing the song or quoting the verbal exchange between George and the animals can be seen as a first step towards retelling the whole story.

Winnie the Witch (Thomas and Paul, 1987) tells the story of a witch named Winnie, who lives with her black cat in her black house. The potential problem is already highlighted through the peritext, in this case the cover of the picture book which shows Winnie tripping over Wilbur as she is going down the stairs (Figure 23). Three times Winnie runs into problems because she cannot see her cat before she decides to do some magic. Wilbur undergoes a couple of colour changes until Winnie changes him back to black but her house into normal colours. The story exhibits a prototypical narrative structure. Main aspects of the story appear three times, as is common in traditional fairy tales, such as Winnie not seeing Wilbur and hurting him or herself as a consequence. Not only are actions repeated, they also become more intense. Sitting on Wilbur is less serious than falling down a flight of stairs, and while Winnie waves her wand just once when she first uses magic, she waves it numerous times later on.

With the repetitive narrative structure, language is also repeated, such as 'with his eyes open, Winnie could see him', 'she picked up her magic wand' and 'waved it'. The illustrations complement the storyline and provide extra details that are not mentioned in the verbal text, such as the various other animals who are also in Winnie's house. The illustration can therefore provide depth of detail that enriches the storyline and makes the text more interesting. Details in the pictorial representation, such as Winnie's underwear hanging on the washing line, add a humorous note (Figure 23). At the same time, the verbal text stays uncluttered and to the point, focusing the attention of the audience on the central aspects of the 
narrative. This is of relevance for teaching purposes since it allows both, opportunities for multiple readings of the text, because there is always some more detail that can be discovered, as well as repetitive language that supports and guides understanding of the narrative.

\section{Figure 23: Winnie the Witch (Thomas and Paul, 1987), cover and first double spread}

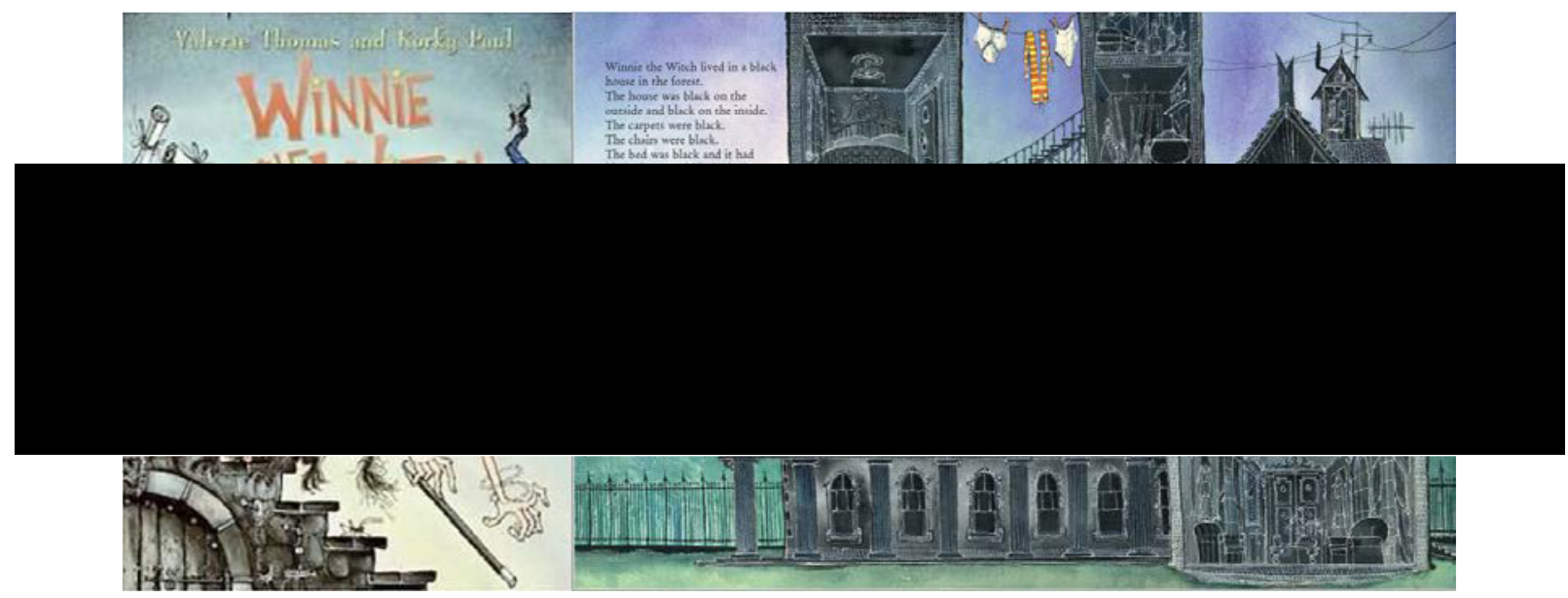

The analysis of the texts that were used in classrooms under investigation shows the versatile character of songs, chants and stories. Not only is there great variety in the length of texts, there are also differing degrees of exact and varied repetition of language, and there are differences in the extent to which visualization and acoustic devices are used. However, the minimum proportion of repetition is rarely below 35 percent, which is the case for only 4 out of a total of 24 texts. Almost always, there are either different kinds of visualization or acoustic cues, and quite often both. Pictures, actions, onomatopoeia and rhyme are among the most common features. These create access points into the song, chant or story. They highlight language and support a basic understanding of content.

\subsubsection{Lesson organisation: Analysis of example lessons}

In the following, three 45-minute lessons will be studied in greater detail. In order to illustrate the different teaching styles that could be found at the school under investigation, lessons from the three qualified teachers, Sophie, Julia and Ruth, will be reported on. The lessons have been chosen for their use of stories and embedded teaching of song and chant.

Various recommendations for teachers of young EFL learners suggest a three-part structure for such lessons. With regard to storytelling, the different stages 
have, for example, been termed 'preparation', 'core' and ‘follow-up' activities (L. Cameron, 2001). During preparation, the teacher is supposed to raise interest in the story, introduce main characters or the conflict and prepare learners for the language of the story. During the core activity, the children experience the story either through the teacher reading it out to them or telling them the story making use of different voices, gestures and additional props (Wright, 1995). During follow-up activities that can involve role-play or artwork, for example, children have the opportunity to experience parts or all of the storyline again and reproduce its language. It is this last stage of dealing with stories that tends to be undervalued and given too little time (L. Cameron, 2001). In a similar way, for listening, which instances of singing, chanting and storytelling in primary EFL normally are, a similar structure of 'pre-', 'while-' and'post-listening' activities has been suggested and similar functions have been attributed to the different stages (Read, 2007). I will refer to Cameron's terms since the use of songs and chants was embedded into the teaching of stories in all of the example lessons, which could be reconstructed on the basis of fieldnotes. In two cases, Lesson 7 and 10, transcripts were also available for analysis.

\subsubsection{Sophie's lesson on April Weather}

In Lesson 7, a Year 3 group repeated the Weather Song and was introduced to the April Weather story by Sophie (Table 37). For that session, Sophie used teaching suggestions by Diekmann published in a magazine for primary teachers (Grundschule Englisch 22). According to these, the story is supposed to be presented without any preparation. Sophie, however, used the opportunity at the beginning of the lesson to practise the Weather Song, which she had introduced to the children in the last EFL session a week before, thereby creating a thematic link to the story. She started by asking the children, who sat on their chairs in a circle, to remember the lyrics by looking at the picture they had drawn in the previous lesson (Figure 24). In both texts, the focus is on the weather, and similar vocabulary is used. By singing the Weather Song, learners were prepared for the content and language of the story. 
Table 37: Overview of Lesson 7 (Sophie), Weather Song \& April Weather

\begin{tabular}{|l|l|}
\hline Stage of the lesson & Description \\
\hline Preparation activity & $\begin{array}{l}\text { 1. Teacher asks learners to take out pictures they created for the } \\
\text { Weather Song. } \\
\text { 2. Teacher asks learners for the lines of the song. } \\
\text { 3. Teacher presents song line by line, learners repeat. } \\
\text { 3. Teacher and learners sing the song together (6 times). }\end{array}$ \\
\hline Core activity & $\begin{array}{l}\text { Teacher asks learners to look at her and imitate actions as } \\
\text { she presents story April Weather with actions (3 times). }\end{array}$ \\
\hline Follow-up activity & $\begin{array}{l}\text { 1. Teachers asks learners to listen to her telling the story and do } \\
\text { the actions on their own. } \\
\text { 2. Teacher asks learners to listen to story presented by native } \\
\text { speaker from CD and do actions. } \\
\text { 3. Teacher says parts of the story and asks learners to do the } \\
\text { appropriate actions. } \\
\text { 4. Teacher asks learners to sit down, look at copy of story and } \\
\text { point to right picture as she tells part of the story. } \\
\text { 5. Teacher asks learners to listen to CD and write number of } \\
\text { instruction from story next to appropriatepicture. } \\
\text { 6. Teacher asks learners to colour pictures on the copy. }\end{array}$ \\
\hline
\end{tabular}

Figure 24: Drawing for Weather Song according to Sophie's instructions

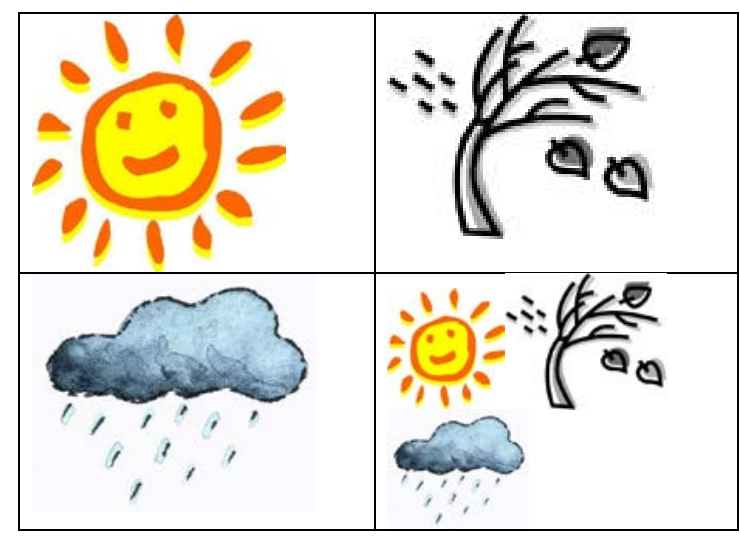

For core activity and most follow-up activities, Sophie followed the teaching suggestions, which meant a strong focus on listening comprehension and which involved taking parts of the story out of context for the purpose of testing listening comprehension. None of the recommended follow-up activities encouraged oral language production. Sophie introduced one variation, however, concerning the last 
follow-up activity. Learners were asked to colour in the pictures instead of cutting them out, arranging them chronologically and placing the appropriate sentence underneath. This is in line with guidelines for primary EFL in Rhineland-Palatinate at the time that stated that the focus should be on oral communication rather than the written word (Ministerium für Bildung, Frauen und Jugend, 2005).

Transcribed classroom discourse of Lesson 7 can also provide some information on how much language was involved in each stage of the lesson and how much the target language was used (Table 38). While these calculations can only serve as a rough indication, because transcripts do not reflect all that is going on in a classroom, they can still provide a basic idea of the learning environment.

Table 38: FL input during preparation, core \& follow-up activities in Lesson 7

\begin{tabular}{|c|c|c|c|c|c|c|}
\hline & $\begin{array}{l}\text { Word } \\
\text { count }\end{array}$ & $\begin{array}{l}\text { Percentage } \\
100 \%=4,538^{*}\end{array}$ & $\begin{array}{l}\text { of which } \\
\text { English }\end{array}$ & $\% * *$ & $\begin{array}{l}\text { of which } \\
\text { German }\end{array}$ & $\% * *$ \\
\hline Preparation & 932 & 20.5 & 888 & 95.3 & 44 & 4.7 \\
\hline Core & 905 & 20.0 & 800 & 88.4 & 105 & 11.6 \\
\hline Follow-up & 2,701 & 59.5 & 1,883 & 69.7 & 818 & 30.3 \\
\hline
\end{tabular}

*Of the transcript's word count of 5,373, all references to non-verbal communication and extra comments were deducted, leaving a body of 4,538 words referring to verbal interaction only.

**The percentage of $100 \%$ refers to the word count of each stage of the lesson.

The overview for Lesson 7 indicates that about one fifth of classroom interaction was devoted to the preparation and the actual presentation of the story, while most of the classroom interaction, that is about $60 \%$, was used for follow-up activities. However, in terms of English-speaking input, the follow-up activities provided least exposure to the target language. The most 'effective' use of classroom time, because there was a high proportion of FL use, was reached during the preparation phase, when the Weather Song was performed repeatedly. A more thorough analysis of the transcript shows that if the mother tongue was used, it was in connection with instructions before each use of the CD and disciplinary remarks.

\subsubsection{Julia's lesson on Easter Bunny's Book}

In Lesson 10, Julia introduced a Year 1 group to the Easter Bunny's Book (Englisch begegnen 16). Julia had created a set of enlarged copies that she had coloured in for her storytelling. She had also prepared small cards with eggs and she asked some children to stand next to an animal and hide the egg in the appropriate hiding place 
during the storytelling. Julia used the story over three sessions, reading parts of the story several times with different children acting as helpers hiding the eggs in sessions one and two. Lesson 10 was the second of these. The children had not listened to all of the story yet.

For preparation as part of Lesson 10, Julia presented the children, who all sat on their chairs in a circle, with the cover copy of the Easter Bunny's Book and asked them to name animals that they had already spoken about in the previous session on the book and to point to them in the picture (Table 39). This led to the children repeating both meaning and spoken form of individual items, such as 'pig', 'cat' and 'dog'. During the core activity, Julia went through the story twice. While she was reading out the dialogue between Easter Bunny and various different animals, some of her learners were asked to put the pictures of eggs into the hiding places and to speak the lines of their animal with the teacher, that is 'hello' and 'yes, little Easter Bunny, hide your egg in my grass', for example. The lesson was the last for the day and learners were exhausted and easily distracted. The use of the Easter Chant was a spontaneous measure that Julia took to get her learners' attention and boost motivation levels. Learners were merely asked to join in the action, that is hopping. Then, Julia went through the story one more time with the children. The follow-up activity involved colouring in pictures from the story book, but did not include any receptive or productive use of the language that occurred in the Easter Bunny's Book.

Table 39: Overview of Lesson 10 (Julia), Easter Bunny’s Book \& Easter Chant

\begin{tabular}{|l|l|}
\hline Stage of the lesson & Description \\
\hline Preparation activity & $\begin{array}{l}\text { 1. Teacher shows learners cover page of Easter Bunny Book } \\
\text { and asks them to name animals they can remember. } \\
\text { 2. Teacher asks learners to point to the animal as they name } \\
\text { them. }\end{array}$ \\
\hline Core activity & $\begin{array}{l}\text { Teacher asks some learners, one for each animal, to help her } \\
\text { tell the story. They are supposed to put the picture of the eggs } \\
\text { in the appropriate places and speak the dialogue with her (2 } \\
\text { times). Before the story is told a second time, the teacher asks } \\
\text { all learners to get up and join in with the actions of the Easter } \\
\text { Chant. }\end{array}$ \\
\hline Follow-up activity & $\begin{array}{l}\text { 1. Teacher asks learners to colour in copies form the Easter } \\
\text { Bunny's Book at their desk. }\end{array}$ \\
\hline
\end{tabular}


A look at the transcript for this session reveals that the proportion of English that can be associated for various stages of the storytelling is rather low (Table 40). This is due to the fact that Julia needed to respond to disciplinary issues, which she did in German, but she also used the learners' mother tongue for instructions. The use of English is mainly restricted to presenting the story and the chant. Indeed, it is during the core activity that the proportion of English is highest.

Table 40: FL input during preparation, core \& follow-up activities in Lesson 10

\begin{tabular}{|c|c|c|c|c|c|c|}
\hline & $\begin{array}{l}\text { Word } \\
\text { count }\end{array}$ & $\begin{array}{l}\text { Percentage } \\
100 \%=2,964 *\end{array}$ & $\begin{array}{l}\text { of which } \\
\text { English }\end{array}$ & $\% * *$ & $\begin{array}{l}\text { of which } \\
\text { German }\end{array}$ & $\% * *$ \\
\hline Preparation & 947 & 32.0 & 116 & 12.2 & 831 & 87.8 \\
\hline Core & 1,959 & 66.0 & 1,058 & 54.0 & 901 & 46.0 \\
\hline Follow-up & 58 & 2.0 & 5 & 8.6 & 53 & 91.4 \\
\hline
\end{tabular}

*Of the transcript's word count of 3,410, all references to non-verbal communication and extra comments were deducted, leaving a body of 2,964 words referring to verbal interaction only.

**The percentage of $100 \%$ refers to the word count of each stage of the lesson.

\subsubsection{Ruth's lesson on The Three Little Pigs}

In Lesson 34, Ruth introduced her Year 3 group to the traditional story The Three Little Pigs, for which she used pictures, storyline and teaching suggestions from a magazine for primary EFL teachers (Grundschule Englisch 23). All in all, five sessions were devoted to the story, during three of which learners worked in groups on additional follow-up activities for all of the lesson time.

Ruth started by asking the children to sit down in two rows on the floor before she showed them a box that was covered up (Table 41). In turn, learners put their hands inside the box and talked about what they thought was inside. While the learners made suggestions in German, such as 'Stein', 'Stroh', 'Zweig', the teacher provided the English words, 'stone' and 'brick', 'straw', 'twigs'. Ruth then held up laminated pictures of the main characters and gave them to the learners, asking them to hold them up as they heard their names during storytelling. As Ruth read the story once, she held up 13 laminated coloured copies of the main scenes in the story. As a follow-up, Ruth gave her learners the choice of three different tasks, a matching pairs exercise with pictures and words from the story, an exercise which asked learners to put pictures into the correct order and a creative task that involved inventing a rhyme about the story in German. The time frame of 45 minutes was not enough for the learners to finish their follow-up activities. 
Table 41: Overview of Lesson 34 (Ruth), The Three Little Pigs

\begin{tabular}{|l|l|}
\hline Stage of the lesson & Description \\
\hline Preparation activity & $\begin{array}{l}\text { 1. Teacher asks learners to feel inside a covered box and make } \\
\text { suggestions of what they think is inside. } \\
\text { 2. Teacher presents characters of the story by holding up } \\
\text { pictures. }\end{array}$ \\
\hline Core activity & $\begin{array}{l}\text { Teacher reads the story and holds up pictures that illustrate each } \\
\text { scene. Learners hold up pictures of characters as they hear their } \\
\text { names. }\end{array}$ \\
\hline Follow-up activity & $\begin{array}{l}\text { 1. Teacher asks learners to match pictures and words from the } \\
\text { story. / Teacher asks learners to put pictures into the correct } \\
\text { order. / Teacher asks learners to write a rhyme about the story in } \\
\text { German. }\end{array}$ \\
\hline
\end{tabular}

As for the use of the FL and mother tongue, fieldnotes indicate that mainly English was used throughout the preparation and core activities, with only the learners' remarks being in German. The follow-up activities, however, only involved minimal use of English in the matching pairs exercise that referred to individual lexical items only. For the other activities, the main focus was on reconstructing the storyline on the basis of images or referring to aspects of the plot in German, and so the use of English was not necessary. However, in the following lessons after having listened to the story a second time, more follow-up activities were introduced that involved creating puppets and using these for retelling the story in a role play.

If one compares the three example lessons by different teachers, one can identify some similarities. First of all, lesson organisation normally followed a threepart structure that involved a warm-up that was used to reactivate learners' knowledge or stimulate interest, a second phase during which a text was presented once or numerous times and some follow-up practice that focused on reconstructing content or language of the text. Visual stimuli, such as pictures and actions, were used in all three lessons to support memory during the preparation phase, to facilitate understanding during the core activity and to consolidate knowledge about storyline and language during follow-up activities. Another similarity was the lack of productive language use during follow-up activities. The proportion of target language was highest during core and preparation activities.

However, there are also differences. The proportion of FL and German, for example, varied greatly between different teachers. The number of encounters of the 
same text differed as well, which can be explained by the different lengths of the stories. A shorter text, such as April Weather, can more easily be repeated in the 45minute time frame than a longer text, such as The Three Little Pigs. The number of different preparation and follow-up activities, and therefore the amount of language that was practised, also varied, with Lesson 7 displaying the most versatile character. There was also a difference in the degree of creativity and responsibility that was demanded of learners, with Lesson 34 being the most demanding in that respect.

While an analysis of lesson organisation can explain how encounters with songs, chants and stories are planned from the perspective of the teacher, it cannot provide any information on how learners experience these encounters and how they respond to them.

\subsubsection{Analysis of learners' response to songs, chants and stories}

In the following, I will focus on extracts from different primary EFL classrooms of the school and analyse learners' nonverbal and verbal reaction to the presentation of all three genres. For each extract, I will briefly describe the context of the lesson from which each extract has been taken.

\subsubsection{Songs}

With regard to songs, transcribed classroom discourse is available for the teaching of the Weather Song (Boogie Beebies, 2005) to two groups of Year 3 learners. On the teachers' request, I had brought a box with children's books and DVDs to school for them to look at, and Sophie had found the video clip about the weather in the Boogie Beebies programme very useful, because she had talked about the weather with her two Year 3 groups. In Lessons 4 and 5 she introduced her two parallel groups to the song. Sophie used roughly the same lesson plan for both sessions, but had less time available for the second group because the lesson started late.

Before Sophie started the DVD in Lesson 4, she involved her learners in a conversation about the weather, revising multi-item chunks such as 'it's not windy' and 'it's not cloudy'. She did not have time for this pre-listening activity in Lesson 5. Sophie told both learner groups about her plans to watch a DVD with them, which entailed moving to an open area at the end of the hallway. She stressed disciplinary aspects and pointed out that they would listen to native speakers and that this would sound different. 
While learners were watching the video clip for the first time, Sophie stopped regularly to check for understanding. The DVD was stopped after the song had been sung once, and then in between the presenters' talk about the weather and the moves that represented the weather changes and were later used for the song (Extract 1). Here, Sophie checks comprehension (Turns 2 \& 4) and wants her learners to do the action with her (6). Her learners' verbal and non-verbal response show that they have understood. One learner provides the correct German and English words ( 3 \& 5), all learners seem to join in the action correctly, judging from Sophie's positive feedback (6) and they also imitate the relevant phrase 'a big round sun' straight away (6) and again during the second time they watch this part of the video clip (7). Although Sophie had only asked her learners to do the actions (6), they also join in with the speaking $(6,7)$. Moving about and speaking occur simultaneously.

Extract 1: Joining in actions and instructions for the Weather Song (Lesson 4)

\begin{tabular}{|c|c|c|}
\hline Turns & Presenter and Sophie & Learners (C1, Cn) \\
\hline 1 & $\begin{array}{l}\text { ((DVD starts) })[\ldots] \\
\text { ah:::, the sun is coming ... let’s swoop up our } \\
\text { arms and make a big round sun }\end{array}$ & \\
\hline 2 & $\begin{array}{l}\text { so, what's coming? what's coming? ... Y... } \\
\text { what's coming ... hm? ... }\end{array}$ & \\
\hline 3 & & C1: XXX Sonne \\
\hline 4 & yes, in English ... do you know it in English? & \\
\hline 5 & & C1: ... the sun \\
\hline 6 & $\begin{array}{l}\text {... the sun, yes ... the sun is coming ... and she } \\
\text { says, let's move our arms and make a big round } \\
\text { sun ... okay? ... move your arms and make a big } \\
\text { round sun ... like this ... come on ... a [big round } \\
\text { sun] okay, everybody, come on ... make [a big } \\
\text { round sun] ...okay, again ... [a big round sun.] } \\
\text { good, okay. now, we listen again, you will ... } \\
\text { XXX... (wir machen das noch mal an) und ihr } \\
\text { macht mit. }\end{array}$ & $\begin{array}{l}\text { Cn: [big round sun] } \\
\text { ((Cn move accordingly)) } \\
\text { Cn: [a big round sun] ... [a } \\
\text { big round sun] } \\
\text { ((Cn move accordingly)) }\end{array}$ \\
\hline 7 & $\begin{array}{l}\text { ((DVD starts again)) } \\
\text { come on, you try. swoop up your arms and make } \\
\text { [a big round sun!] ... come on, you try ... }\end{array}$ & $\begin{array}{l}\text { Cn: [a big round sun] } \\
\text { ((Cn move accordingly)) }\end{array}$ \\
\hline
\end{tabular}


In the parallel lesson held in the other year group, this mechanism is also observable and becomes even more pronounced (Extract 2). Sophie explicitly tells her learners not to join in verbally but to only do the actions (2), and yet they keep moving and speaking at the same time ( 2 \& 3).

This extract also shows that Sophie changed her agenda. In contrast to Lesson 4, Sophie is no longer interested in checking comprehension, but wants to focus on getting her learners to join in the actions. This may be due to time constraints, because Sophie knows she does not have as much time for the video clip with this group of learners, or her change of priorities is a consequence of her previous experience with her other Year 3 group, who did not have any difficulties in understanding. Moreover, by doing the actions, learners already demonstrate a basic understanding of the situation and an exact translation may therefore not be necessary at this point.

Extract 2: Joining in actions and instructions for the Weather Song (Lesson 5)

\begin{tabular}{|c|c|c|}
\hline Turns & Presenter (P) and Sophie (S) & Learners (C, Cn) \\
\hline 1 & $\begin{array}{l}\text { ((DVD starts)) [...] } \\
\text { ah::.: the sun is coming ... let's swoop up } \\
\text { our arms and make a big round sun }\end{array}$ & \\
\hline 2 & $\begin{array}{l}\text { ((Sophie stopping the DVD) } \\
\text { okay, she said, let's swoop up our arms and } \\
\text { make a big round sun okay, do that ... I } \\
\text { don't want you to translate, I want you to do } \\
\text { it, m[ake a big round sun] ... [make a big } \\
\text { round sun] ... I don't want to hear you, I } \\
\text { want to see you. I think you understand, } \\
\text { [make a big round sun] now, she will say it } \\
\text { again, and you will do it with her, okay? she } \\
\text { will say it again and you will do it with her. } \\
\text { okay. }\end{array}$ & $\begin{array}{l}\text { ((children’s voices, already } \\
\text { moving)) } \\
\text { Cn: [make a big round sun] ... } \\
\text { [make a big round sun] } \\
\text { ((moving accordingly)) } \\
\text { [make a big round sun] } \\
\text { ((moving accordingly)) }\end{array}$ \\
\hline 3 & $\begin{array}{l}\text { (DVD starts)) } \\
\text { come on, you try. swoop up our arms and } \\
\text { [make a big round sun] come on, you try ... }\end{array}$ & $\begin{array}{l}\text { Cn: [make a big round sun] } \\
\text { ((moving accordingly)) }\end{array}$ \\
\hline
\end{tabular}

Learners also displayed their readiness to join in and imitate the presenter at other parts of the video clip (Extracts 3 \& 4). For example, when the actions for the line 'it will be windy later on' were demonstrated, learners in Lesson 5 joined in the 
onomatopoeic utterance that was used. In a similar way, learners in Lesson 4 joined in the onomatopoeic 'pitter patter' to represent the rain. In both cases, onomatopoeic expressions support understanding of the situation, but they also seem to form an access point for learners' language production. In Lesson 4, especially, the onomatopoeic expressions are the starting point for more, related language that is imitated (Extract 4, Turn 3).

Extract 3: Joining in onomatopoeic utterances for the Weather Song (Lesson 5)

\begin{tabular}{|l|l|l|}
\hline Turns & Presenter (P) and Sophie (S) & Learners (Cn) \\
\hline 1 & $\begin{array}{l}\text { ((DVD starts) }) \\
\text { P: swoop up our arms and [make a big round } \\
\text { sun] come on, you try ... oh, the symbols } \\
\text { have changed ... and when the symbols are } \\
\text { like that it means it's going to be windy ... (I } \\
\text { know) let's pretend we are swept off our feet } \\
\text { sun]] } \\
\text { ((moving accordingly) })\end{array}$ \\
\hline 2 & by the wind...uh::: [uh::: ] ((DVD stops)) & Cn ((many)): [uh::: ] ((giggling)) \\
\hline 3 & \multicolumn{2}{|c}{ [make a big round } \\
\hline
\end{tabular}

Extract 4: Joining in onomatopoeic utterances for the Weather Song (Lesson 4)

\begin{tabular}{|c|c|c|}
\hline Turns & Presenter (P) and Sophie (S) & Learners (Cn) \\
\hline 1 & $\begin{array}{l}\text { ((DVD playing)) } \\
\text { P: : pitter patter, here comes the rain } \\
\text { ((teacher stopping the DVD)) }\end{array}$ & \\
\hline 2 & & Cn ((some)): pitter, patter \\
\hline 3 & $\begin{array}{l}\text { S: pi[tter, patter, here comes the rain, } \\
\text { pitter, patter, here comes the rain, pitter, } \\
\text { putter, here comes the rain] }\end{array}$ & $\begin{array}{l}\text { Cn:[pitter, patter, here comes the } \\
\text { rain, pitter, patter, here comes the } \\
\text { rain, pitter, putter, here comes the } \\
\text { rain] }\end{array}$ \\
\hline
\end{tabular}

In both lessons, Sophie used the same procedure for the DVD clip. After going through the demonstration of the different weather changes and equivalent moves step by step, Sophie encouraged her learners to speak all the lines of the song together with the presenter by joining in herself (Extract 5 , Turn 1 ) before the song was finally sung with accompanying actions three times without interruption (3 \& 4). There is no extra instruction for the children to join in verbally (2), but children 
started singing to differing degrees in both sessions, with more children participating right from the beginning of the song as the video progresses.

\section{Extract 5: Joining in the singing with presenter of the Weather Song (Lesson 5)}

\begin{tabular}{|c|c|c|}
\hline Turns & Presenters (P1, P2) and Sophie (S) & Learners \\
\hline 1 & $\begin{array}{l}\text { ((DVD playing)) } \\
\text { P1\&S: this morning there'll be sun, } \\
\text { P1: wind now, } \\
\text { P1\&S: [it will be windy later on], } \\
\text { P1: now rain, } \\
\text { P1\&S:[some heavy rain is on the way, } \\
\text { the weather will be everything today], }\end{array}$ & $\begin{array}{l}\text { Cn: [it will be windy later on] } \\
\text { Cn((some)): [some heavy rain is on } \\
\text { the way, the weather will be } \\
\text { everything today] }\end{array}$ \\
\hline 2 & S: okay & \\
\hline 3 & $\begin{array}{l}\text { P1: let’s wriggle, wriggle over here and } \\
\text { wriggle over there ... I am feeling good } \\
\text { again ... and I feel that you feel good too. } \\
\text { so, let’s do all the moves together, with } \\
\text { music ((music starts)) starting with the } \\
\text { sun ... [this morning there'll be sun], } \\
\text { wind, [it will be windy later on], rain, } \\
\text { [some heavy rain is on the way] ... yes, I } \\
\text { am having fun, and I hope you are having } \\
\text { fun too, let’s do it all again and at the end } \\
\text { add a big weather wriggle ... here we } \\
\text { go ... [this morning there'll be sun, it will } \\
\text { be windy later on, some heavy rain is on } \\
\text { the way, the weather will be everything, } \\
\text { today] ... uh:.:., did you remember to do } \\
\text { all the different weather moves? }\end{array}$ & $\begin{array}{l}\text { ((Cn’s voices)) } \\
\text { Cn ((some joining in)): } \\
\text { [this morning there'll be sun] } \\
\text { ((many)) [it will be windy later on] } \\
\text { ((many)) [some heavy rain is on the } \\
\text { way] } \\
\text { Cn: ((some children joining in)) } \\
\text { [this morning there'll be sun, it will } \\
\text { be windy later on, some heavy rain } \\
\text { is on the way, the weather will be } \\
\text { everything, today] } \\
\text { ((children giggling)) }\end{array}$ \\
\hline 4 & $\begin{array}{l}\text { P2: yeah, I think we got it. let's try it } \\
\text { again ... [this morning there'll be sun ... it } \\
\text { will be windy later on ... some heavy rain } \\
\text { is on the way ... the weather will be } \\
\text { everything ... today] ... ((teacher stopping } \\
\text { the DVD)) }\end{array}$ & $\begin{array}{l}\text { Cn: ((some children joining in)) } \\
\text { [this morning there'll be sun ... it } \\
\text { will be windy later on ... some } \\
\text { heavy rain is on the way ... the } \\
\text { weather will be everything ... } \\
\text { today] }\end{array}$ \\
\hline
\end{tabular}


This marks the end of the while-listening activities. Sophie went back to the classroom with her learners in order to perform the song with the actions. First, she asked learners to repeat the lines after her several times, then they sang the song together. Extract 6 illustrates how learners responded to Sophie’s instructions to speak after her.

\section{Extract 6: Joining in with teacher for the Weather Song (Lesson 5)}

\begin{tabular}{|c|c|c|}
\hline Turns & Sophie & Learners \\
\hline 1 & $\begin{array}{l}\text { okay ... now, I want to sing the song with } \\
\text { you. in order to sing the song, we've got to } \\
\text { know the lines and I will say them and you } \\
\text { will repeat them, okay? like we always do, I } \\
\text { speak, you speak ... this morning there'll be } \\
\text { sun. }\end{array}$ & \\
\hline 2 & & Cn: this morning there'll be sun. \\
\hline 3 & XXX again ... this [morning there & Cn: [morning there- \\
\hline 4 & no, listen again ... [this morning & Cn: [this mor[ning \\
\hline 5 & & $\begin{array}{l}\text { Cf: [oh sei doch mal leise } \\
\text { [oh be quiet }\end{array}$ \\
\hline 6 & $\begin{array}{l}\text { can you please just listen? listen, okay? } \\
{ }^{\circ} \mathrm{XXX}^{\circ} \ldots \text { this morning there'll be sun. }\end{array}$ & \\
\hline 7 & & Cn: this morning there'll be sun. \\
\hline 8 & $\begin{array}{l}\text { good ... again ... [this morning there'll be } \\
\text { sun] }\end{array}$ & $\begin{array}{l}\text { Cn ((some)): [this morning } \\
\text { there'll be sun.] }\end{array}$ \\
\hline 9 & & $\begin{array}{l}\text { Cn ((all)): this morning there'll } \\
\text { be sun. }\end{array}$ \\
\hline 10 & $\begin{array}{l}\text { okay, so ... if I point to myself, I say it, if I } \\
\text { point at you, you say it, okay? }\end{array}$ & \\
\hline
\end{tabular}

Extract 6 reveals that some learners tend to join in the lines of the song straight away, rather than listening to them again first, as is asked of them $(1,4,6,10)$. They do try to follow the instructions at first ( $1 \& 2$ ), and directly after being reminded ( $6 \& 7$ ), but repeatedly go back to joining in. Rather than disrupting the lesson by making unrelated comments, learners here demonstrate eagerness to join in the classroom activity. They see the teacher performing the actions and hear the relevant language, and their reaction to imitate their teacher seems automatic. This is remarkable since 
the routine of repeating language after the teacher seems to be well established. Not only does Sophie refer to this as something they always do (1), but in Lesson 4, when she used the same follow-up activity, learners followed the routine without any problems. So, if this practice is familiar, and children do not show any sign of disrupting the learning environment intentionally, then their not following instructions here has a different reason. Rather than disinterest, it is most likely a sign of high levels of engagement in the song, which clashed with their teachers' agenda to focus on the correct production of language involved. While learners focused on participation, Sophie focused on formal linguistic aspects.

The following sing along with the teacher proves that Sophie's focus on correct language production was well founded (Extract 7). Children displayed some uncertainty about the first part of the line 'the weather will be everything today', for example, compensating for that by singing the last part, the lexical item 'today' that they recognized and knew very well, more loudly.

\section{Extract 7: Singing the Weather Song (Lesson 5)}

\begin{tabular}{|c|c|c|}
\hline Turns & Sophie & Learners \\
\hline 1 & $\begin{array}{l}\text { yes ... okay, can you try to sing along with } \\
\text { me? Try to sing along, altogether, } \\
\text { okay? ... one, two, three, four ... [this } \\
\text { morning there will be sun ... it will be } \\
\text { windy later on ... some heavy rain is on the } \\
\text { way ... the weather will be everything } \\
\text { TODAY] ... okay I see you want to make the } \\
\text { moves again, fair enough ... try to do it with } \\
\text { moves, okay? .... one, two, three, four ... } \\
\text { [this morning there will be sun ... it will be } \\
\text { windy later on ... some heavy rain is on the } \\
\text { way ... the weather will be everything } \\
\text { TODAY ... }\end{array}$ & $\begin{array}{l}\text { Cn ((all)): [this morning there } \\
\text { will be sun ... it will be windy } \\
\text { later on ... some heavy rain (is on } \\
\text { the way ... the weather will be } \\
\text { everything) TODAY] } \\
\text { ((children’s voices)) } \\
\text { Cn ((all)): [this morning there } \\
\text { will be sun ... it will be windy } \\
\text { later on ... some heavy rain is on } \\
\text { the way ... the weather will be } \\
\text { (everything) TODAY ... }\end{array}$ \\
\hline
\end{tabular}

In Lesson 4, Sophie had had enough time to let her learners create a picture about the Weather Song, and she used that at the beginning of the following session in the same year group when she wanted her learners to remember the lyrics of the song before telling them the story April Weather (Extract 8). 
Extract 8: Trying to remember the Weather Song (Lesson 7)

\begin{tabular}{|c|c|c|}
\hline Turns & Sophie & Learners $(\mathrm{C} 1, \mathrm{C})$ \\
\hline 1 & $\begin{array}{l}\text {... I want to know if you can remember the } \\
\text { lines of the song ... the lyrics ... do you } \\
\text { remember the song? ... can you sing it? ... } \\
\text { try, come on ... ... do you need help? with } \\
\text { Y together? can you do it together? okay? }\end{array}$ & $\begin{array}{l}\text { ((one child humming the tune of } \\
\text { the song)) }\end{array}$ \\
\hline 2 & & C1: this morning there'll be sun \\
\hline 3 & yes, good & \\
\hline 4 & & $\begin{array}{l}\text { ((another child singing the line } \\
\text { again)) }\end{array}$ \\
\hline 5 & & C1: it will be windy later on \\
\hline 6 & wow, good & \\
\hline 7 & & ((another child singing)) \\
\hline 8 & & $\begin{array}{l}\text { C1: a XXX rain is on the way ... } \\
\text { the weather like (it) everything } \\
\text { today }\end{array}$ \\
\hline 9 & $\begin{array}{l}\text { yes, good ... the first three lines were very } \\
\text { good, but the ... four, five was not that } \\
\text { good ... the weather will be everything } \\
\text { today ... XXX [the weather will be } \\
\text { everything today }\end{array}$ & ((children joining in)) \\
\hline 10 & $\begin{array}{l}\text {... I will say the lines, and you will repeat } \\
\text { that and then we sing the song again ... [this } \\
\text { morning there'll be sun] }\end{array}$ & $\begin{array}{l}\text { C ((one child joining in)):[this } \\
\text { morning there'll be sun] }\end{array}$ \\
\hline
\end{tabular}

One child correctly reproduces the first part of the Weather Song and remembers most of the second part ( 2 \& 5), which, as Sophie's comments suggest, is quite a remarkable achievement that she did not expect (6). After all, the children only had one English lesson per week, they had not written down the lyrics in the previous lesson but could only rely on the pictures that they had drawn. Moreover, it is most unlikely that they could have practised the song with somebody else. The Weather Song is not a well-known song and the children did not have access to it in between lessons. The recording also suggests that not only one child could remember the song well. There is another child who keeps singing in the background (1, 4 \& 7). The retrieval of the song lyrics raises the question of how important images are in 
language learning. Here, they not only support understanding but also memory and reproduction of language.

Enthusiasm for participating in singing and accompanying actions was found in other groups of learners and with other teachers. In Lesson 9, for example, when Sophie taught her Year 1 group the song If You Are Happy And You Know It, learners joined in singing although they did not really want to sing. They had practised body parts and expressed their wish to play Simon Says, but Sophie asked them to sing a song first, and they did sing along with the teacher most of the time (Appendix 9). Joining in singing unprompted has also been observed for Lessons 21 and 25 when Year 3 learners initiated singing during portfolio work. Ruth had asked them to name titles of songs they knew, and learners started humming and singing (Appendix 9).

\subsubsection{Chants}

If music and body movement cause high levels of learners' involvement, then chants would be expected to have a similar effect, especially if they are accompanied with actions. Chants may lack tonality but their rhythmic nature makes them a relative of song. In the following, learners' response to chants will be examined.

In Lesson 6, Sophie decided to show the children a football warm-up routine from the Boogie Beebies programme (2005) on DVD in a Year 4 group. The video clip consisted of a list of instructions with passages of chanting. The children had been playing football and had also discussed the rules of football in the two previous lessons. During Lesson 6, the children first watched the clip with the teacher stopping frequently to discuss the meaning of the instructions (Extract 9).

The first impression is that children find it difficult to use German words and when they answer the teacher's question, they refer to what they have seen rather than to what they might have heard (3). While the teacher's agenda seems to be to make sure that the children do not misunderstand 'keep the ball up' as 'kick the ball up', the children seem less focused on the language but more on what they see; the language that is being used seems of secondary importance to them. To the teacher's question of who understood the phrase 'keep the ball up' (2), one child responds by describing the situation or the image of someone keeping the ball up (3) rather than focusing on key words of this phrase. The child introduces words, such as 'Knie'(knee) and ‘hochmachen’(lift) and neglects the English words ‘ball’ or 'keep up', which make up this phrase. The learner does not seem to analyse the linguistic 
input that has been received but to process the visual image that was presented. The teacher, on the other hand, does not appreciate the child's answer as a correct answer. Her further questions about the phrase reveal that she is more interested in the linguistic form. She wants the children to recognize the different parts of the phrase. So, she breaks it up and asks for the meaning of 'the ball' (4), which the children are likely to know from previous English classes, as well as providing them with a translation of 'keep up'. She feels it necessary to point out the difference between 'kick’ and 'keep’. Phonetically, 'kick’ and 'keep’ might be mistaken for each other. However, this is something that the children with their attention being on the situation rather than the language neither recognize nor show any interest in.

\section{Extract 9: Children using visual clues for comprehension (Lesson 6)}

\begin{tabular}{|l|l|l|}
\hline Turns & Sophie (S), Presenter (P) & Learners (C1, C?) \\
\hline 1 & $\begin{array}{l}\text { P: }[\ldots] \text { keep on dribbling ... XXX ...okay, let's keep } \\
\text { the ball up ... that's it ... ((teacher stops DVD)) }\end{array}$ & \\
\hline 2 & S: who did understand? yes? & $\begin{array}{l}\text { C1: also, wir sollen den, } \\
\text { die Knie hoch machen und } \\
\text { dann so ... } \\
\text { well, we are supposed to } \\
\text { lift the knee and then ... }\end{array}$ \\
\hline 4 & $\begin{array}{l}\text { S: so, let's keep the ball up ... keep the ball up ... } \\
\text { what does it mean? ... keep the ball up ... the } \\
\text { ball ... that's easy ... oh, no, the ball ... the ball ... } \\
\text { what is the ball? ... Y }\end{array}$ & $\begin{array}{l}\text { keep the ball up, mit den Knien with your knees ... } \\
\text { keep the ball up, okay? ((DVD starts again)) }\end{array}$ \\
\hline 5 & $\begin{array}{l}\text { S: yes ... keep the ball up ... keep the ball up .... } \\
\text { what does it mean ... keep the ball up ... keep the } \\
\text { ball up ... Y }\end{array}$ & \\
\hline 6 & $\begin{array}{l}\text { S: yes, now, not kick the ball up, but keep ... lass } \\
\text { den Ball oben keep the ball up, halte den Ball oben }\end{array}$ & \\
\hline 8 & & \\
\hline 7 & & \\
\hline
\end{tabular}


Later, the children watched the warm-up again and were asked to join in the actions, but they very quickly joined in the chanting as well (Extract 10).

Learners start by participating in the action, that is clapping after the word 'football'. Then, they start chanting this lexical item. Having talked about football before, it is a well-known word, it is also very similar to its German equivalent 'Fußball' and it is the only instruction (if we can call it that) that consists of one word only. Thus, it is hardly surprising that the children are able to use it. However, we have to remember that the word 'football' occurs in the midst of many other words and phrases that are still new to the learners or only partly known. Words and phrases such as 'clear a space', 'put on a smiley face', 'dribble', 'keep the ball up', 'chest and head' and 'save the goal' had only been discussed a few minutes before when the extract on DVD was watched and listened to for the very first time.

\section{Extract 10: Joining in the Football Warm-up (Lesson 6)}

\begin{tabular}{|c|c|c|}
\hline Turns & Sophie (S), Cbeebies Presenter (P) & Learners \\
\hline 1 & $\begin{array}{l}\text { S: yes, it’s football ((clap, clap, clap))... } \\
\text { football ((clap, clap, clap)) ... football ((clap, } \\
\text { clap, clap)) ... okay, now, let’s try ... to, to do } \\
\text { it again without XXX ... you just watch it and } \\
\text { do it, okay? ... wir machen’s noch mal ... } \\
\text { ((DVD starts)) }\end{array}$ & $\begin{array}{l}\text { ((children joining in with } \\
\text { clapping)) }\end{array}$ \\
\hline 2 & $\begin{array}{l}\text { P: hello, it’s BoogieBeebies. your chance to } \\
\text { dance. I'm Pete, and I want you to join in and } \\
\text { copy me. you can do as little as you want or as } \\
\text { much as you like. but first of all, let’s clear a } \\
\text { space, put on a smiley face because today we } \\
\text { are going to do some football moves ... } \\
\text { football ... [football ((clap, clap, clap))... } \\
\text { football ((clap, clap, clap))] ... let’s dribble } \\
\text { with the ball ... that's it ... keep dribbling ... } \\
\text { dribble with that ball ... okay let’s keep the ball } \\
\text { up ... that's it ... keep that ball up ... uuuhh ... } \\
\text { here we go ... let’s dribble with the ball again, } \\
\text { keep on dribbling ... show me your football }\end{array}$ & $\begin{array}{l}\text { Cn: [football ((clap, clap, } \\
\text { clap))... football ((clap, clap, } \\
\text { clap))] }\end{array}$ \\
\hline
\end{tabular}




\begin{tabular}{|c|c|c|}
\hline 2 & $\begin{array}{l}\text { skills ... okay ... let's chest and head ... [chest } \\
\text { and head ... chest and head ... chest and } \\
\text { head] ... let's dribble with the ball again ... oh } \\
\text { yeah ... here we go ... are you doing okay? ... } \\
\text { okay, let's run after that ball ... it seems to be } \\
\text { getting away ... keep on running after that } \\
\text { ball ... that's it ... we've got it ... let’s dribble } \\
\text { with it again ... keep on dribbling ... that's } \\
\text { it ... now, let’s save this ... save the goal ... } \\
\text { [save the goal ... save the goal] ... and save } \\
\text { it ... okay ... foot[ball ((clap, clap, } \\
\text { clap)) ... .... football ((clap, clap, clap)) ... } \\
\text { football ((clap, clap, clap)) ... football ((clap, } \\
\text { clap, clap))] ... keep it up... that's it ... and } \\
\text { keep it up, and keep it up ... are you ready to } \\
\text { chest it ... chest it and head it ... [chest it, head } \\
\text { it ... chest it and head] ... you'd better run } \\
\text { after the ball ... keep on running ... that's it ... } \\
\text { okay ... let's save the goal ... ... [save the } \\
\text { goal ... save the goal ... save the goal] ... yeah }\end{array}$ & $\begin{array}{l}\text { ((many)) [save the goal ... } \\
\text { save the goal] ((many)) [ball } \\
\text { ((clap, clap, clap)) ... ... } \\
\text { football ((clap, clap, } \\
\text { clap)) ... football ((clap, } \\
\text { clap, clap)) ... football } \\
\text { ((clap, clap, clap))] } \\
\text { ((some)) [chest it, head it ... } \\
\text { chest it and head] } \\
\text { [save the goal ... save the } \\
\text { goal ... save the goal] }\end{array}$ \\
\hline
\end{tabular}

Extract 10 shows that the children demonstrated a high level of motivation to participate physically as well as verbally. All through the Football Warm-up, there was music in the background. As with the songs, we have language in connection with movement and music that seems to hold the children's attention and animate them to join in.

Sophie used the football warm-up again twice, once at the end of Lesson 6 and then again at the beginning of the following lesson with this year group. In both situations, she did not have any background music. However, the rhythm with which the instructions had been given alongside the music was retained even in these later uses. The version of the Football Warm-up that Sophie and the children used after the video clip was also a highly compressed version without fillers, such as 'are you doing okay’. For post-listening, Sophie asked her learners to do a move and then she wanted the others to remember the relevant language (Extract 11).

This incident is interesting because it suggests that movement and language have become inseparable for this learner. It is not that the learner has not understood Sophie's instruction in English (1, 3, 5, 7), it is repeated in German by him (4), and 
Sophie's comment suggests that he does the action (5), but as he shows the action, he almost automatically also uses the language that goes with it.

\section{Extract 11: Moving \& speaking simultaneously in post-listening activity (Lesson 6)}

\begin{tabular}{|c|c|c|}
\hline Turns & Sophie & Learner (Cm) \\
\hline 1 & $\begin{array}{l}\text { [...] so, I want one of you, one of you to make a } \\
\text { move ... like the ones we just saw ... one of } \\
\text { you to make a move, and the others ... are } \\
\text { supposed to guess, or to say what this move is } \\
\text { called ... yes, Y }\end{array}$ & \\
\hline 2 & & Cm: ehm, ehm ... \\
\hline 3 & $\begin{array}{l}\text { and you just ... just do one ... just do it ... } \\
\text { don't say it, just do it }\end{array}$ & \\
\hline 4 & & Cm: also ... zeigen well ... show \\
\hline 5 & yes $\ldots$ without speaking $\ldots$ just do it $\ldots$ yes $\ldots$ & \\
\hline 6 & & $\begin{array}{l}\text { Cm: ... say ... goal ... save the } \\
\text { goal }\end{array}$ \\
\hline 7 & $\begin{array}{l}\text { okay ... don't say anything, just do it, okay ... } \\
\text { do it like this ... }\end{array}$ & \\
\hline 8 & & $\begin{array}{l}\text { Cm: ... save the goal, save the } \\
\text { goal- }\end{array}$ \\
\hline 9 & $\begin{array}{l}\text { yes, so ... who can remember ... Y just said it, } \\
\text { but you can say it again ... Y }\end{array}$ & \\
\hline
\end{tabular}

It is almost as if doing the action triggers speaking, and it is reminiscent of previous incidents during which children started speaking when joining in the action although they had been asked not to. The learners finally get to grips with this routine and reconstruct five instructions from the Football Warm-up that were chanted one after the other. The text that was produced in this way could have been a simple listenand-copy exercise, but because of the retained rhythm of the music it may have seemed like a chant to the children, who demonstrate considerable enthusiasm (Extract 12). 
Extract 12: Increasing verbal participation in the Football Warm-up (Lesson 6)

\begin{tabular}{|c|c|c|}
\hline Turns & Sophie & Learners \\
\hline 1 & $\begin{array}{l}\text { now, ... XXX with moves ... ehm ... three } \\
\text { times each ... okay? three times ... so, it's save } \\
\text { the goal ... come on, do it with me ... [save the } \\
\text { goal ... save the goal ... save the goal] ... } \\
\text { good! now it’s foot[ball ((clap, clap, clap)) ... } \\
\text { football ((clap, clap, clap)) ... football ((clap, } \\
\text { clap, clap))] ... dribble with the ball ... }\end{array}$ & $\begin{array}{l}\ldots \text {.. [save the goal ... save the } \\
\text { goal ... save the goal] } \\
\text { [ball ((clap, clap, clap)) ... } \\
\text { football ((clap, clap, clap)) ... } \\
\text { football ((clap, clap, clap))] }\end{array}$ \\
\hline 2 & & dribble with the ball \\
\hline 3 & dribble with the ball & \\
\hline 4 & & dribble with the ball \\
\hline 5 & good! now, it’s keep the ball up & \\
\hline 6 & & keep the ball up \\
\hline 7 & keep the ball up & \\
\hline 8 & & keep the ball up \\
\hline 9 & keep the ball up & \\
\hline 10 & & keep the ball up \\
\hline 11 & $\begin{array}{l}\text { good, okay ... now chest and [head ... chest } \\
\text { and head ... chest and head ... good] ... and } \\
\text { now it's run after the ball }\end{array}$ & $\begin{array}{l}\text { [head ... chest and head ... } \\
\text { chest and head] }\end{array}$ \\
\hline 12 & & ((some)): chest and head \\
\hline
\end{tabular}

Learners respond by speaking some of the instructions with Sophie (1 \& 11), rather than repeating them. All of these phrases, 'save the goal', 'football' and 'chest and head', they had produced before when they joined in the chanting during the video clip, and they are confident to reproduce them now. This was not the case for 'keep the ball up' and 'dribble with the ball', which explains why learners repeat these phrases after Sophie $(2,4,6,8,10)$, but do not say them at the same time.

At the end of the lesson, Sophie wrote down the instructions on the blackboard and asked her learners to choose two of these, to write them down and draw a picture underneath each of them illustrating the relevant action (Figure 25) thereby visualizing language from the chant. 
Figure 25: Drawing for the Football Warm-up according to Sophie's instructions

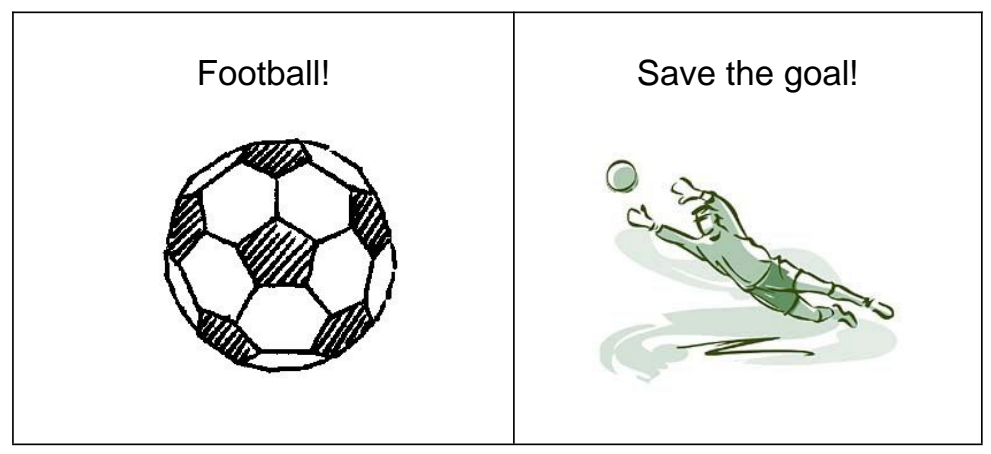

Apart from the Football Warm-up, two more chants could be observed being used at the school. In the following session in the same year group, in Lesson 11, Sophie used a chant again. The Easter Bunny Chant (Diekmann, 2008a) also engaged children very quickly. Before presenting the chant, she showed her learners flash cards and introduced words, such as 'Easter Bunny', 'to hide', 'basket' and 'nest'. Then, she presented the Easter Bunny Chant. As Sophie started the last part of the chant 'Easter Bunny, Easter Bunny, thank you very much', children joined in for 'Easter Bunny, Easter Bunny’, but stopped when Sophie told them that they should listen to the end. When she had finished, she asked them to join her and although it was only the second time they heard the chant, learners spoke the chant with her from beginning to end.

The third chant, the Easter Chant, was introduced by Julia to her Year 1 group. During Lesson 10, she had worked on the Easter Bunny's Book with her children when concentration levels seemed to decrease. The spontaneous use of the Easter Chant was intended to get children's attention back on track and did not follow specific language learning objectives. Julia’s main focus seemed to be on getting her learners to move about and get rid of some extra energy so that they would later be able to concentrate again. She did not seem to be interested in getting them to join in verbally at that point, but that is precisely what happened (Appendix 9). In this episode, speaking occurs as a by-product in a situation that could easily be regarded as counterproductive to language learning. The children were very tired and not encouraged by the teacher to join in the chant verbally. For all the chants, then, children showed high levels of engagement, both in joining in verbally as well as physically. 


\subsubsection{Stories}

The first story that could be observed being used was the picture book Froggy Gets Dressed. Since this was Lesson 1 and recording did not start straight away for the teacher to get used to the situation, only fieldnotes are available for analysis. Sophie used this book in one of her Year 3 groups. Before she told the story, she asked the children about the weather. Then, she told her learners that she brought a story and that it was snowy in the story. Sophie asked her learners what they wore in winter and used the opportunity to introduce some new words, all of them pieces of clothing, such as 'pants', 'mittens', 'gloves', 'boots', ‘scarf' etc. She did not discuss the meaning of 'to put on' and 'to take off', neither did she mention any synonyms for these. She also ignored the onomatopoeic expressions. However, Sophie, showing her group of learners the cover of the book, read out the title of the story and asked the children which animal the story was about and what these animals did in winter. Then she started to read out the story and to show the pictures to the children. The children listened, they guessed what might happen next and made comments in German without being asked. They seemed to understand what was going on and they seemed very interested in the story. They started imitating parts of the recurring dialogue, that is 'Froggy!' and 'What?', during the first reading of the book. Both of these words are not difficult. One is very similar to a word they know and have used before, 'frog', and the other, 'what' is well known to them as well. Yet they appear in a pool of new lexical items. Instead of showing concern for what particular sounds or words may mean, the children seemed to be content with a partial understanding of the situation that must have been based on their processing of pictures and recognition of individual words. Moreover, it can be anticipated that children, with their knowledge of how stories work, quickly realized that whenever Froggy was missing a piece of clothing, he had to go back inside, undress and put everything back on again. This explains why they seemed to understand the storyline and did not seem confused by language that they did not know. Sophie read the picture book twice. Before the second reading, every child was given a flash card on which there was a piece of clothing. The children were supposed to hold it up when they heard the word. They did not seem to have any difficulties with this activity, which indicates that they recognized words as they appeared in the story.

As mentioned before, the children listened with great interest, and one reason for their high level of involvement may have been that they could easily identify with the setting and the main character's actions. Most children are fascinated by 
snow and would not hesitate to run out into the snow, and children know that many mothers worry about them not being warm enough and catching a cold. Being able to identify with the characters in a story is believed to be an indicator for children's involvement and their learning of new vocabulary from stories(Elley, 1989).

As a follow-up, Sophie asked her learners to draw a picture of themselves with winter clothes on, and she finished her class by letting the children talk about their picture, using the phrase 'I am wearing'. The pictures visualized parts of clothing that the children had encountered through the story, but they were wordless. Not all children, however, drew themselves nor did they draw winter clothes. Some of them misunderstood or seemed to get carried away and drew Froggy instead and opted for a day in spring (Figure 26).

Figure 26: One learner's drawing of Froggy

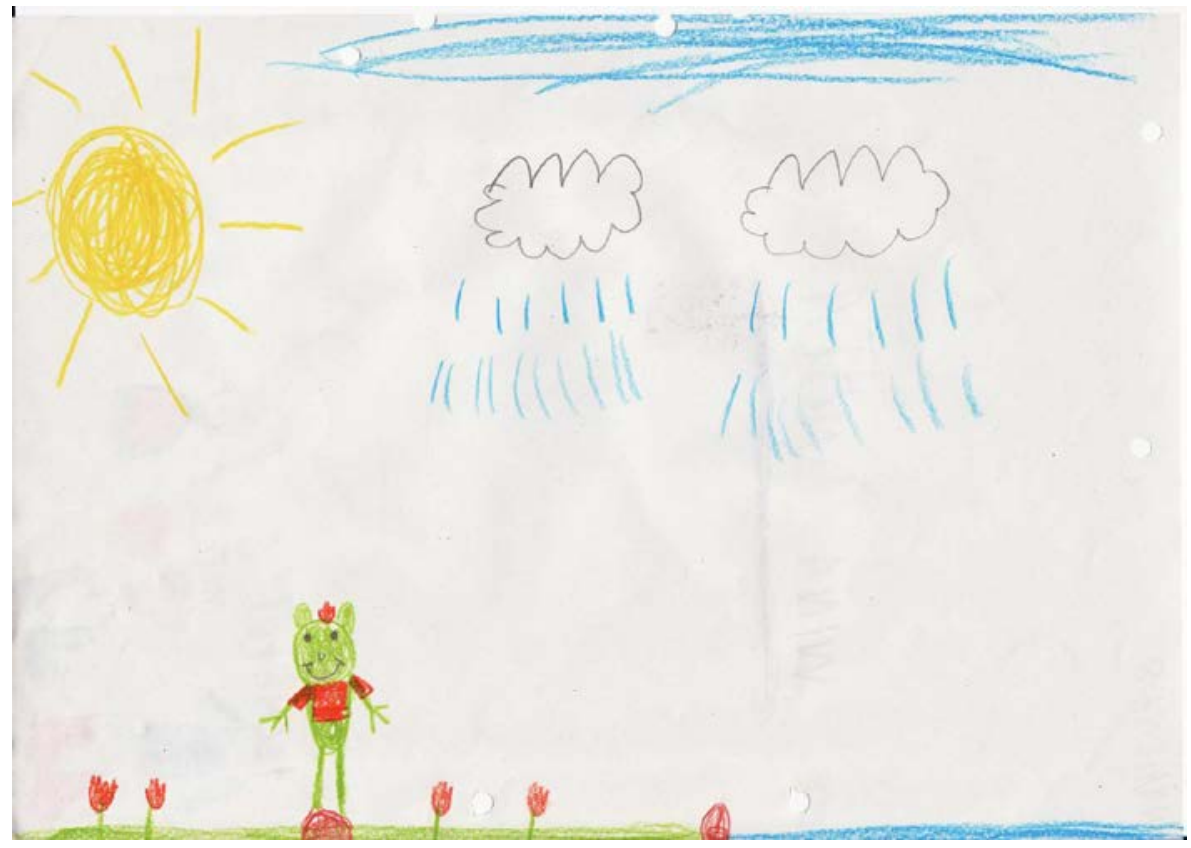

Another story that was used by Sophie in her Year 3 group was April Weather (Diekmann, 2008). Before the storytelling, Sophie had asked the children to stand in a circle behind their chairs. She had explained that she wanted them to listen and to join in with the actions (Extract 13). It was the first time that the children heard the story. 
Extract 13: Learners' determination to participate in storytelling (Lesson 7)

\begin{tabular}{|c|c|c|}
\hline Turns & Sophie & Learners \\
\hline 1 & $\begin{array}{l}{[\ldots] \text { look out of the window, please ... so, when I }} \\
\text { say: look out of the window, look out of the } \\
\text { window ... [okay] ... it's sunny }\end{array}$ & XXX ((children’s voices)) \\
\hline 2 & & sunny \\
\hline 3 & no ... it's sunny & \\
\hline 4 & & sunny \\
\hline 5 & $\begin{array}{l}\text { don’t repeat. just do the moves, okay ... make the } \\
\text { moves ... ... it's sunny }\end{array}$ & \\
\hline 6 & & sunny \\
\hline 7 & $\begin{array}{l}\text { what a nice day ... let’s go for a walk ((trampling } \\
\text { noise)) ... open the door ... open the door ... } \\
\text { good ... oh, no, it's cold ... [uuuhhh] ... okay, go to } \\
\text { your room ((trampling noise)) ... put on a } \\
\text { sweater ... this is a sweater ... put on a sweater ... } \\
\text { yes, okay ... open the door ... but, oh no ... it’s } \\
\text { raining ... take an umbrella ... open the door ... but, } \\
\text { oh [no] ((giggling)) ... it's stormy ... it’s stormy ... } \\
\text { your umbrella flies away ... }\end{array}$ & $\begin{array}{l}\text { ((children trampling)) } \\
\text { [uuuhhh] } \\
\text { ((one child)) [no] ((many } \\
\text { children giggling)) }\end{array}$ \\
\hline 8 & & XXX ((children’s voices)) \\
\hline 9 & $\begin{array}{l}\text { okay .... open the door ....... now, close the door ... } \\
\text { sit down in the kitchen ... have a cup of hot } \\
\text { chocolate ... yu[mmy] ... }\end{array}$ & [yummy] \\
\hline 10 & & $\begin{array}{l}\text { yummy ((some } \\
\text { children)) ... YUMMY! } \\
\text { ((one child)) }\end{array}$ \\
\hline 11 & $\begin{array}{l}\text { okay, I think you understood most of the words ... } \\
\text { what does 'stormy' mean? ... } \underline{\text { stormy }}\end{array}$ & \\
\hline
\end{tabular}

As has been observed with songs and chants, the children not only demonstrate great enthusiasm to imitate the actions but they also join in the storytelling. Even when the teacher specifically asks them only to listen (Extract 13, Turn 1), their response is to imitate the words as well $(2,4,6)$. The word 'sunny' is a word that they know and they had just sung the Weather Song. What seems to be happening here is that the teacher's plan of how to introduce the story is challenged by the children's 
determination to participate in the storytelling. In the end, the teacher decides not to insist on her teaching method but lets the children join in. And the children do join in $(7,9,10)$. They clearly take pleasure in the repeated negation and onomatopoetic expressions.

Again, children recognize utterances such as 'sunny' or 'yummy' in a text which also contains lexical items that may be unfamiliar or not as well known, such as 'sweater', 'umbrella', 'flies away' and 'hot chocolate'. However, they do not seem confused or irritated by that. Accompanying actions, such as the movements of arms when the umbrella flies away or the teacher's gesture of pointing to somebody's sweater, create a basic framework that ensures understanding of the situation. The children might have experienced days when they misjudged the weather and had to change plans, and they may also be attracted to this mix of playfulness and physical activity. And thus, levels of engagement are high, and there appears to be good potential for learning language although this is not an authentic story.

Sophie’s learners demonstrated an even greater willingness to participate in the storytelling when it was told a second time (Extract 14).

\section{Extract 14: Joining in the story April Weather (Lesson 7)}

\begin{tabular}{|l|l|l|}
\hline Turn & Sophie & Learners \\
\hline 1 & $\begin{array}{l}\text {.. yes, okay ... now, let's do it again ... just } \\
\text { make the moves with me ... ready? ... } \\
\text { okay ... look out of the window ...it's sunny }\end{array}$ & \\
\hline 2 & $\begin{array}{l}\text { what a nice day ... let's go for a walk ... open } \\
\text { the door ... but, oh [no] ... it’s [cold] ... go to } \\
\text { your room ... put on a sweater ... open the } \\
\text { door ... but, oh [no] ... it’s [rainy] ... take an } \\
\text { umbrella ... open the door ... but, oh [no... } \\
\text { it’s stormy] ... uu[uhhh] ... your umbrella } \\
\text { flies away ... }\end{array}$ & $\begin{array}{l}\text { ((trampling noise) }) \\
\text { ((trampling noise) })\end{array}$ \\
\hline
\end{tabular}

As before, Sophie gives the instruction to just join in the moves (1), but they also join in verbally. They imitate 'sunny', 'no' and the onomatopoeic 'uh' again, but they also join in with 'cold', 'rainy' and 'it's stormy'. Their verbal contribution 
increases and some of them now also start to produce multi-item chunks of language from the story (3).

More verbal response could be observed during a third storytelling (Extract 15). Learners now also say words such as 'window', 'sweater', 'rainy', 'umbrella', 'hot chocolate' and chunks such as 'open the door' and 'sit down in the kitchen'.

\section{Extract 15: Increasing verbal response from children (Lesson 7)}

\begin{tabular}{|c|c|c|}
\hline Turns & Sophie & Learners \\
\hline 1 & $\begin{array}{l}\text { okay, again ... once again, okay ... once again, try } \\
\text { to do ...((children’s voices)) ....[... }{ }^{\circ} \text { once } \\
\text { again }^{\circ} . . \text { look out of the window }\end{array}$ & \\
\hline 2 & & window \\
\hline 3 & it's [sunny] & ((many)) [sunny] \\
\hline 4 & $\begin{array}{l}\text { what a nice day ... let's go for a walk ((trampling } \\
\text { noise)) ... open the door ... [oh no] ... it’s cold ... } \\
\text { go to your room ((trampling noise)) ... put on a } \\
\text { sweater }\end{array}$ & $(($ many $))$ [oh no] \\
\hline 5 & & ((some)) sweater \\
\hline 6 & open the door & \\
\hline 7 & & ((one child)) open the door \\
\hline 8 & but, [oh no ... it’s raining] & $\begin{array}{l}\text { ((many)) [oh no ... it’s } \\
\text { RAINING] }\end{array}$ \\
\hline 9 & take an umbrella & \\
\hline 10 & & ((some)) (take an) umbrella \\
\hline 11 & but, [oh no ... it’s stormy ... uuuhhh] & $\begin{array}{l}\text { ((many)) [oh no ... it’s } \\
\text { STORMY ... uuuhhh] }\end{array}$ \\
\hline 12 & $\begin{array}{l}\text { your umbrella flies away ... close the door ... sit } \\
\text { down in the kitchen }\end{array}$ & \\
\hline 13 & & $\begin{array}{l}\text { ((many)) sit down in the } \\
\text { kitchen }\end{array}$ \\
\hline 14 & have a cup of hot chocolate & \\
\hline 15 & & ((some)) hot chocolate \\
\hline 16 & yummy & \\
\hline 17 & & ((many)) yummy \\
\hline
\end{tabular}


The children are well on their way to reproduce the whole story with the teacher as they perform the actions, but Sophie did not decide to work on that joint storytelling but continued with a listening exercise on the story at this point.

Verbal participation in storytelling also occurred during Ruth’s presentation of The Three Little Pigs story to a Year 3 group in Lesson 34. According to the fieldnotes, as Ruth told the story, children started to imitate parts of the recurring dialogue, such as 'let me in, let me in' and 'huffed and puffed', and when the story was presented again a week later, they also joined in with phrases, such as 'knock, knock, knock' and 'little pig, little pig'.

However, in contrast to songs and chants, there were also two storytelling instances when engagement levels seemed rather low. One example was the session on the Easter Bunny's Book in Lesson 10 (Extract 16). Like the story April Weather it is not an authentic story but had been taken from material specifically designed for learners of English at primary school (Englisch Begegnen 16).

Extract 16: Lack of participation with the Easter Bunny's Book (Lesson 10)

\begin{tabular}{|c|c|c|}
\hline Turns & Julia & $\begin{array}{l}\text { Learners } \\
\text { (C1, C2, C3) }\end{array}$ \\
\hline 1 & & C1: hello, cow \\
\hline 2 & may $\ldots$. I ... hide $\ldots$ my egg... in $\ldots$ your grass? & \\
\hline 3 & & C1: ... yeah \\
\hline 4 & $\begin{array}{l}\text { yes ... little Easter Bunny ... hide your egg in my } \\
\text { grass ... strengt ihr euch 'n bißchen mehr an, bitte, die } \\
\text { Kinder, die 'ne Rolle haben, nicht nur „yes“, sondern } \\
\text { versucht's mitzusprechen ... there is Porky, the } \\
\text { pig ... ... hello } \\
\text { [...] try a little harder, please, all children who have a } \\
\text { part, don't just say 'yes' but try and speak with me [...] }\end{array}$ & \\
\hline 5 & & C2: hello p[ig] \\
\hline 6 & $\begin{array}{l}\text { p[ig] may ... I ... hide ... my egg ... in your pud[dle?] } \\
\text { asks the Easter Bunny }\end{array}$ & $\mathrm{C} 2:\left[{ }^{\circ} \mathrm{dle}^{\circ}\right]$ \\
\hline 7 & & C3: yes \\
\hline
\end{tabular}

One gets the impression that the children's contribution is minimal and reduced to naming the animals and the greeting $(1,5)$. This seems to be an observation shared by Julia who urges the children to speak more (4). The children's lack of 
participation could derive from the fact that they are faced with a long phrase, which is hard to remember in one piece. The teacher explicitly asks for speaking with her and not after her (4), which is more challenging for FL learners.

It could also be that children were not used to using polite requests with 'may'. And indeed, one gets the impression that the use of 'may' in this type of story seems odd. In classroom discourse, polite requests with 'could I' or 'could you' seem to be more frequently used. This raises the question if the Easter Bunny's Book was mainly created to practise this polite phrase and not so much to provide children with an engaging story and examples of natural language. This assumption is supported by the fact that the text cannot be regarded as a typical story. Although we have a short description of the setting and characters, the text is lacking a conflict and therefore a solution to the problem. There is no humour or playfulness as in Froggy Gets Dressed or April Weather and there is no surprise event. Although the teacher introduces some physical action for the children by asking them to hold a flash card and to hide it, the text works very well without that. Physical action is not a natural ingredient of the storytelling as it is in the story April Weather. A negative impact on the children's engagement and consequently on their learning can be expected if features that we have previously linked with high levels of involvement are missing. Indeed, the lack of verbal participation here stands in stark contrast to observations of other lessons I have discussed.

However, another explanation is possible. It seems that the teacher used the same kind of method throughout three English sessions on the same story. It may well be that the children would have needed more variety in the presentation and participation of the storytelling. We also have to remember that this was a Year 1 group of seven-year olds, who were attending their last lesson of the day and they may have simply been exhausted.

Many aspects influence children's motivation and participation in class. The evidence from two different classrooms is not sufficient to explain exactly how the quality of narrative texts impacts on participation levels and learning success in primary school FL classrooms. However, there is some indication that stories written or presented purely for didactic purposes may negatively influence learners' involvement and therefore contribute less to language learning if they lack key features of literary texts.

Children also showed signs of fatigue when the story of Winnie the Witch (Thomas and Paul, 1987) was used to practise vocabulary and patterns in a Year 3 
group (Extract 17). The real book was not read out, but the student teacher talked about the story as she turned the pages in the book. The children could see the illustrations but because the story was summarized, they did not experience the original language of the book nor did they have much time to look at the illustrations. After this presentation of the story, learners were asked to look at the copy of a house, which was not Winnie's house from the book, and answer questions, such as 'Where is the sofa?' by saying 'It's in the living room'.

\section{Extract 17: Low levels of engagement during question-answer activity (Lesson} 22)

\begin{tabular}{|c|c|c|}
\hline Turns & Student Teacher & Learners(Cf, Cm, C?) \\
\hline 1 & $\begin{array}{l}\text { the toilet is in the bathroom ... where is } \\
\text { the toilet? ... ... where is the toilet? ... } \\
\text { hello! hello! ... where is the toilet? }\end{array}$ & \\
\hline 2 & & Cf: the toilet is green... ehm- \\
\hline 3 & $\begin{array}{l}\text { yes, it's green } \ldots \text { but where is it? ...... } \\
\text { where? }\end{array}$ & \\
\hline 4 & & $\mathrm{Cm}$ : the toilet is in the... bathroom \\
\hline 5 & $\begin{array}{l}\text { the toilet is in the bathroom ... } \\
\text { okay ... ... and what colour is it? ... it's } \\
\text { green ... and? }\end{array}$ & \\
\hline 6 & & $\begin{array}{l}\text { C?: yellow ((one child repeats word, } \\
\text { then others, too)) }\end{array}$ \\
\hline 7 & yes ... the toilet is & \\
\hline 8 & & C?: the toilet is ... green and yellow \\
\hline 9 & yes ... okay, very good & \\
\hline & {$[\ldots]$} & {$[\ldots]$} \\
\hline 10 & okay ... can you say it? & \\
\hline 11 & & Cm: the shower is in the bathroom \\
\hline 12 & $\begin{array}{l}\text { okay ... and Wilbur can stand under the } \\
\text { shower ....... Wilbur- }\end{array}$ & \\
\hline 13 & & $\begin{array}{l}\text { Cm: Katzen sind doch wasserscheu! } \\
\text { Cats don't like water. }\end{array}$ \\
\hline
\end{tabular}

The children here seem passive in that they have to be reminded to say more and produce complete sentences (Extract17, Turns 1 \& 7). In Turns 12 and 13, it 
becomes obvious that while the teacher is focused on language, children are focused on meaning, which is why a statement such as 'Wilbur can stand under the shower' does not make sense to them, since cats do not like water. In this session, the real book with its humorous story, its elaborate illustrations as well as its rich and repetitive language cannot be experienced by the children. The book, or rather what is left of it, becomes a didactic tool. It is only used as a stimulus for form-focused language practice that is decontextualized from the story and its characters.

What one can learn from this is that exploiting a story for purely didactic purposes and stripping it of its artistic qualities may lead to lower levels of involvement in the learners or even resistance, which reminds one of Wright's story health warning (1995). It is ironic that by trying to make a language lesson more efficient and not to 'waste' time on enjoying the story and indulging in its aesthetic qualities, language learning actually becomes less likely. While accompanying actions, pictures and literary devices, such as onomatopoeia, rhyme and rhythm, invite participation in learners and encourage them to reproduce individual words as well as multi-item language chunks from songs, chants and stories; ignoring these aesthetic qualities can lead to reluctant language use.

\subsubsection{The participant observer as teacher - analysis of a picture book session} During observations at the school in 2008 and 2009, I got involved in the teaching process in order to gain an insider perspective, both as an assistant supporting teachers during busy periods of group work or self-directed periods of learning and as a teacher for all of the class for parts of a session. The storytelling session that is reported on in this section is an example of this involvement in the classroom. In my analysis, I will focus on children's verbal and non-verbal response to the book, and reflect on what this suggests for the impact of illustrations, literary and acoustic devices of the text on the FL learning process.

Having expressed interest in trying out some of the storytelling myself, Ruth invited me to read The Smartest Giant in Town (Donaldson and Scheffler, 2002) to another Year 3 group using the same technique as the teacher herself a few days previously. The method that the teacher had used placed great importance on the visual aspect of the picture book. The children sat close to the teacher in two half circles so that they could always look at the picture book as the teacher held it up. On turning the page, the teacher let the children look at the pictures and waited for their ideas and comments that were naturally expressed in German, their mother 
tongue or the most commonly used language at school for all the bilingual and trilingual children. The teacher would respond to the children's comments by nodding or reformulating parts of their contribution in English thereby introducing English words that would appear in the text of that particular double spread in the book. This method of presenting children with material and inviting their comments is not unusual in a primary school setting in Germany. It is a technique commonly used in other subjects other than English.

With regard to the picture book, it has to be said that none of the children could have seen or read a German version of the picture book before the storytelling session took place in March 2009. The Smartest Giant in Town was first published in 2002, but a German version did not enter the German book market until May 2009, when a translation by Susanne Koppe became available. However, it is true that many children must have had experience with reading books by Julia Donaldson and Axel Scheffler. Many of their books have been translated into German and have found their way into German kindergartens. The most famous examples are The Gruffalo (1999) and The Gruffalo's Child (2004) both translated by Monika Osberghaus. So, although the children cannot have known the German version of The Smartest Giant in Town prior to the storytelling session, we have to acknowledge that they were likely to have been experts in understanding the authors' characteristic style of narration in text and illustration.

Before the story was read, the children were shown a picture of George in his old clothes taken from double spread one. They were told that they would be going to listen to a story about a giant named George who only had old clothes and sandals. The individual pieces of clothing were pointed at and the equivalent word was said in English.

For the core activity, I tried to use the same technique as the teacher of presenting the illustration and waiting for learners' comments, but I did not manage, maybe due to nervousness, to use this routine right from the start. Therefore, children's first noticeable response to the picture book occurred when the first double page had been read, and the page was turned to reveal the second double spread, showing George peeking into a shop where two shop assistants were handling enormous socks and where on the right-hand side different parts of clothing could be seen (Figure 27 \& Extract 18). 
Figure 27: Double Spread No. 2, The Smartest Giant in Town

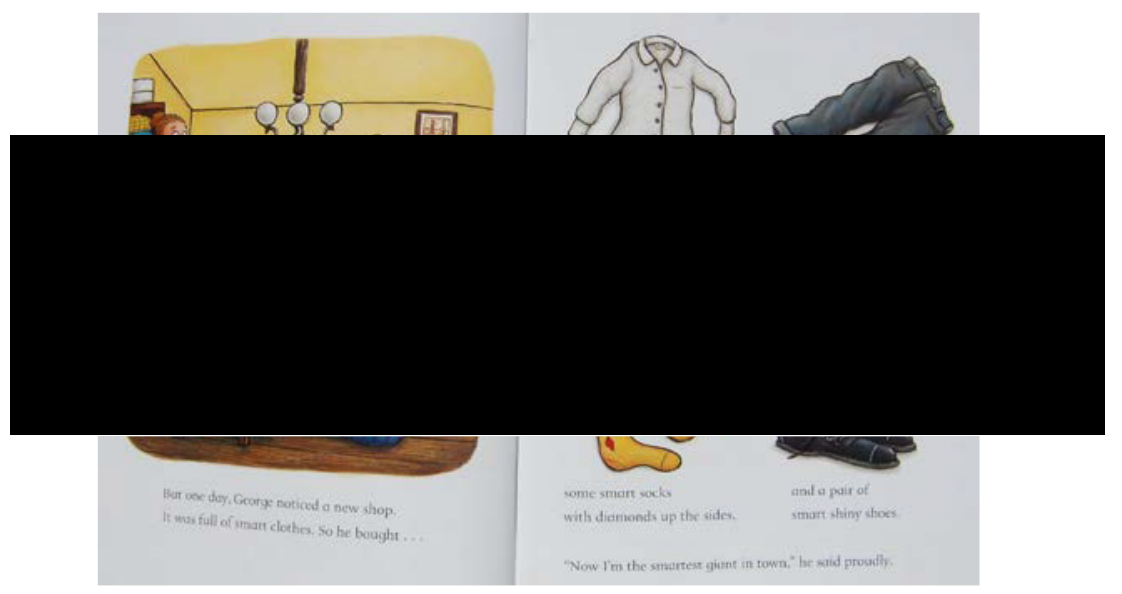

\section{Extract 18: Children's first response to illustrations (Lesson 16)}

\begin{tabular}{|c|c|c|}
\hline Turn & Researcher & Learners (Cn, Cf, Cm, C?) \\
\hline 1 & $\begin{array}{l}\text { [...] I wish I wasn't the scruffiest giant in } \\
\text { town ... so what did he do? ...... } \\
\text { ((turning page, pause of } 6 \text { secs)) }\end{array}$ & \\
\hline 2 & & Cn: oh! \\
\hline 3 & yeah? & \\
\hline 4 & & Cf: he got (hisself) new clothes \\
\hline 5 & $\begin{array}{l}\text { yes }[\ldots] \text { where did he buy new clothes? } \\
\text { where is that? yes? }\end{array}$ & \\
\hline 6 & & Cm: in e (schuhlade) in a (shoe shop) \\
\hline 7 & in a shop? & \\
\hline 8 & & Cf: maybe $=$ \\
\hline 9 & $\begin{array}{l}=\text { and maybe this person sells shoes as } \\
\text { well ... yeah? }\end{array}$ & \\
\hline 10 & & C?: hmmm ... Schneider tailor \\
\hline 11 & a tailor? $=$ & \\
\hline 12 & & $\mathrm{Cm}:=$ ja! yes! $=$ \\
\hline 13 & $\begin{array}{l}\text { = maybe a tailor who makes new } \\
\text { clothes ... yes, hmhm? }\end{array}$ & \\
\hline 14 & & $\begin{array}{l}\text { C?: vielleicht'n Geschäft maybe a } \\
\text { shop }\end{array}$ \\
\hline 15 & maybe it's a shop ... maybe ... yes? & \\
\hline 16 & & $\begin{array}{l}\text { Cm: vielleicht’n Kleidergeschäft } \\
\text { maybe a shop for clothes }\end{array}$ \\
\hline
\end{tabular}


Extract 18 reveals that the turning of the page is accompanied by a silence that is 6 seconds long. The reason why there is no immediate response from the children may well be that they are busy scanning the pictures, processing the information that is provided through the images before some of them show signs of astonishment (Turn 2). Only then, there is a first remark referring to the situation displayed in the pictures (4). This response is unusual since it is in English. The girl who makes it speaks American English and Spanish at home, and German at school.

After this first statement by a child, the researcher then extends the response by adding a question (5). The boy who speaks next responds to that and does so in the local dialect (6). Although he uses German, he seems to answer the researcher's question posed in English (5), thus signaling that he understands the contributions in English made before. As the discourse unfolds, children sometimes seem to relate their answers to the teacher's remarks ( 8 \& 12). However, at other times the children's responses may not necessarily relate to somebody else's contribution (10 \& 14). These remarks could also be regarded as individual responses linked to what particular children discover in the pictures and the conclusions they draw from them. A new thought is introduced in Turn 10, whereas in Turns 14 and 16 children repeat or extend what has been said before: 'shop', 'shop for clothes'. It is difficult to judge if this indicates that the children do not really listen to one another, or if it is simply their way of extending someone else's answer. They may not be able to process everything that is being said while they are looking at the pictures and trying to work out their meaning. However different their first thoughts on the pictures might be, each new comment provides a possible thread for uncovering the ideas conveyed in the illustrations, and so they jointly construct meaning on the basis of the pictures before they have listened to this part of the story.

A similar pattern can be detected at the turn from third to fourth double spread (Appendix 9). Children's comments referred to details in the illustrations that help to understand the developing plot, such as when they spot the giraffe wearing George's scarf and realize that George has given away a piece of clothing, an important detail that is going to recur every time George meets an animal in need. One child also noticed another lady giant in the background. There are other visual details here too that were not mentioned by the children: Hansel and Gretel, one of the three pigs, Hans in luck, a dwarf, and a hare to name but a few. Characters from famous folk tales and nursery rhymes can also be found on other pages of the picture book. Puss-in-boots among others can easily be recognized in the first double spread, 
the mice family living in a shoe is a reminder of the nursery rhyme There Was an Old Woman Who Lived in a Shoe on double spread 7, and there is a very frustrated princess with her frog prince three pages later. We have to assume that not all of these intertextual references are found immediately, with the children concentrating on reaching a basic understanding of the storyline during this first encounter with the story. There is a richness of visual stimuli. Multiple readings of the picture book are needed to discover all these visual clues, and in turn these visual clues provide an invaluable source for discussion.

At the end of this episode with the giraffe, the children had experienced all narrative features that are going to recur. The problem in the form of an animal in need, the problem's solution which involves George giving away one piece of his new clothing, the accompanying dialogue and song. However, in the following episode with the goat, children did not yet offer any comments on future events. It is only after experiencing the narrative pattern one more time that the children started making accurate predictions (Extract 19).

\section{Extract 19: Predicting how the story goes on (Lesson 16)}

\begin{tabular}{|l|l|l|}
\hline Turns & Researcher & Learners (Cm, Cn , Cf, C?) \\
\hline 1 & = George came to a tiny [XXX house] & \\
\hline 2 & & Cm: [Schuh! Shoe!] \\
\hline 3 & $\begin{array}{l}\text { mouse [with lots and lots and lots of } \\
\text { baby mice] ... yeah? }\end{array}$ & Cn: [XXX] ((whispering)) \\
\hline 4 & & $\begin{array}{l}\text { Cf: da ist das Haus ab ... das is } \\
\text { abge[brannt the house burnt down] }\end{array}$ \\
\hline 5 & C?: [XXX] \\
\hline 6 & yes, it burnt down ... yeah? ${ }^{\circ}$ & $\begin{array}{l}\text { Cm: und ich glaub, der schenkt ihnen } \\
\text { dann die Schuhe and I think he ‘s going } \\
\text { to give them his shoes = }\end{array}$ \\
\hline 7 & & $\begin{array}{l}\text { Cf: = ja yes = } \\
\text { Cm: da könn' se dann drin lebe they } \\
\text { can live in them then ... ((more } \\
\text { children’s voices in the background)) }\end{array}$ \\
\hline 8 & &
\end{tabular}


This is the episode with the mouse family on double spread no. 7. The reading is immediately interrupted by the children who want to express what they see - clearly a sign of high levels of engagement. The children are busy constructing meaning from what they are looking at $(2,4)$, and predicting what might happen next using their knowledge about the narrative structure (7-9). Rather than waiting for a response from the teacher, they now seem to continue their line of thought unprompted. Before listening to this part of the story, they have constructed a version of the upcoming events which is accurate and does not rely on an understanding of the text they are going to be presented with. The impact of the pictures on the meaning-making process is of great significance. They provide a scaffolding device that helps the children to sustain interest. Rich language that would otherwise be incomprehensible can be decoded, enabling the children to experience extended and complex discourse in the FL.

In the English lesson the following week, which was the last before the Easter Holidays, George’s song was practised in different ways involving a matching pairs activity as well as copying song lyrics and joint speaking. Children were also encouraged to write a card in German to say thank you to someone. However, the story was not read out again. Thus, the children's first encounter with the picture book was also the only time the children experienced the whole text in the classroom.

Classroom discourse of the follow-up session that was co-taught by Ruth and the researcher a week after the storytelling took place reveals that the children were not able to recall the spoken form of George's clothes, which highlights the fact that during their first encounter with the book, their focus was on decoding the storyline and 'reading the pictures' (Appendix 9). However, they did retrieve the meaning of the individual items of clothing once provided with the spoken form, and they also reproduced the spoken form without any difficulty once they had heard it again. Nevertheless, when children were working at their desks matching pictures and lines from the song and sticking these onto paper, there was some evidence that children were able to continue and retrieve whole lines from the song after prompts were given (Appendix 9).

The analysis of classroom discourse during the storytelling session with The Smartest Giant in Town shows that children demonstrated a high level of interest in the picture book. They responded by expressing astonishment at the visual stimuli on turning pages, which is reminiscent of the description of a picture book as an art 
form that 'hinges on the interdependence of pictures and words, on the simultaneous display of two facing pages, and on the drama of the turning page' (Bader, 1976: 1). The picture book triggered interest in the children, which motivated them to stay attentive and engaged in constructing meaning and discovering more about the story, which was evident in their assumptions about the developing narrative.

The extracts from classroom discourse also show that learners used visual clues to understand the plot, and once they unlocked the narrative code, the children in this study also made accurate predictions about the evolving storyline. The pictorial representation acted as a scaffolding device enabling them to make sense of a story told in the FL, although the complexity and richness of the language used in the picture book was well beyond their command of the FL at the time. However, the visual images not only led to the learners' following the plot and actively constructing meaning from them, they also encouraged them to tolerate extended input in the FL, which has been found lacking even in secondary EFL classrooms (Dalton-Puffer, 2007).

\subsection{Discussion of Findings}

Participant observation was carried out for mainly two reasons. Firstly, it was seen as a means to triangulate questionnaire results, and secondly it was hoped that it could shed some light on aspects of teaching and learning that the questionnaire failed to produce. In the following, I will discuss in how far the analysis of observational data confirmed questionnaire findings and which new insights could be drawn from it with reference to refined research questions as formulated at the end of the questionnaire chapter.

\subsubsection{Lesson organisation, teaching objectives, materials and activities}

The analysis of classroom observation data from one particular school has confirmed some of the questionnaire findings with regard to lesson organisation, teachers' choice of materials and activities, teaching objectives and the role of musical and literary texts.

English was mainly taught as a separate lesson due to staffing. Not every primary school teacher at the school had undergone training yet, and EFL teaching was therefore provided by the few qualified staff in one session per week, which was mostly scheduled in the last lesson of the day between 12 and $1 \mathrm{pm}$. This signals that timetabling and staffing are not unproblematic, as in other contexts of 
primary EFL in Europe (Eurydice, 2012; Harris and O’Leary, 2009; Oostdam and van Toorenburg, 2009).

Teachers in the school under study used a variety of materials, such as real picture books, copies of stories or chants from teachers' magazines, flash cards, CD and DVD. No textbook for primary EFL was used in the classroom. Teachers also made ready use of materials that were shown to them by the researcher on their request, such as the Boogie Beebies programme and The Smartest Giant in Town, which strengthens the assumption based on questionnaire findings that teachers lack a rich common source of easily accessibly teaching materials.

As questionnaire findings had suggested, there was a strong focus on listening comprehension and, to a lesser extent, speaking. Playing games, such as Simon says, involved listening, and so did the teaching of songs, chants and stories. There seemed to be a tendency to choose material that combines oral practice and physical actions. In the questionnaire, dancing was among the top five favourite activities, and indeed during observation the teaching of stories, songs and chants was very often linked to movement in the form of TPR activities (Asher, 1969), as with the Weather Song, the Easter Chant and April Weather, for example.

Speaking normally involved reproduction of individual items or chunks of language from songs, chants and stories. At times, learners were encouraged to generate statements on the basis of patterns, such as 'I am wearing + noun' (in connection with Froggy Gets Dressed) or ‘In my picture you see + noun’ (in connection with the Easter Bunny Chant) during post-listening activities. Writing only occurred irregularly in the form of individual words or short sentences in Year 3 during portfolio work and in Year 4 during post-listening activities, such as with the Football Warm-up. More often, children were asked to create a wordless drawing about the song or story they had encountered, as with The Weather Song and Froggy Gets Dressed. Reading was never observed during normal classroom routine, but it was used as optional activity during project work in one Year 3 group when children chose to work with graded readers.

Data from primary EFL classrooms in the school under investigation have shown that songs were indeed very popular with children, even if they were not used as often as teachers' answers in the questionnaire suggested. Stories were used more frequently than songs, and chants were only used occasionally, and did seem to be linked to seasons, such as Easter time. In general, one can say that songs, stories and chants indeed formed a substantial part of English tuition, with $76 \%$ of lessons 
observed, $49 \%$ of recording time and $62 \%$ of transcribed classroom discourse being linked to the teaching and learning of these genres.

\subsubsection{The nature of FL input and its impact on FL learning}

The analysis of classroom observation data showed that the texts of songs, chants and stories that teachers used varied greatly in their length, linguistic complexity and degree of repetition. Word count of texts ranged from 14 words of a chant to 1,065 words in a picture book. Repetition of lexical items or patterns varied most in song lyrics, with proportions between $7 \%$ to $100 \%$.

FL input in the form of songs, chants and stories was almost always accompanied by either actions, pictures or a combination of both. Texts also exhibited frequent use of onomatopoeia and rhyme. In this way, FL input was supported through visualization and acoustic clues.

The use of the mother tongue varied between different teachers, which is in line with other research (Eurydice 2012; Harris and O’Leary, 2009; Oostdam and van Toorenburg, 2009). However, the proportion of FL input in comparison to the use of the mother tongue was found highest during the presentation of a musical or literary text. While the text was presented, teachers had to use the FL. Because the text had to be experienced and performed, learners were exposed to a certain amount of the FL, independently of how much of the FL the teacher used at other times of the lesson. The use of these texts guaranteed FL input, even if a teacher normally tended to use the mother tongue for most of the time. In some cases, as in the reading of picture books, this input was extended due to the length of the texts. This is especially important for non-native teachers of English, who do not always achieve C1 English (Enever, 2011a; Garton, Copland and Burns, 2011), since it means that songs, chants and stories can help them provide their young learners with rich FL input nonetheless.

Presentations of a text, such as a song, chant or story, if not interrupted by comprehension checks, meant extended exposure to stretches of authentic FL use. Because of their nature and function, songs, chants and stories created opportunities for extended FL in- and output, both of which are needed for developing competent use of the FL (Krashen, 1981, 2003; Swain and Lapkin, 1995). These texts have to be presented, that is they have to be spoken, and in the case of songs, chants and action stories, they also invite learners to take part and perform them. The practice and repeated encounter with such texts becomes a meaningful endeavour. 


\subsubsection{The teaching of vocabulary, the role of visualization and acoustic cues}

Questionnaire findings suggested that teachers placed great importance to the issue of vocabulary. Not only did they refer to the 'memorable' quality of songs, rhymes and stories, but they also saw vocabulary as a problematic issue when dealing with these genres.

Observational data suggest that teachers in this study made frequent use of visualization to scaffold learners' reception of songs, chants and stories. Teachers used actions (Weather Song, Football Warm-up, April Weather story, Easter Chant), drawings, flash cards and pictures (picture books, The Three Little Pigs) or a combination of these (Milly the Mouse, Rudy is Falling). This ensured that learners had a basic understanding of the situation, which is also in line with literature on FL learning where the importance of visual aids in language learning is widely agreed upon (Brewster, Ellis and Girard, 2002; L. Cameron, 2001; Nation, 2001). In guide books for primary EFL teachers, techniques for introducing new words and teaching their meaning to children mention visualizing meaning through the use of realia, drawings or illustrations for example (Brewster, Ellis and Girard, 2002; L. Cameron, 2001). Literature on vocabulary learning in another language also features basic techniques to explain the meanings of new vocabulary items, which includes visual representation of meaning in the form of demonstration or the use of pictures (Nation, 2001). While Nation does not refer to young learners in particular, it can be argued that pictures are especially important in the teaching of young learners, since their analytic thinking skills as well as their vocabulary size in their mother tongue are still developing. Therefore, a definition or a translation into the L1 may be less successful than a clear visual representation of the target word.

Interestingly, observational data in this study indicate that visualization is also used for retrieval of vocabulary. Teachers were frequently found to ask learners to create pictures about the songs, chants and stories they had practised during postlistening activities. These most often wordless pictures were then used in following sessions to reconstruct language from songs, chants or stories (Weather Song, Football Warm-up, Easter Chant). This suggests that children's reliance on their visual sense to understand and remember situations and therefore language is maybe of a fundamental nature, and more poignant in young learners than in adults.

Acoustic stimuli also played a role in the reception and reproduction of song, chant and story. Observational data revealed that onomatopoeia was not only a frequent feature in the texts that teachers used but also noticed and reacted upon by 
learners. Onomatopoeic expressions were easily noticeable, attracted children’s attention and by doing so, functioned as access points into the text.

\subsubsection{Learners' response to songs, chants and stories}

The analysis of classroom discourse revealed some recurrent patterns in learners' response to songs, chants and stories that sparked their interest. Learners tended to participate both verbally and non-verbally by joining actions and also speaking, even if they had been asked only to listen. Speaking and performing actions occurred simultaneously and unprompted with different texts of all genres and with different groups of learners and teachers. There was no evidence of learners showing signs of confusion or being overwhelmed by songs, chants and stories.

On the contrary, classroom discourse showed children's focus on visual clues, which they used for comprehension. They also seemed to make use of their knowledge of how stories work to unlock the narrative code, which was especially evident during picture book sessions. Illustrations and actions helped them to reach a partial understanding of a situation, which learners were content with and which seemed to clash with teachers' agendas. Potential for conflicting interests could be detected in so far as teachers' focus on linguistic form sometimes led to an overuse of question-and-answer activities to practise patterns, while children demonstrated great eagerness to listen, join in and reproduce longer stretches of text.

At the same time, follow-up activities sometimes included question-andanswer activities which focused on producing individual words from texts in a new context, as with the story of Winnie the Witch. If used in that way, stories are no longer interesting in their own right, but only to create a link to individual words or patterns that teachers think need to be practised. This leads to an increase of question-and-answer activities that goes hand in hand with an increase of triadic discourse (Lemke, 1990) or IRF structures in classrooms (Sinclair and Coulthard, 1975). While IRF sequences are not necessarily detrimental to learning, overuse of triadic discourse can be problematic. They cause a decrease in extended text and more elaborate input in the FL, which as Dalton-Puffer suspects may be partly responsible for learners' inability to produce extended texts in the FL (Dalton-Puffer, 2007). 


\subsubsection{The nature of learners' FL output}

The analysis of repeated encounters of the same texts showed that children first joined in verbally for individual words that they already knew and recognized as well as for onomatopoeic expressions before their contributions became longer and included multi-item chunks of language from the original song, chant or story. This behaviour could be found for different texts of all the three genres in different groups of learners, e.g. Weather Song in Year 3, Easter Chant in Year 1, April Weather action story in Year 3 and the Football Warm-up in Year 4. Through repeated encounters with these texts, children memorized and reproduced multiitem sequences as they performed songs, chants and stories. These chunks of language were sometimes also reconstructed during follow-up activities later in the same session or at the beginning of the following session a week later. However, since texts were rarely revisited more than once over consecutive weeks, there is no evidence that suggests that children were able to memorize these multi-item sequences over longer periods of time, or if they were able to break them up and 'recycle' patterns and individual lexical items.

These chunks of language from songs, chants and stories included adjectives, verbs and nouns with concrete meaning. For example, there were pieces of clothing, different rooms in a house, verbs such as 'hop' and 'stop', and adjectives such as 'sunny' or 'rainy', all of which can be illustrated or mimed. This is in line with suggestions for the FL teaching of young learners, especially very young children of 5 years of age (L. Cameron, 2001). Although the learners in this project were older, between 6 and 10 years of age, they were still within the age span during which the 'syntagmatic-paradigmatic shift' is believed to take place (L. Cameron, 2001; Singleton, 1999; Miller and Johnson-Laird, 1976), and so they probably benefited from the teaching of concrete vocabulary.

\subsection{Concluding Remarks}

Data collected during participant observation in EFL classrooms in different year groups and with different teachers in one particular primary school confirmed some of the questionnaire findings with regard to EFL organisation, preferred materials and popular activities. Moreover, participant observation also provided more insights into the actual teaching and learning process, in particular about teacher's presentation of songs, chants and songs and their learners response to these texts. 
However, these findings did not answer all research questions as formulated at the end of the questionnaire chapter sufficiently. In particular, I wanted to know in how far learners' ability to produce multi-item sequences from songs, chants and stories could have a long-term effect on their performance, and if their FL use would also show traces of out-of school exposure to English texts they had enjoyed, as found in other studies (Enever, 2011a and b). I also needed to know how teachers experienced the teaching of songs, chants and stories and in how far their insights in their own teaching practice would confirm or contradict results from the analysis of classroom observation data. 


\section{Chapter 7}

\section{Interviews with Participating Learners and Teachers}

Once researchers have gathered their observational data, and sit down to analyse fieldnotes and recordings away from the field, they become somehow detached from the community they have studied. While a certain degree of detachment can be helpful to avoid 'going native', it also creates new pitfalls. Researchers, in the solitude of their offices, try to make sense of behaviour they have observed without the person in question being present during this meaning-making process. Data analysis involves interpretation, and without the participants' voice being heard, the researcher runs the risk of reading meaning into participants' behaviour that was not there. In this study, interviews were used to reduce the risk of biased results and interpretation. Interviews were conducted to allow participants to voice concerns and to respond to the researchers' findings. They functioned as an invaluable triangulation device.

\subsection{Methodology and Data Collection}

In-depth interviews were carried out with representatives of both parties in the classroom, teachers as well as learners. While interviews with teachers have been a natural part of classroom research for quite some time, interviews with young learners have only more recently started to become acceptable due to a new understanding of children's rights, such as the right 'to be heard', and of their competence, that is their ability 'to understand, to reflect and to give accurate and appropriate responses’ (Brooker, 2001: 163). In this study, children’s views were seen as valuable and essential contributions for a better understanding of the learning environment.

Whereas standard interview practice may aim at producing a great amount of interview data that can be compared and used for quantitative analysis, I saw the interview as an opportunity for researcher as well as teacher and pupil to discuss issues that had come up during observation and to reach a mutual understanding during the course of the interview. In this sense, my interview procedure was intended to serve 'the original purpose of interviewing as a research method, namely, to understand what respondents mean by what they say in response to our queries' (Mishler, 1986: 7). The aim was to encourage meaningful discourse in order to reach 
a better understanding of the teaching and learning of English as a FL through the use of songs, stories and chants in a primary school setting.

If one wants to create a setting where meaningful discourse is possible, then this has implications for interview procedures. One of the measures to be taken into account is the 'empowerment of respondents', which contrasts standard interview practice with its ‘striking asymmetry of power' (Mishler, 1986). In a standard interview, 'topics, definitions of events, categories for response and evaluation are all introduced, framed, and specified by interviewers', and they, not the interviewees, 'determine the adequacy and appropriateness of responses' (Mishler, 1986: 122). In other words, the interviewer has total control over the interview situation. Not only that, respondents' biographical or social background and the alienating context in which the interview takes place are very often either ignored or analysed separately from the interview as a whole in a 'identity-stripping process' (Goffman, 1961). Alternatively, the researcher creates an interview situation that gives interviewees enough room to yield control of the 'flow and content of the interview' and to enter into ‘a collaborative relationship' (Mishler, 1986: 131-132). This may always be beneficial, but it is of even greater importance for the quality of data obtained in interviews with children. Especially young children have been found to communicate better when given some control over the interview situation and less when given the feeling of being questioned (Wood, MacMahon and Cranstoun, 1980; Tizard and Hughes, 1984).

Two measures were taken. Firstly, interviews had to be held in an environment in which interviewees did not feel intimidated. Secondly, the 'interview guide', which is the term suggested by Richards (2003: 69) for less predetermined interviews, had to allow for some flexibility. I had to ensure that a natural flow of the interview was maintained, which meant that questions had to be worded so that they created a link to the respondents' answers, and the respondents had to be given as much time as they wanted to answer a question. I also had to be ready to ask an extra question if a response seemed to need further investigation, and to abandon any questions that seemed irrelevant during the course of the interview.

If researchers allow for a freer form of discourse, they might ultimately be presented with longer responses and with narrative accounts:

We are more likely to find stories reported in studies using relatively unstructured interviews where respondents are invited to speak in their own voices, allowed to control the 
introduction and flow of topics, and encouraged to extend their responses. (Mishler, 1986: 69)

Extended answers from participants hold advantages as well as disadvantages. While narrative accounts are difficult to categorize and quantify, they also provide a richer source of data that allows for a more thorough interpretation of the answer and hopefully leads to a better understanding of that answer. 'Telling stories' seems to be a universal human trait and a means for us to make sense of our world (Mishler, 1986; Gee, 1985). The idea that stories are created by human beings in order to structure and organize information found in their environment is also highlighted by Cortazzi (1993). The stories that our interviewees may be prepared to tell us can be regarded as a mirror reflecting their interpretation of the world they live in (Cortazzi, 1993), or in this case, the classroom they teach and learn in. The interview guides in this project had to ensure a degree of openness so as to let stories emerge.

There is, however, a problematic aspect of less unstructured approaches to interviews:

[A] woman, when interviewed without a questionnaire and asked to tell about growing up in Philadelphia, became very annoyed and told the interviewer to decide exactly what she wanted to know, write down the questions and come back another day when she was better prepared. (Wolfson, 1976: 196)

Interviewees can have clear expectations of what an interview situation should entail. It is a proper speech event that follows a predefined script: the interviewer asks questions and the interviewee answers them. Part of this script, according to Wolfson (1976), is the notion that because the interviewer introduces topics in the form of questions, the interviewees have fewer opportunities to introduce narratives. Moreover, in their role as respondents, they are aware that a number of questions have to be answered and therefore answers tend to be short and straight to the point, which excludes extensive use of narratives. Wolfson (1976) also highlights the fact that when narratives do occur in interviews, they appear in the form of summaries, and elaboration of detail is only used to refer directly to aspects of the interviewer's question.

With this in mind, interviews were designed so that the need for more flexible, empowering procedures were balanced with the need for a clearly defined speech event that addresses the participants' understanding of an interview situation 
and does not confuse them. In both learner and teacher interviews, I used materials and interview guides that communicated that this event had been planned and that I had an agenda that was not meant to be disguised or covered up. This procedure was intended to instill a sense of transparency and trust. Moreover, all interviewees were informed about the reasons for the interview and assured about confidentiality (Appendix 1; Dörnyei, 2003; Brooker, 2001; Mishler, 1986; Briggs, 1986).

Without a relationship that is built on trust, we cannot assume that an interviewee will readily speak her or his mind. However, trust evolves over time. This had to be acknowledged in the organisation of interviews. All formal interviews conducted during this project were held after participants had known the researcher for a year or more and had ample opportunity to experience her presence in the classroom. Where it was felt that not enough time had been spent with one particular teacher or in one class, no interviews were conducted. Therefore, interviews were conducted with Sophie, Ruth and some of their learners, but not envisaged with Julia and the Student Teacher. Familiarity with the interviewer and the environment in which an interview takes place is especially important for interviews with children (Pinter, Kuchah and Smith, 2013; Brooker, 2001).

A sound and trustworthy relationship between interviewer and interviewee not only encourages interviewees to open up their minds, it also leads to a better understanding of interviewees' responses. Having observed and experienced the teaching environment in the school for an extended period of time, I was familiar with the norms and values of this small community and was able to interpret interviewees' responses without ignoring the context in which they were formed. Briggs (1986) mentions this as an essential pre-requisite for any research based on interviews. Although he refers to research projects in anthropology, the basic principle applies to communities within one culture as well:

Adequate applications of interviewing techniques presuppose a basic understanding of the communicative norms of the society in question. Obtaining this awareness should accordingly constitute the first item on researchers' agenda. (Briggs, 1986: 94)

By gaining a thorough understanding of the sociocultural setting in which research is undertaken, it was hoped that decontextualization could be avoided, which is often regarded as a main weakness of standard interview design and analysis (Mishler, 1986). In the following, the interview guides for both children and teacher 
interviews as well as the context in which interviews were carried out will be commented on.

\subsubsection{Procedures for learner interviews}

Interviews with children were seen as a valuable research instrument. By talking directly to them in a small group, more details could be uncovered about their attitude towards the FL, their worries or hopes with regard to learning English and their actual ability to produce language related to topics they had discussed. I was especially interested in long-term effects. Therefore, all interviews with children were scheduled after at least 12 months and up to 15 months after observations had taken place. Since I had spent most time with Sophie’s and Ruth’s Year 3 groups, all interviews were conducted with Year 4 learners.

Four out of five interviews took place in the self-study area in the main hallway during regular classroom time, and one interview was carried out in a classroom that was empty at the time. The children knew the interview environment, as they had worked in that setting with the researcher before during the observational period she spent in their year groups. All 21 interviewed children were a few months away from starting secondary school. For most of the school year, school life for them had centred on which school they would go to. Children were aware that some of their friends would go different ways. They were sensitive to the fact that everyday school life would change for them, and so an interview in which they could somehow take stock, by showing what they had learnt, talking about activities they had enjoyed, and articulating their hopes and worries for the future, addressed the reflective mood they were in.

Individual interviews with children were avoided so as not to intimidate them (Moon, 2000). Group interviews were conducted, with four to five children in each group. Only children who wanted to be interviewed were chosen (Pinter, Kuchah and Smith, 2013; Brooker, 2001). Parents had been informed about the purpose of the interviews and had been asked to give their consent (Appendix 1). During the opening of the interview, the researcher explained to the children why she wanted to talk to them and what the interview would be about. All interviews were audio-recorded, and transcribed in full. Fieldnotes were taken immediately after the interviews took place.

A semi-structured design was chosen consisting of two phases. Concrete stimuli were used for both parts of the interview to strengthen learners' confidence, 
to raise and sustain their interest and to counterbalance the effects of the questionanswer format (Pinter, Kuchah and Smith, 2013; Brooker, 2001). The interviews started with a warm-up, as suggested by Pinter (2006). The children were asked to open their portfolios and talk, in German, about activities they had enjoyed and others that they had not. This allowed them to speak freely and ensured that they did not feel intimidated by the interview situation (Wood, MacMahon and Cranstoun, 1980). Children were encouraged to extend their answers and explain reasons for their approval or disapproval of certain activities.

The second phase of the interview was devoted to language production. Children were encouraged to produce individual words, phrases or sentences in English. For this, two different formats were experimented with, both based on the observation that children had demonstrated great pleasure in artwork and in playing games during their lessons. Moreover, learners were used to these activities, and I felt it was important to choose a task that they were familiar as well as comfortable with and that did not make them nervous about the interview (Pinter, 2006; Brooker, 2001).

The first format involved the creation of a mandala (Figure 28). For their mandala, the children took it in turns to choose pictures that were spread out on the table in front of them. These pictures depicted scenes of family life, objects, fruits and vegetables, animals, numbers. The children were asked to say something in English about the picture they had chosen and then they could keep the picture. Later they stuck these pictures on paper in the form of a mandala. A week later, they received a copy they could then colour in and add to their portfolio. As the illustration shows, the form of a mandala, a round pattern of different pictures or shapes, did not allow for a great degree of flexibility. One child, who found it impossible to arrange her favourite pictures in the form of a mandala, decided for a different layout when she stuck her pictures onto paper. Due to this experience another interview format was designed. 
Figure 28: Two examples of mandalas that children produced
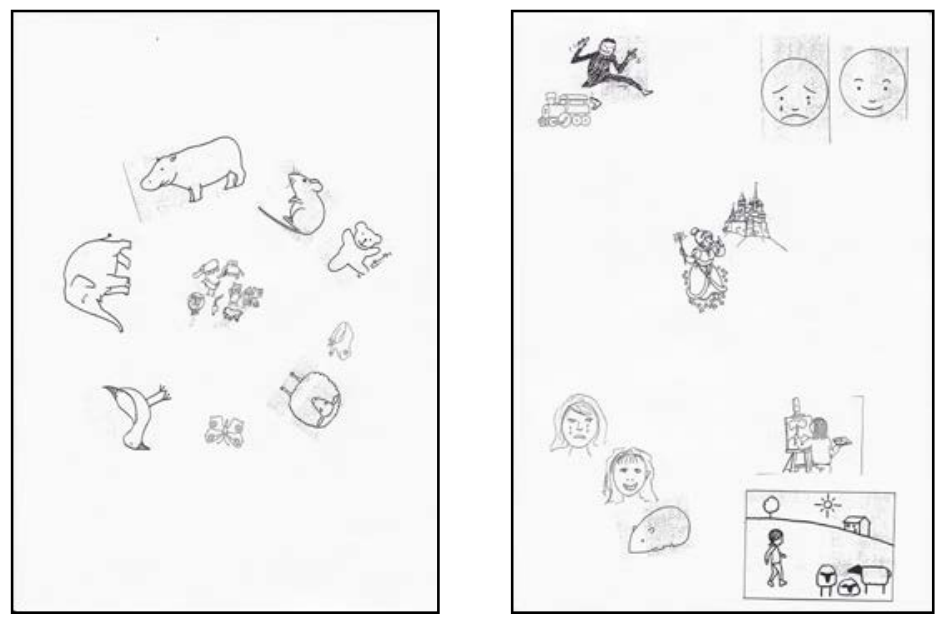

The second format was based on a card game. Children were presented with a set of 65 coloured cards each showing a different picture, which depicted object names (such as pieces of furniture, fruits, animals) that they had learnt as well as numbers, scenes from family life and from stories they had heard and talked about. Among them were also five cards featuring characters of The Smartest Giant in Town (Appendix 9 and Figure 29). Children were told that they would play a game whereby they could collect cards. Whenever it was their turn to choose one of the nine cards displayed from the top of the pile, they could say something about their card in English. Once they had talked about the picture on the card, which could be anything from a single word to a sentence, they would keep the card and later get a colour copy of all of their cards for their portfolio.

Figure 29: Examples of interview cards

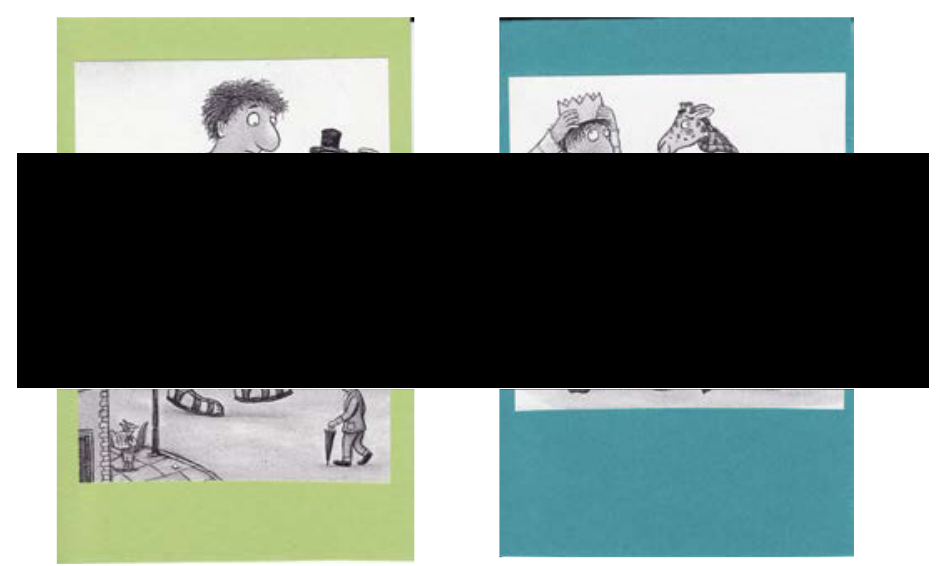

No. 60

No. 65 
All instructions were given in German, but if children wanted to know a word in English, it was provided and repeated a few times. The aim was to give learners some stimuli to speak English and to provide them with a positive learning opportunity in order to foster their self confidence and to avoid any distress (Brooker, 2001) that would have a negative impact on their future FL learning.

\subsubsection{Procedures for teacher interviews}

Interviews with teachers were conducted for two reasons. Firstly, they were seen as an opportunity to triangulate findings from classroom observation. By sharing key results from the analysis of classroom data, teachers were able to voice any concerns with my interpretation of incidents or to confirm these insights, all of which contributed to the process of making sense of the collected data. Secondly, teachers also provided valuable information on aspects that other research instruments failed to produce, such as exact details on children's ethnic and linguistic background.

It was paramount that I was careful to keep interviews short and not to tire participants or exploit their willingness to support my project. In accordance with Wallace's suggestion (1998), teacher interviewees received information about the purpose of the interview and about the nature of questions being asked beforehand so that a more relaxed atmosphere could be created (see also Statement of Ethics and consent forms in Appendix 1). Both interviews were carried out after data from classroom observation had been screened. Time and venue of the interviews were chosen by the two teachers in order to give them some control over the interview situation. The context and progress of each interview was recorded in fieldnotes.

As for interview design, a list of questions that were of interest or needed clarification had been drawn up after recordings, transcripts and fieldnotes had been studied (Appendix 10). Therefore it was important to have some control over the way in which the interview unfolded. A semi-structured interview provided both flexibility as well as direction (Wallace, 1998: 147). The interview guides for the teacher interviews were organised in sets of questions for different aspects, such as children's enthusiasm for joining in songs, chants and stories verbally and nonverbally, or the role of translation, for example. For each set of questions, the following discourse structure was used. First, I informed the interviewee about one aspect that had caught my attention during observation or transcription, and then I asked the teacher for more information on that particular aspect, e.g. if the observed 
behaviour was indeed characteristic, and in how far this was in line with or in contrast to her own teaching experience.

While some questions, e.g. on teacher training or the introduction of FLT at primary school, were the same or similar in both interviews, the nature of other questions varied due to the fact that different aspects of learner and teacher behaviour became prominent in the classrooms of both teachers. In the case of Sophie, for example, classroom observation and data analysis had revealed the children's enthusiasm for imitating language as a prominent aspect, and this needed to be addressed in the interview. On the other hand, observation of Ruth's classroom had highlighted children's ability to reproduce songs from memory about a year after regular singing had been part of the classroom routine. Furthermore, there was Ruth's storytelling technique that focused on the impact of pictures before providing language in the FL. This needed to be given some room for discussion in the interview.

As for the overall structure of the interview, it was my intention to start on a positive note and with some general remarks before moving to questions that could possibly be perceived as 'tricky'. At the end of the interview, I meant to give interviewees the opportunity to express their thoughts and concerns about the training of future teachers, which was supposed to act as a platform for the teachers to raise any other issues that they might have in connection with primary EFL.

\subsection{Procedures for Data Analysis}

Recordings of five group interviews with 21 learners in total and two teacher interviews were available for analysis (Table 42). Learner interviews were of similar length, between 28 to 36 minutes long. The two teacher interviews, however, were of very different length, with Ruth's interview being almost twice as long as Sophie’s. All recordings were transcribed from beginning to end, and produced a data base of 49,376 words. 
Table 42: Interview Matrix

\begin{tabular}{|l|l|l|l|l|l|r|}
\hline $\begin{array}{l}\text { Observa- } \\
\text { tional } \\
\text { period }\end{array}$ & $\begin{array}{l}\text { Type of } \\
\text { interview }\end{array}$ & $\begin{array}{l}\text { Time of } \\
\text { interview }\end{array}$ & $\begin{array}{l}\text { No. of } \\
\text { interviews }\end{array}$ & $\begin{array}{l}\text { No. of } \\
\text { participants }\end{array}$ & $\begin{array}{l}\text { Length of } \\
\text { interviews }\end{array}$ & $\begin{array}{l}\text { Word } \\
\text { count } \\
\text { of } \\
\text { transcripts }\end{array}$ \\
\hline 2008 & teacher & Sept. 2008 & 1 & 1 & $29: 19$ & 6,780 \\
& learner & $\begin{array}{l}\text { March \& } \\
\text { June 2009 }\end{array}$ & 1 & 4 & $36: 40$ & 6,350 \\
& teacher & Oct. 2010 & 1 & 4 & $29: 34$ & 4,643 \\
& learner & March 2010 & 1 & 4 & $58: 00$ & 12,848 \\
& & 1 & 4 & $28: 25$ & 5,774 \\
& & 1 & 5 & $35: 55$ & 7,513 \\
& & & & $30: 03$ & 5,468 \\
\hline
\end{tabular}

TOTAL: $247: 56$

For the analysis of interview data, two aspects needed to be considered, that is what respondents said and how they said it. How interviewees respond to questions reflects their attitude to the interview situation, their enthusiasm, their apprehension, hesitation or reluctance, for example. This in turn determines how one has to interpret the content of their utterance. All interviews were therefore screened for these two aspects.

For the analysis of interviews, a two-step process has been suggested whereby 'the interview must be analysed as a whole before any of its component utterances are interpreted' (Briggs, 1986: 104). Each of the learner and teacher interviews was studied as a whole text first, before it was analysed in how far individual utterances 'fit into the broad communicative outlines that have been sketched for the interview as a whole' (Briggs, 1986: 105). Apart from listening to all of the conversations and reading transcripts repeatedly, contextual information about the interview situations provided by fieldnotes was also considered to gain a better understanding of how the discourse developed and how interviewer and interviewee responded to each other's comments.

One crucial aspect seemed to be the way in which both parties developed concepts of meanings, since even 'relatively straightforward' questions can leave sufficient room for different interpretations (Mishler, 1986). The interview then reflects how both parties, interviewers and interviewees, 'through repeated reformulations of questions and responses' reach a mutual understanding (Mishler, 1986: 65). According to this view, interviewer and respondent shape the meaning of 
key words as the interview unfolds. An analysis of the structure of the whole interview had to focus on how interviewees perceived questions and whether questions caused any misunderstandings that needed clarification.

Metacommunicative features, such as the visual, prosodic and verbal qualities of statements, are of relevance here. Audiotapes offered information on prosodic features, such as loudness, stress, intonation and pitch, as well as verbal features, such as the choice of lexical items, verb tenses and grammatical structures. For example, signals that were used to monitor each other's comments and ensured shared understanding, such as 'Do you really mean that?', were available for analysis (Briggs, 1986).

The study of these contextual features was seen as a means of proofreading the researcher's interpretations, and provided an alternative for techniques where participants are given the opportunity to comment on the researcher's interpretation of their remarks. The latter can easily become flawed, because 'human introspective capacities do not necessarily extend to recalling exactly what one was intending to say at some point in the past' and 'taking a tape or transcript back to the interviewee(s) creates another speech event', again shaped by contextual aspects (Briggs, 1986: 108). This last idea was especially worthwhile considering for this project. An interviewee asked to explain what they meant in the interview was likely to become self-conscious. After all, this would have been a highly artificial situation, maybe more so than the original interview. Apart from that, taking the recording or the transcript back to the interviewee would have also created organisational problems, especially in this school setting where teachers were under constant time pressure and groups of pupils may not have been able to attend further interviews due to tests, projects, day trips, or illness.

As for the analysis of what respondents said, data was screened for any information that could provide answers to research questions and that would strengthen or contradict earlier findings. With regard to learners, I was interested in finding out which activities they found popular and why, what the nature of their FL output was, if they used lexical items they had learnt in connection with songs, chants and stories, and if any traces of out-of-school exposure to the FL could be found. With regard to Ruth and Sophie, I was interested in their views of the children's verbal and non-verbal participation in songs, chants and stories, the role they attributed to repetition, visualization, acoustic cues and actions in the process of teaching the FL. 


\subsection{Results of the Analysis of Interview Data}

In the following, I will concentrate on what interviewees said, that is main issues that teachers and learners touched during interviews. The analysis of contextual features, that is the interviewee's response to being interviewed, is documented in Appendix 12.

\subsubsection{Learners' views on popular activities and their FL production}

In the analysis of individual questions there are two main areas to consider, namely what children said about their portfolio in the first phase of the interview and what kind of language they produced in the second phase of the interview.

Certain activities were named in most interviews and received more support than negative responses. One of these was drawing (Extract 20). Although learners first confirm that it does not really matter which activities they do (Turn 3), and that they like all the things they have mentioned in connection with their English lessons (7), they later unanimously state they prefer drawing (9), which was matched by children's positive attitude towards artwork in the FL classroom. Negative responses towards drawing came only from two individual children. One child in Interview 4 pointed out that while drawing meant a lot to him, he disliked colouring in. In Interview 5, one child expressed dislike about one particular artwork activity, but not on drawing or artwork in general.

\section{Extract 20: Popular activities (Interview 1/2009)}

\begin{tabular}{|c|c|c|}
\hline Turn & Interviewer & Interviewed children \\
\hline 1 & $\begin{array}{l}\text { gibt's irgendwas, was euch besser } \\
\text { gefällt? also, wenn du jetzt sagst, das } \\
\text { und das Mal'n oder jetzt eben das ... } \\
\text { is there something you prefer doing? } \\
\text { So, you say this and drawing or what } \\
\text { you just mentioned ... }\end{array}$ & \\
\hline 2 & & Cf1: [das \\
\hline 3 & $\begin{array}{l}\text { [hm, ist das egal oder is das } \\
\text { does it matter, or is it }\end{array}$ & \\
\hline 4 & & $\begin{array}{l}\text { Cf1: egal ... eigentlich egal } \\
\text { it doesn't matter ... it doesn't really } \\
\text { matter }\end{array}$ \\
\hline 5 & ${ }^{\circ}$ eigentlich egal ${ }^{\circ}$ & \\
\hline
\end{tabular}




\begin{tabular}{|l|l|l|}
\hline 6 & & Cf1: also ... \\
\hline 7 & & $\begin{array}{l}\text { Cf2: uns gefällt eigentlich alles } \\
\text { we really like everything }\end{array}$ \\
\hline 8 & $\begin{array}{l}\text { okay ... was macht euch denn in } \\
\text { Englisch am meisten Spaß? } \\
\text { okay, ... what is most fun then? }\end{array}$ & $\begin{array}{l}\text { Cn: (more than one child)) das Mal'n! } \\
\text { drawing }\end{array}$ \\
\hline 9 & & \\
\hline
\end{tabular}

Stories, songs and rhymes also received mostly positive feedback, with some of the texts being mentioned in more than one interview, such as The Three Little Pigs, Winnie the Witch and Milly the Mouse. Learners expressed their hopes that stories and books would also be part of their secondary EFL tuition in two interviews. Interestingly, it is two of the above mentioned stories that also received negative comments. One child expressed dislike about having to create a rhyme about The Three Little Pigs, and another child reported not having enjoyed the vocabulary practice in connection with Winnie the Witch:

\section{Extract 21: Children commenting on a vocabulary activity (Interview 4/2010)}

\begin{tabular}{|l|l|l|}
\hline Turn & Interviewer & Interviewed children \\
\hline 1 & & $\begin{array}{l}\text { C?: das hab' ich auch bescheuert } \\
\text { gefunden- } \\
\text { I also didn't like that- }\end{array}$ \\
\hline 2 & $\begin{array}{l}\text { das is doch Winnie the Witch, oder? } \\
\text { isn't that Winnie the Witch? }\end{array}$ & Cf1: $[\mathrm{XXX}]$ \\
\hline 3 & & Cf2: [XXX] ja \\
\hline 4 & $\begin{array}{l}\text { Cf1: XXX } \\
\text { (erzähl ma)- } \\
\text { and what were you supposed to do? } \\
\text { (tell)- }\end{array}$ & $\begin{array}{l}\text { Cf2: nee, da sollten wir halt so } \\
\text { rausfinden, wie die Sachen heißen } \\
\text { nee, we were supposed to find out what } \\
\text { the things were called }\end{array}$ \\
\hline 6 & &
\end{tabular}




\begin{tabular}{|l|l|l|}
\hline 8 & & $\begin{array}{l}\text { Cf1: }{ }^{\circ} \text { genau }^{\circ} \\
{ }^{\circ} \text { exactly }^{\circ}\end{array}$ \\
\hline 9 & $\begin{array}{l}\text { ehm ... aus-, aus'm Kopf, oder [hat } \\
\text { euch da jemand?] } \\
\text { ehm ... by, by heart, or [did } \\
\text { somebody?] }\end{array}$ & $\begin{array}{l}\text { Cf2: [aus'm Kopf] oder ma jemanden } \\
\text { fragen ... } \\
\text { [by heart] or asking someone }\end{array}$ \\
\hline 10 & $\begin{array}{l}\text { ach so } \\
\text { I see }\end{array}$ & $\begin{array}{l}\text { Cf2: so die Sachen aufschreiben, die du } \\
\text { weißt ... dann immer ... so 'ne, eine } \\
\text { Frage auf Englisch stell’n ... äh ... } \\
{ }^{\circ} \text { weiß [ich grad' nich } \\
\text { write down the things that you know ... } \\
\text { always ... a question in English ... } \\
\text { ehm ... }{ }^{\circ} \text { don't [know right now }\end{array}$ \\
\hline 12 & &
\end{tabular}

From what is being said, one can assume that the children are talking about a typical vocabulary exercise during which children have to name and label objects (Turn 7) and then ask and answer questions using these words (10). The children's negative comments support evidence from classroom discourse discussed in the previous chapter, where children were found to be less enthusiastic and even reluctant during a question-and-answer activity on the vocabulary of the story Winnie the Witch.

In fact, if one looks at the children's negative comments, a pattern emerges. The activities that attract criticism all involve writing, productive language use and decontextualization. Very often, they involve abstract thinking skills, as in a listening exercise that was perceived as a test or the above mentioned vocabulary practice. Most of the learners who were interviewed in this project favoured an environment that features artwork, stories, songs, rhymes and games with an emphasis on listening. There was only one child in Interview 5 who also expressed great interest in writing something down, especially on worksheets.

In terms of language production, the second phase of the interview was aimed at eliciting contributions in the FL from learners. An overview of learners' FL output reveals some characteristic features (Appendix 13). Most of the children's comments 
in English can be attributed to the categories animals, homes and people. However, they nonetheless also included individual words that can be linked to other categories, such as numbers or colours. Children not only answered by providing individual words, which were mostly concrete nouns that label objects or people (Appendix 13), more frequently they produced chunks of language consisting of two or more items (Table 43).

\section{Table 43: Learners' FL output}

\begin{tabular}{|l|r|r|}
\hline No. of words as part of learners' contributions in English & 1,244 & $100 \%$ \\
\hline of which individual items & 80 & $6.4 \%$ \\
\hline of which individual words that combined German \& English elements & 20 & $1.6 \%$ \\
\hline of which items as part of two-word combinations & 36 & $2.9 \%$ \\
\hline of which words as part of multi-item combinations & 1,108 & $89.1 \%$ \\
\hline
\end{tabular}

On closer inspection, one finds that children in all interview groups made use of patterns (Brewster, Ellis and Girard, 2002) or formulaic language, that is sequences with open slots (Weinert, 1995), which are combinations of syntactic elements such as ‘this is a(n) + noun' or 'a(n) + adjective + noun' (Table 44). These can be used for many different statements about various topics, e.g. 'this is a tiger', 'this is a scarf”, 'this is a birthday cake'. Other examples show that children tried to produce longer statements by extending a simple pattern (Table 44).

\section{Table 44: Examples of learners' contributions}

\begin{tabular}{|l|l|}
\hline $\begin{array}{l}\text { individual } \\
\text { items }\end{array}$ & $\begin{array}{l}\text { mouse, snail, snake, chicken, sheep, birds, tiger, straw, twigs, hay, sock, } \\
\text { kitchen, eight, three, plum, orange, lemons, yum, yes, clown, mum, dad, } \\
\text { loser, ghosts }\end{array}$ \\
\hline $\begin{array}{l}\text { two-word } \\
\text { combinations }\end{array}$ & $\begin{array}{l}\text { three sheeps, a monkey, a cat, a lion, a hat, sorry Floppy, lazy town, two } \\
\text { circles, big feet }\end{array}$ \\
\hline $\begin{array}{l}\text { multi-item } \\
\text { combinations }\end{array}$ & $\begin{array}{l}\text { This is a(n) + noun: this is a crocodile, this is a cat, this is a bear, this is a } \\
\text { bird, this is a red strawberry } \\
\text { A(n) + adjective + noun: a big tiger, a little mouse } \\
\text { Noun + is + adjective: the tree is green ... big and brown, the apple is } \\
\text { green ... or yellow ... or red } \\
\text { Noun + verb + preposition + noun: the family sit on the sofa and they } \\
\text { show pictures in the book, snowman ... stands in the snow ... with a long nose }\end{array}$ \\
\hline
\end{tabular}


Some of these patterns are more complex formulae, such as 'noun + verb + preposition + noun' or variations of it. There are also instances of children using present progressive and present simple verb forms, as in 'I'm playing the football', 'it is raining', 'Lisa ... ehm ... eats cookies' and 'the monkey has fun'. There is even scattered evidence of children using modal verbs as in 'I can [i]t [d]is' as well as negation as in 'I don’t know' (Appendix 13).

Learners used a great number of words that can be directly traced back to songs, stories and chants they learnt inside as well as outside the classroom (Table 45, Appendix 13). These include individual words, two-word combinations and multiitem sequences.

\section{Table 45: Traces of songs, chants and stories in learners' FL output}

\begin{tabular}{|l|l|}
\hline Songs & $\begin{array}{l}\text { who's afraid of the big bad wolf, the big bad wolf, the big bad wolf } \\
\text { I'm sailing } \\
\text { it's raining men } \\
\text { we are family ... I brought all my sisters with me }\end{array}$ \\
\hline Chants & football ... football \\
\hline Stories & $\begin{array}{l}\text { this is a story ... go away Floppy, look at me mum, big feet (graded readers) } \\
\text { it is raining and Lisa ... and Lisa is, Lisa take an umbrella and will go out (April } \\
\text { Weather) } \\
\text { this is the house of Milly (and) her hat (Milly the Mouse) } \\
\text { this is the story of the giant (The Smartest Giant in Town) } \\
\text { and I huff ... and I puff and I blow your house down (The Three Little Pigs) }\end{array}$ \\
\hline
\end{tabular}

In fact, the chunks of language that can be linked to the teaching of stories or songs as observed during 2008 and 2009 or to familiar pop songs that children must have come across through the media are among the most complex sequences that children produced. Of course, most of this is language that has been reproduced. It is memorized language rather than genuine language produced by the learner, such as sequences from The Three Little Pigs story and the accompanying song, which children from Ruth’s class started singing in all three interviews (Extract 22). 
Extract 22: Learners start singing (Interview 5/2010)

\begin{tabular}{|c|c|c|}
\hline Turn & Researcher & Learners \\
\hline 1 & & Cf1: [d]is is the three little pigs \\
\hline 2 & $\begin{array}{l}\text { hmhm ... und was mach 'n } \\
\text { die 'n da? hmhm ... and what } \\
\text { are they doing? }\end{array}$ & \\
\hline 3 & & Cf1: tanzen they are dancing \\
\hline 4 & $\begin{array}{l}\text { hmhm ... und was mach'n die } \\
\text { noch? hmhm ... and what else } \\
\text { are they doing? }\end{array}$ & \\
\hline 5 & & Cf2 ((trilingual child): ${ }^{\circ}$ celebrate ${ }^{\circ}$ \\
\hline 6 & & $\begin{array}{l}\text { Cf1: }{ }^{\circ} \text { sie freu’n sich they are happy ... sie sind } \\
\text { happy they are happy }\end{array}$ \\
\hline 7 & & Cf3: happy ... sind se happy ... they are \\
\hline 8 & they are [happy & \\
\hline 9 & & $\begin{array}{l}\text { Cf?: [ }{ }^{\circ} \text { da ham wir so ’n Lied gesung' ... dazu } \\
\text { ham wir 'n Lied we had a song ... we sang a } \\
\text { song with that }{ }^{\circ} \text { - }\end{array}$ \\
\hline 10 & & $\begin{array}{l}\text { Cn ((singing)): who's afraid of the big bad wolf, } \\
\text { the big bad wolf, the big bad wolf ... who's } \\
\text { afraid of the big bad wolf lalalalala }\end{array}$ \\
\hline
\end{tabular}

Still, reproduced language is language nonetheless that can be used whenever appropriate and more importantly it can be taken apart, and various elements of the phrase, such as 'afraid of' or 'let (someone) in', can later be re-assembled with other chunks of language. In fact, if we look at children's contributions that can be linked to April Weather, this procedure of dismantling and 'recycling' is already visible. Children produced multi-item sequences, such as '[d]is is a umbrella, this is a scarf and it k[e]ps warm', 'when you put this on ...[then]... is eh... don't so cold' and 'Lisa ... take an umbrella and will go out' (Appendix 13, Table 45). Here, individual words and short phrases, such as 'umbrella', 'put on', 'take an umbrella' and 'go out', are interwoven with either new linguistic chunks or ones derived from other situations.

There is a lot of other language produced by the children in the interviews, for example ‘this is the Easter Bunny' and 'music man' (Appendix 13), that seems to be reminiscent of songs, rhymes and chants that were taught, but of course it is 
problematic to attribute the learning of individual words that might also have come up in other lessons to one particular text. This is especially the case since not all EFL lessons that these children were ever taught have been observed.

Of special interest in this respect are references that children made to English texts they experience every day outside their classroom. They live in a globalised world where texts such as television programmes, advertisement, songs or electronic documents that contain technical terms provide them with English-speaking input. Simple examples are the term 'lazy town' that one child used in Interview 2 or the brand name 'Apple' that occurred in Interview 3. More elaborate references, however, can also be found and they include multi-word sequences from pop songs, such as 'I am sailing', 'it is raining men' or 'we are family ... I brought all my sisters with me', all of which learners started singing. Interestingly, these references were still very much embedded in the context in which the children had experienced them. Although they did not dismantle these multi-word strings or decontextualize parts of the sequence, but used them as unanalysed chunks, they did use them with purpose, that is to say whenever it was appropriate, for example, when someone chose a picture of a sailing boat, a picture of a rainy day or a family.

However, learners were not always able to reproduce language from texts that they had encountered. This became obvious when learners chose to talk about The Smartest Giant in Town. In two interviews conducted twelve months after they had been exposed to the picture book once, three cards each showing a scene from The Smartest Giant in Town were chosen by children to talk about. In each case, individual children displayed a partial knowledge of the storyline (Extract 23). First, there is a bewildered 'what?' coming from more than one child $(3,4)$ when one child can name the title of the story (1). However, the child who picked the card remembers the plot, and his comment acts as a prompt (7). The others start to reactivate their knowledge as well and together the children jointly reconstruct the storyline, helping each other out as they go along (9-17). There is also some English embedded in the children's responses $(1,4,18-20)$. In Turns 18-20, the children try to remember the correct pronunciation of the word giraffe, but they have difficulties, which also occurred in the other interview with respect to cards featuring The Smartest Giant in Town. However, learners demonstrate a sound memory of the plot, which could also be observed for other texts. Learners made correct comments on the storyline of The Three Little Pigs and Winnie the Witch. They also summarized the graded readers Big Feet, Look at Me and Go Away Floppy. 
Extract 23: Responding to card featuring giant George (Interview 3/2010)

\begin{tabular}{|c|c|c|}
\hline Turn & Researcher & Learners \\
\hline 1 & & Cm1: this is the story of the giant $=$ \\
\hline 2 & $=\mathrm{ah} !$ & \\
\hline 3 & & Cn: was? was? what? \\
\hline 4 & & Cm2: was? what? the story of the...was? what? \\
\hline 5 & & Cm1: giant \\
\hline 6 & $\begin{array}{l}\text { giant ... weißt du } \\
\text { noch, was da do you } \\
\text { know, what- }\end{array}$ & \\
\hline 7 & & $\begin{array}{l}\text { Cm1: ja ... der is in die Stadt gegangen, da hat er 'ne Gir- } \\
\text { Giraffe ge ... getroffen, da hat er ihr den Schal gegeben, } \\
\text { weil ihr Hals frierte yes ... he went into town where he met } \\
\text { a giraffe, he gave her his scarf, because the giraffe had a } \\
\text { cold neck = }\end{array}$ \\
\hline 8 & & $\mathrm{C} ?:=\mathrm{hm} !$ \\
\hline 9 & & $\begin{array}{l}\text { Cm1: dann hat er ... dann noch ...'n Hund getroffen then } \\
\text { he met a dog = }\end{array}$ \\
\hline 10 & & Cm2: = dem hat er den Schuh gegeb- he gave him a shoe- \\
\hline 11 & & C?: nein! no! \\
\hline 12 & & C?: dem Fuchs hat er den Schuh gebe he gave it to the fox $=$ \\
\hline 13 & & $\begin{array}{l}\mathrm{C} ?:=\text { nein, den Mäusen hat er den Schuh gegeben no, he } \\
\text { gave it to the mice= }\end{array}$ \\
\hline 14 & & $\begin{array}{l}\text { Cm: = ja den Mäusen für das Haus yes, the mice for the } \\
\text { house }\end{array}$ \\
\hline 15 & & $\begin{array}{l}\text { Cf: ja, weil die abgebrannt waren yes, because it had burnt } \\
\text { down }\end{array}$ \\
\hline 16 & & $\begin{array}{l}\text { Cm: dann hat er dem Hund den ... ich glaube ... den Gürtel } \\
\text { gegeben then he gave his belt to the dog I think [...] }\end{array}$ \\
\hline 17 & $\begin{array}{l}\text { und ... ehm ... wisst } \\
\text { ihr noch das Wort für } \\
\text { Giraffe? and do you } \\
\text { remember the word } \\
\text { for giraffe? }\end{array}$ & \\
\hline 18 & & Cm: [g]iraffe oder irgend or something like [was that \\
\hline 19 & & Cm: [dzI] raffe \\
\hline 20 & & C?: [dzaI]raffe \\
\hline
\end{tabular}


Another characteristic feature of children's contributions in the FL was the use of their native language or the language used at school, namely German, whenever there was not an appropriate English word available to them, as in '[t]is is a ... ehm ... Bild', 'this is a story ... von ... XXX bikes' and 'in the night ... in the XXX ... Burg' (Appendix 13). In all of these examples, there is a pause prior to the use of German, which suggests that children were trying to think of or remember a word in the FL. While it might be tempting to conclude that children made use of German whenever they realized that they did not know the proper English word, this might be too simplistic. Other examples of children's statements in these interviews show that sometimes a German word was used in a sequence of English spoken at normal speed without any pauses and hesitations before the use of German, e.g. 'this sin grandma and ... Grandpa' or 'and two sticks als Hand'. Instances of L1 use such as these could be explained in two ways, namely either that children were not even aware of the fact that they were codeswitching in the middle of an utterance, due to the fact that they were only concentrating on expressing meaning, or that from the start they set out to get information across, even if that involved occasional use of the native language. In the latter case, codeswitching between L1 and FL would have to be regarded as strategic, as has also been suggested for emergent bilingual writing in primary schoolchildren (Gort, 2006 and 2012). Whether codeswitching is always conscious and therefore used strategically or maybe at times also unintended and unconscious, especially in oral communication, it does occur as a characteristic feature of emergent fluency in the FL in these interviews.

Noticing a word and its usefulness alongside retrieval of its meaning and form are considered essential ingredients in the learning of new vocabulary (Nation, 2001). From this perspective, incidents that display children becoming aware of or trying to retrieve a word in the FL can shed some light on the mechanisms at work during these stages of the word learning process (Extracts 24 and 25). 
Extract 24: Children retrieving an individual word (Interview 1/2009)

\begin{tabular}{|l|l|l|}
\hline Turn & Interviewer & Interviewed children \\
\hline 1 & & $\begin{array}{l}\text { Cf: ehm ... XXX was heißt das? } \\
\text { ehm ... XXX what is that in English? }\end{array}$ \\
\hline 2 & $\begin{array}{l}\left((\text { whispering) })^{\circ} \text { strawberry ... }\right. \\
\text { strawberry, yes ... strawberry }\end{array}$ & \\
\hline 3 & & Cf: this is a strawberry \\
\hline 4 & hmhm & Cf: and a strawberry is yummy \\
\hline 5 & & \\
\hline
\end{tabular}

The above extract is an example of a situation in which one of the learners realizes that she does not know the word for 'strawberry' in English and communicates that to the interviewer (Turn 1), who provides her with the word she is looking for (2). The learner's response in Turn 3, however, is not a simple repetition of what the researcher has said but a grammatically correct sentence suggesting that the word 'strawberry' was indeed familiar to the child. She seems to recognize it immediately, and uses it in a multi-word sequence (3) that she even extends in Turn 5, illustrating her confidence. This is not unusual. Children tended to retrieve or reproduce words relatively quickly once help was offered. The above mentioned example is also not the only incident where a child instantly incorporated a word into a longer utterance (Extract 25).

\section{Extract 25: Children learning from one another (Interview 5/2010)}

\begin{tabular}{|c|c|c|}
\hline Turn & Interviewer & Interviewed children \\
\hline 1 & & $\begin{array}{l}\text { Cf1: ja ... ehm ... }{ }^{\circ} \text { was heißt 'n Wolke auf Englisch? } \\
\text { yes ... ehm ... }{ }^{\circ} \text { what do you say for cloud in English? }\end{array}$ \\
\hline 2 & & Cf2: ${ }^{\circ}$ cloud $^{\circ}$ \\
\hline 3 & cloud, hmhm & \\
\hline 4 & & Cf1: [d]is is a cloud and sun \\
\hline
\end{tabular}

There was also a tendency to repeat 'rediscovered' words or chunks more than once and by different children, not only the one who asked for help (Extract 26). 
Extract 26: Children retrieving a chunk of language (Interview 3/2010)

\begin{tabular}{|l|l|l|}
\hline Turn & Interviewer & Interviewed children \\
\hline 1 & & Cm1: und da pustet er das Haus weg \\
\hline 2 & he's blowing the house down, hmhm & $\begin{array}{l}\text { Cm2: and I huff ... [and I puff and I blow } \\
\text { your house down }\end{array}$ \\
\hline 4 & & $\begin{array}{l}\text { Cn: ((joining in)) [and I puff and I blow } \\
\text { your house down }\end{array}$ \\
\hline
\end{tabular}

The tendency to repeat individual words or phrases that caused difficulty in retrieval was not limited to chunks of language taken from songs, stories or chants. This pattern also occurred in the retrieval of 'ordinary' vocabulary:

\section{Extract 27: Children using analytic thought for retrieval (Interview 3/2010)}

\begin{tabular}{|c|c|c|}
\hline Turn & Interviewer & Interviewed children \\
\hline 1 & & Cm1: I am flying \\
\hline 2 & aha- & \\
\hline 3 & & $\begin{array}{l}\text { Cm2: flyer ... Flieger heißt flyer, oder? } \\
\text { flyer ... plane is flyer, isn't it? }\end{array}$ \\
\hline 4 & it's a plane & \\
\hline 5 & & Cm: plane \\
\hline 6 & $\begin{array}{l}\text { that's correct ... I'm flying ... wenn } \\
\text { ma-, wenn man jetzt zum Beispiel } \\
\text { wie ein Vogel fliegt, würde man das } \\
\text { so sag'n } \\
\text { [...] if you-, if you fly like a bird for } \\
\text { example, then you'd say that }\end{array}$ & \\
\hline 7 & & Cm: cool! \\
\hline 8 & $\begin{array}{l}\text { ja ... oder I'm on a plane ... ich bin } \\
\text { im Flugzeug ... I'm on a plane } \\
\text { yes or I'm on the plane ... I'm on the } \\
\text { plane ... I'm on the plane }\end{array}$ & \\
\hline 9 & & Cm: I'm on the plane \\
\hline 10 & hm ... on a plane, yeah & \\
\hline 11 & & Cm: [d]is is a plane- \\
\hline
\end{tabular}


This example reveals how one learner was trying to retrieve the correct word. Using his classmate's comment as a starting point (Turn 1), he concludes that the noun that is linked to the verb 'to fly' has to be formed using the suffix '-er', which indeed is the case for one of the nouns that can be derived from the verb 'to fly' and that has several meanings, including a 'vehicle that moves very quickly' according to the Oxford Advanced Learner's Dictionary (1989: 468). The individual word 'plane' (5) is repeated and the phrase 'I'm on a plane' changed to 'I'm on the plane' (9). The learners then offer a new chunk of language that incorporates the word 'plane' (11). Learners demonstrate considerable confidence in using a word that was either new to them or that they had forgotten.

In general, one can conclude that the interviews with children exhibit high levels of motivation and enthusiasm for the learning of English. Data from different interviews have shown that the learners played an active part in the development of the interview discourse. They made positive comments on their EFL sessions, and seemed to be particularly fond of a playful and contextualized learning environment that involved songs, stories and artwork, while they expressed dislike of more formfocused and decontextualized language practice. In terms of their FL output, one can say that there is ample evidence of them using not only individual words, with an emphasis on concrete nouns, but also multi-word sequences in the form of unanalysed chunks of language or reassembled stretches of broken-up phrases. There are traces of language in children's speech that they encountered in connection with stories, songs and rhymes or chants. Moreover, their FL output is characterized by the occasional use of German, confident reproduction of any English vocabulary that is offered to them by the adult interviewer or another child, and a tendency to incorporate these words into longer utterances quickly.

\subsubsection{Teachers' views on learner participation, visualization and acoustic cues}

In the following, I will concentrate on a selection of extracts from both teacher interviews to analyse Ruth's and Sophie’s views on characteristic learner behaviour as observed in the primary EFL classrooms of the school under study.

One of these typical features of learner behaviour was their response to the texts, which was mostly characterized by enthusiasm and tolerance towards extended FL input, as in instances of storytelling. In the interview with Sophie, she was asked if children always showed a high degree of engagement in EFL sessions, and in reply she stressed age-related aspects (Extract 28). According to her, learners 
demonstrate great enthusiasm for English because sessions are packed with activities they enjoy at that particular age, such as storytelling, playing games, using rhymes and singing.

Extract 28: Learner participation and popular activities (Teacher Interview 1)

\begin{tabular}{|c|c|c|}
\hline Turn & Interviewer & Interviewed Teacher: Sophie \\
\hline 1 & $\begin{array}{l}\text { [...] also ... was mir beim } \\
\text { Transkribieren aufgefallen } \\
\text { ist, ist, dass die Kinder so } \\
\text { enthusiastisch sind, also ... } \\
\text { ehm, dass sie, sie schein' } \\
\text { unheimlich begeistert zu } \\
\text { sein, und ich frag' mich } \\
\text { jetzt, ob das immer so ist } \\
\text { bei Englisch, ... [...] [...] } \\
\text { what struck me during the } \\
\text { process of transcription is } \\
\text { that the children are very } \\
\text { enthusiastic and I wonder if } \\
\text { that is always the case in } \\
\text { English ... [...] }\end{array}$ & \\
\hline 2 & & $\begin{array}{l}\text {... hm ... also ich glaube, Grundschüler sind } \\
\text { schon sehr begeisterungsfähig, je nachdem, wie } \\
\text { man ... das Ganze aufzieht, sind die ... bei vielen } \\
\text { Themen total dabei und Englisch ist natürlich, } \\
\text { hm, 'n Fach, wo, wo viele Sachen gemacht } \\
\text { werden, die Kinder total gerne machen = } \\
\text { I believe that primary children are generally } \\
\text { enthusiastic depending how something is } \\
\text { presented to them ... many topics appeal to them } \\
\text { and English is of course a subject where there } \\
\text { are a lot of activities that they enjoy= }\end{array}$ \\
\hline 3 & $=\mathrm{hm}=$ & \\
\hline 4 & & $\begin{array}{l}\text { = Bilderbücher lesen, hm, neue Sachen lernen. } \\
\text { die sind auch ganz stolz auf ihr Englisch. also } \\
\text { das macht auch schon was aus = } \\
\text { reading picture books, learning new things, they }\end{array}$ \\
\hline
\end{tabular}




\begin{tabular}{|c|c|c|}
\hline & & are also very proud of their English= \\
\hline 5 & $=\mathrm{hm}=$ & \\
\hline 6 & & $\begin{array}{l}\text { = neue Wörter zu lernen und ... ja dann macht } \\
\text { man viel Spiele, viel Reime, man singt. das sind } \\
\text { Sachen, das machen die gerne und deswegen } \\
\text { machen die auch ... fast alle gerne Englisch. } \\
\text { also, ich glaube, mir fällt jetzt eigentlich } \\
\text { niemand ein, der das nicht gerne macht = } \\
\text { learning new words and ... you do a lot of } \\
\text { games, many rhymes, you sing. all of these are } \\
\text { things that most of them enjoy and that's why } \\
\text { they ... almost all enjoy English , well, I think I } \\
\text { can't think of anyone who doesn't enjoy that= }\end{array}$ \\
\hline 7 & $=\mathrm{hm}=$ & \\
\hline 8 & & $\begin{array}{l}\text { = von den Kindern und ich glaube, das hängt mit } \\
\text { dem Alter der Kinder zusammen, aber auch mit } \\
\text { dem Fach Englisch = } \\
=\text { and I think that has to do with their age but } \\
\text { also with the subject= }\end{array}$ \\
\hline
\end{tabular}

In the interview with Ruth, I addressed the tolerance to extended FL input. Children had been observed listening to stories presented in English attentively, such as the picture book The Smartest Giant in Town. Ruth explained children's involvement by referring to aesthetic aspects of the texts that address different senses (Extract 29). She attributes high levels of engagement to the use of pictures, such as illustrations or flash cards and to the rhythmic nature of the language that is a result of repetitive language, both of which mean that the text can be enjoyed visually and acoustically. Ruth also highlights the fact that stories touch their audience emotionally, because they relate to aspects of our lives.

\section{Extract 29: Learners' engagement \& aesthetic qualities (Teacher Interview 2)}

\begin{tabular}{|l|l|l|}
\hline Turn & Interviewer & Interviewed Teacher: Ruth \\
\hline 1 & [...] bei den Geschichten is mir & \\
& das ganz stark aufgefall'n, wie & \\
& konzentriert die [Kinder] doch & \\
& war'n [...] it was especially & \\
\hline
\end{tabular}




\begin{tabular}{|c|c|c|}
\hline & $\begin{array}{l}\text { evident during storytelling, } \\
\text { how focused they [children] } \\
\text { were }[. . .]\end{array}$ & \\
\hline 2 & & $\begin{array}{l}\text { ich glaub’, je mehr Kanäle ma anspricht, um so } \\
\text { konzentrierter sind die = } \\
\text { I think the more modes of presentation one } \\
\text { uses the more concentrated they are = }\end{array}$ \\
\hline 3 & $=\mathrm{hm}=$ & \\
\hline 4 & & $\begin{array}{l}\text { = also des is ja wirklich bei den Geschichten is } \\
\text { es ja ... also die Bilder zu gucken, dann hat ma } \\
\text { ja oft auch Flash-Cards noch dabei und dann } \\
\text { hört ma, dann is oft in den Bilderbüchern, } \\
\text { kommt oft was vor, was sich wiederholt in' } \\
\text { bestimmten Rhythmus ... also der ganze } \\
\text { Körper is dabei = } \\
\text { = well with the stories .... well, looking at the } \\
\text { illustrations, very often there are also flash } \\
\text { cards and then listening, in picture books there } \\
\text { are bits that are repeated in a certain } \\
\text { rhythm ... and the whole body is involved }\end{array}$ \\
\hline 5 & $=\mathrm{hm}=$ & \\
\hline 6 & & $\begin{array}{l}\text { = mit Rhythmus ... dann sehr emotionale, } \\
\text { affektive Aspekt, ne? = } \\
=\text { with rhythm ... then there is the emotional, } \\
\text { affective dimension, isn't there? = }\end{array}$ \\
\hline 7 & $=\mathrm{hm}=$ & \\
\hline 8 & & $\begin{array}{l}\text { = die Geschichte, die-, das hat immer was mit } \\
\text { dem Lebe zu tue = } \\
=\text { the story, the-, that has to do with life = }\end{array}$ \\
\hline
\end{tabular}

Learners' high level of engagements was manifest in their determination to participate verbally and non-verbally in the presentation or performance of the text, which seemed to be an automatic and involuntary response by the children. Sophie pointed out that she placed great importance on giving children the opportunity to join in verbally (Extract 30). She starts her response in an anecdotal tone and with a slightly narrative style in Turn 9. She talks about a time when she observed the lack 
of joint speaking in the teaching of a teacher trainee, and suggests that repetition of what has been said helps children to remember new vocabulary.

\section{Extract 30: Sophie on children's verbal participation (Teacher Interview 1)}

\begin{tabular}{|c|c|c|}
\hline Turn & Interviewer & Interviewed Teacher: Sophie \\
\hline 1 & $\begin{array}{l}\text { hm, ich hab’ auch den Eindruck } \\
\text { gehabt, dass dieser Enthusiasmus, } \\
\text { der hat sich besonders darin gezeigt, } \\
\text { dass sie ... nachsprechen wollten = } \\
\text { I had the impression that the } \\
\text { children's enthusiasm manifested } \\
\text { itself in their eagerness to imitate } \\
\text { language = }\end{array}$ & \\
\hline 2 & & $=\mathrm{hmhm}=$ \\
\hline 3 & $\begin{array}{l}=\text { und zwar immer ... egal, ob sie } \\
\text { eigentlich zuhören woll- ... sollten = } \\
=\text { and that always ... whether they } \\
\text { were supposed to just listen = }\end{array}$ & \\
\hline 4 & & $=\mathrm{hmhm}=$ \\
\hline 5 & $\begin{array}{l}=\text { oder, oder nicht, sie haben sofort } \\
\text { probiert nachzusprechen = } \\
=\text { or, or not, they have tried to } \\
\text { imitate language immediately = }\end{array}$ & \\
\hline 6 & & $\begin{array}{l}=\text { genau }= \\
=\text { exactly }=\end{array}$ \\
\hline 7 & $\begin{array}{l}=\text { und ehm ... ... ja, wie ... wie } \\
\text { wichtig ist dir das ... dass das } \\
\text { Nachsprechen auch wirklich seinen } \\
\text { Platz hat im Englischunterricht- } \\
=\text { and ... yes, how important is that } \\
\text { to you ... that imitating language is } \\
\text { part of an English lesson- }\end{array}$ & \\
\hline 8 & & $\begin{array}{l}\text { wichtig ... also ich hab’s jetzt grad } \\
\text { noch mal gemerkt, hm, als ich der } \\
\text { Praktikantin zugeguckt hab’, die das } \\
\text { oft ... weggelassen hat und da hab } \\
\text { ich ... dann noch hinter(her) immer } \\
\text { dran erinnert, dass ich’s ganz wichtig }\end{array}$ \\
\hline
\end{tabular}




\begin{tabular}{|l|l|l|}
\hline \multicolumn{1}{|l|}{} & & $\begin{array}{l}\text { finde, dass die Kinder das nachsprechen } \\
\text { können = } \\
\text { important ... well, I have noticed that } \\
\text { recently as I watched our teacher } \\
\text { trainee who didn't make use of it and I } \\
\text { have ... reminded her always that I find } \\
\text { that important that children get the } \\
\text { chance to imitate language }=\end{array}$ \\
\hline 9 & $=$ hm = & [aha, okay, hm ... \\
\hline 10 & $\begin{array}{l}\text { = weil sonst die Wörter ganz schnell } \\
\text { weg sind, die könn' sich die nich } \\
\text { merken ... also 's is schon schwierig } \\
\text { sich die zu merken, wenn sie sie } \\
\text { nachgesprochen hab'n, aber wenn das } \\
\text { keinen Platz hat, dann sind die Wörter } \\
\text { sofort [wieder weg } \\
=\text { because the words get lost very } \\
\text { quickly otherwise, they can't remember } \\
\text { them ... it is already difficult enough for } \\
\text { them to remember them even if they } \\
\text { repeated them, but if there is no room } \\
\text { for imitating language, then they forget } \\
\text { the words [immediately }\end{array}$ \\
\hline
\end{tabular}

The extent to which children participated in the performance of songs, chants and stories sometimes even surprised teachers. Sophie, for example, admits to having been apprehensive about using a DVD because she thought her learners might be overexcited and because she did not expect children to join in easily (Extract 31). She expresses her astonishment about the children's eagerness to participate (12) and their ability to comprehend a native speaker in an authentic TV programme (5). According to Sophie, the visual stimuli in the form of maps, pictures and actions provided by the audiovisual material supported comprehension (5), but also and maybe more importantly for Sophie, because she mentions that several times, her learners were spurred on by the authenticity of the text, and the experience of 
having watched a piece of English TV had a positive impact on their selfconfidence $(1,3,9)$.

\section{Extract 31: Children's response to the Weather Song (Teacher Interview 1)}

\begin{tabular}{|c|c|c|}
\hline Turn & Interviewer & Interviewed Teacher: Sophie \\
\hline 1 & & $\begin{array}{l}\text { = also, das is jemand, der spricht Englisch ... das würden } \\
\text { englische Kinder auch gucken oder amerikanische Kinder } \\
\text { auch gucken = } \\
=\text { well, there is someone who is speaking English ... } \\
\text { English or American children would also watch this = }\end{array}$ \\
\hline 2 & $=\mathrm{hm}=$ & \\
\hline 3 & & $\begin{array}{l}=\text { also, ich glaube, das is so 'n bisschen das Faszinierende } \\
\text { dabei = } \\
=\text { well, I think that is the fascinating bit about it }=\end{array}$ \\
\hline 4 & $=\mathrm{hm}=$ & \\
\hline 5 & & $\begin{array}{l}\text { = und wie viel sie auch verstanden hab’n ... das war } \\
\text { natürlich auch unterstützt mit diesen Karten und den } \\
\text { Bildern = } \\
=\text { and how much they understood ... of course that was } \\
\text { supported by the maps and the pictures = }\end{array}$ \\
\hline 6 & $=\mathrm{ja}=$ & \\
\hline 7 & & $\begin{array}{l}=\text { und den Bewegungen ... aber sie war'n, glaub ich, } \\
\text { auch schon ganz stolz hinterher = } \\
=\text { and the actions ... but I think they were really proud } \\
\text { afterwards = }\end{array}$ \\
\hline 8 & $=\mathrm{hm}=$ & \\
\hline 9 & & $\begin{array}{l}\text { = sie ham englisches Fernseh'n geguckt und sie ham's } \\
\text { verstand'n ... und jetzt könn se auch sogar noch was } \\
\text { davon [...] } \\
=\text { they watched English TV and they understood it ... and } \\
\text { now they can even do some of that themselves [...] }\end{array}$ \\
\hline \multicolumn{3}{|l|}{$[\ldots]$} \\
\hline 10 & & $\begin{array}{l}\text { also, dass ich dachte, das wird dann schwierig vorm } \\
\text { Fernseher, wo alles sowieso so aufregend is = } \\
\text { well, I thought that would be difficult in front of the TV } \\
\text { with everything being so exciting = }\end{array}$ \\
\hline 11 & $=\mathrm{hm}=$ & \\
\hline
\end{tabular}




\begin{tabular}{|l|l|l|}
\hline 12 & & $\begin{array}{l}\text { = sie auch noch dazu zu kriegen, dass sie ... ehm ... das } \\
\text { mitmachen, aber das war ja dann erstaunlicherweise gar } \\
\text { nich so. die war'n ja so gebannt davon, dass es- } \\
\text { = and to get them to ... ehm ... to join in, but that was } \\
\text { surprisingly not an issue at all. they were mesmerized that } \\
\text { it- }\end{array}$ \\
\hline 13 & $\begin{array}{l}\text { das hätte man } \\
\text { glaub' ich- } \\
\text { I think one could } \\
\text { have- }\end{array}$ & $\begin{array}{l}\text { super war }= \\
\text { was super }=\end{array}$ \\
\hline 14 & $\begin{array}{l}\text { mehrmals } \\
\text { abspiel'n könn' }= \\
\text { = watched it } \\
\text { several times } \\
\text { without a break }=\end{array}$ & $\begin{array}{l}\text { ohne Stopp } \\
\text { wa! ... [die (hätten) immer mitgemacht }\end{array}$ \\
\hline 16 & yeah! [and they (would have) still joined in \\
\hline
\end{tabular}

In the above extract, Sophie assumes that learners would have enjoyed repeated encounters with the video clip (13 \&15). Indeed, children’s enjoyment in repeated encounters of texts that sparked their interest was observed frequently in the classrooms and was another characteristic feature of learners' response to songs, chants and stories. Ruth makes a very similar point when I asked her how children responded to using the same stories more than once (Extract 32). In Ruth's experience, children seem to tolerate more repeated encounters with stories than she expects them to (1), which, as she suggests, might be an age-related phenomenon, since she cannot imagine adolescents to respond in that way to repetition (3).

\section{Extract 32: Repeated encounters with stories (Teacher Interview 2)}

\begin{tabular}{|l|l|l|}
\hline Turn & Interviewer & Interviewed Teacher: Ruth \\
\hline 1 & & $\begin{array}{l}\text { also ich mach` die Erfahrung, dass die Kinder öfter } \\
\text { Geschichte hör’n könn` wie ich des vermut’ } \\
\text { well I find that children can listen to a story more often }\end{array}$ \\
\hline
\end{tabular}




\begin{tabular}{|l|l|l|}
\hline & & than I think \\
\hline 2 & hmhm & \\
\hline 3 & & $\begin{array}{l}\text { ich glaub', dass das bei Jugendliche, wenn se älter werd'n } \\
\text { schwieriger wär', dass e-, dass die mehr verlangen-, mehr } \\
\text { so auf Neues aus sind = } \\
\text { I think that this would be difficult with adolescents, when } \\
\text { they grow older, that-, that they demand, prefer } \\
\text { something new }=\end{array}$ \\
\hline 4 & $=$ ah, okay $=$ & \\
\hline
\end{tabular}

Ruth later refers to the graded readers Big Feet, Go Away Floppy, Kipper's Diary and Look at Me and stresses again children's enjoyment in repeated readings of these books (Extract 33). Children not only read these texts for themselves, they also enjoyed reading them out aloud to others (Turns 1 and 5), which seemed to boost their confidence (3). This is especially important to Ruth, it seems, because she emphasizes the fact that among these children there were learners who had learning difficulties (5).

\section{Extract 33: Repeated encounters with graded readers (Teacher Interview 2)}

\begin{tabular}{|c|c|c|}
\hline Turn & Interviewer & Interviewed Teacher: Ruth \\
\hline 1 & & $\begin{array}{l}=\text { ich weiß nit, wie oft die das gemacht ham } \\
=\text { I don't know how often they did that }\end{array}$ \\
\hline 2 & $\begin{array}{l}\text { ich hab’ auch gestaunt- } \\
\text { I was also amazed- }\end{array}$ & \\
\hline \multicolumn{3}{|l|}{$[\ldots]$} \\
\hline 3 & & $\begin{array}{l}\text { die war'n so stolz }= \\
\text { they were so proud }=\end{array}$ \\
\hline 4 & $\begin{array}{l}=\mathrm{ja}= \\
=\text { yes }=\end{array}$ & \\
\hline 5 & & $\begin{array}{l}\text { = die konnten das irgendwann lesen. da war'n ja } \\
\text { Kinder dabei, die ja wirklich Lernschwierigkeiten ham } \\
\text { und die ham das dann-, konnten das lesen ... ich weiß } \\
\text { nit, wie oft die das jemandem vorgelesen ham } \\
=\text { they were able to read that. there were children with } \\
\text { learning difficulties and they could-, could read that ... } \\
\text { I don't know how often they read this to someone }\end{array}$ \\
\hline
\end{tabular}


The high levels of involvement in children as observed and commented on by both teachers when children experience songs, chants and stories repeatedly are, however, in stark contrast to learners' behaviour during form-focused language work that also aims at repeating language items.

On being asked about her experience with different EFL teaching practices over the years, Ruth points to decontextualized vocabulary training (Extract 34). In her response, she highlights that an overemphasis of cognitive aspects that seems to lead to an excessive focus on new words (Turns $7 \& 9$ ) does not seem to work. Novices to teaching, according to Ruth, sometimes lack the skill to incorporate new words so that learners can practice them naturally (9). This repetition of language through decontextualized vocabulary practice is not effective, in her experience.

\section{Extract 34: Repetition through decontextualized practice (Teacher Interview 2)}

\begin{tabular}{|c|c|c|}
\hline Turn & Interviewer & Interviewed Teacher: Ruth \\
\hline 1 & & $\begin{array}{l}\text { Vokabeltraining, reines Vokabeltraining } \\
\text { bewährt sich überhaupt net ... das hab’ ich } \\
\text { immer wieder gesehe- bei Stu-, Studierende also } \\
\text { = vocabulary practice, pure vocabulary practice } \\
\text { does not work ... I have seen that again and } \\
\text { again with stu-, students = }\end{array}$ \\
\hline 2 & $=\mathrm{hmhm}=$ & \\
\hline 3 & & $\begin{array}{l}=\text { die versucht ham so dann irgendwie ... äh ... } \\
\text { Vokabeln zu [trainier’n } \\
=\text { who tried to somehow ... ehm ... [practise } \\
\text { vocabulary }\end{array}$ \\
\hline 4 & $\begin{array}{l}\text { [wie meinst 'n du das genau? } \\
\text { was- } \\
\text { [how do you mean? what- }\end{array}$ & \\
\hline 5 & & $\begin{array}{l}\text { also ... äh ... es is ja immer schwer so-, so Ziele } \\
\text { zu formulier'n, ne? = well ... ehm ... It is always } \\
\text { difficult to formulate objectives, isn't it? = }\end{array}$ \\
\hline 6 & $=\mathrm{hmhm}=$ & \\
\hline 7 & & $\begin{array}{l}\text { = und ehm ... wenn ma so am Anfang Ziele } \\
\text { formuliert, sind die oft sehr kognitiv } \\
\text { ausgerichtet = and ehm ... if you try to } \\
\text { formulate objectives at the beginning, they are }\end{array}$ \\
\hline
\end{tabular}




\begin{tabular}{|l|l|l|}
\hline 8 & $\begin{array}{l}\text { = die Kinder sollen ... } \\
\text { ehm ... zu irgend 'nem } \\
\text { Thema ... zehn Vokabeln } \\
\text { können = the children are } \\
\text { supposed ... ehm ... to know } \\
\text { ten words ... about a topic }=\end{array}$ & often very much focused on cognitive aspects $=$ \\
\hline 9 & $\begin{array}{l}\text { = hm. und dann probier'n se’s dann auch so } \\
\text { irgendwie und ... ehm ... wissen aber auch-, ... } \\
\text { ham vielleicht auch jetzt nit die Erfahrung, wie } \\
\text { ma des so-, wie ma eigentlich ... Wörter } \\
\text { einbau'n kann, dass ma das trainiert ... so was } \\
\text { bewährt sich halt meistens überhaupt nit [...] } \\
\text { = hm and then they try that somehow ... ehm ... } \\
\text { but also know-, ... don't have the experience } \\
\text { how you-, how you ... incorporate words so that } \\
\text { you train them ... that does not work at all [...] }\end{array}$ \\
\hline
\end{tabular}

During observations, learners had also been found to make active use of visual clues, such as pictures and actions, and also acoustic clues, such as onomatopoeia, rhyme and rhythmic language, both for processing language input as well as for retrieving language chunks. On being asked about difficulties that teachers might encounter when using authentic stories, such as the picture book Froggy Gets Dressed, especially when it comes to understanding the storyline, Sophie explains that, in her experience, children do not seem to be distracted by unfamiliar words. In fact, they seem to blank out or ignore the fact that there is language that they do not understand (Extract 35). Instead, their focus is on the illustrations and on decoding them to understand what the story is about (1). They do not seem to be interested in lexical items at that moment (3 and 5).

Extract 35: Sophie on visual clues as part of storytelling (Teacher Interview 1)

\begin{tabular}{|l|l|l|}
\hline Turn & Interviewer & Interviewed Teacher: Sophie \\
\hline 1 & & $\begin{array}{l}{[\ldots] \text { das is aber oft so, dass die Kinder das eben ausblenden ... die }} \\
\text { hör'n die Geschichte, versuchen zu verstehen, sehen die Bilder ... } \\
\end{array}$ \\
& $\begin{array}{l}\text { und das is das, worum's geht = } \\
{[\ldots] \text { but that happens a lot that children blank that out ...they }}\end{array}$ \\
\hline
\end{tabular}




\begin{tabular}{|l|l|l|}
\hline & & $\begin{array}{l}\text { listen to a story and try to understand it, they look at the pictures } \\
\text { and that is what it is all about = }\end{array}$ \\
\hline 2 & $=\mathrm{hm} \mathrm{=}$ & $\begin{array}{l}\text { = die fragen nich nach einzelnen Wörtern, es sei denn es is so'n } \\
\text { Schlüsselwort, das sie wirklich brauchen, um weiter versteh'n zu } \\
\text { könn' = } \\
=\text { they don't ask about individual words, unless it is a key word } \\
\text { that they really need in order to understand = }\end{array}$ \\
\hline 4 & $=\mathrm{hmhm}=$ & $\begin{array}{l}\text { = ansonsten ... Satzstrukturen oder bestimmte Verben, Adjektive, } \\
\text { die ham kein'- ... keine Bedeutung in dem Sinne in dem Moment- } \\
=\text { other than that ... sentence structures or certain verbs, } \\
\text { adjectives, they don't have any- ... any meaning as such at that } \\
\text { moment- }\end{array}$ \\
\hline 5 & &
\end{tabular}

Ruth also stressed the importance of letting children talk about illustrations in picture books in order to foster understanding of the storyline. She also mentioned visual as well as acoustic clues in connection with repeated encounters of texts (Extract 36). In her experience, children readily join in with texts that exhibit rhythmic language coupled with pictures and actions (1 and 3). She assumes that these aesthetic qualities help to involve different senses and involve the whole learner, which sustains their interest in listening and performing, and she compares this effect to the singing of songs (3, 5 and 7$)$.

\section{Extract 36: Ruth on rhythmic language and actions (Teacher Interview 2)}

\begin{tabular}{|c|c|c|}
\hline Turn & Interviewer & Interviewed Teacher: Ruth \\
\hline 1 & & $\begin{array}{l}\text { ((talking about We Are Going on a Bear Hunt)) } \\
\text { = ja, so-, ich mach’s aber nur so über's Bilderbuch und sie rufen } \\
\text { dann halt schon alles mit, was da passiert und ... äh ... mach' da } \\
\text { gar nit so groß Action = } \\
\text { = yes, well-, I only use the picture book and they shout out with me } \\
\text { what is happening and ... ehm ... I do not use the actions = }\end{array}$ \\
\hline 2 & $=\mathrm{hm}=$ & \\
\hline \multicolumn{3}{|l|}{ [3-4] } \\
\hline 5 & & $\begin{array}{l}\text { = also, natürlich is alles was mit Rhythmus un Bewegung noch } \\
\text { gekoppelt is, das is ja wie 'n Lied, 'n Lied singt ma millionenfach, }\end{array}$ \\
\hline
\end{tabular}




\begin{tabular}{|l|l|l|}
\hline & & $\begin{array}{l}\text { also [das] macht einem ja gar nix aus, das macht ma gerne } \\
\text { = well, of course everything that is also coupled with rhythm and } \\
\text { action is, that's the same as with a song, a song you sing millions of } \\
\text { times, well [you don't mind that, you enjoy it }\end{array}$ \\
\hline 6 & $\begin{array}{l}{[\text { [ja] }} \\
\text { [yes] }\end{array}$ & $\begin{array}{l}\text { weil der ganze Körper irgendwie zum Einsatz kommt }= \\
\text { because the whole body is in action }=\end{array}$ \\
\hline 7 & $=\mathrm{hm}=$ & $\begin{array}{l}\text { = und das is natürlich bei-, bei Texten auch so ... je mehr ma } \\
\text { irgendwie involviert is, um so öfter hört man's = } \\
=\text { and that is of course also the case with, with texts .... the more } \\
\text { involved you are, the more often you listen to it }=\end{array}$ \\
\hline 9 & &
\end{tabular}

Ruth's learners had been found to reproduce song lyrics readily and confidently. On being asked to comment on that (Extract 37), she explains that they had learnt these songs as part of their music instruction with another teacher in the school year prior to the observations, and had not practised them in school afterwards, since they had a new music teacher in Year 3 (8) and there was not enough time during the English sessions (10). She suggests that her learners' ability to reproduce song lyrics may be due to the musical training they had received from Year 1 onwards (2), and supposes that they have learnt to use acoustic clues, such as rhythm and melody, for processing and memorizing texts (4 and 5).

\section{Extract 37: Ruth on learners' ability to reproduce songs (Teacher Interview 2)}

\begin{tabular}{|l|l|l|}
\hline Turn & Interviewer & Interviewed Teacher: Ruth \\
\hline 1 & $\begin{array}{l}{[\ldots] \text { ham die sich da wirklich }} \\
\text { ungefähr neun Monate nach } \\
\text { ihrem letzten Musikunterricht, } \\
\text { hattest du gesagt [...] an die } \\
\text { Lieder erinnern könn’? = } \\
\text { [...] were they really able to } \\
\text { remember the songs nine } \\
\text { months after their last music } \\
\text { lesson, that's when you said } \\
\text { they practised them [...]?= }\end{array}$ & \\
\hline 2 & \multicolumn{2}{|c|}{} \\
\hline
\end{tabular}




\begin{tabular}{|c|c|c|}
\hline & & $\begin{array}{l}\text { der Klasse is es jetzt noch ma speziell, weil die } \\
\text { so von Anfang an ... ehm ....... intensiven } \\
\text { Musikunterricht hatten ... und = yes, I think so ... } \\
\text { well, that year group of course is special, } \\
\text { because they had intensive music sessions ... } \\
\text { ehm ... from the beginning ... and = }\end{array}$ \\
\hline 3 & $=\mathrm{hm}=$ & \\
\hline 4 & & $\begin{array}{l}\text { = täglich dieses Singen-Können auch wirklich } \\
\text { gelernt ham ... und das von Anfang-, von der } \\
\text { ersten Klasse an sehr genutzt wurd', ne? } \\
=\text { they really learnt how to sing ... and from the } \\
\text { beginning, from Year } 1 \text { onwards, it was used a } \\
\text { lot, wasn't it? }\end{array}$ \\
\hline & $\mathrm{hm}$ & \\
\hline 5 & & $\begin{array}{l}\text { und das war wirklich den ihr Vorteil. die konnten } \\
\text { ganz schnell auch die Fremdsprache da } \\
\text { adaptieren ... damit ... sie ... sich schnell Texte } \\
\text { ler-, [...] im ... äh ... im Rhythmus sich was } \\
\text { merken = and that was really their advantage. } \\
\text { They could also use the foreign language } \\
\text { quickly ... that way ... quickly learn texts by } \\
\text { heart ... [...] ehm ... recall something in rhythm= }\end{array}$ \\
\hline \multirow[t]{2}{*}{6} & $=\mathrm{hm}=$ & \\
\hline & {$[\ldots]$} & \\
\hline 7 & $\begin{array}{l}\text { = aber du weißt jetzt zum } \\
\text { Beispiel nich, wie oft die die } \\
\text { Lieder vielleicht im } \\
\text { Musikunterricht ... ehm ... } \\
\text { geübt ham? = but you don't } \\
\text { know, for example, how often } \\
\text { they sang the songs during } \\
\text { their music lessons?= }\end{array}$ & \\
\hline 8 & & $\begin{array}{l}\text { = nee, die ham mit Sicherheit in der dritten } \\
\text { Klasse ni mehr so viel, weil die erschtens ma- } \\
\text { 'ne ... ehm ... andere Musiklehrerin dann da war } \\
=\text { no, they have certainly not sung them a lot } \\
\text { during their third year, because they, first of all, }\end{array}$ \\
\hline
\end{tabular}




\begin{tabular}{|l|l|l|}
\hline & & had ... ehm ... a different teacher then \\
\hline 9 & hm & \\
\hline 10 & & $\begin{array}{l}\text { und ... und das im Englischunterricht mit der } \\
\text { einen Stunde net ständig wiederholt wird = } \\
\text { and ... and we don't repeat a lot in that one hour } \\
\text { we have for English= }\end{array}$ \\
\hline
\end{tabular}

In both interviews, teachers confirmed the observation that children readily join in verbally and non-verbally in songs, chants and stories. While Sophie highlighted the importance of letting children join in and imitate language so that they can repeat phrases from stories, songs and chants, Ruth also referred to the joy of imitating language in her explanation of how learners memorize song lyrics. It is a form of 'joyful repetition' that both teachers described and that can be identified as common ground in both interviews. This is strengthened by the fact that both, Sophie and Ruth, expressed criticism of teaching practice that either ignores the importance of encouraging children's enthusiasm to imitate language during storytelling or singing, or that overemphasizes decontextualized language practice. Sophie and Ruth both identified artistic features, such as pictures, illustrations, actions or rhythmic language, as important ingredients in the teaching of songs, chants and stories as part of primary EFL. In their experience, these aesthetic qualities of the genres support learners' understanding of FL input, sustain interest during repeated encounters with these texts and encourage reproduction of language from them.

\subsection{Discussion of Findings}

The interviews provided a platform for learners and teachers to express their views on aspects of EFL practice and to respond to research findings from classroom observation. In this way, the interviews functioned as a triangulation device. Learners were also given the opportunity to produce English, which provided insights into their command of the FL. In the following, I will discuss how far interview data from participating learners and teachers can contribute to a better understanding of the use of songs, chants and stories in the primary EFL classroom. In particular, I will focus on learners' views of popular activities, on the nature of their FL output, teachers' views on learner participation and the role of repetition as well as visual and acoustic support in the teaching of songs, chants and rhymes. 


\subsubsection{Popular activities}

In the interviews, drawing, storytelling, singing and rhyming received mostly positive feedback, which confirms findings from the analysis of questionnaire and observational data, and is in line with other studies of EFL classroom practice (Roos, 2006; Harris and O’Leary, 2009). However, children expressed dislike of more form-focused and decontextualized language practice. The children's negative comments on decontextualized language practice in connection with stories support evidence from classroom observations.

Teachers also stressed that songs, rhymes, chants and stories appealed to the children on more than the cognitive level and therefore engaged them. Teachers highlighted the fact that experiencing authentic examples of these genres had a positive impact on learners' motivation and self-confidence, which has also been found in other studies of primary classrooms (e.g. Kolb, 2013). As in the learner interviews, there was doubt about an overemphasis on decontextualized vocabulary training.

\subsubsection{Long-term impact of songs, chants and stories in learners' FL output}

In the interviews, learners' FL output consisted of individual words, many of them concrete nouns, as well as multi-item sequences. The latter were mostly simple sentences, based on formulaic language, in particular sequences with open slots, or unanalysed chunks of language that they had encountered in connection with songs, rhymes, chants and stories. However, there was also some evidence of reassembled stretches of broken-up phrases that could be linked to songs, chants and stories.

Among the multi-word sequences were also lines from pop songs that the learners must have encountered outside the classroom. These multi-item sequences were still very much embedded in the context in which the children experienced them. They used them as unanalysed chunks, but with purpose, that is to say whenever it was appropriate and relevant because the picture depicted a scene that fit the lyrics of the song. The picture then triggered children's verbal response. It reminded them of the song, and they produced the equivalent language. This suggests that out-of-school exposure to the FL can have a lasting effect on learners' FL output, which has also been found in other studies with primary school EFL learners (Szpotowicz and Lindgren, 2011).

Much of this language was reproduced, or memorized language rather than genuine language produced by the learner. However, reproduced language is 
language that can be used again whenever appropriate, and it can be taken apart, and various elements of it can later be re-assembled with other chunks of language. In this way, the correct production of language chunks from songs, chants and stories can be assumed to be a first step towards a more genuine and creative use of language derived from example texts of these genres. Once example language can be produced fluently, it is also available for deconstruction and reassembling. This is a process which has also been suggested on the basis of observation in secondary FL classrooms where French learners were found to first use unanalysed chunks of language before recombining them (Mitchell and Martin, 1997). This suggestion is further strengthened by the fact that in the interviews, learners were found to readily extend their answers in the FL to create more complex statements once they had received some help. Thus they are on the verge of producing more genuine FL output, and it follows that teachers should not only create opportunities for learners to perform these texts repeatedly but also to recycle language from songs, chants and stories for their own statements in new contexts.

Reproduction or more flexible use of language from songs, chants and stories could only be attributed to texts that the learners had experienced repeatedly. For texts such as picture books that had only been encountered once there was no evidence of FL output in the interviews. However, learners still displayed partial memory of the storyline. Together they were able to reconstruct the plot, which suggests that the narrative can provide a support framework, that is a meaningful context, which is accessible over extended periods of time. If teachers create opportunities for the children to read the story again at a later time and if they help them to notice new words during these repeated encounters (Nation, 2001; Schmidt \& Frota, 1986), children are very likely to expand their vocabulary, as has been found in L2 research (Elley and Mangubhai, 1983). Therefore, the narrative code of a story can act as a form of scaffolding device that supports memory and allows language learning within a meaningful context.

\subsubsection{Learner response, multimodal features of texts and the role of repetition}

The interviews with the teachers confirmed findings from classroom observation on children's high participation levels during the teaching of songs, chants and stories.

According to the teachers' experience, the observed behaviour was not exceptional. They had experienced their learners’ enthusiasm about these genres 
before. Teachers attributed high levels of attention and participation firstly to the fact that these texts were appropriate for this age group since they addressed their need for a playful and highly engaging learning environment. Secondly, teachers pointed to the aesthetic qualities of these texts, that is illustrations, accompanying actions, rhythmic language, rhyme and melody, that appealed to the learners' different senses. These different modes of presentation offered various ways of engaging with the text. The multimodal nature of songs, chants, stories and picture books addressed the whole personality of learners, their cognitive ability, motor skills, emotional intelligence and appreciation for aesthetics, which has also been stressed in research on literature in young learners’ EFL classrooms (Ghosn, 2004; Mourão, 2012).

Learners' enthusiasm manifested itself in their tolerance of and demand for repetition. They were not only found to almost automatically repeat lexical items they recognized, they were also observed to enjoy repeated joint performances of songs, chants and stories. Teachers confirmed these observations in the interviews, and suggested that firstly this spontaneous response of repeating what has been said was essential for helping young learners remember words, and secondly that the tolerance towards repeated encounters with a text was characteristic of this age group. However, it is not repetition and form-focused practice of isolated vocabulary taken out of context that learners are willing to endure. On the contrary, it is the repetition of performing the whole text that young learners seem to enjoy. They appear to take pleasure in the aesthetic experience of the multimodal text.

\subsection{Concluding Remarks}

In this chapter, extracts from both learner as well teacher interviews have been analysed to triangulate findings from questionnaire data and classroom observations.

The contributions of children and teachers alike have shown that there was great enthusiasm to share knowledge and opinions. This supports the mostly positive attitudes towards the learning and teaching of English that were found in the data collected earlier. Other aspects that were revealed in the analysis of questionnaire and observational data were confirmed in the interviews, such as the children's joy in imitating language, their ability to recall chunks of language from stories, chants and songs, as well as the problematic issue of decontextualized word learning with regard to literary texts or songs.

The children's enthusiasm for imitating language and joining in storytelling, singing or chanting is a form of repetition, which the data suggest is favourable to 
the language learning process, both in terms of motivation as well as ability to recall words. This seems to only be true for the exposure to the whole text, while other forms of repetition, such as a repetition of individual language items isolated from the original context of the song, chant or story, can have the opposite effect.

The experience of the whole text of a song, chant or story involves the experience of all the aesthetic qualities, such as rhythmic and repetitive language, onomatopoeia, accompanying pictures, illustrations, actions or tunes. These multimodal features appealed to the learners of this study and motivated them to tolerate extended FL input, and to try to understand it. They also initiated them to join in the performance of texts and supported the recall of language from them. 


\section{Chapter 8 \\ Discussion}

The majority of data collected for this project on primary EFL classrooms was provided through recorded classroom discourse. This type of data, which was supported by questionnaire and interview data, allowed a microscopic view of the actual teaching situation, and its analysis revealed recurrent patterns of behaviour among learners and teachers.

One of the most striking features was learners' tendency to join in with accompanying actions and to imitate FL chunks immediately and unprompted. Learners were also found to exhibit contentedness with a partial understanding of a situation when confronted with songs, chants and stories, which seemed to clash with teachers' focus on linguistic aspects. Learners' focus was on the joint performance, and their verbal participation increased with repeated encounters of these texts. Moreover, learners demonstrated tolerance of extended input in the FL during instances of singing, chanting and storytelling and of repeated encounters with texts that had sparked their interest.

In the following, I will discuss in how far this learner behaviour is relevant to FL learning and which role the aesthetic qualities of songs, chants and stories play in that process.

\subsection{Imitation and FL learning}

When learners imitate words from songs, chants and stories, they repeat samples of the FL. The notion that repetition is a major ingredient in learning is far from being a new idea. There is general agreement among psychologists that for information to be recalled, it has to be passed from working memory, which functions as a 'loading platform' (Gleitman et al., 1999) and is of limited capacity (Miller, 1956), to longterm memory where more information can be stored for longer. It is rehearsal that enables this transfer to long-term memory (Gleitman et al., 1999).

With regard to FL learning, repetition has also been identified as an important instrument to defy the process of forgetting. For example, early experiments on the retention of Latin words and phrases showed that for the Year 7 learners who took part in the study, most forgetting took place in the very short interval of first encounter and immediate recall. However, the rate of forgetting 
slowed down afterwards as tests a day, one week, three weeks and eight weeks later demonstrated (Anderson and Jordan, 1928). Accordingly, suggestions were made for how repetition could be spaced in FL learning. Pimsleur's proposed memory schedule (1967), a programme of repetitions after 5 seconds, 25 seconds, then 125 seconds and so on, followed the arithmetics of exponential scales and was, in that respect, arbitrary. Still, it reflected the main idea for more repetitions shortly after the first encounter with a word and for the intervals of repetitions becoming bigger, which has been further strengthened by more recent research (e.g. Bloom and Shuell,1981; Dempster, 1987).

It must be said that the notion of spaced repetition, with a strong focus on repetition seconds after the first encounter of a word, is in agreement with psychologists' present argumentation that immediate rehearsal of new information is vital for transfer into long-term memory. The children's behaviour of immediate imitation of language items they heard, as observed in this study, has to be seen as a valuable learning mechanism that defies the process of forgetting and supports word learning. It is a behaviour that would need to be encouraged at all times, especially if one considers that short-term phonological memory plays a key role in successful FL learning.

Evidence for the impact of the phonological short-term memory (STM) on vocabulary growth has been found for both L1 and L2 learning processes. For example, the ability to repeat unfamiliar nonwords correctly was found to be the best predictor of FL learners' future performance in English (Service, 1992). In a similar way, young native speakers' ability to repeat unfamiliar nonwords at the age of four was a reliable predictor of their vocabulary knowledge at the age of 5 (Gathercole and Baddeley, 1989). However, while the dependency upon the phonological STM seems to decrease for native speakers' word growth as they get older and for L2 learners with extensive vocabulary knowledge (Gathercole, Willis, Emslie and Baddeley, 1992; Chen and Leung, 1989), this does not seem to be the case for learners who cannot rely on a sound knowledge of lexical items in the FL (Cheung, 1996). It follows that especially beginners of a foreign language depend on their phonological STM when they try to learn new words in the FL. It has been argued that this is due to the unfamiliarity of foreign words (Masoura and Gathercole, 1999).

While repeating a word's spoken form may therefore be of utmost importance in the primary EFL classroom, it is also true that the notion of repetition 
in the FL classroom has attracted criticism among educationalists. Repetition was a major ingredient in the Direct Method of FL teaching developed during the Reform Movement. Viëtor's proposed lesson plan included repeated exposure to a text in the FL presented by the teacher (Viëtor, 1905). Repetition has also played an important role in other teaching methods that evolved after the Reform Movement, such as the audiolingual method or TPR (Asher, 1969). It was especially the extensive use of pattern drill exercises as part of the audiolingual method that was criticized for its monotonous nature and its low level of cognitive involvement on the part of the learner, as 'there is nothing else to be gained from it - no academic knowledge or problem-solving ability' (Cook V, 2008: 246). This criticism seems to be confirmed by scientific evidence that deeper mental processing leads to better retention (Craik \& Lockhart, 1972). Moreover, the focus on meaningful activities in the FL classroom as a consequence of Communicative Language Teaching (Hymes, 1973; Brumfit and Johnson, 1979) has led to the rejection of monotone repetition of language patterns and scepticism towards form-focused instruction.

Yet repetition is an integral part of naturalistic language learning. The lack of exposure to natural language in an FL learning environment means that repetition becomes even more important rather than less. Even if exposure is maximized by the teacher through exclusive use of the FL, learners still only have limited opportunities to encounter a word repeatedly. It is partly through carefully planned, spaced repetition that teachers can ensure that learners have a fair chance of successful transfer of new words to long-term memory. Therefore, it seems problematic that our critical view of repetition might prevent us from making the most of this learning device.

During classroom observations carried out as part of this study, there were instances when repetition was not encouraged, as mentioned in the analysis of classroom discourse. However, children almost automatically responded by doing the actions and joining in with whatever language items they recognized or which they found easy to echo. This is reminiscent of very young children learning their L1. They also tend to pick up fragments of speech presented to them by their carers and older siblings, and then repeat them. This imitation does not occur at random, rather it seems to be restricted to language items native speakers are about to master (Lightbown and Spada, 2006). Thus, with young FL learners, even if they have 
passed the stage of echoing their environment because they have become confident users of their first language, this learning mechanism still seems to be in place.

Young children repeat what they hear, and it has been suggested that this behaviour is also evidence of the egocentricity that is characteristic of children aged between 2 and 7 according to Piaget $(1923,1959)$ and that, in fact, humans never really lose the need to use egocentric language, which might explain our predisposition to song to some extent (Murphey, 1992). It is worth considering that rhythmic language as found in other genres, such as rhymes and chants, or language that fascinates the listeners through other qualities, such as onomatopoeia or unusual choice of vocabulary in stories, might trigger this behaviour as well.

Imitating stretches of language has also been associated with the process of decoding meaning, in the sense that humans tend to repeat something when they are trying to read meaning into it (Murphey, 1992). If we understand repetition in this way, then of course, repetition would be more cognitively demanding than we sometimes consider it to be. The notion that 'involuntary repetition' of a word's spoken form can also function as a means to decode meaning leads back to Craik and Lockhart (1972). Their model of mental processing is based on the idea that processing levels must be understood as a continuum of analysis. They distinguish between two types of processing, Type I that equals recirculating information at sensory level and Type II that equals deeper analysis through 'semantic-associative operations'. The researchers argue that

if the subject's task is merely to reproduce a few words seconds after hearing them, he need not hold them at a level deeper than phonemic analysis. If the words form a meaningful sentence, however, they are compatible with deeper learned structures and larger units may be dealt with. (Craik and Lockhart, 1972: 679)

Thus, Craik and Lockhart's theory cannot be seen as a dismissal of repetition as such, but of a certain kind of repetition, namely a repetition that is limited to a word's form isolated from its meaning and the context in which it occurs. It is likely that semantic analysis of a word is facilitated if it appears in a meaningful context, such as a story, song or rhyme, and if accompanying images or actions as in TPR activities also aid the process of decoding meaning. If that was the case, then repeated storytelling, singing and chanting accompanied by dance moves or pictures would lend itself to deeper mental processing and aid word learning. 
However, it is questionable whether children always try to understand or recall a word's or a chunk's meaning when they listen to a piece of rhythmic language such as a rhyme, for example. Children seem to tolerate unknown words to some extent, and they probably do so because they regard these unknown words as decorative detail that creates the special atmosphere of the text (G. Cook, 2000; Widdowson 1992). According to Cook, there are two possible ways to explain what happens when children encounter rhymes that consist of new, unknown vocabulary:

The first is that the child accepts the rhyme, or bits of it, as rhythmic sound without meaning $[\ldots]$ for the moment the rhyme is like music which occasionally merges into language [...] The second possible answer is that children do perceive the rhyme as meaningful language, but invest the words they do not understand with their own idiosyncratic interpretations [...] It may be that the child moves gradually from one kind of understanding to another [...]. (G. Cook, 2000: 25)

Cook's two interpretations of the situation in which a child is confronted with new language in a rhyme both place emphasis on the rhythmic, and therefore melodic qualities of the text. It is the musical element that catches and sustains the young child's attention so that this piece of language is listened to and enjoyed even if only fragments are understood. And even when the presumably older child assigns meaning to the words in the rhyme, it is still the musical element of the language that helps to sustain the child's interest and functions as encouragement for repeated encounters with the text until the riddle is solved and the text is decoded and understood (G. Cook, 2000).

Within this line of argumentation, then, repeated encounters with a rhyme fulfil different purposes. While the mere repetition of sound may not involve deep mental processing, there has been evidence of L2 learners encoding new vocabulary into both 'acoustic and semantic memory clusters' and of beginners relying on acoustic memory more heavily (Henning, 1973: 185). This indicates that repetition of sound may still be of benefit to learners at a low level of proficiency, which is in line with more recent research (Cheung, 1996; Masoura and Gathercole, 1999). It is also true that the fascination that is created by a piece of rhythmic and melodic language provides the motivation for the child to listen to it again. And it is through these repeated encounters with the text that fragments of language can be decoded. These individual fragments can then function as access points to a basic 
understanding of the text. The more language items have been understood, however, the more the child can focus on the meaning through repeated encounters, turning these instances of repetition into instances of revisiting meaningful language, thereby allowing for a 'deeper analysis' of language items and for word learning.

Rhyme does not only occur in poems. Rhyme is also a common feature in songs, chants and sometimes in recurrent language patterns of stories, such as folk tales. Moreover, as mentioned before, even without rhyme, language can appear rhythmic or melodic, inviting the listener to repeated encounters with the text. By choosing texts that capture and sustain children's interest due to their 'musical' qualities, teachers in FL classrooms can create an environment in which revisiting language and repetition is welcomed and children are guided on their journey from an appreciation of the text as 'music' to an understanding of its meaning.

It has to be noted that lesson planning that is based on the principle of 'efficiency' may have less desirable effects, since a swift decoding of the text would only lead to the children losing interest quickly, which would limit the number of opportunities to listen to a text again. If one continues Cook's argumentation (2000), it follows that the more often a text needs to be repeated until it is completely understood and until it has lost the mystery that shrouded it, the higher the chances are that word learning can take place on the basis of deep mental processing. The degree to which new words are analysed in terms of their meaning will differ from one individual learner to the next, but if children listen to the text repeatedly and join in verbally, then this creates ample opportunities for noticing words and for the teacher to support this first stage of word learning.

Thus, the imitation of language fragments as observed in children taking part in this project should be seen as a positive sign in the language learning process. It demonstrates some word knowledge at recognition level. If children recognize language items within the flow of natural FL language, even if it is just an onomatopoetic expression, they have found some access to the language presented to them. They have noticed language items, which is the starting point in the word learning process (Nation, 2001, Schmidt, 1990). Recognizing these items and being able to playfully use language during each repetition of a chant, song or story helps to sustain their interest and paves the way for the reproduction of more and more language items. 
Unlike the repetition of language patterns in conventional language exercises, learners are not presented with isolated fragments of speech but with language that is embedded in the context of a story, song or chant. Individual language items derive their meaning from the context in which they appear, and the wider context of a plot, chant or of song lyrics creates meaning. Therefore, the repetition of a song, chant or story cannot be assumed to function in the same way as the repetition we find in pattern drill exercises.

Also, one should not forget that songs, chants and stories were created for a purpose, which is their performance. These texts invite the listener to enjoy their performance and to join in. At the same time, children's impulsive repetition of what they have heard is also purposeful. 'Involuntary repetition', as argued before, fulfils the need for egocentric language and it supports the meaning-making process. 'Involuntary repetition', as observed in children, is self-directed and not controlled by the teacher, which is in stark contrast to conventional language exercises in the FL classroom. Repetition in the form of imitating language is a naturally occurring by-product of storytelling, singing and chanting in the classroom and must therefore be distinguished from its strategic use as classroom practice in pattern drill exercises, for example. Imitation of sample language from songs, chants and stories here allows for optimum conditions for memorizing pre-fabricated language, namely situational context, shortness and self-directedness (Nattinger and DeCarrico, 1992).

\subsection{Visualization and FL learning}

Apart from rhythmic language, rhyme and onomatopoeia in songs, chants and stories, visual cues in the form of pictures and accompanying actions also provided access points into the FL, and teachers as well as learners were observed to make active use of them. Teachers always provided some sort of visual representation of the song, chant or story they introduced to their learners, and learners demonstrated that accompanying actions and pictures provided them with a partial understanding of the text. When asked to translate a certain phrase, learners referred to the image they had seen rather than the language they had heard.

This, again, is reminiscent of L1 acquisition. Word learning in the L1 has been suggested to be facilitated, among others, by gaze following, the ability of infants to look at the same objects or persons as their communication partners 
(Bloom, 2002). This enables young children to understand what their caregivers refer to when they are speaking, which helps them to make sense of what has been said. For visually impaired children, it is the sense of touch that supports this meaning-making process. Early L1 acquisition sets into motion a learning mechanism for the decoding of language that is also available for the learning of additional languages at a later stage.

Learners' reliance on decoding meaning on the basis of visual clues became evident during the first encounter with a picture book. In contrast to less elaborate texts in terms of storyline and language, the children did not start to join in verbally in the FL, which suggests that their main focus was on decoding the meaning of the text. Indeed, their contributions in the L1 showed that they used visual clues to understand the plot, and once they unlocked the narrative code, the children in this study also made accurate predictions about the evolving storyline. The pictorial representation acted as a scaffolding device enabling them to make sense of a story told in the FL, although the complexity and richness of the language used in the picture book was well beyond their command of the FL at the time. Studies in both L1 as well as L2 acquisition have shown that visual stimuli during storytelling are vital for word growth (Elley, 1989; Elley and Mangubhai, 1983). Pictures are also seen as an important ingredient for the meaning-making process in the L1, which has been supported by researchers who studied children's responses to visual representations in picture books (Doonan, 1993; Arizpe and Styles, 2003).

While visual clues then provide access points into the song, chant or story, they also seem to hold learners' attention and encourage them to tolerate extended input in the FL. Extended input in the FL is unquestionably one way to maximize exposure to the FL, which is critical (Foster-Cohen, 1999). However, there is not always sufficient provision of extended input in the FL, as observations of secondary CLIL classrooms suggest (Dalton-Puffer, 2007). Teacher monologues, traditionally the main source of extended FL input, seem to be avoided in order to allow for more interaction between teacher and learner. As a consequence, FL input is restricted, and students' FL output fragmentary. Dalton-Puffer (2007) concludes that if one wants students to make extended statements and be able to talk about complex concepts, they need to be exposed to extensive input of the same sort. Storytelling sessions, in which primary schoolchildren listen attentively for 15 or 20 minutes, can be seen as a very first step in that direction. They can help to prepare 
our learners for extended and complex classroom talk and may also lay the foundations for rich output.

Visual stimuli have been attributed an important role in the teaching of a new word (Nation, 2001). It is therefore not surprising that teachers in this study were not only found to use visual aids in the form of images or actions to illustrate the meaning of new words but also to make use of visualization in follow-up activities. In most cases, English sessions ended with an art activity that visualized the topic of the lesson. Sometimes, children were asked to colour in pictures and at other times they were asked to create their own drawings. It was not common practice for teachers to instruct children to write down English words.

Yet children were found to be able to retrieve song lyrics on the basis of wordless pictures. This highlights the role of images in language learning, and it reminds one of young $\mathrm{L} 1$ children reciting parts or the whole text of a story by looking at the illustrations. The pictures seem to act as stimuli for the recall of chunks of language that have been encountered a great number of times. There is reason to believe that drawings even without any written notes may help young learners with the recall of newly learnt FL vocabulary as well. It has been argued that visualization supports the creation of mental images, which in turn facilitate recall of words (e.g. Damasio, 1994; Fogarty, 1994; Marks, 1973; Paivio, 1971). It has also been suggested that visual images stimulate an emotional reaction that help us pay attention and make the stimulus more salient (Arnold, 1999). The effect of visualization during instances of singing, chanting and storytelling may then be twofold. First, the pictorial representation of language in the form of illustrations or accompanying actions affords dual encoding, that is the storage of material in verbal and image memory that can both be accessed for retrieval (Paivio, 1971). Second, the aesthetic qualities of song, chant and story afford an emotional engagement that goes hand in hand with a more focused attention to the visual stimuli that are provided and therefore enhance the effect of visualization.

Even when longer texts, such as picture books, were not revisited, visual stimuli were still found to support memory in this study. Children were able to jointly reconstruct the plot 12 months after the storytelling session. If children can successfully retrieve the storyline and therefore the situation in which words in the FL have been used, they are equipped with a meaningful context that will support their vocabulary learning as well. Provided that the teacher creates opportunities for 
the children to read the story again and to notice new words (Nation, 2001; Schmidt \& Frota, 1986), children are very likely to expand their vocabulary, as has been found in L2 research (Elley and Mangubhai, 1983).

Observations in the primary classrooms under study have shown that learners took great pleasure in joining in actions during repeated encounters and their attentiveness during picture book sessions also suggests that they would tolerate revisiting the same story. Indeed, a picture book can provide a rich visual experience that invites repeated encounters with it. Visual images may go beyond the meaning of the text, may question the events as told in the text, and may add new layers of meaning (Mariott, 1998). All of these aspects create opportunities for classroom talk. The 'gaps' or juxtapositions of verbal text and illustration invite discussion (Bland, 2013a and 2013b), and the classroom talk that can evolve helps to develop multiliteracy (Bland 2013a; Burwitz-Melzer, 2013). Illustration and verbal text in picture books might question learners’ values, their stereotypes and attitudes towards otherness (Lütge 2013). Learners might identify with the characters, and their worries, joy or fear might touch them, which can help them to come to terms with their own feelings (Mourão, 2012). There might also be intertextual links embedded in the verbal or pictorial text of a picture book. Giving children the opportunity to discover and talk about these makes them aware of intertextual links. This will sensitize them to the fact that texts very often refer to other texts. If teachers get primary schoolchildren to understand this, they would help them to be more fluent readers at secondary level (Kramsch, 1993).

It seems then that the aesthetic qualities, such as illustrations and accompanying actions, can afford numerous encounters that are also needed to discover and process all the facets that an artistic text has to offer. This, in turn, contributes to the learning process. Every time learners revisit a text, they also experience the language of the text again, which provides them with opportunities for noticing new words, retrieving meaning and reproducing language whenever they join in the storytelling themselves. As they enjoy the aesthetic qualities that songs, chants or stories offer, they also encounter samples of contextualized language use that support the creation of mental images and facilitate language learning. 


\subsection{Memorized language chunks and fluency in the FL}

Aesthetic qualities sustain interest, they aid comprehension and also encourage the production of language during repeated encounters. The children in this study were found to produce more and longer stretches of speech and also to recycle language from songs, chants and stories that were encountered inside the classroom. They also used multi-item sequences from pop songs that they must have been exposed to outside the classroom confidently and in an appropriate context. This raises the question as to what role memorized language chunks have in the mastery of the FL.

Mastery of a language is normally associated with skill and the concept of skill as part of FLT terminology involves the notion of fluency (Johnson, 1996). The aspect of fluency that has also been described as 'speed' (Reed, 1968), 'automatism' (Shiffrin and Dumais, 1981), ‘smooth and fluid actions’ (Dreyfus and Dreyfus, 1986) or 'automatization' (Dekeyser and Criado, 2013) plays a part in different models that describe the concept of skill outside and inside the world of language-teaching professionals (Johnson, 1996). Confident and competent use of a language seems to require the ability to choose and produce language structures quickly and with ease.

For example, it has been suggested that native speakers memorize 'lexical units of different sizes, including many partly-fixed frames’ (Wray, 2008: 18) and develop 'a huge sensitivity to which items can be put into those frames' (Wray, 2008: 18). The latter touches the issue of idiomatic use of a language that has been attributed to native-like control of a language. Native speakers do not seem to make full use of the ‘creative potential of syntactic rules’ (Pawley and Syder, 1983: 193). Moreover,

only a small proportion of the total set of grammatical sentences are nativelike in form - in the sense of being readily acceptable to native informants as ordinary, natural forms of expression. (Pawley and Syder, 1983: 193)

It follows that speakers of a language community tend not to use novel utterances but refer to multi-item sequences that have been used before and have become familiar. The use of preconstructed multi-word combinations has been termed ‘idiom principle’ (Sinclair, 1991), but it is also a reminder of Bakhtin’s idea (1986) that we always speak with the voice of others, that everything has been said before, and that the level of creativity is rather low in many genres of speech. Too much creativity in someone else's speech would only make communication more difficult, 
since encoding as well as decoding messages take up more processing resources which are limited. Native speakers have been found to be hesitant when describing something new and using novel speech (Pawley and Syder, 1983). Memorized multi-item sequences, on the other hand, allow for fluent communication. According to this argumentation, native speakers are fluent speakers because they have memorized a stock of 'hundreds of thousands' of lexicalized sentence stems, that is units of 'clause length or longer whose grammatical form and lexical content is wholly or largely fixed' (Pawley and Syder, 1983: 192). In other words, these are pieces of prefabricated language, or language chunks. Weinert (1995), who reviewed literature on the subject, found two different types of definitions for the phenomenon of formulaic language. They are either described as multi-item sequences that are 'produced and recalled as a whole chunk' or they are categorized as 'fixed strings' and 'sequences with open slots' (Weinert, 1995: 182-183). This suggests that automatization does not necessarily start with the smallest possible unit, such as a syllable or an individual word, but rather with a multi-word chunk.

Within Johnson's argumentation (1996), the learning or memorizing of whole multi-item phrases can be compared to the idea that automatization does not always start with declarative knowledge which is then converted into procedural knowledge. On the contrary, we also seem to have direct access to procedural knowledge without going through a declarative stage first (Karmiloff-Smith, 1992). After all, children learning their first language do not seem to develop declarative knowledge, that is knowledge about grammatical rules, before they produce their first multi-item utterances, and this is also difficult to imagine for a child who learns another language (Johnson, 1996). Although the teaching of a foreign language at secondary school is traditionally structured so that declarative knowledge is taught from the beginning, it is questionable if this is suitable for primary schoolchildren.

It must also be noted that the teaching of skills in other disciplines points towards a strategy that places importance on imitation rather than the compilation of declarative knowledge in the early stages of learning a new skill (Johnson, 1996). For example, it has been put forward that learning how to play tennis could be supported by mimicking the movements and personal style of a good tennis player (Gallwey, 1974). If we transfer this insight to the teaching of languages, then our teaching would stress presenting samples of natural language and encouraging children to imitate them, which is something they are inclined to do anyway. 
Notably, there is a certain element of play involved in the practical suggestion that role models should be mimicked, and this is, indeed, a strategy that is evident in language learning. One example is young children’s ‘vocal play’ (Crystal, 2005), which imitates speech and is a precursor for the production of proper words and utterances. Examples of 'involuntary repetition' as mentioned earlier have also been associated with language play as part of L1 (Kuczaj, 1983) and L2 acquisition (Peck, 1980; Saville-Troike, 1988).

Imitating language chunks repeatedly leads to their memorization. It has been put forward that 'ready-made chunks of unanalyzed language' play an important role in language learning (Weinert, 1995). These memorized stretches of speech can be astonishingly elaborate and enable the learner to communicate with native speakers (Hatch et al, 1979; Huang and Hatch, 1978). In this way, formulaic language creates a threshold for communication in the L2 and is a precursor for language analysis and rule formation (Vihman, 1982; Hatch et al, 1979; WongFillmore, 1976).

However, this might not be true for all learners, since there have been reports of adult learners who had learnt a great number of formulaic phrases but who had not developed an understanding of their underlying grammatical structures (e.g. Rehbein, 1987; Schmidt, 1983). Similar observations have been made with young learners of a foreign language. In a study on French FL classrooms, some but not all learners were found to break up memorized chunks of language and recombine parts of these, thereby displaying some awareness of the structure of the sequence (Mitchell and Martin, 1997). Interestingly, it is argued that learners who seemed unable to free items from language chunks had not memorized the initial multi-item sequences yet (Mitchell and Martin, 1997). These studies suggest that not only need these language chunks be memorized, learners might also need some guidance for analysing them.

Memorized language chunks in a classroom setting have also been associated with extensive rote learning and 'overlearning of grammatical structures' (Weinert, 1995). Formulaic language use in classrooms seems to have a more artificial demeanour than in a naturalistic setting. It is 'formally highly constrained', 'highly complex', 'situationally highly unconstrained' and 'controlled' by the teacher (Weinert, 1995: 193). Weinert notes that this is in stark contrast to the environment that Peters (1983) and Nattinger and DeCarrico (1992) envisaged for the teaching of 
language using formulaic language. First of all, learners should encounter chunks of varying size, but especially below clause size. Secondly, these chunks need to be embedded in a situational context. Thirdly, learners need to have some control over the learning of language chunks, and finally they need opportunities for analysis.

In this study on the use of songs, chants and stories in the primary EFL classroom, young learners were repeatedly found to imitate language chunks unprompted, and although there were also times when they were encouraged to join in, imitation of language was also initiated by the children themselves and triggered by the aesthetic qualities of the song, chant or story. In this way, the setting differs from a traditional rote-learning situation in the classroom where learners are asked to repeat phrases that have been taken out of context, do not mean anything to the learners and have not sparked any interest. However, whole texts that appeal to learners, and can be decoded through pictures or accompanying actions, create a context that invites participation and therefore a setting that is beneficial to the memorization of ready-made language chunks and that in fact resembles a naturalistic setting. For the world of a story, song or chant creates its own alternative reality (G. Cook, 2000) and provides a meaningful context for language use.

As we have seen, ready-made language chunks from stories, songs and chants were memorized and could be reproduced fluently. The knowledge of these prefabricated chunks of language seemed relatively robust, with children using them in interviews about a year after first encountering them. These findings support results from a study of an adult who was taught prefabricated language over four days in order to be able to present a cookery programme in Welsh at the end of the week, and who was able to reproduce 39 per cent of the memorized stretches of speech nine months after she had practised them (Wray, 2008).

With memorized and contextualized language at hand, learners should be able to analyse it, understand it and draw 'declarative knowledge' from it, as has been suggested for children learning their first language:

a degree of declarative knowledge will, for the first language, occur naturally; humans will speculate, attempt to analyse. It is reasonable to suggest that the same process will occur for a second language - declarative knowledge will to a certain extent form itself. (Johnson, 1996: 112) 
With regard to the development of fluency in FL use, this insight holds the key to solving a problem of traditional EFL teaching that understands the development of declarative knowledge as a starting point for proceduralization. Johnson (1996) terms this approach 'DECPRO sequence' and argues that it leads to a situation where the process of proceduralization, that is the development of fluency, is hindered and interrupted by the focus on declarative knowledge. Instead,

it may well be that declarative knowledge as data base occurs best after proceduralization has occurred - at a point when complexities may be presented to the learner without fear of obstructing the proceduralization process. (Johnson, 1996: 104)

In other words, we could focus on providing children with the opportunity to memorize ready-made language chunks first, thereby helping them to build up a large base of language that can be analysed when children no longer need to focus on fluency. This approach to language learning and teaching is in line with Newmark’s proposed teaching strategy (1979) and it is also comparable to McLaughlin’s (1990) concept of 'restructuring', which suggests that practice not only enables automatization but also affords reorganization of knowledge.

The idea that the learning of ready-made language chunks could be a prerequisite for a basic command of the language is also expressed by Wray (2008). She argues that an approach that puts heavy emphasis on the learning of great amounts of prefabricated language especially at beginner's level is in stark contrast to traditional teaching where 'a small number of formulaic word strings is soon swamped by isolated lexis and grammatical rules' (Wray, 2008: 232). While adults seem to be in favour of an approach that centres on 'noticing patterns' and are therefore more likely to generate unidiomatic language on the basis of rules that they have extracted; children may be less likely to do so. Children's cognitive abilities have not yet fully developed, which means that they cannot make full use of abstract thinking skills (Piaget, 1959). Children's need for contextualized learning suggests that children learning a foreign language may use similar strategies as children learning their first language, namely that of reproducing multi-word sequences that have been perceived as one item rather than trying to break the sequence down into smaller parts: 
The process of analysis which the [native speaker] child engages in is not that of breaking down as much linguistic material as possible into its smallest components. Rather, nothing is broken down unless there is a specific reason. (Wray, 2002: 130)

It follows that an approach that focuses on the presentation of language chunks that can be memorized is more suited to a child's natural way of learning. However, one could go even further and suggest that 'a sizeable series of such inputs [...] might between them provide a learner with a usable version of the language' (Wray, 2008: 229).

Arguably, we should strive for more than a 'usable version of the language'. After all, our FL learners will need more than a basic command of the language in a globalised world. At the same time, it is worthwhile considering that by encountering a great variety of different stories, songs and chants that allow for memorization of prefabricated language, learners at primary school may be able to build up a reservoir of language chunks that lays the foundations for further FL learning. Relying on a rich source of memorized language chunks, learners are then in the position to analyse language that they know. The regularities in language use that they can discover on the basis of known lexis that they have encountered in a meaningful context and reproduced repeatedly can be expected to be understood and applied more easily. Declarative knowledge derived from reflecting on language patterns that learners already use fluently can be anticipated to be robust since learners can associate regularities in language use with example language.

And yet, people's ability to reproduce stretches of language fluently is sometimes associated with a lack of cognitive involvement and creativity and discarded as 'mimicking' which is seen as inferior to 'proper' language use that has been entirely made up by the speakers themselves. As pointed out before, the idea that people create novel language whenever they speak is in itself a myth. Language will always consist of 'borrowed' language to differing degrees. On the contrary, fluent and effortless use of ready-made language chunks not only enables speakers to enter communication with a native speaker (Hatch et al., 1979), it also creates opportunities for the speaker to manipulate and play with language as well as ideas. It is through this process that creativity can emerge:

[...] formulas are automatic sequences which, by freeing processing time, allow the planning of propositional speech which has to be 
generated. Prefabricated formulas therefore, indirectly, make creative speech possible. (Weinert, 1995: 184)

Supporting evidence for a theory that links creativity to fluency based on a high number of repetitions can be found in other disciplines as well. With reference to the creativity exhibited in jazz improvisations, Wray (2008) notes that 'a great deal of rehearsal, founded on intense familiarity with the material, precedes good quality improvisation' (Wray, 2008: 39). If we apply this line of thought to language learning, then one would have to argue that before children can start using language creatively, they need to have learnt and memorized language so that they are familiar with it. Moreover, a high degree of fluency has to be reached through rehearsing before creativity can evolve.

A similar consideration has been made by Boden (2001), who argues that creativity, whether it is 'combinational' or 'exploratory' as well as 'transformational', is built on knowledge. In this concept, knowledge is a deep understanding of the subject and knowledge also involves practice, maybe comprising 'years of study or apprenticeship' (Boden, 2001: 6, referring to exploratory and transformational creativity). With regard to creativity in language use, Pawley and Syder (1983) highlight that novelty is only one aspect of speech production. There is also timing, tone, rhythm for example, or unusual variation of familiar language patterns that can be used creatively:

coming ready-made, the memorized sequences need little encoding work. Freed from the task of composing such sequences word-byword, so to speak, the speaker can channel his energies into other activities [...] we believe that memorized sentences and phrases are the normal building blocks of fluent spoken discourse, and at the same time, that they provide models for the creation of many (partly) new sequences which are memorable and in their turn enter the stock of familiar usages. (Pawley and Syder, 1983: 208)

In a recent article by Tin (2013), traditional communication language learning tasks such as ‘information gap’ activities have been criticized for their overly focus on 'known meaning'. Although students can transfer information, which makes communication meaningful; learners do not really get the chance to 'construct new meaning', which results in a 'lack of desire to explore, develop and retrieve less accessible language' (Tin, 2013: 2). The activities that Tin suggests for ELT challenge learners to create novel meaning in their statements, as in 'If I were a 
kangaroo, I would put you in my pocket, keep you close to my heart, and would hop around the town.' (Tin, 2013: 7). Activities such as these involve a high degree of language production, even if some language patterns, namely 'If I were ..., I would' are provided to the learners. In order to come up with language as Tin suggests, learners must have access to idiomatic language and collocational word knowledge, or it would be difficult for them to produce phrases, such as 'close to your heart' or 'hop around town'. Yet these are the kind of language chunks found in texts, such as songs, stories and chants. Therefore, if learners had been subjected to a great number of literary and musical texts from which they could memorize strings of words, they could go on and create new meanings in language tasks, as illustrated above. By doing so, they would in turn become aware of how these language chunks worked, because they would be encouraged to use them in new contexts and to break them up and reassemble them in a new way. This developing awareness of memorized sequences can be seen as a type of declarative knowledge that leads to a balanced use of memorization of prefabricated language supported by a deep understanding of its underlying structure.

\subsection{Summary}

This chapter was devoted to aspects of children's behaviour that were identified as characteristic during the analysis of recorded classroom and interview discourse. The discussion of children's unprompted repetition of language items, their response to visual stimuli as well as their ability to reproduce memorized language chunks, as observed in this study, suggest that these features are relevant for different stages of FL learning.

While ‘involuntary repetition’ during repeated encounters with a story, song or chant can support the meaning-making process during the stage of noticing a new word, it also seems to afford retrieval at a later stage. In the same way, images have been found to act as a scaffolding device that sustains children's interest and guides their developing understanding of a text while listening to the FL. Visual stimuli also seem to play a supporting role during retrieval.

Memorized language chunks, on the other hand, form a basis for creative language use in so far as these chunks allow learners to produce language fluently, which means that they can concentrate on other aspects of communication, such as content in order to produce ‘creative speech' (Weinert, 1995). Moreover, ready- 
made unanalysed language chunks that have been memorized also provide a basis for declarative knowledge to evolve. Learners have a reservoir of language to rely on that can be manipulated and recycled for other purposes.

The discussion of the above features also indicates that theses aspects are interrelated. For example, children's tendency to imitate what they hear reinforces the process of memorization, which in turn facilitates 'appropriation' of linguistic resources (Lantolf \& Thorne, 2006; Dufra, Aro \& Suni, 2014). Pictures, too, play a role in this process, since they help children find some access to language that otherwise could not be understood. Once a partial understanding is reached, children's imitation of language goes hand in hand with retrieval of its meaning, which in turn ensures that memorized language can be reproduced in an appropriate context at a later stage. 


\section{Chapter 9 \\ Conclusion}

This project on primary EFL classrooms explored the role of songs, chants and stories in the FL learning process. In order to understand how teachers made use of these genres and how learners responded to them, different kinds of data, that is questionnaire, observational and interview data, were collected and analysed. In this way, it was hoped that the lack of research based on studying young FL learners in the setting of their classrooms could be addressed.

In the first phase of this project, primary teachers of an urban community and its neighbouring villages and small towns in Rhineland-Palatinate in Germany provided valuable first insights by answering an anonymous questionnaire in 2007 . In the second phase, between 2008 and 2009, participant observations were conducted in one school in the area involving three qualified teachers, one student teacher and their learners. Interviews with five groups of 4 to 5 children as well as two participating teachers were carried out between 2009 and 2011 and provided a platform for triangulating preliminary research findings.

Two umbrella questions, which were refined after each stage of the project, guided my research:

1. How do primary teachers teach English to young learners in and around a medium-sized town in Rhineland-Palatinate?

1.1 In how far is exposure to the FL influenced by timetabling and staffing issues and teachers' use of German?

1.2 What role does singing, rhyming, chanting and storytelling play in teacher's lesson organisation in comparison to other activities and with reference to the teaching objectives they set themselves?

2. How do learners respond to being taught English in these classrooms?

2.1 Is there any evidence of children's enthusiasm for singing, rhyming, chanting and storytelling and how does that compare to or compete with teachers' agendas?

2.2 What do children's non-verbal or verbal responses tell us about how they manage FL input in the form of songs, rhymes, chants and stories, construct meaning and learn to use the FL? 
2.3 What is the nature of learners' FL output, such as individual words, especially nouns, or multi-item sequences, and are there any traces of out-of-school exposure to English in learners' use of English?

\subsection{Aspects of FL Teaching}

The analysis of questionnaire data suggests that timetabling and staffing issues interfere with official guidelines for the integration of the FL into the teaching of other subject areas by the class teacher. Among teachers, concerns were voiced over lack of training as well as the limited time that is allocated to English. One fifth of the participating teachers reported having received EFL tuition only at school, and therefore it is not surprising that teachers found their training insufficient. 62 percent of teachers reported that they managed to integrate English into three subject areas at the most, among which music, science and German were most often referred to. The FL was most often used as part of rituals at the beginning and end of lessons, which restricts the opportunity for varied and rich input. According to teachers, however, EFL sessions are mostly provided as separate lessons. Observations confirmed this.

However, great differences were found between schools and between teachers within schools with regard to the number of subject areas that were used for EFL, the number of different teaching materials and the titles of course books available. This suggests a lack of shared resources and communication among teachers involved in EFL. Great differences between individual teachers were also found in the amount of FL input that teachers provided during observations, ranging from 9 to 54\% for one teacher and from 70 to 95\% for another during different stages of one example lesson.

There was agreement on teaching objectives, with teachers placing more importance on developing an open attitude towards the FL and other cultures, oral communication, especially listening, and vocabulary than on improving knowledge of cultural facts, written language and grammar. Teachers indicated that they supported a playful and motivating approach to EFL. They reported using songs most often, followed by nursery rhymes and picture stories. This was partly confirmed by observations, during which musical and literary texts dominated EFL sessions. About three quarters of observed lessons featured the use of these genres. However, during observations stories were more frequently used than songs. Chants, 
two of them containing rhyme, were used occasionally and mostly linked to the teaching of seasonal aspects, e.g. Easter. Nursery rhymes and poems were not used.

Observational data revealed that teachers used visualization in the form of pictures and accompanying actions for the presentation of songs, chants and stories as well as for retrieval. Follow-up activities were dominated by artwork, not the production of the target language. The emphasis was therefore on listening, and to a lesser extent on speaking, in accordance with teachers' objectives. Longer texts, such as picture books, were normally not revisited in full again, but shorter texts, such as songs and chants, were performed repeatedly.

\subsection{Aspects of FL Learning}

According to the majority of teachers, songs as well as rhymes and poems were among the most popular activities for children. Classroom observation confirmed this.

Across different learner groups and with different teachers, learners tolerated FL input of different length from short rhymes and songs to picture books. They did not seem overwhelmed by this exposure to the FL. They seemed to construct meaning from accompanying pictures and actions. Acoustic clues, such as rhyme and onomatopoeia, also created access points into these texts. Learners were found to join in physically and imitate accessible language items straight away when presented with high-interest songs, chants and both illustrated as well as action stories. They seemed content with a partial understanding of the text that was based on processing visual clues, while teachers' remarks indicated their focus on linguistic input. Children were also found to join in repeated singing, chanting and storytelling encounters if the text had sparked their interest. Gradually, they reproduced more and longer stretches of speech from these texts.

Multi-item language sequences from texts that had been rehearsed many times were found in children's speech in interviews 12-15 months after the initial and only practice in the classroom. Moreover, there was some evidence of children breaking up memorized multi-item sequences for their statements in the interviews. Learners were also observed to jointly reconstruct the plot of stories that they had encountered in the classroom. Visual stimuli in the form of pictures or actions were found to support this recall. 
These findings suggest that the aesthetic qualities of song, chant and story afford learners' participation. Aesthetic qualities aid comprehension, sustain interest for extended exposure and repeated encounters and stimulate language production. Young learners of a foreign language seem to make use of learning mechanisms that are characteristic of L1 acquisition, such as imitation, or 'involuntary repetition', as well as using visual clues for meaning making. Imitation does not exhaust itself in the repetition of individual items, but extends to the repetition of chunks of language. This facilitates memorization and fluent production of individual words and language chunks.

\subsection{Implications for Teaching}

For language learners to become fluent speakers, they need to be able to rely on memorized language and not only on grammar rules that they learnt. The data collected and analysed in this study suggest that young learners can memorize and learn to use FL chunks fluently if they are presented with high interest songs, chants and stories and if their tendency to imitate stretches of speech is supported. In this way, young learners can build up a reservoir of memorized prefabricated language that is available for 'recycling' at a later stage.

Of course, at some point, unanalysed strings of language would have to be studied for patterns in order to understand the underlying grammatical structure (Wray, 2008). However, linguistic analysis might be best suited to learners aged 11+ who are in full command of abstract thinking skills (Piaget, 1959) and who make less use of memory (Vygotsky, 1978). Up to then, primary teachers' main function could be to develop fluency in memorized language chunks and make the children aware of patterns. These memorized stretches of speech could act as a sort of mnemonic device for retrieving declarative knowledge at a later stage and could guide learners' decisions when they generate new statements.

Nonetheless, the fluent reproduction of memorized language chunks has to be regarded as important in its own right and should not only be seen as an auxiliary for the development of declarative knowledge. This is because memorized sequences enable the speaker to use his or her cognitive capacities more independently and effectively. Not having to waste cognitive energy on finding novel expressions for every little detail, the speaker can decide where to use more cognitive effort and creativity. 
Research findings of this study suggest that chants, songs and stories can create affordances in the FL classroom (van Lier, 2004; Gibson, 1986) by providing a learning environment that accounts for primary schoolchildren's need for contextualized learning material. These text genres also address young learners’ predisposition for egocentric speech and pretend play (Piaget, 1959). By presenting memorable language in the form of unanalysed sequences that can be rehearsed, teaching taps into young learners’ preference for recalling observed behaviour from memory (Vygotsky, 1978). Children can revisit the meaningful context of a song, chant or story, incorporate that into their play that goes on outside their classrooms, and appropriate samples of authentic FL use, which lays the foundations for idiomatic FL use.

\subsection{Limitations}

It is important to note that within the scope of a PhD project such as this, the amount of data that can be analysed and studied in detail is limited. This project has to be considered a small-scale study that can only make a modest contribution to a body of research that ideally should integrate data from a great number of different schools from different areas. More data is needed to investigate whether the findings from this study can be supported by evidence from other teachers and learner groups. Moreover, further data is necessary to investigate how young learners can also be encouraged to 'recycle' memorized language creatively within normal classroom routine (Tin, 2013) in order to aid the process of breaking up and recombining language chunks.

The limitations of each research instrument applied during the course of this study have been reflected upon in the relevant chapters. However, there is an issue that needs to be flagged again. While it is true that it was one of the objectives to find out how EFL worked in 'real' classrooms, it cannot be denied that the presence of the researcher always has an impact on the teaching that is going on. Some of the materials that have been used during the observational periods might not have entered the classrooms at that point if the teachers had not requested to screen material that the researcher had access to. However, evidence from the teachers' classroom also shows that apart from the new material that they tried out straight away, their own teaching material also consisted of a mix of songs, stories and chants. If anything, the teachers' enthusiasm to make use of new texts only demonstrates 
their curiosity and interest in songs, stories and chants for their classrooms. In this way, the study has partly revealed what goes on in the 'real' classroom, but it has also shown to some extent what can be done in 'real' classrooms when teachers have access to a variety of DVDs, picture books and graded readers to choose from.

\subsection{Closing Words}

In this study, songs, chants and stories facilitated language learning in different ways. Firstly, songs, chants, simple stories and recurrent dialogues in longer stories, such as picture books, offered memorable language and invited participation through their aesthetic qualities. This allowed for fluent reproduction of individual words and multi-item sequences from these texts. Secondly, more elaborate texts, such as picture books, encouraged learners to experience extended discourse that entailed rich vocabulary as well as inter-textual and cultural references. During this input in the FL, accompanying actions or images acted as a scaffolding device for comprehension. Once the 'storyline' was decoded, the meaningful context of a song, chant or story was accessible for future encounters with the text and its language.

In this way, learners can benefit from repeated encounters with musical and literary texts, affording comprehension of FL input, increasing verbal participation and memorization of ready-made language chunks. Taught in this way, learners will be better prepared for reading extensively and for reflecting on language when they enter secondary school, and their natural inclination for individual, independent learning and analytical thinking as teenagers can be supported (V. Cook, 2008). By addressing age-related differences in EFL programmes, primary curricula can be more than a 'watered-down' (L. Cameron, 2001) version of a secondary curriculum. 


\section{Bibliography}

Allwright D and Bailey KM (1991) Focus on the Language Classroom.

Cambridge: Cambridge University Press.

Almond D (1998) Skellig. London: Hodder Children’s Books.

Anderson JI and Jordan AM (1928) Learning and retention of Latin words and phrases. Journal of Educational Psychology 19, 485-496.

Arizpe E and Styles M (2003) Children Reading Pictures. Interpreting Visual Texts.

Abingdon: Routledge.

Arndt E (1989) Deutsche Verslehre. Bindlach: Gondrom Verlag.

Arnold J (1999) Visualization: Language learning with the mind's eye. In: Arnold J (ed)

Affect in Language Learning. Cambridge University Press: Cambridge.

Asher J (1969) The total physical response approach to second language learning.

The Modern Language Journal 53 (1): 3-17.

Auden WH (1968) Secondary Worlds. London: Faber \& Faber.

BAAL (2006) Recommendations on good practice in Applied Linguistics. Available at: http://www.baal.org.uk/dox/goodpractice_full.pdf.

Bader B (1976) American Picturebooks from Noah's Ark to the Beast within.

New York: Macmillan Publishing.

Bakhtin MM (1986) Speech Genres \& other Late Essays. Austin: University of

Texas.

Barber EJW (1980) Language acquisition and applied linguistics. ADFL Bulletin 12:

26-32.

Baske S (ed) (1979) Bildungspolitik in der DDR 1963-1976. Dokumente.

Wiesbaden: Harrassowitz.

Beckmann U (2006) Frühes Fremdsprachenlernen: Historischer Überblick. In: Pienemann

M, Keßler J-U and Roos E (eds) Englischerwerb in der Grundschule. Paderborn: Schöningh, pp. 11-23.

Bland J (2013a) Children's Literature and Learner Empowerment. Children and

Teenagers in English Language Education. London and New York: Bloomsbury Academic. 
(2013b) Fairy tales with a difference: Creating a continuum from primary to secondary ELT. In: Bland J and Lütge C (eds) Children's Literature in Second Language Education. London and New York: Bloomsbury Academic, pp. 85-94. (2015) Teaching English to Young Learners: Critical Issues in Language

Teaching with 3-12 Year Olds. London and New York: Bloomsbury Academic. Bland J and Lütge C (2013) Children's Literature in Second Language Education. London and New York: Bloomsbury Academic.

Bloom KC and Shuell TJ (1981) Effects of massed and distributed practice on the learning and retention of second-language vocabulary. Journal of Educational Research 74: 245-248.

Bloom P (2002) How Children Learn the Meanings of Words. Cambridge, MA and London: The MIT Press.

Blubaugh JA (1969) Effects of positive and negative audience feedback on selected variables of speech behavior. Speech Monographs 36: 131-137.

Boden, MA (2001) Creativity and knowledge. In: Craft A, Jeffrey B and Leibling M (eds) Creativity in Education. London: Continuum.

Boers F and Lindstromberg S (eds) (2008) Cognitive Linguistic Approaches to

Teaching Vocabulary and Phraseology. Mouton de Gruyter: Berlin.

Bond. M (1958) A Bear Called Paddington. New York: Harper Collins.

Boogie Beebies. Get Ready to Boogie (2005) London: BBC Worldwide Ltd.

Boyd S (2001) Teaching Modern Languages. Policy and Practice in England, Wales and

Northern Ireland. Slough: NFER. Available at: https://www.nfer.ac.uk/ publications/91173/91173.pdf (accessed 4 March 2015).

Börner O (ed) (2007) Green Keystones. Braunschweig: Diesterweg.

Bradley L and Bryant PE (1983) Categorising sounds and learning to read - A casual connection. Nature 301: 419-421.

Brady SA (1991) The role of working memory in reading disability. In: Brady S and Shankweiler D (eds) Phonological Processes in Literacy: A Tribute to Isabelle $Y$ Liberman, Hillsdale, NJ: Laurence Erlbaum Associates, pp. 129-151.

Brandt A, Gebrian M and Slevc LR (2012) Music and early language acquisition. Frontiers in Psychology 3(327): 1-17. Available at: www.frontiersin.org 
(accessed 29 March 2015).

Bredella L (1996) The anthropological and pedagological significance of aesthetic reading. In: Bredella L and Delanoy W (eds) Challenges of Literary Texts in the Foreign Language Classroom. Tübingen: Gunter Narr, pp. 1-29.

Bredella L and Delanoy W (1996) Challenges of Literary Texts in the Foreign Language Classroom. Tübingen: Gunter Narr.

Brewster J, Ellis G and Girard D (2002) The Primary English Teacher's Guide. Harlow: Penguin.

Briggs CL (1986) Learning How to Ask: A Sociolinguistic Appraisal of the Role of the Interview in Social Science Research. Cambridge: Cambridge University Press.

Bronfenbrenner U (1979) The Ecology of Human Development. Cambridge, MA: Harvard University Press.

Brooker L (2001) Interviewing children. In: MacNaughton G, Rolfe SA and Siraj-Blatchford (eds) Doing Early Childhood Research. International Perspectives on Theory and Practice. Maidenhead: Open University Press, pp. 162-177.

Brown JD and Rodgers, TS (2009) Doing Second Language Research. Oxford: Oxford University Press.

Brumfit CJ and Johnson K (eds) (1979) The Communicative Approach to Language Teaching. Oxford: OUP.

Bryant PE, Bradley L, Maclean M and Crossland J (1989) Nursery rhymes, phonological skills and reading. Journal of Child Language 89(16): 407-28.

Burmeister P (2006) Immersion und Sprachunterricht im Vergleich. In: Pienemann M, Kessler J-U, and Roos E (ed) (2006) Englischerwerb in der Grundschule. Paderborn: Schöningh, pp. 197-216.

Burstall C (1974) Primary French in Balance. Slough: National Foundation for Educational Research (NFER).

Burwitz-Melzer E (2013) Approaching literary and language competence: Picturebooks and graphic novels in the EFL classroom. In: Bland $\mathrm{J}$ and Lütge $\mathrm{C}$ (eds) Children's Literature in Second Language Education. London and New York: 
Bloomsbury Academic, pp. 55-70.

Byram M (1989) Cultural Studies in Foreign Language Education. Clevedon:

Multilingual Matters.

Cameron D (2001) Working with Spoken Discourse. London: Sage.

Cameron L (2001) Teaching Languages to Young Learners. Cambridge: Cambridge

University Press.

Carle E (1969) The Very Hungry Caterpillar. New York: Philomel Books.

Carle E and Martin B (1967) Brown Bear, Brown Bear, What Do you See? New York:

Doubleday \& Company.

Cave K and Riddell C (1994) Something Else. London: Viking.

Chaudron C (1988) Second Language Classrooms. Cambridge: Cambridge

University Press.

Chen HC and Leung YS (1989) Patterns of lexical processing in a non-native language.

Journal of Experimental Psychology: Learning, Memory and Cognition 15(2): 316-25.

Cheng-Ying L (2004) Storyreading in an EFL primary classroom: An analysis of teacher-student interaction. Annual Review of Education, Communication \& Language Sciences 1:1-13.

Cheung H (1996) Nonword span as a unique predictor of second-language vocabulary learning. Developmental Psychology 32(5): 867-73.

Chobert J and Besson M (2013) Musical expertise and second language learning. Brain Sciences 3(2): 923-940.

Chomsky N (1957) Syntactic Structures. The Hague: Mouton.

Christiani R and Cwik G (eds) (2008) Englisch unterrichten in Klasse 1 und 2. Berlin: Cornelsen.

Christiner M and Reiterer SM (2013) Song and speech: examining the link between singing talent and speech imitation ability. Frontiers in Psychology 4(874): 1-11. Available at: www.frontiersin.org (accessed 30-03-2015).

Cook G (1997) Language play, language learning. ELT Journal 51: 224-231. (2000) Language Play, Language Learning. Oxford: Oxford University Press. Cook V (2008) Second Language Learning and Second Language Teaching. 
London: Hodder Education.

Copland F and Enever J (2015) ELT Journal/IATEFL Debate: Primary ELT does more harm than good. In: Pattison T (ed) IATEFL 2014. Harrogate Conference Selections. IATEFL: Faversham.

Cortazzi M (1993) Narrative Analysis. London and New York: Routledge.

Council of Europe (2007) From Linguistic Diversity to Plurilingual Education:

Guide for the Development of Language Education Policies in Europe.

Strasbourg.

Coyle Y and Gómez Gracia R (2014) Using songs to enhance L2 vocabulary acquisition in preschool children. ELT Journal 86(3): 276-285.

Craik F and Lockhart R (1972) Levels of processing: A framework for memory research. Journal of Verbal Learning and Verbal Behavior II: 671-684.

Creswell JW (2007) Qualitative Inquiry \& Research Design. Thousand Oaks: Sage.

Crystal D (2005) How Language Works. New York: Avery.

Dale, P (1988) Ten in the Bed. London: Walker Books.

Dalton-Puffer C (2007) Discourse in Content and Language Integrated Learning (CLIL) Classrooms. Amsterdam/Philadelphia: John Benjamin.

Damasio A (1994) Descartes’ Error: Emotion, Reason and the Human Brain. New York: Avon.

Davis KA (1995) Qualitative Theory and Methods in Applied Linguistics Research. TESOL Quarterly 29(3): 427-453.

DeKeyser RM and Criado R (2013) Automatization, skill acquisition, and practice in second language acquisition. In: Chapelle CA (ed) The Encyclopedia of Applied Linguistics. Oxford: Wiley Blackwell, pp. 1-18.

Dempster FN (1987) Effects of variable encoding and spaced presentation on vocabulary learning. Journal of Educational Psychology 59: 202-206.

Diekmann A (2008a) The Easter Bunny Chant. Grundschule Englisch 22: 32-33.

Diekmann A (2008b) April Weather - an action story. Grundschule Englisch 22: 34-37. Donaldson J and Scheffler A (1999) The Gruffalo. London: Macmillan. (2002) The Smartest Giant in Town. London: Macmillan. (2004) Gruffalo’s Child. London: Macmillan. 
(2011) Grüffelokind. Translation by M. Osberghaus. Weinheim: Beltz.

Doonan J (1993) Looking at Pictures in Picture Books. Bath: Thimble Press.

Doyé P and Lüttge D (1977) Untersuchungen zum Englischunterricht in der

Grundschule. Bericht über das Forschungsprojekt FEU. Braunschweig:

Westermann.

Dörnyei Z (2003) Questionnaires in Second Language Research. London: Erlbaum.

Drew I (2009) Using the early years literacy programme in primary EFL Norwegian

classrooms. In: Nikolov M (ed) Early Learning of Modern Foreign Languages.

Processes and Outcomes. Bristol/Buffalo/Toronto: Multilingual Matters, pp. 108-119.

Dreyfus HL and Dreyfus SE (1986) Mind over Machine: The Power of Human

Intuition and Expertise in the Era of the Computer. New York: The Free Press.

Dufra H, Aro M and Suni M (2014) Language learning as appropriation: how linguistic resources are recycled and regenerated. Available at: http://www.academia.edu/7432473 (accessed 17 July 2014).

Easter Bunny’s Book (2008) Englisch begegnen 16. Available at: www.raabe.de (accessed 7 October 2015).

Edelenbos P, Johnstone R and Kubanek A (2006) The main pedagogical principles underlying the teaching of languages to very young learners. Languages for the children of Europe. Published research, good practice \& main principles. Available at: http://ec.europa.eu/education/policies/lang/doc/young_en.pdf. (accessed 20 May 2012).

Edmondson W (1997) The role of literature in foreign language learning and teaching: Some valid assumptions and invalid arguments. In: Mauranen A and Sajavaara K (eds) Applied Linguistics Across Disciplines. AILA Review 12, pp. 42-55.

Elley WB (1989) Vocabulary acquisition from listening to stories. Reading Research Quarterly XXIV(2): 174-187. (1991) Acquiring literacy in a second language: The effect of book-based programs. Language Learning 41(3): 375-411. 
(1998) Raising Literacy Levels in Third World Countries: A Method That Works.

Culver City, CA: Language Education Associates.

Elley WB and Mangubhai F (1983) The impact of reading on second language

learning. Reading Research Quarterly 19: 53-67.

Ellis NC (1996) Sequencing in SLA. Phonological memory, chunking and points of order.

Studies in Second Language Acquisition 18(1): 91-126.

Ellis NC and Larsen-Freeman D (2006) Language emergence: Implications for applied linguistics - Introduction to the special issue. Applied Linguistics 27(4): 558-589.

Enever J (2009) Can today's early language learners in England become tomorrow's plurilingual European citizens? In: Nikolov M (ed) Early Learning of Modern Foreign Languages. Processes and Outcomes. Bristol/Buffalo/Toronto: Multilingual Matters, pp 15-29. (ed) (2011a) ELLiE. Early Language Learning in Europe. British Council. Available at: www.teachingenglish.org.uk/sites/teaching/files/B309 (accessed 15 January 2015).

(2011b) ELLiE. Early Learning in Europe. Final Report. Public Part. Available at: http://www.ellieresearch.eu/docs/2007_1994_FR_ELLiE-public.pdf (accessed 15 January 2015).

Engel G, Groot-Wilken B and Thürmann E (2009) (eds) Englisch in der Prmarstufe Chancen und Herausforderungen. Evaluation und Erfahrungen aus der Praxis. Berlin: Cornelsen.

Entwisle DR (1966) Word Associations of Young Children. Baltimore, MD: John Hopkins Press.

Erickson, F (1981) Some approaches to inquiry in school-community ethnography. In: Trueba H, Guthrie GP and Au KHP (eds) Culture and the Bilingual Classroom: Studies in Classroom Ethnography. Rowley, MA: Newbury House, pp. 17-35. European Commission (1995) White Paper on Education and Training - Teaching and Learning - Towards the Learning Society. Available at: http://ec.europa.eu/white-papers/index_en.htm\#block_13 (accessed 26 February 2015). 
European Commission (2011) First European Survey on Language Competences.

Available at: http://ec.europa.eu/languages/policy/strategic-framework/ documents/language-survey-final-report_en.pdf (accessed 27 February 2015).

European Council (2002) Presidency Conclusions. Barcelona European Council 15-16

March 2002. Available at: http://ec.europa.eu/invest-in-research/pdf/download_en/ barcelona_european_council.pdf (accessed 27 February 2015).

Eurydice (2012) Key data on teaching languages at school in Europe 2012. Report, Brussels: Education, Audiovisual and Culture Executive Agency. Available at: http://eacea.ec.europa.eu/education/eurydice/documents/key_data_series/ 143en.pdf (accessed 24 February 2015).

Feu Guijarro MJ and Piñero Gil E (1996) El mundo sonoro y la adquisición del lenguaje

Revista Música, Arte y Proceso 2: 38-49.

Foddy W (1993) Constructing Questions for Interviews and Questionnaires.

Cambridge: Cambridge University Press.

Fogarty R (1994) The Mindful School. How to Teach for Metacognitive Reflection.

Palantine, IL: IRI/ Skylight.

Fonseca Mora C (2000) Foreign language acquisition and melody singing. ELT Journal 54(2): 146-152.

Fonseca Mora C, Jara Jiménez P and Gómez Dominguez M (2015) Musical plus phonological input for young foreign language readers. Frontiers in Psychology 6(286): 1-16. Available at: www.frontiersin.org (accessed 28 March 2015).

Foster-Cohen S (1999) An Introduction to Child Language Development. London: Longman.

Fröhlich-Ward L, Lehnart-Adler I \& Wessel-Schmidt C (2001) IKURU. Berlin: Cornelsen.

Gallwey WT (1974) The Inner Game of Tennis. New York: Random House. Gardener, H (1983) Frames of Mind: The Theory of Multiple Intelligences. New York: Basic Books.

Garton S, Copland, F and Burns A (2011) Investigating Global Practices in Teaching English to Young Learners. London: British Council.Available at: www.britishcouncil.org (accessed 15 January 2015). 
Garvie E (1991) Teaching English through story. In: Kennedy C and Jarvis J (eds) Ideas and Issues in Primary ELT. Walton-on-Thames: Nelson, pp. 56-65.

Gathercole SE and Baddeley AD (1989) Evaluation of the role of phonological STM in the development of vocabulary in children: A longitudinal study. Journal of Memory and Language 28: 200-213.

Gathercole SE, Willis CS, Emslie H and Baddeley AD (1992) Phonological memory and vocabulary development during the early school years: A longitudinal study. Developmental Psychology 28: 887-898.

Gee JP (1985) The Narrativization of Experience in the Oral Style. Journal of Education 167: 9-35.

(2011) How to Do Discourse Analysis. Oxon and New York: Routledge.

Geibert E (1995) Der Modellversuch ‘Integrierte Fremdsprachenarbeit in der

Grundschule‘ im Überblick: Intentionen, Organisation, Inhalte. In:

Staatliches Institut für Lehrerfort- und -weiterbildung Speyer (ed)

Entwicklung und Erprobung eines didaktischen Konzeptes zur

Fremdsprachenarbeit in der Grundschule. Saarburg: SIL, pp. 15-34.

Ghosn IK (2004) Four good reasons to use literature in primary school EL. In: Ellis

G and Morrow K (eds) ELT Journal. Year of the Young Learner Special Collection, Oxford: Oxford University Press, pp. 56-65.

Gibson JJ (1979) The Ecological Approach to Visual Perception. Boston: Houghton Mifflin.

(1986) The Ecological Approach to Perception. Hillsdale, NJ: Lawrence

Erlbaum Associates.

Gillham B (2000) Developing a Questionnaire. London: Continuum.

Gleitman H et al. (1999) Psychology. $5^{\text {th }}$ ed. New York \& London: Norton.

Goffman E (1961) Asylums. New York: Anchor Books.

Goleman D (1995) Emotional Intelligence. New York: Bantam Books.

Gompf G (1971) Englisch in der Grundschule. Schulversuche in der BRD, Frankreich, Schweden und der CSSR. Weinheim: Beltz. (1975) Englischunterricht auf der Primarstufe. Didaktische Modelle und Perspektiven. Weinheim: Beltz. 
(2006) Fremdsprachen in der Grundschule. In: Gompf G (ed) Kinder lernen europäische Sprachen. Available at:

http://www.kles.org/frameset.html?mainFrame=http://www.kles.org/ herausgeberin_1.html (accessed 12 May 2012).

(2008) (ed) Kinder lernen europäische Sprachen. Available at:

http://www.kles.org/frameset.html?mainFrame=http://www.kles.org/ herausgeberin_1.html (accessed 08 May 2012).

(2009) Fremdsprachen ab Klasse 1 - Schuljahr 2009/10. In: Gompf G (ed)

Kinder lernen europäische Sprachen. Available at:

http://www.kles.org/frameset.html?mainFrame=http://www.kles.org/

herausgeberin_1.html (accessed 28 May 2012).

Gompf G and Helfrich H (2005) Englisch ab 3. Grundschuljahr ohne Noten? In:

Kinder lernen europäische Sprachen. Available at:

http://www.kles.org/frameset.html?mainFrame=http://www.kles.org/

herausgeberin_1.html (accessed 13 May 2012).

Gort M (2006) Strategic codeswitching, interliteracy, and other phenomena of emergent bilingual writing: lessons from first grade dual language classrooms. Journal of Early Childhood Literacy 6: 323-354.

Gort M (2012) Codeswitching patterns in the writing-related talk of young emergent bilinguals. Journal of Literacy Research 44 (1): 45-75.

Green JL and Bloome D (1997) Ethnography and ethnographers of and in education: a situated perspective. In: Flood J, Heath SB and Lapp D (eds) Handbook of Research on Teaching Literacy Through Communicative and Visual Arts. New York: Macmillan, pp. 181-202.

Green JL, Skukauskaite A and Baker WD (2012) Ethnography as epistemology: an introduction to educational ethnography. In: Coe R, Arthur J, Hedges L and Waring W (eds) Research Methodologies and Methods in Education. London: Sage, pp. 309-22.

Guderian, C and Guhe, I (2001) Englisch - keine Hexerei. Berlin und München: Langenscheidt.

Hall JK (2011) Teaching and Researching Language and Culture. $2^{\text {nd }}$ ed. London: 
Pearson.

Hall G (2005) Literature in Language Education. Basingstoke and New York:

Palgrave Macmillan.

(2015) Literature in Language Education. $2^{\text {nd }}$ ed. Basingstoke and New

York: Palgrave Macmillan.

Harris J and O’Leary D (2009) A third language at primary level in Ireland: an

independent evaluation of the modern languages in primary schools initiative. In:

Nikolov (ed) Early Learning of Modern Foreign Languages. Processes and

Outcomes. Bristol/Buffalo/Toronto: Multilingual Matters, pp. 1-14.

Harrison L, Prochazka A and Rychli E (2005) Supermouse. Ismaning: Hueber.

Hatch E et al. (1979) A look at process in child second language acquisition. In:

Ochs E and Schieffelin B (ed) Developmental Pragmatics. New York:

Academic Press, pp. 269-78.

Helfrich H (1995) Evaluation des Modellversuchs 'Integrierte Fremdsprachenarbeit an Grundschulen in Rheinland-Pfalz’. In: Staatliches Institut für Lehrerfortund -weiterbildung Speyer (ed) Entwicklung und Erprobung eines didaktischen Konzeptes zur Fremdsprachenarbeit in der Grundschule, Saarburg: SIL, pp. 97-123.

Henning G (1973) Remembering foreign language vocabulary: acoustic and semantic parameters. Language Learning 23 (2): 185-196.

Holdaway D (1979) The Foundations of Literacy. Sydney: Ashton-Scholastic.

Holland NN (1968) The Dynamics of Literary Response. New York: Oxford University Press.

Howatt APR and Widdowson HG (2004) A History of English Language Teaching.

Oxford: Oxford University Press.

Höweler M (1972) Diversity of word usage as a stress indicator in an interview situation.

Journal of Psycholinguistic Research I(3): 243-248.

Huang J and Hatch E (1978) A Chinese child's acquisition of English. In: Hatch E (ed) Second Language Acquisition. A Book of Readings. Rowley, MA: Newbury House, pp. 118-31.

Hulme C and Snowling MJ (2014) The interface between spoken and written language: 
developmental disorders. Philosophical Transactions of the Royal Society B:

Biological Sciences 369(1634). Available at: http://rstb.royalsocietypublishing. org/content/369/1634/20120395 (accessed 01 April 2015).

Hunt P (2001) Children's Literature. Malden, MA and Oxford: Blackwell Publishing. Hunt R and Brychta A (2000a) Big Feet. Oxford: Oxford University Press.

(2000b) Go Away, Floppy. Oxford: Oxford University Press.

(2000c) Kipper’s Diary. Oxford: Oxford University Press.

(2000d) Look at Me. Oxford: Oxford University Press.

Huschner A (1997) Fremdsprachliche Spezialklassen als Strukturmerkmal des

DDR-Schulsystems (1967/68 bis 1989/90). In: Tenorth, H-E (ed) Kindheit,

Jugend und Bildungsarbeit im Wandel. Ergebnisse der

Transformationsforschung. Weinheim: Beltz, pp. 203-225.

Hymes D (1973) On communicative competence. In: Pride, JB and Holmes, J (eds)

Sociolinguistics. Harmondsworth: Penguin, pp. 269-93.

Iser W (1978) The Act of Reading: A Theory of Aesthetic Response. London: Routledge \& Kegan Paul.

Jefferson G (1983) Issues in the transcription of naturally-occurring talk: caricature versus capturing pronunciational particulars. Tilburg Papers in Language and Literature 34(1-12) Tilburg: Tilburg University.

Jefferson G (2004) Glossary of transcript symbols with an introduction. In: Lerner

GH (ed) Conversation Analysis. Studies from the First Generation.

Amsterdam and Philadelphia: John Benjamins.

Johnson K (1996) Language Teaching \& Skill Learning. Oxford: Blackwell.

Jolly YS (1975) The use of songs in teaching foreign languages. The Modern Language Journal 59(1/2): 11-14.

Jongejan W, Verhoeven L and Siegel LS (2007) Predictors of reading and spelling abilities in first- and second-language learners. Journal of Educational Psychology 13, pp. 19-27.

Karmiloff-Smith A (1992) Beyond Modularity. Cambridge, Mass.: MIT Press.

Klippel F (2000) Englisch in der Grundschule. Berlin: Cornelsen.

Kolb A (2013) Extensive reading of picturebooks in primary EFL. In: Bland J and Lütge, 
C (eds) Children's Literature in Second Language Education. Bloomsbury: London and New York, pp.33-43.

Kramsch C (1993) Context and Culture in Language Teaching, Oxford and New York: Oxford University Press.

Krashen SD (1977) Some issues relating to the monitor model. In: Brown H, Yorio C and Crymes R (eds) Teaching and Learning English as a Second Language: Trends and Research in Practice. On TESOL '77: Selected Papers from the Eleventh Annual Convention of Teachers of English to Speakers of Other Languages, Miami, Florida, April 26 - May 1, 1977. Washington, DC: Teachers of English to Speakers of Other Languages, pp. 144-158. (1981) Second Language Acquisition and Second Language Learning. Oxford: Pergamon. (2003) Explorations in Language Acquisition and Use. The Taipai Lectures. Portsmouth, NH: Heinemann.

Kubanek-German A (2000) Early Language Programmes in Germany. In: An Early Start: Young Learners and Modern Languages in Europe and Beyond. Available at: http://www.poliglotti4.eu/docs/Research/An_Early_Start_Young_Learners_and_ Modern_Languages_in_Europe_and_Beyond.pdf (accessed 12 May 2012). (2001) Kindgemäßer Fremdsprachenunterricht. Bd.1. Ideengeschichte, Münster: Waxmann.

Kuczaj SA (1983) Crib Speech and Language Play. Springer Verlag: New York. Labov W (1970) The study of language in its social context. In: Labov W (1972) Sociolinguistc Patterns. Oxford: Basil Blackwell, pp. 30-87. (1972) Language in the Inner City. Oxford: Basil Blackwell.

Lakoff G and Johnson M (1999) Philosophy in the Flesh: The Embodied Mind and its Challenge to the Western Thought. New York: Basic Books.

Lantolf JP, and Thorne SL (2006) Sociocultural Theory and the Genesis of Second Language Development. Oxford: Oxford University Press.

Lemke JL (1990) Talking Science, Language, Learning, and Values. Norwood, NJ: Ablex. 
Lewin K (1943) Defining the 'field at a given time’. Psychological Review 50: 292-310.

Lightbown PM, and Spada N (2006) How Languages Are Learned. $3^{\text {rd }}$ edition.

Oxford: Oxford University Press.

London J and Remkiewicz F (1992) Froggy Gets Dressed. New York, London,

Victoria, Toronto and Auckland: Puffin.

Lopriore L and Krikhaar E (2011) The school. In: Enever (ed) ELLiE. Early Language

Learning in Europe. British Council. Available at: www.teachingenglish.org.uk/ sites/teaching/files/B309 (accessed 15 January 2015).

Lütge C (2013) Otherness in children’s literature. Perspectives for the EFL Classroom. In: Bland J and Lütge C (eds) Children's Literature in Second Language Education. London and New York: Bloomsbury Academic, pp. 97-105.

Mariott S (1998) Picture books and the moral imperative. In: Evans J (ed) What's in

a Picture? Responding to Illustrations in Picture Books. London: Sage, pp. 1-24.

Marks D (1973) Visual imagery differences in the recall of pictures. British Journal of

Psychology 64(1): 17-24.

Martin I (2006) Terms of Integration: Educating Primary EFL Teacher Learners. In:

Paran A (ed) Literature in Language Teaching and Learning. Case Studies in TESOL Practice. Alexandria, VA: TESOL, pp. 87-100.

Masoura EV and Gathercole SE (1999) Phonological Short-term memory and foreign language learning. International Journal of Psychology 34(5/6): 383-88.

Maybin J (1994) Children’s voices: talk, knowledge and identity. In: Graddol D, Maybin J and Stierer B (eds) Researching Language and Literacy in Social Context. Clevedon, Philadelphia, Adelaide: Multilingual Matters Ltd and The Open University, pp. 131-150.

(2007) Literacy under and over the desk: oppositions and heterogeneity.

Language and Education 21(6): 515-530.

McCracken RA (1971) Initiating 'Sustained Silent Reading'. Journal of Reading 14(8): 521-529.

McKee D (1968) Elmer. London: Andersen.

McLaughlin B (1990) Restructuring. Applied Linguistics 11: 113-128.

Mehler J and Dupoux E (1992) Nacer sabiendo. Introducción al Desarrollo Cognitivo del 
Hombre. Madrid: Alianza.

Melby-Lervåg M, Lyster S and Hulme C (2012) Phonological skills and their role in learning to read: A meta-analytic review. Psychological Bulletin 138(2): 322-352.

Miller GA (1956) The magical number seven, plus or minus two: Some limits on our capacity for processing information. Psychological Review 63: 81-97.

Miller GA and Johnson-Laird P (1976) Language and Perception. Cambridge: Cambridge University Press.

Ministerium für Bildung, Frauen und Jugend (2004a) Verwaltungsvorschrift des Ministeriums für Bildung, Frauen und Jugend vom 14. Juli 2004, Mainz. Available at: http://grundschule.bildung-rp.de/amtliches-alt/ unterrichtsorganisation-in-der-Grundschule.html (accessed 13 February 2015). (2004b) Rahmenplan Grundschule. Teilrahmenplan Fremdsprache, Mainz. Available at: http://grundschule.bildung-rp.de/fileadmin/user_upload/grundschule.bildung-rp. de/Downloads/Rahmenplan/Rapla-FS-Druckfassung.pdf (accessed 30 June 2012).

(2005) Integrierte Fremdsprachenarbeit in der Grundschule. Informationen zum frühen Fremdsprachenlernen. Mainz. Available at: http://grundschule.bildung-rp.de/fileadmin/user_upload/ grundschule.bildung-rp.de/Downloads/Fremdsprachen/Amtliches/ FlyerIntegrierteFremdsprachenarbeitinderGrundschule.pdf (accessed 15 May 2012).

(2007) Fremdsprachen von Anfang an. Mainz. Available at: http://grundschule.bildung-rp.de/fileadmin/user_upload/ grundschule.bildung-rp.de/Downloads/Fremdsprachen/IFA_Broschuere_Januar2 007. pdf (accessed 15 May 2012).

Ministerium für Bildung, Wissenschaft, Jugend und Kultur (2009) PFIFF Projekt Fort-und Weiterbildung im frühen Fremdsprachenlernen. Mainz. Available at: http://grundschule.bildung-rp.de/fileadmin/user_upload/ grundschule.bildung-rp.de/Downloads/Fremdsprachen/PFIFF/PFIFF_3_Auflage 
_7_September_09.pdf (accessed 15 May 2012).

(2011) Fremdsprachen von Anfang an, Mainz. Available at:

http://grundschule.bildung-rp.de/fileadmin/

user_upload/grundschule.bildung-rp.de/Downloads/Fremdsprachen/

Fremdsprachen_Broschuere_2011.pdf (accessed 30 June 2012).

Mishler EG (1986) Research Interviewing: Context and Narrative, Cambridge, MA:

Harvard University Press.

Mitchell R and Martin C (1997) Rote Learning, creativity and 'understanding' in

classroom foreign language teaching. Language Teaching Research I(1): $1-27$.

Moon J (2000) Children Learning English. Oxford: Macmillan Heinemann.

Moskowitz, G (1967) The Flint system: an observational tool for the foreign language class. In : Simon, A and Boyer, EG (eds) Mirrors for Behavior: An Anthology of Classroom Observation Instruments. Section 15. Philadelphia: Cener for the Study of Teaching, Temple University, pp. 1-15. (1971) Interaction analysis - a new modern language for supervisors.

Foreign Language Annals 5: 211-221.

(1976) The classroom interaction of outstanding foreign language teachers. Foreign Language Annals 9: 135-143, 146-157.

Mosquito Song. Available at: weesing.com/songsheets/lyricLearn Bugs.pdf. (accessed 7 October 2015)

Mother Goose's Melody or Sonnets for the Cradle (1780) Newbery: London. Mourão S (2012) Supporting the development of emotional intelligence. In: IATEFL

Young Learner and Teenager SIG Publication 2012(1): 8-11, 34-35. (2013) Picturebook: Object of Discovery. In: Bland J and Lütge C (eds) Children's Literature in Second Language Education. Bloomsbury: London and New York, pp. 71-84.

Muñoz C and Lindgren E (2011) Out-of-school factors: the home. In: Enever (ed) ELLiE. Early Language Learning in Europe. British Council. Available at: www.teachingenglish.org.uk/sites/teaching/files/B309 (accessed 15 January 2015). 
Murphey T (1990) The Song stuck in my head phenomenon: A melodic Din in the LAD? System 18(1): 53-64.

(1992) Music \& Song. Resource Books for Teachers. Oxford: Oxford University Press.

(1995) Identity and beliefs in language learning. The Language Teacher 19(4): 34-36.

Myles F (2012) Learning French from ages 5, 7 and 11: An investigation into starting ages, rates and routes of learning amongst early foreign language learners. Available at: http://www.esrc.ac.uk/my-esrc/grants/RES-062-23-1545/read (accessed 20 May 2012).

Nation P (2001) Learning Vocabulary in Another Language. Cambridge: Cambridge University Press.

Nattinger JR and DeCarrico JS (1992) Lexical Phrases and Language Teaching. Oxford: OUP.

Neisser U (1976) Cognition and Reality: Principles and Implications of Cognitive Psychology. New York: Freeman.

New London Group (1996) A pedagogy of multiliteracies: Designing social futures. Harvard Educational Review 66(1): 64.

Newmark L (1979) How not to interfere with language learning. In: Brumfit CJ and Johnson K (eds) The Communicative Approach to Language Teaching. Oxford: Oxford University Press, pp. 160-166.

Nikolov M (2000) Issues in research into foreign language programmes. In: Moon J and Nikolov M (eds) Research into Teaching English to Young Learners. Pecs: University of Pecs Press. (ed) (2009) Early Learning of Modern Foreign Languages. Processes and Outcomes. Bristol/Buffalo/Toronto: Multilingual Matters.

Ochs E (1979) Transcription as theory. Developmental Pragmatics 10(1): 43-72. O!Kay! Die Englischzeitschrift für Grundchulkinder (1999) München: Domino. Oostdam R and van Toorenburg H (2009) Alive but not kicking: State of the art in the Netherlands of learning English as a foreign language in primary and the transition to secondary education. In: Engel G, Groot-Wilken B and Thürmann E 
(eds) Englisch in der Primarstufe - Chancen und Herausforderungen.

Evaluation und Erfahrungen aus der Praxis. Berlin: Cornelsen, pp. 76-91.

Oxford Advanced Learner's Dictionary (1989) Oxford: Oxford University Press.

Paivio A (1971) Imagery and Verbal Processes. New York: Holt, Rinehart and Winston.

Paran A (2008) The role of literature in instructed foreign language learning and teaching:

An evidence-based survey. Language Teaching 41(4): 465-496.

(2010) Between Scylla and Charybdis: The dilemmas of testing language and

literature. In: Paran A and Sercu L (eds) Testing the Untestable in Language

Education. Bristol: Multilingual Matters, pp. 143-64.

(2013) Content and Language Integrated Learning: Panacea or policy borrowing myth? Applied Linguistics Review 4(2): 317-342.

Paran A and Watts E (eds) (2003) Storytelling in ELT. Whitstable: IATEFL.

Paterson A and Willis A (2008) English through Music. Oxford: Oxford University Press.

Pawley A and Syder FH (1983) Two puzzles for linguistic theory: nativelike selectionand

nativelike fluency. In: Richards JC and Schmidt RW (eds) Language and

Communication. London and New York: Longman, pp. 191- 225.

Peck S (1980) Language play in child second language acquisition. In: Larsen-

Freeman, D (ed) Discourse Analysis in Second Language Research. Rowley, MA: Newbury House, pp. 154-164.

Peters AM (1983) Units of Language Acquisition. Cambridge: Cambridge University Press.

Peterson RA (2000) Constructing Effective Questionnaires. London: Sage.

Petillon H (1995) Integrierte Fremdsprachenarbeit in der Grundschule aus der Perspektive der beteiligten Kinder: eine Pilotstudie. In: Staatliches Institut für Lehrerfort- und -weiterbildung Speyer (ed) Entwicklung und Erprobung eines didaktischen Konzeptes zur Fremdsprachenarbeit in der Grundschule, Saarburg: SIL, pp. 141-53.

Piaget J (1923) Le Language et la pensée chez l'enfant. Neuchâtel, Paris: Delachaux et Niestlé. (1959) The Language and Thought of the Child. 3rd ed. London and New York: Routledge. 
Pienemann M (1998) Language Processing and Second Language Development.

Processability Theory. Amsterdam: Benjamins.

Pienemann M, Kessler J-U, and Roos E (ed) (2006) Englischerwerb in der

Grundschule. Paderborn: Schöningh.

Pimsleur P (1967) A memory schedule. Modern Language Journal 51: 73-75.

Pinker S (1997) How the Mind Works. New York, NY: W.W. Norton and Company, Inc.

Pinter A (2006) Teaching Young Language Learners. Oxford: Oxford University Press.

Pinter A, Kuchah K and Smith R (2013) Researching with children. ELT Journal 67(4): 484-487.

Politzer RL (1970) Some reflections on 'good' and 'bad' language teaching behaviors.

Language Learning 20: 31-43.

Politzer RL and Weiss L (1969) Characteristics and Behaviors of the Successful Foreign

Language Teacher. Technical Report No. 5. Stanford, CA: Stanford Center for

Research and Development in Teaching. Available at:

http://eric.ed.gov/?id=ED031124 (accessed 30 May 2015).

Primary Colours. Resources for the EFL classroom. Available at

http://primaryeflresources.wordpress.com/tag/were-going-on-a-bear-hunt/

(accessed 18-10-13)

Propp V (1958) Morphology of the Folk Tale. Austin, Texas: University of Texas Press.

Read C (2007) 500 Activities for the Primary Classroom. Oxford: Macmillan.

Reed GF (1968) Skill. In: Lunzer EA and Morris JF (eds) Developments in Human

Learning. New York: Spales, pp. 104-43.

Rehbein J (1987) Multiple formulae aspects of Turkish migrant workers' German in

intercultural communication. In: Knapp K, Enninger W and Knapp-Potthoff A

(eds) Analysing Intercultural Communication. Berlin: Mouton de Gruyter, pp.

215-48.

Reilly V and Ward S (1997) Very Young Learners. Oxford: Oxford University Press.

Richards K (2003) Qualitative Inquiry in TESOL. Basingstoke: Palgrave Macmillan.

Ricketts J (1982) The effects of listening to stories on comprehension and reading achievement. Directions Fiji 8: 29-36.

Rinvolucri M (1999) The humanistic exercise. In: Arnold J (ed) Affect in Language 
Learning. Cambridge: Cambridge University Press, pp. 194-210.

Rogers C (1983) Freedom to Learn for the 80s. Columbus, Ohio: Charles E. Merrill. Roos E (2006) Unterrichtskonzeption und Spracherwerb. In: Pienemann M, Keßler J-U and Roos E (eds) Englischerwerb in der Grundschule. Paderborn: Schöningh, pp. 217-235.

Rosen, M and Oxenbury H (1989) We 're Going on a Bear Hunt. London: Walker Books. (1997) We 're Going on a Bear Hunt. Board Book. London: Walker Books. (2004) We 're Going on a Bear Hunt. London: Walker Books. (2007) We 're Going on a Bear Hunt. A celebratory pop-up edition. London: Little Simon. (2009) We 're Going on a Bear Hunt. Anniversary edition of a modern classic. New York: Margaret K. McElderry Books.

Rosenblatt LM (1978) The Reader, the Text, the Poem: The Transactional Theory of the Literary Work. Carbondale, IL: Southern Illinois University Press.

Rowling JK (1997) Harry Potter and the Philosopher's Stone. London: Bloomsbury. Rück H (1995) Theoretische Grundlagen und praktische Formen des Spracherwerbs im Modellversuch. In: Staatliches Institut für Lehrerfortund -weiterbildung Speyer (ed) Entwicklung und Erprobung eines didaktischen Konzeptes zur Fremdsprachenarbeit in der Grundschule, Saarburg: SIL, pp. 57-95.

Sacks H (1984) Notes on methodology. In: Atkinson JM and Heritage J (eds) Structures of Social Action: Studies in Conversation Analysis. Cambridge: Cambridge University Press, pp. 21-7.

Salovey P and Mayer J (1990) Emotional intelligence. Imagination, Cognition and Personality 9: 185-211. Available at: http://www.unh.edu/ emotional_intelligence/EIAssets/EmotionalIntelligenceProper/ EI1990\%20Emotional\%20Intelligence.pdf. (accessed 17 March 2015).

Samph T (1976) Observer effects on verbal teacher classroom behavior. Journal of Educational Psychology 68(6): 736-741.

Sauer H (1993) Der Beginn des Fremdsprachenunterrichts in der Grundschule. Neusprachliche Mitteilungen aus Wissenschaft und Praxis 25(3): 129-137. 
Saville-Troike M (1988) Private speech: evidence for second language learning strategies during the 'silent period'. Journal of Child Language 15: 567-90.

Scherer GAC and Wertheimer M (1964) A Psycholinguistic Experiment in Foreign Language Teaching. New York: McGraw-Hill.

Schieffelin BB and Ochs E (1986) Language Socialization. Annual Review of Anthropology 15: 163-191.

Schmid-Schönbein G (2008) Didaktik und Methodik für den Englischunterricht. Berlin: Cornelsen. (ed) (2009) Zur Effektivität des Englischunterrichts. Baustellen Übergang. Grundschulmagazin 3: 6-7.

Schmidt RW (1983) Interaction, acculturation, and the acquisition of communicative competence: a case study of an adult. In: Wolfson $\mathrm{N}$ and Elliot J (eds) Sociolinguistics and Language Acquisition. Rowley, MA: Newbury, pp. 137174.

Schmidt RW (1990) The role of consciousness in second language learning. Applied Linguistics II (2): 129-158.

Schmidt RW and Frota S (1986) Developing basic conversational ability in a second language: a case study of an adult learner of Portuguese. In: Day R (ed) Talking to Learn: Conversation in Second Language Acquisition. Rowley, MA: Newbury House, pp. 237-326.

Schumann JH (1999) A neurobiological perspective on affect and methodology in second language learning. In: Arnold J (ed) Affect in Language Learning. Cambridge: Cambridge University Press, pp. 28-57.

Schwarz M (2012) Learning with Lady Gaga \& Co: Incidental EFL Vocabulary Acquisition from Pop Songs. Unpublished Masters thesis. University of Vienna, Austria. Available at: http://othes.univie.ac.at/20795/ (accessed 31 March 2015).

Service E (1992) Phonology, working memory, and foreign language learning. The Quarterly Journal of Experimental Psychology 45(A): 21-50.

Shiffrin RM and Dumais ST (1981) The development of automatism. In: Anderson JR (ed) Cognitive Skills and Their Acquisition. Hillside, NJ: Lawrence Erlbaum, pp. 111-40. 
Sinclair J (1991) Corpus, Concordance, Collocation. Oxford: OUP.

Sinclair J and Coulthard M (1975) Towards an Analysis of Discourse: The English

Used by Teachers and Pupils. Oxford: OUP.

Singleton D (1999) Exploring the Second Language Mental Lexicon. Cambridge:

Cambridge University Press.

(2007) The critical period hypothesis: some problems. Interlingüística 17: 48-56.

Stevens R (1912) The Question as a Measure of Efficiency in Instruction. Teachers College Contribution to Education 48. New York: Teachers’ College, Columbia University.

Stevick EW (1999) Affect in learning and memory: From alchemy to chemistry. In:

Arnold J (ed) Affect in Language Learning. Cambridge: Cambridge University Press, pp. 43-57.

Swain M and Lapkin S (1995) Problems in output and the cognitive process they generate: a step towards second language learning. Applied Linguistics 16(3): 371-391.

Szpotowicz M and Lindgren E (2011) Language achievements: a longitudinal perspective. In: Enever J (ed) ELLiE. Early Language Learning in Europe. British Council. Available at: www.teachingenglish.org.uk/sites/teaching/ files/B309 (accessed 15 January 2015).

Teflnet. Available at: http://www.tefl.net/ (accessed 18-10-13).

The Three Little Pigs (2008) Grundschule Englisch 23: 22-27.

Thomas V and Paul K (1987) Winnie the Witch. Oxford: Oxford University Press. Tin, TB (2013) Towards creativity in ELT: the need to say something new. ELT Journal. Available at: http://eltj.oxfordjournals.org/ (accesssed 12-02-2014). Tizard B and Hughes M (1984) Young Children Learning. Fontana: London.

Toscano-Fuentes C (2010) Estudio empírico de la relación existente entre el nivel de adquisición de una segunda lengua, la capacidad auditiva y la inteligencia musical del alumnado. Unpublished PhD thesis. University of Huelva, Spain. Available at: http://rabida.uhu.es/dspace/bitstream/handle/10272/4507/ b16147960.pdf (accessed 31 March 2015). 
Tragant Mestres E and Lundberg G (2011) The teacher's role: what is its significance in early language learning? In: Enever (ed) ELLiE. Early Language Learning in Europe. British Council. Available at: www.teachingenglish.org.uk/sites/teaching/files/B309 (accessed 15 January 2015).

van Lier L (1988) The Classroom and the Language Learner: Ethnography and Second Language Classroom Research. London: Longman. (2004) The Ecology and Semiotics of Language Learning: A

Sociocultural Perspective. Dordrecht: Kluwer.

Viëtor W (1905) Der Sprachunterricht muss umkehren. Leipzig: O.R. Reisland. Vihman MM (1982) Formulas in First and Second Language Acquisition. In: Menn L and Obler L (eds) Exceptional Language and Linguistics. New York: New York Academic Press, pp. 261-83.

von Wilpert, G (1989) Sachwörterbuch der Literatur. Stuttgart: Alfred Kröner Verlag. Vygotsky L (1962) Thought and Language. New York: Wiley.

(1978) Mind in Society. Cambridge, MA: Harvard University Press.

Waddel M and Barton J (1992) The Pig in the Pond. Cambridge, MA: Candlewick Press. Wallace MJ (1998) Action Research for Language Teachers. Cambridge: Cambridge University Press.

Watson-Gegeo KA (1988) Ethnographic Inquiry into Second Language Acquisition and Instruction. Paper presented at the TESOL Convention, 9 March, Chicago. Available at: http://files.eric.ed.gov/fulltext/ED295466.pdf (accessed 31-08-2014).

(1992) Thick explanation in the ethnographic study of child socialization and development: A longitudinal study of the problem of schooling for Kwara'ae (Solomon Islands) children. In: Corsaro WA and Miller PJ (eds) New Directions for Child Development: Vol. 58. The Production and Reproduction of Children's Worlds: Interpretive Methodologies for the Study of Childhood Socialization. San Francisco: Jossey-Bass, pp. 51-66. (2004) Mind, Language, and Epistemology: Toward a Language socialization paradigm for SLA. The Modern Language Journal 88(3): 
331-350.

Weinert R (1995) The role of formulaic language in second language acquisition: a review. Applied Linguistics 15: 180-205.

Weskamp R (2009) Fremdsprachenlernen in der Grundschule: Das badenwürttembergische Forschungsprojekt „WiBe“. In: Engel G, Groot-Wilken B and Thürmann E (eds) Englisch in der Primarstufe - Chancen und Herausforderungen. Evaluation und Erfahrungen aus der Praxis. Berlin: Cornelsen, pp. 47-66.

Widdowson HG (1992) Aspects of the relationship between culture and language. In: Antor H and Ahrens R (eds) Text-Culture-Reception. Cross Cultural Aspects of English Studies. Carl Winter Universitaetsverlag, pp. 147-61.

Wilson EO (2012) The Social Conquest of the Earth. New York, NY: Liveright Publishers.

Wilson S (1977) The use of ethnographic techniques in educational research. Review of Educational Research 47(1): 245-265.

Wolfson N (1976) Speech events and natural speech: some implications for sociolinguistic methodology. Language in Society 5(2): 189-209.

Wong Fillmore L (1976) The Second Time Around: Cognitive and Social Strategies in Second Language Acquisition. PhD Thesis, Stanford University, US.

Wood D, MacMahon L and Cranstoun Y (1980) Working with Under-Fives. Grant McIntyre: London.

Woodgate-Jones A (2005) The purpose of modern foreign languages in the primary school: an investigation into tutors' and trainees' perceptions. In: European Conference on Educational Research (ECER) 2005, Dublin, 07 - 10 September 2005. Available at: http://eprints.soton.ac.uk/54565/ (accessed 20 May 2012).

Wragg, EC (1970) Interaction analysis in the foreign language classroom. Modern Language Journal 54: 116-120. (1999) Introduction to Classroom Observation. London: Routledge.

Wray A (2002) Formulaic Language and the Lexicon. Cambridge: Cambridge University Press. (2008) Formulaic Language: Pushing the Boundaries. Oxford: Oxford 
University Press.

Wright A (1995) Storytelling with Children. Oxford: Oxford University Press.

(2003) The place of stories in ELT. In: Paran A and Watts E (eds)Storytelling in ELT. Whitstable: IATEFL, pp. 7-10. 
Appendix 1: Statement of Ethics, letters to teachers and parents \& consent forms

\section{Statement of Ethics}

It is my promise that, while carrying out this research that I consider worthwhile and of benefit to all participants, I have observed the highest possible ethical standards.

I have reported my findings honestly and truthfully. While acknowledging the rights of all research participants, I also retain the right to report in compliance with all the ethical protocols outlined here.

- All participants were informed about the nature of the research in writing prior to data collection and have been made aware that participation is voluntary.

- Strict confidentiality has been adhered to. No real names have been included in the written report. Pseudonyms have been used for participating schools and teachers.

- The permission of the participating children and the written consent of their parents were obtained before the study commenced.

- Greatest care was taken to ensure that research did not detract from the normal work of the classes.

- Participating teachers have been informed about key findings of the research undertaken, and wherever possible been given the opportunity to share their views on these in interviews.

31 January 2016

Annett Kaminski 


\section{INSTITUT FÜR FREMDSPRACHLICHE Philologien / FACH ANGListik}

\author{
ANNETT SCHÄFER, M.A.
}

\section{UN I VER S I TÄ T KOBLENZ $\cdot$ LANDAU}

\section{Forschungsarbeit/ Englisch in der Grundschule}

Liebe Grundschullehrerin, lieber Grundschullehrer,

wie Sie sicherlich wissen, besuchen seit dem Wintersemester 2002/2003 alle zukünftigen Grundschullehrer Seminare in Französisch oder Englisch. Unsere Studenten belegen Sprachkurse sowie Veranstaltungen zu Landeskunde, Kinderliteratur, Linguistik und Fachdidaktik.

Als Dozentin im Bereich Anglistik bin ich darum bemüht, Seminare anzubieten, die sich an den Anforderungen der Praxis orientieren. Mein Ziel ist es, herausfinden, welche Aktivitäten sich im Englischunterricht bewährt haben und welche Probleme beim Heranführen der Kinder an die Fremdsprache auftreten. Im Rahmen meiner Forschungsarbeit interessiert mich insbesondere der Einsatz von Geschichten, Gedichten und Liedern im Englischunterricht. Ich wende mich heute in der Hoffnung an Sie, dass Sie mich mit Ihren Erfahrungen, die Sie tagtäglich in diesem Bereich sammeln, unterstützen.

Beiliegend $\mathrm{zu}$ diesem Brief finden Sie einen anonymen Umfragebogen zur Fremdsprachenarbeit/Englisch. Der Umfragebogen umfasst sowohl allgemeine Fragen zur integrierten Fremdsprachenarbeit als auch Fragen zur Verwendung von Geschichten, Gedichten und Liedern.

Ich habe den Umfragebogen so konzipiert, dass er von Ihnen relativ schnell und einfach ausgefüllt werden kann. Alle Antworten werden streng vertraulich behandelt. Bitte stecken Sie Ihren ausgefüllten Bogen in den beiliegenden Rückumschlag und geben Sie diesen verschlossen im Sekretariat ab. Die Fragebögen werden bis zum 15. Juni zurück in Ihrer Schule abgeholt.

Ich würde mich freuen, wenn Sie sich an der Umfrage beteiligen könnten. Für Ihre Mühe bedanke ich mich bereits im Voraus und verbleibe

mit freundlichen Grüßen 


\section{INSTITUT FÜR FREMDSPRACHLICHE PHILOLOGIEN / FACH ANGLISTIK} ANNETT SCHÄFER, M.A.

\section{UNIVER S I TÄT KOBLENZ $\cdot$ LANDAU

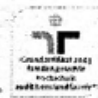

Campus Landau

Postanschrift: Im Fort 7

Besucheradresse: Marktstr. 40

D - 76829 Landau

Telefon

Telefax

E-mail:

19.02.09

Projekt "Wie Kinder englischen Wortschatz lernen“

\section{Liebe Eltern,}

Englisch in der Grundschule gibt es erst seit relativ kurzer Zeit. Mit dem Schuljahr 2005/2006 wurde der Fremdsprachenunterricht in Rheinland-Pfalz flächendeckend eingeführt. Zusammen mit Baden-Württemberg ist Rheinland-Pfalz damit bundesweit Vorreiter beim frühen Fremdsprachenerwerb ab der ersten Klasse. Ihre Kinder gehören zu der ersten Generation an Grundschülern, die von Anfang an Englisch lernen und ich hoffe, sie haben viel Freude daran!

Als wissenschaftliche Mitarbeiterin im Bereich Anglistik an der Universität Landau unterrichte ich die zukünftigen Grundschullehrer in Englisch. Um gute Lehrer für die Zukunft auszubilden, muss man wissen, was in der Schule passiert. Deshalb werde ich in den nächsten Wochen den Englischunterricht in der besuchen. Ich werde mit an den Arbeitstischen der Kinder sitzen, ihnen beim Arbeiten helfen und hoffe, so mehr darüber zu erfahren, wie die Kinder englischen Wortschatz lernen, welche Aktivitäten gut funktionieren und welche Probleme auftauchen können.

Um meine Beobachtungen und Gespräche mit den Kindern auch auswerten zu können, möchte ich die Englischstunden gern mit einem kleinen Diktiergerät aufnehmen. Alle Aufnahmen werden grundsätzlich anonym analysiert. Sollten Sie trotzdem nicht wünschen, dass $\mathrm{Ihr}$ Kind beim Sprechen aufgenommen wird, so geben Sie das bitte auf dem unteren Abschnitt an.

Mit freundlichen Grüßen,

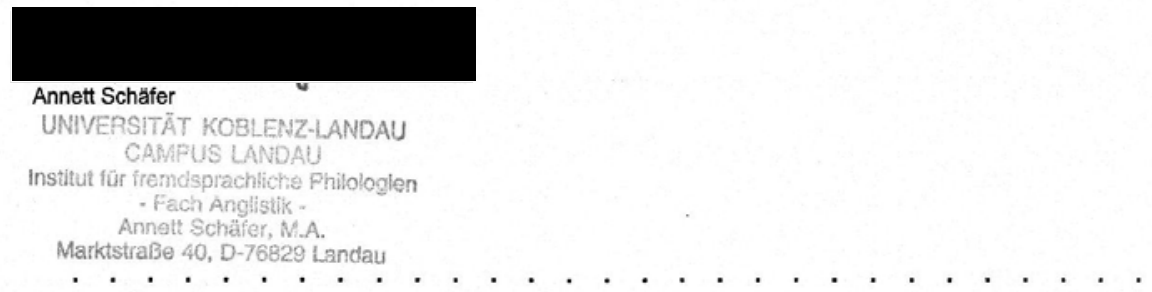

Ich bin über das Projekt "Wie Kinder englischen Wortschatz lernen" informiert worden

a und bin damit einverstanden, dass mein Kind am Projekt teilnimmt.

a und möchte nicht, dass mein Kind am Projekt teilnimmt.

Unterschrift der/des Erziehungsberechtigten 


\section{Letter to parents requesting permission to record interviews with children}

\section{INSTITUT FÜR FREMDSPRACHLICHE $\equiv \cup N \mid$ E $U$ E R S I T A T PHILOLOGIEN / FACH ANGLISTIK

ANNETT SCHÄFER, M.A.

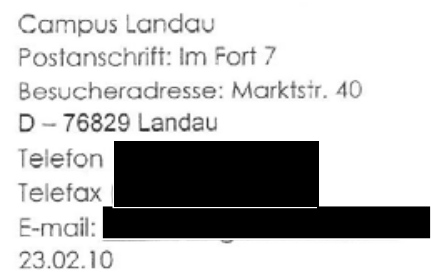

Projekt „Wie Kinder englischen Wortschatz lernen“, 2. Teil

Liebe Eltern,

Ihre Kinder lernen nun schon seit fast 4 Jahren in der Grundschule Englisch. Flächendeckenden Englischunterricht ab der ersten Klasse gibt es außerhalb von Rheinland-Pfalz momentan nur in drei weiteren Bundesländern. Ihre Kinder sind damit ganz weit vorn im landesweiten Vergleich!

Genau vor einem Jahr habe ich für einige Wochen den Englischunterricht in der besuchen dürfen und sehen können, dass Ihre Kinder mit sehr viel Elan und Enthusiasmus Englisch lernen. Beim gemeinsamen Lesen folgen sie den englischen Geschichten scheinbar mühelos. Sie verstehen beim Betrachten von Büchern neuen Wortschatz oder erfragen neue Wörter wissbegierig und sprechen innen lieb gewordene Redewendungen immer wieder nach. Ich habe viele Anregungen für die Ausbildung zukünftiger Grundschullehrer mit an die Universität zurücknehmen können.

Auch in diesem Jahr möchte ich gern wieder die Semesterpause nutzen, um etwas Zeit in der Schule zu verbringen. Ich werde wieder mit an den Arbeitstischen der Kinder sitzen, ihnen beim Arbeiten helfen und mit einigen von ihnen über ihre Erfahrung mit dem Fach Englisch in der Grundschule sprechen.

Um die Gespräche mit den Kindern auch auswerten zu können, möchte ich diese gern mit einem kleinen Diktiergerät aufnehmen. Alle Aufnahmen werden grundsätzlich anonym analysiert. Sollten Sie trotzdem nicht wünschen, dass Ihr Kind aufgenommen wird, so geben Sie das bitte auf dem unteren Abschnitt an.

Mit freundlichen Grüßen

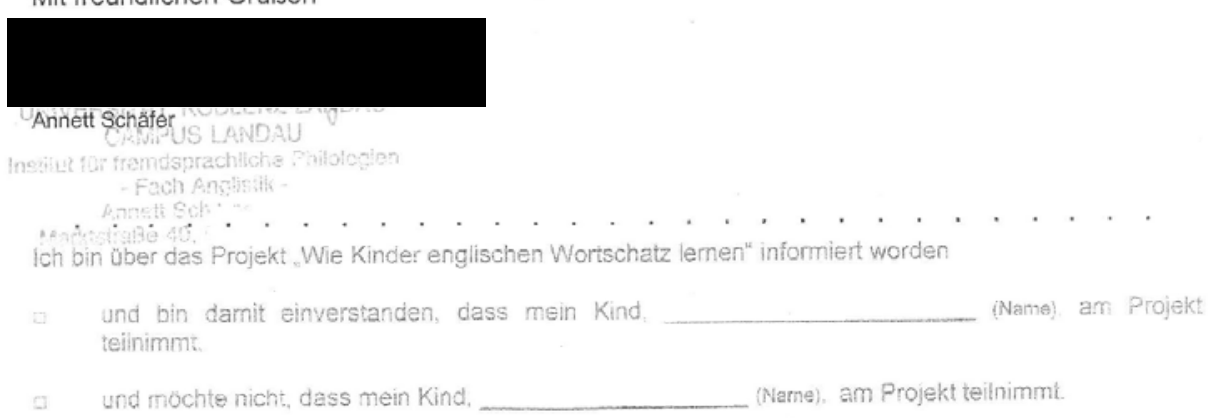

Unterschrift desider Erziehungsberechtigten 
Consent form for teacher interviews

Einverständniserklärung zur befristeten Auswertung von Forschungsdaten für die Forschungsarbeit mit dem Arbeitstitel "The use of singing, storytelling and chanting in the primary EFL classroom”

Für die Auswertung von Forschungsdaten bitte ich, Annett Kaminski, um die Erlaubnis, Interviewdaten in Form von Transkriptionen verwenden zu dürfen.

Ich versichere, dass ich die beteiligten Person über das Projekt informiert und Einsicht in gewonnene Forschungsergebnisse gegeben habe.

Alle Daten wurden anonymisiert. Eine Erlaubnis zur Nutzung der Interviewaufnahmen ist auf die oben genannte Forschungsarbeit beschränkt.

Datum

Unterschrift der Forscherin

Datum

Unterschrift der Teilnehmerin 


\section{Englisch in der Grundschule Geschichten, Gedichte und Lieder in der Fremdsprachenarbeit}

Bitte kreuzen Sie alle Antworten an, die auf Sie zutreffen. Das Ankreuzen von mehreren Antworten ist möglich. Wenn Sie eine Frage nicht beantworten möchten, dann lassen Sie diese einfach frei und schreiben „k.A." (keine Auskunft) daneben. Vielen Dank! Alle Aussagen werden streng vertraulich behandelt!

\section{Allgemeine Fragen zur Fremdsprachenarbeit/Englisch}

1a. In welchen Lernbereichen haben Sie im letzten Schuljahr Englisch in der Grundschule eingesetzt?
$\square$ Deutsch
$\square$ Mathematik
$\square$ Sachunterricht
$\square$ Kunst
$\square$ Musik
$\square$ Religion/ Ethik
$\square$ Sport

1b. Englisch wird als eigene Unterrichtseinheit angeboten. $\square$ immer $\quad \square$ oft $\quad \square$ manchmal $\square$ nie

1c. Englisch wird ins außerunterrichtliche Schulleben integriert:
$\square$ Feste/ Darbietungen/ Theater
$\square$ Elternabende
$\square$ Exkursionen/ Wandertage
$\square$ sonstiges:

1d. Ich integriere Englisch in
$\square$ die Eröffnungs- und Abschlussphasen des Unterrichts:
$\square$ immer $\square$ oft $\square$ manchmal
$\square$ die Arbeit im Sitzkreis:
$\square$ immer $\square$ oft $\square$ manchmal
$\square$ die Partner-/ Gruppenarbeit:
$\square$ die Freiarbeit:
$\square$ die Projektarbeit:
$\square$ immer $\square$ oft $\square$ manchmal
$\square$ immer $\square$ oft $\square$ manchmal
$\square$ immer $\square$ oft $\square$ manchmal

2. Welche Materialien stehen für den Englischunterricht zur Verfügung?

\begin{tabular}{|c|c|c|}
\hline i) & $\square$ & 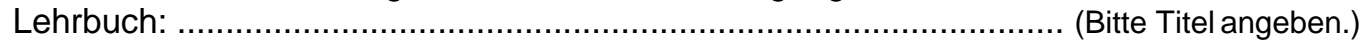 \\
\hline ii) & $\square$ & CD/ Kassette zum Lehrbuch \\
\hline iii) & $\square$ & englischsprachige Kinderbücher \\
\hline iv) & $\square$ & Bildkarten/ Flashcards \\
\hline v) & $\square$ & Kopiervorlagen für Spiele, Lieder, Geschichten und Kinderreime \\
\hline vi) & $\square$ & zusätzliches Hörmaterial für Lieder, Geschichten und Kinderreime \\
\hline vii) & $\square$ & Video und DVD \\
\hline viii) & $\square$ & $\begin{array}{l}\text { englischsprachige Anleitungen zum Basteln und Backen für Feste wie Weihnachten, } \\
\text { Ostern etc. }\end{array}$ \\
\hline ix) & $\square$ & Handpuppe \\
\hline$x)$ & $\square$ & Material: \\
\hline
\end{tabular}

3a. Welche Materialien aus Frage 2 setzen Sie besonders gern ein?
i) ii)
iii)
iv)
v)
vi)
vii)
viii)
ix) $\quad x$ )

3b. Warum?

4. Welche Aktivitäten im Englischunterricht sind bei den Kindern besonders beliebt? 
5. Bei welchen Aktivitäten im Englischunterricht können Kinder Ihrer Erfahrung nach ihre sprachlichen Fähigkeiten besonders gut verbessern?

6. Welchen Stellenwert haben für Sie folgende Lernziele in der Fremdsprachenarbeit in der Grundschule? (sehr hoher Stellenwert = 1, sehr geringer Stellenwert = 5)

\begin{tabular}{|c|c|c|c|c|c|}
\hline & sehr hoch & hoch & mittel & gering & sehr gering \\
\hline & 1 & 2 & 3 & 4 & 5 \\
\hline \multicolumn{6}{|l|}{ grammatische Regeln verstehen } \\
\hline \multicolumn{6}{|l|}{ grammatische Regeln anwenden } \\
\hline \multicolumn{6}{|l|}{ Gehörtes verstehen } \\
\hline \multicolumn{6}{|l|}{ einfache geschriebene Texte verstehen } \\
\hline \multicolumn{6}{|l|}{ Bedeutung von Wörtern erarbeiten } \\
\hline \multicolumn{6}{|l|}{ Wörter richtig aussprechen } \\
\hline \multicolumn{6}{|l|}{ einzelne Wörter/Sätze laut lesen } \\
\hline \multicolumn{6}{|l|}{ kurze Texte laut lesen } \\
\hline \multicolumn{6}{|l|}{ auf Fragen antworten } \\
\hline \multicolumn{6}{|l|}{ frei sprechen } \\
\hline \multicolumn{6}{|l|}{ einzelne Wörter/Sätze schreiben } \\
\hline \multicolumn{6}{|l|}{ kurze Texte schreiben } \\
\hline \multicolumn{6}{|l|}{$\begin{array}{l}\text { landeskundliche Kenntnisse erarbeiten } \\
\text { (typisches Essen. Feste. Schulalltaq) }\end{array}$} \\
\hline \multicolumn{6}{|l|}{$\begin{array}{l}\text { die Aufgeschlossenheit fremden Kulturen } \\
\text { gegenüber fördern }\end{array}$} \\
\hline \multicolumn{6}{|l|}{$\begin{array}{l}\text { die Bereitschaft zum Lernen einer fremden } \\
\text { Sprache fördern }\end{array}$} \\
\hline andere Lernziele: & & & & & \\
\hline
\end{tabular}

\section{Geschichten, Gedichte und Lieder in der Fremdsprachenarbeit}

7. Verwenden Sie in der Fremdsprachenarbeit Geschichten, Gedichte bzw. Lieder?

$\square$ ja $\quad \square$ nein $\rightarrow$ Bitte gehen Sie zu Frage 12.

8a. Wie oft arbeiten Sie mit Geschichten, Gedichten und Liedern?

\begin{tabular}{|l|l|l|l|l|l|}
\hline & $\begin{array}{l}\text { in jeder } \\
\text { UE }\end{array}$ & $\begin{array}{l}\text { in jeder 3. bis 5. } \\
\text { UE }\end{array}$ & $\begin{array}{l}\text { nicht regelmäßig, aber } \\
\text { mehrmals im Schuljahr }\end{array}$ & $\begin{array}{l}\text { ein- oder zweimal } \\
\text { im Schuljahr }\end{array}$ & gar nicht \\
\hline i) Bildergeschichten (wenig Text) & & & & & \\
\hline ii) Geschichten (überwiegend Text) & & & & & \\
\hline iii) Kinderreime/ Nursery Rhymes & & & & & \\
\hline iv) Gedichte & & & & & \\
\hline v) Lieder & & & & & \\
\hline
\end{tabular}

${ }^{\star} \mathrm{UE}=$ Unterrichtseinheit meint hier jede Beschäftigung mit Englisch. Es ist dabei unerheblich, ob diese 10 Minuten lang ist und jeden Tag stattfindet oder auch 45 Minuten dauert und nur einmal in der Woche durchgeführt werden kann.

8b. Welche der genannten Materialien eignen sich Ihrer Erfahrung nach besonders für die Fremdsprachenarbeit in der Grundschule?

i) $\quad$ ii) $\quad$ iii) $\quad$ iv) v) Warum?

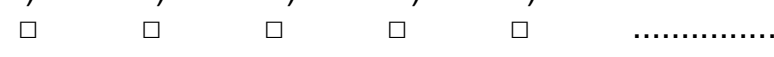


8c. Welche Geschichten, Gedichte oder Lieder haben sich besonders bewährt? Geben Sie bitte einige Titel an.

Bildergeschichten:

Geschichten:

Kinderreime:

Gedichte:

Lieder:

8d. Welche der genannten Materialien eignen sich Ihrer Erfahrung nach weniger für die Fremdsprachenarbeit in der Grundschule?
i) ii)
iii)
iv)
v)
Warum?

$\square$

$\square \quad \square$

$\square$

9. Wozu dient Ihnen der Einsatz von Gedichten, Geschichten und Liedern in Ihrem Unterricht? $($ sehr hoher Stellenwert $=1$, sehr geringer Stellenwert $=5$ )

\begin{tabular}{|l|c|c|c|c|c|}
\hline \multirow{2}{*}{} & sehr hoch & hoch & mittel & gering & sehr gering \\
\cline { 2 - 6 } & 1 & 2 & 3 & 4 & 5 \\
\hline Förderung der Lernmotivation & & & & & \\
\hline Abwechslung & & & & & \\
\hline Unterstützung der Wortschatzarbeit & & & & & \\
\hline Freude an Musik und Literatur fördern & & & & & \\
\hline Verbesserung der Aussprache & & & & & \\
\hline Freude am Spiel mit Sprache fördern & & & & & \\
\hline Einüben grammatischer Strukturen & & & & & \\
\hline Schulung des Hörverständnisses & & & & & \\
\hline Vermitteln von landeskundlichen Fakten & & & & & \\
\hline sonstiges: & & & & & \\
\hline
\end{tabular}

10. Verwenden Sie Geschichten, Gedichte oder Lieder als Ausgangspunkt für weiterführende Tätigkeiten in der Fremdsprache?
$\square$ ja
$\square$ nein $\rightarrow$ Bitte gehen Sie zu Frage 12.

11. Welche weiterführenden Tätigkeiten in Englisch schließen Sie an die Behandlung von Geschichten, Gedichten oder Liedern an?

-

12. Welche Probleme kann es aus Ihrer Sicht bei der Verwendung von Geschichten, Gedichten oder Liedern geben?

-

13. Wenn Sie weitere Bemerkungen zu Englisch an der Grundschule machen möchten, dann können Sie das hier tun: 


\section{Angaben zu Lehrer und Schülern}

Diese Informationen sind für die statistische Analyse Ihrer Antworten aus dem Hauptteil wichtig. Wenn Sie jedoch eine Frage nicht beantworten möchten, dann lassen Sie diese frei und schreiben „k.A." daneben. Alle Aussagen werden streng vertraulich behandelt!

14. Wie lange arbeiten Sie schon als Grundschullehrer/in (Auszeiten, z.B. Elternzeit, nicht eingerechnet)? seit weniger als 3 Jahren

seit weniger als 5 Jahren seit weniger als 10 Jahren seit mehr als 10 Jahren seit mehr als 20 Jahren seit mehr als 30 Jahren

15. Welche Fächer unterrichten Sie zur Zeit?
Deutsch
Mathematik
Sachunterricht
Kunst
Musik
Religion/Ethik
Sport

16. Wie lange unterrichten Sie schon Englisch in der Grundschule? seit weniger als 3 Jahren seit weniger als 5 Jahren seit weniger als 10 Jahren seit mehr als 10 Jahren

17. In welchen Klassenstufen unterrichten Sie zur Zeit Englisch? in der ersten Klasse

in der zweiten Klasse

in der dritten Klasse

in der vierten Klasse

18. Haben Sie auch an anderen Bildungseinrichtungen Englischunterrichtet? ․ nein
ja,
Jahre in einem Kindergarten
Jahre an einer Hauptschule
Jahre an einer Realschule
Jahre an einem Gymnasium
Jahre an einer Gesamtschule
Jahre an einer berufsbildenden Schule
Jahre an einer Fachhochschule/ Hochschule/ Universität
Jahre, sonstiges:

19. Wie haben Sie Englisch gelernt?

Ich habe in der Schule Englischunterricht gehabt.

Ich habe zusätzlich zu meinem Schulenglisch Weiterbildungen besucht.

Ich habe während meiner Ausbildung an der Universität/ Hochschule Englisch studiert.

Ich habe Jahre im englischsprachigen Ausland gewohnt.

Ich habe ........... Jahre in einem englischsprachigen Umfeld gearbeitet.

Ich bin Muttersprachler.

sonstiges:

20. Ihre Erfahrungen mit Musik und Literatur:

Ich kann ein Instrument/ mehrere Instrumente spielen.

Ich singe in einem Chor.

Ich lese in meiner Freizeit Erzählungen, Romane u.ä.

sonstiges:

$\square \quad$ Ich habe einmal in einem Chor gesungen.

$\square \quad$ Ich habe früher viel gelesen.
21. Englisch ist für

$\begin{array}{lrlll}\square \text { keinen } & \square \text { bis zu 25\% } & \square 25-50 \% & \square \text { mehr als } 50 \% & \square 100 \% \\ \square \text { keinen } & \square \text { bis zu 25\% } & \square 25-50 \% & \square \text { mehr als } 50 \% & \square 100 \% \\ \square \text { keinen } & \square \text { bis zu 25\% } & \square 25-50 \% & \square \text { mehr als } 50 \% & \square 100 \% \\ \square \text { keinen } & \square \text { bis zu 25\% } & \square 25-50 \% & \square \text { mehr als } 50 \% & \square 100 \%\end{array}$

meiner Schüler erste Fremdsprache. meiner Schüler neben Deutsch 2. Fremdsprache. meiner Schüler zweite Fremdsprache. meiner Schüler Zweitsprache/ 2. Muttersprache.

22. Englisch im Kindergarten:
$\square$ Keiner
$\square$ Bis zu $25 \%$ 口 $25-50 \%$
$\square$ Mehr als 50\%
$\square 100 \%$
meiner Schüler hatte/n schon im Kindergarten Englischunterricht. 


\section{English at primary school \\ Stories, poems and songs in ELT}

Please tick the appropriate answers. It is possible to tick more than one answer for each question. If you don't want to answer a question, leave it blank and put a "k.A." Thank you! All information will be treated in the strictest confidence!

\section{General questions about integrated foreign language teaching}

1a. In which subject areas have you used English in this school year?

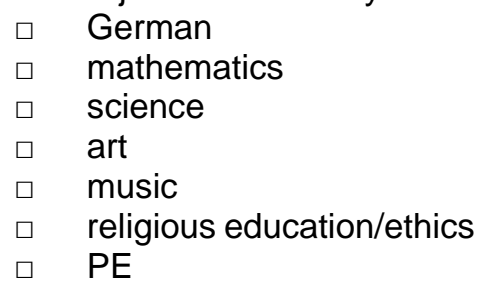

1b. English is offered as a separate session. $\quad \square$ always $\square$ often $\quad \square$ sometimes $\square$ never

1c. English is used for extra-curricular activities:

$$
\begin{aligned}
& \square \text { school fête/ shows/ theatre } \\
& \square \text { parents' evening } \\
& \square \text { excursions/field trips } \\
& \square \text { other: }
\end{aligned}
$$

1d. I use English

$\begin{array}{llll}\square \text { at the beginning and at the end of class: } & \square \text { always } & \square \text { often } & \square \text { sometimes } \\ \square \text { when the children sit in a circle: } & \square \text { always } & \square \text { often } & \square \text { sometimes } \\ \square \text { for pair/group work: } & \square \text { always } & \square \text { often } & \square \text { sometimes } \\ \square \text { for self-study activities: } & \square \text { always } & \square \text { often } & \square \text { sometimes } \\ \square \text { for projects: } & \square \text { always } & \square \text { often } & \square \text { sometimes }\end{array}$

2. Which material is available for teaching English?

i) $\square$ text book:

ii) $\square \mathrm{CD}$ /tape in connection with the textbook

iii) $\square$ English children's books

iv)) $\square \quad$ pictures

v) $\square$ copy material for games, songs, stories and nursery rhymes/poems

vi) $\square \quad$ additional listening material for songs, stories and nursery rhymes

vii) $\square \quad$ Video and DVD

viii) $\square \quad$ English instructions for artwork/decorations for Christmas or Easter

ix) $\square$ puppet

x) $\square \quad$ other material:

3a. Which material mentioned in question 2 do you particularly like to use?

i) $\quad$ ii) iii) iv) v) vi) vii) viii) ix) $x$ )

3b. Why? 
4. Which activities in English are very popular with the children?

-

5. Which activities do you find especially helpful for the children to improve their command of English?

6. How important do you rate the following learning objectives with regard to FLT in primary school? (very important $=1$, not very important at all $=5$ )

\begin{tabular}{|l|c|c|c|c|c|}
\hline & $\begin{array}{c}\text { very } \\
\text { important }\end{array}$ & important & $\begin{array}{c}\text { somehow } \\
\text { important }\end{array}$ & $\begin{array}{c}\text { not very } \\
\text { important }\end{array}$ & $\begin{array}{c}\text { not very } \\
\text { important at } \\
\text { all }\end{array}$ \\
\cline { 2 - 6 } & 1 & 2 & 3 & 4 & 5 \\
\hline $\begin{array}{l}\text { Understanding grammatical } \\
\text { rules }\end{array}$ & & & & & \\
\hline Using grammatical rules & & & & & \\
\hline $\begin{array}{l}\text { Understanding what has been } \\
\text { said }\end{array}$ & & & & & \\
\hline Reading short simple texts & & & & & \\
\hline Studying the meaning of words & & & & & \\
\hline Pronounce words correctly & & & & & \\
\hline $\begin{array}{l}\text { Reading out loud single words } \\
\text { or sentences }\end{array}$ & & & & & \\
\hline Reading out loud short texts & & & & & \\
\hline Answering questions & & & & & \\
\hline Speaking freely & & & & & \\
\hline Writing words/sentences & & & & & \\
\hline Writing short texts & & & & & \\
\hline $\begin{array}{l}\text { Getting to know about the } \\
\text { culture (food, festivals, school) }\end{array}$ & & & & & \\
\hline $\begin{array}{l}\text { Being open-minded towards } \\
\text { different cultures }\end{array}$ & & & & & \\
\hline $\begin{array}{l}\text { Being enthusiastic about } \\
\text { learning a foreign language }\end{array}$ & & & & & \\
\hline $\begin{array}{l}\text { Other: } \\
\text { nyyyyy}\end{array}$ & & & & & \\
\hline
\end{tabular}

\section{Stories, poems and songs in ELT}

7. Do you use stories, poems and songs in foreign language teaching?

$\square$ yes

$\square \quad$ no $\rightarrow$ Please go to question 12 . 
8a. How often do you use literary texts and songs in the classroom?

\begin{tabular}{|l|l|l|l|l|l|}
\hline & $\begin{array}{l}\text { In every } \\
\text { session* }\end{array}$ & $\begin{array}{l}\text { In every } \\
\text { 3rd or 5th } \\
\text { session }\end{array}$ & $\begin{array}{l}\text { Not on a regular } \\
\text { basis, but a few } \\
\text { times every }\end{array}$ & $\begin{array}{l}\text { Once or } \\
\text { twice a } \\
\text { year }\end{array}$ & Not at all \\
\hline $\begin{array}{l}\text { i) Picturebooks/Illustrated stories } \\
\text { (little text) }\end{array}$ & & & & & \\
\hline ii) Stories (more text) & & & & \\
\hline iii) Nursery Rhymes & & & & \\
\hline iv) Poems & & & & \\
\hline v) Songs & & & \\
\hline
\end{tabular}

8b. Which of the above mentioned material do you find most suitable?

i) ii) iii) iv) v)

$\square \quad \square \quad \square \quad \square \quad \square$

Why?

8c. Which stories, poems and songs have worked well in the classroom? Please give some titles.

Picturebooks/lllustrated

stories:

Stories:

Nursery Rhymes:

Poems:

Songs:

8d. Which of the above mentioned material is less suited for FLT in primary school?

i) ii) iii) iv) v)

$\square \quad \square \quad \square \quad \square \quad \square$

Why? 
9. Why do you use literary texts and songs in your classroom (very important $=1$, not very important at all $=5$ )?

\begin{tabular}{|l|c|c|c|c|c|}
\hline & $\begin{array}{c}\text { very } \\
\text { imortant }\end{array}$ & important & $\begin{array}{c}\text { somehow } \\
\text { important }\end{array}$ & $\begin{array}{c}\text { not very } \\
\text { important }\end{array}$ & $\begin{array}{c}\text { not very } \\
\text { important } \\
\text { at all }\end{array}$ \\
\cline { 2 - 6 } & 1 & 2 & 3 & 4 & 5 \\
\hline To motivate my pupils & & & & & \\
\hline To bring variety into the classroom & & & & & \\
\hline To support vocabulary acquisition & & & & & \\
\hline $\begin{array}{l}\text { To let pupils enjoy music and } \\
\text { literature }\end{array}$ & & & & & \\
\hline To improve pronunciation & & & & & \\
\hline To let pupils enjoy playing with words & & & & & \\
\hline To train grammatical structures & & & & & \\
\hline To train listening comprehension & & & & & \\
\hline To present cultural facts & & & & & \\
\hline Other: & & & & & \\
\hline
\end{tabular}

10. Do you use stories, poems or songs as a starting point for other activities?

$\square$ yes

$\square \quad$ no $\rightarrow$ Please go to question 12 .

11. Which activities do you use in connection with stories, poems and songs?

-

-

12. Which problems can teachers face when they use literary texts and songs in the classroom?

-

-

13. Please feel free to make comments on the integrated teaching method or teaching of English in primary school: 
Information about teachers and pupils

To help us classify your answers and to make our statistical comparisons, would you please answer the following questions. If you don't want to answer a question, leave it blank. All answers will be treated in the strictest confidence.

14. How long have you been working as a primary school teacher? (maternity leave and similar not included)

for less than 3 years

for less than 5 years

for less than than 10 years

for more than 10 years

for more than 20 years

for more than 30 years

15. Which subjects do you teach at the moment?

German

mathematics

science

art

music

RE/ethics

PE

16. How long have you been teaching English at primary school?

for less than 3 years

for less than 5 years

for less than 10 years

for more than 10 years

17. Which year groups do you teach?

year 1

year 2

year 3

year 4

18. Have you also taught English in other educational settings?

no

yes, $\square$

........ years at a kindergarten

......... years at secondary school/Hauptschule

........ years at secondary school/Realschule

......... years at secondary school/Gymnasium

........ years at secondary school/Gesamtschule

......... years at a vocational college

.......... years at a college/university

......... years, other:

19. How did you learn English?

I learned English at school.

I attended additional professional training courses alongside my work.

I studied English as a subject when I did my academic training at college/university.

I lived in an English speaking country for ......... years.

I worked in an English speaking environment for ........... years.

I am a native speaker of English.

other:

20. Your experience of music and literature:

I play an instrument/instruments.

I am a member of a choir.

I read novels, short stories etc. in my spare time.

other:

- I once read a lot of literary texts.

21. English is for

\begin{tabular}{|c|c|c|c|c|c|}
\hline $\begin{array}{l}\square \text { none } \\
\square \text { none }\end{array}$ & $\begin{array}{l}\square 0-25 \% \\
\square 0-25 \%\end{array}$ & $\begin{array}{l}\square 25-50 \% \\
\square 25-50 \%\end{array}$ & $\begin{array}{l}\square \text { more than } 50 \% \\
\square \text { more than } 50 \%\end{array}$ & $\begin{array}{l}\square 100 \% \\
\square 100 \%\end{array}$ & $\begin{array}{l}\text { of my pupils their FL1 } \\
\text { of my pupils their FL2, } \\
\text { German FL1 }\end{array}$ \\
\hline $\begin{array}{l}\text { none } \\
\text { none }\end{array}$ & $\begin{array}{l}\square 0-25 \% \\
\square 0-25 \%\end{array}$ & $\begin{array}{l}\square 25-50 \% \\
\square 25-50 \%\end{array}$ & $\begin{array}{l}\square \text { more than } 50 \% \\
\square \text { more than } 50 \%\end{array}$ & $\begin{array}{l}\square 100 \% \\
\square 100 \%\end{array}$ & $\begin{array}{l}\text { of my pupils their FL2 } \\
\text { of my pupils their L2. }\end{array}$ \\
\hline
\end{tabular}

22. English in kindergarten:

$\square$ none $\square 0-25 \% \quad \square 25-50 \% \quad \square$ more than $50 \%$

$\square 100 \%$ of my pupils had English lessons in

Thank you for your help!

kindergarten. 
Appendix 4: Return rates of questionnaire

\begin{tabular}{|c|c|c|c|c|c|}
\hline $\begin{array}{l}\text { Admin. } \\
\text { Period }\end{array}$ & Region & School & Nos. distributed & Nos. returned & Return in \% \\
\hline \multirow{9}{*}{ 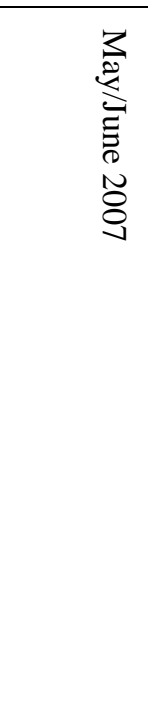 } & \multirow{9}{*}{ 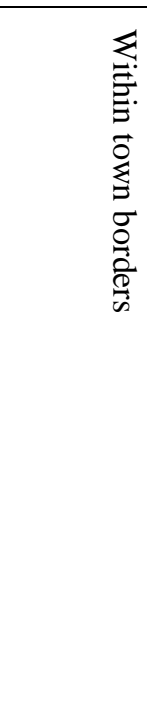 } & 1 & 2 & 2 & 100 \\
\hline & & 2 & 5 & 3 & 60.0 \\
\hline & & 3 & 7 & 2 & 28.6 \\
\hline & & 4 & 8 & 3 & 37.5 \\
\hline & & 5 & 8 & 4 & 50.0 \\
\hline & & 6 & 9 & 7 & 77.8 \\
\hline & & 7 & 9 & 2 & 22.2 \\
\hline & & 8 & 4 & 4 & 100 \\
\hline & & 9 & 8 & 4 & 50.0 \\
\hline \multirow{12}{*}{ 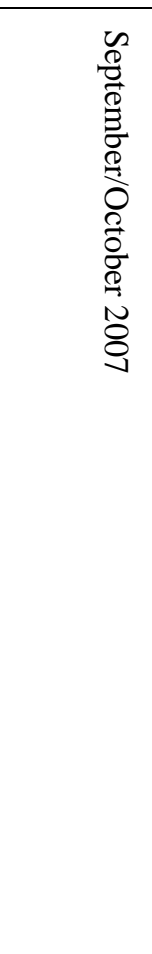 } & \multirow{5}{*}{ 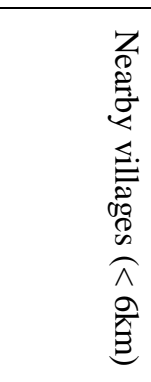 } & 10 & 8 & 4 & 50.0 \\
\hline & & 11 & 2 & \multirow[t]{2}{*}{4} & \multirow[t]{2}{*}{80.0} \\
\hline & & 12 & 3 & & \\
\hline & & 13 & 12 & 4 & 33.3 \\
\hline & & 14 & 2 & 0 & 0 \\
\hline & \multirow{7}{*}{ 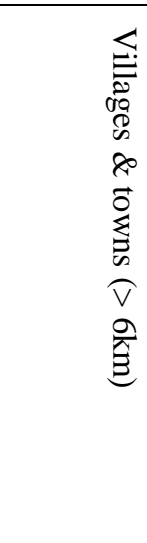 } & 15 & 6 & 6 & 100 \\
\hline & & 16 & 5 & \multirow[t]{6}{*}{11} & \multirow[t]{6}{*}{26.1} \\
\hline & & 17 & 20 & & \\
\hline & & 18 & 5 & & \\
\hline & & 19 & 4 & & \\
\hline & & 20 & 4 & & \\
\hline & & 21 & 4 & & \\
\hline \multicolumn{3}{|c|}{$\begin{array}{l}\text { Total no. of questionnaires } \\
\text { distributed: }\end{array}$} & 135 & & \\
\hline \multicolumn{3}{|c|}{$\begin{array}{l}\text { Total no. of questionnaires } \\
\text { returned: }\end{array}$} & & 60 & \\
\hline \multicolumn{3}{|c|}{ Return rate: } & & & 44.4 \\
\hline
\end{tabular}


Appendix 5: Analysis of questionnaire data, questions 1a and 15 the extent to which EFL is integrated into subject areas that participants teach

Table: Analysis of data elicited by question items $1 \mathrm{a}$ and 15

\begin{tabular}{|c|c|c|c|c|c|}
\hline & $\begin{array}{l}\text { No. of teachers } \\
\text { reporting to teach } \\
\text { subject } \\
\text { (question } 15^{*} \text { ) }\end{array}$ & $\begin{array}{l}\text { Maximum no. } \\
\text { of teachers who } \\
\text { could teach } \\
\text { subject ** }\end{array}$ & $\begin{array}{l}\text { No. of } \\
\text { teachers who } \\
\text { integrate } \\
\text { English into } \\
\text { subject } \\
\text { (question 1a) }\end{array}$ & $\begin{array}{l}\text { Maximum } \\
\text { percentage of } \\
\text { teachers who } \\
\text { integrate } \\
\text { English into } \\
\text { subject }\end{array}$ & $\begin{array}{l}\text { Minimum } \\
\text { percentage of } \\
\text { teachers who } \\
\text { integrate } \\
\text { English into } \\
\text { subject }\end{array}$ \\
\hline German & 58 & 59 & 36 & 62.07 & 61.02 \\
\hline Maths & 51 & 52 & 16 & 31.37 & 30.77 \\
\hline Science & 57 & 58 & 36 & 63.16 & 62.07 \\
\hline Arts & 42 & 43 & 13 & 30.95 & 30.23 \\
\hline Music & 41 & 42 & 42 & 102.44 & 100 \\
\hline RE/Ethics & 33 & 34 & 1 & 3.03 & 2.94 \\
\hline
\end{tabular}

*responding teachers 59 , non-responding teachers 1

** Since one more teacher could have responded, a value of 1 is added.

Figure: Minimum percentage of teachers integrating English into subjects that they teach

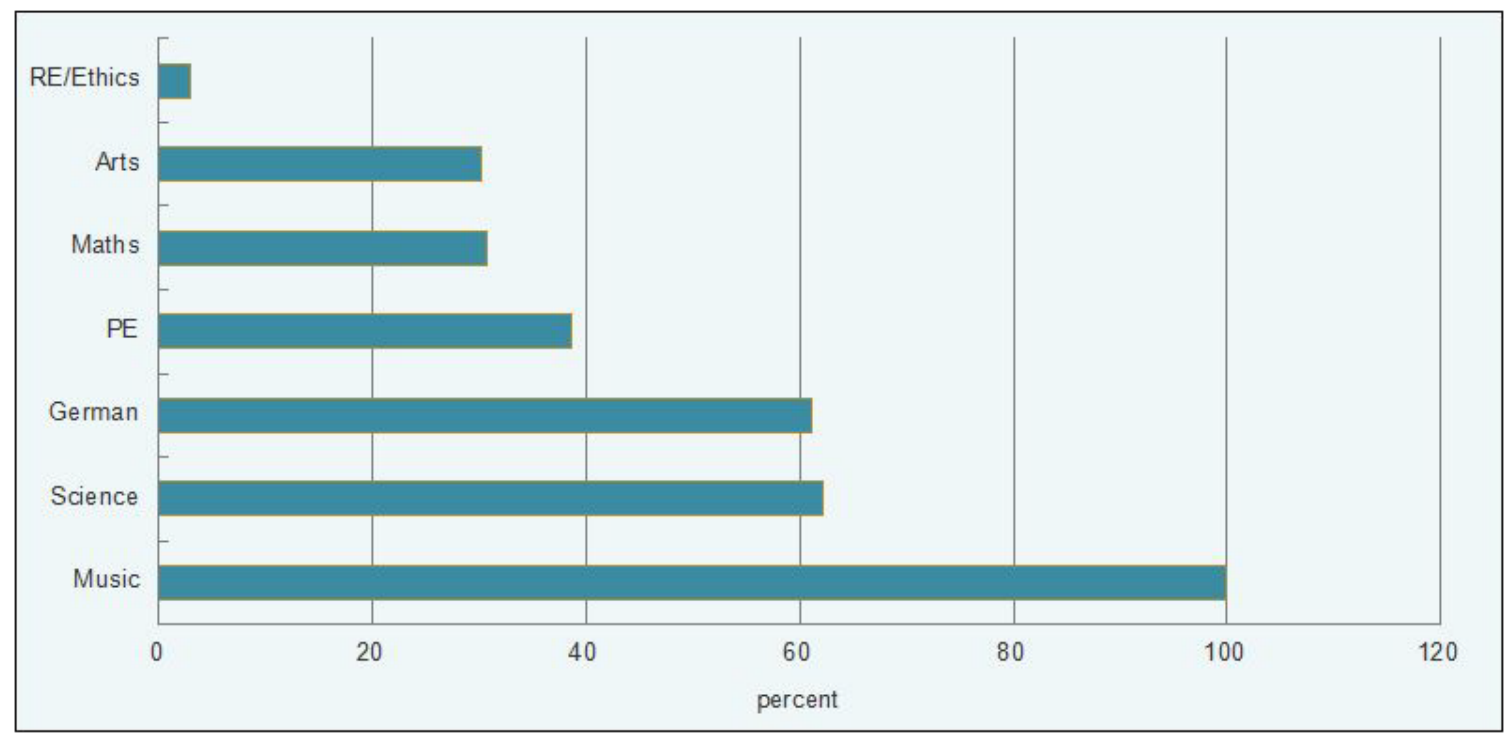


Appendix 6: Titles of songs, rhymes \& stories as mentioned by teachers in questionnaire

in alphabetical order, with difficult-to-read items in grey, numbers indicate frequency of reference

SONGS

\begin{tabular}{|c|c|c|}
\hline ABC rock & 1 & My bonny is over the ocean \\
\hline ABC song & 2 & My favourite pet \\
\hline Beatles songs & 1 & My hen is red \\
\hline Bingo & 2 & Old MacDonald \\
\hline Blue, blue, blue & 1 & One little, two little... \\
\hline Blue red purple & 1 & Picnic rap \\
\hline Bruder Jacob & 1 & Roll over \\
\hline Brother John & 1 & Rudolph the red nosed \\
\hline Check your bike & 1 & reindeer \\
\hline Clap your hands & 2 & Schoolbar rap \\
\hline Dee dee dee dip dip & 1 & Singing in the rain \\
\hline Good morning & 11 & Ten little Indians \\
\hline Halloween rap & 2 & Ten in the bed \\
\hline Happy birthday & 3 & The bus has wheels \\
\hline Happy holiday & 1 & The mini monster's busy \\
\hline Head, shoulders & 23 & week \\
\hline Here comes the snow & 1 & The north wind does blow \\
\hline Hello friends & 1 & The rainbow song \\
\hline Hello, hello what's your name? & 2 & The wheels on the bus \\
\hline Hi hello & 1 & Trick or treat \\
\hline Hokey, pokey & 4 & Today it's very cold and \\
\hline I can hop & 1 & foggy day \\
\hline I can jump & 1 & Two little dicky birds \\
\hline If you are happy & 9 & Shake, shake the apple tree \\
\hline If your birthday is... & 1 & Sing a colour song \\
\hline I hear them & 3 & We wish you a merry \\
\hline I like the flowers & 5 & Christmas \\
\hline I like the summer & 1 & What's the weather \\
\hline Incy, wincy spider & 6 & What's your name \\
\hline Jungle song & 1 & Where is thumbling \\
\hline Let's sing a song & 1 & Who's afraid of the big bad \\
\hline Little bunny & 1 & wolf \\
\hline Little Peter Rabbit & 1 & \\
\hline London & 1 & referring to texts in \\
\hline London is a very big town & 1 & Green Keystones, Magicland \\
\hline Look outside & 1 & and other publications \\
\hline Mary's boy child & 1 & for teachers \\
\hline Music man & 2 & \\
\hline
\end{tabular}


STORIES

A shark in the park 1

At the pond 1

Brown brown bear 4

Chicken, chips and peas 1

Elmer('s colours) 6

Englisch keine Hexerei 1

Farmer Duck 1

Froggy frog 1

Froggy (gets dressed)... $\quad 4$

From head to toe 3

Gingerbread Man 2

Goldilocks \& the three bears 2

Halloween 1

Hello Claire, I miss you 1

Hungry bear 1

I am a clown 1

Little Red Riding Hood 1

Little Roger Rabbit $\quad 1$

Little Snow White 1

Mary and Joseph 1

Mick \& Mo \& the Wild West 1

Milton's Christmas 1

Monkey puzzle 1

Mr Glumy's eating $\quad 1$

Mr Putter

One, two, three to the zoo 1

Owl babies 1

Paddington Bear 1

Peter Rabbit 2

Princess Fizzyfuzz 1

Robin Redbreast 1

Rudolph the red nosed

reindeer

Rudy's story

Scat the cat 1

Snowman 1

Snow Princess Tanana 1

Spot 1

Stop juggling, Violet 3

Ten in the bed 1

Ten little teddy bears $\quad 1$

The chicken and the bunny 1

The Christmas story 1

The frightened house $\quad 1$

The frog 1

The giant turnip 1

The green queen 2

The green bike 1

The Gruffalo 1

The happy hedgehog band 1

The lion and the mouse 1

The lion 1

The little ghost 1

The little hedgehog 1

The little red hen $\quad 1$

The little witch 3

The musicians of Bremen 1

The pig in the pond 1

The rainbowfish 1

The scorceress' apprentice 1

The the three little pigs 3

The very hungry caterpillar 19

The wind and the sun 1

The witch 1

The witch's house 1

We are going on a bear hunt 2

Where's caterpillar $\quad 1$ 


\section{RHYMES}

Apples, peaches, pears 2

Blue blue shoe 1

Bunny Rabbit

Charlie Chaplin went

to France

Easter Bunny

Five little Easter eggs 1

Five little monkeys

Five little elephants

Hickory, dickory...

Humpty Dumpty ...

Incy wincy spider

I walk around

Let's make a snowman 1

Make a snowball

My bike

My snowman

One, two, buckle my shoe

\section{POEMS}

A little garden flower

A little poem

A winter riddle

Bear hunt

Christmas poem

Down, down

Fire

In the dark dark forest

Jack o'lantern

Lady in Spain
One, two, three Kooky is in the tree 1

One, two I see you 1

One, two, three...once I

caught a fish alive 1

Pancake 1

Peter the bunny 1

Pussy cat, pussy cat 1

Put your hand on your head 1

Robby the rabbit 1

Roses are red 1

Six little mice 1

Teddy bear 1

Trick or treat 1

Twinkle, twinkle, little star 1

Two little blackbirds $\quad 1$

Up-down 1

Valentine 1

Mother's Day poem 2

My family 1

Orange is a carrot 1

Shake, shake the apple tree 1

Snow feathers 1

Spring is coming 1

The snowman 1

The sun is shining 1

Weather 1

also just references to “poems on Christmas, Easter, Halloween” without exact titles 
Appendix 7: Frequency of genres being used in the primary EFL classrooms

\section{Use of songs, chants and stories}

\begin{tabular}{|c|c|c|c|c|c|c|}
\hline Lesson & Year & Teacher & Song & Chant & Story & Title of text \\
\hline \multicolumn{7}{|l|}{2008} \\
\hline 1 & $3 \mathrm{~A}$ & Sophie & & & $\mathrm{x}$ & Froggy Gets Dressed \\
\hline 2 & 1 & Julia & & & $\mathrm{x}$ & Easter Bunny Book \\
\hline 3 & 4 & Sophie & & & & - \\
\hline 4 & $3 \mathrm{~A}$ & Sophie & $\mathrm{x}$ & & & Weather Song \\
\hline 5 & $3 \mathrm{~B}^{*}$ & Sophie & $\mathrm{x}$ & & & Weather Song \\
\hline 6 & 4 & Sophie & & $\mathrm{x}$ & & Football Warm-Up \\
\hline 7 & $3 \mathrm{~A}$ & Sophie & $\mathrm{x}$ & & $\mathrm{x}$ & $\begin{array}{l}\text { Weather Song } \\
\text { April Weather }\end{array}$ \\
\hline 8 & $3 \mathrm{~B}^{*}$ & Sophie & $\mathrm{x}$ & & $\mathrm{x}$ & $\begin{array}{l}\text { Weather Song } \\
\text { April Weather }\end{array}$ \\
\hline 9 & 1 & Sophie & $\mathrm{x}$ & & & If You’re Hарру \\
\hline 10 & 1 & Julia & & $\mathrm{x}$ & $\mathrm{x}$ & $\begin{array}{l}\text { Easter Bunny Book, } \\
\text { Easter Chant }\end{array}$ \\
\hline 11 & 4 & Sophie & & $\begin{array}{l}\mathrm{x} \\
\mathrm{x}\end{array}$ & & $\begin{array}{l}\text { Football Warm-up } \\
\text { Easter Bunny Chant }\end{array}$ \\
\hline 12 & $3 \mathrm{~A}$ & Sophie* & & & & - \\
\hline 13 & 1 & Julia* & & & & - \\
\hline \multicolumn{7}{|l|}{2009} \\
\hline 14 & $3 \mathrm{~A}$ & Ruth & & & & - \\
\hline 15 & 4 & Sophie** & & & & - \\
\hline 16 & 3B & Ruth & & & $\mathrm{x}$ & Milly the Mouse \\
\hline 17 & 1 & Ruth & & & & Rudy’s Fall \\
\hline 18 & $3 \mathrm{~A}^{*}$ & Ruth** & & & $\mathrm{x}$ & Milly the Mouse \\
\hline 19 & 4 & Sophie & & & & - \\
\hline 20 & 1 & Julia & & & & - \\
\hline 21 & $3 \mathrm{~A}$ & Ruth & $\mathrm{x}$ & & & $\begin{array}{l}\text { - } \\
\text { Singing initiated by learners } \\
\text { during portfolio work: }\end{array}$ \\
\hline
\end{tabular}




\begin{tabular}{|c|c|c|c|c|c|}
\hline & & & & & $\begin{array}{l}\text { Mosquito Song } \\
\text { One, Two, Three, Four, Five, } \\
\text { Once I Caught A Fish Alive } \\
\text { Jingle Bells (chorus only) } \\
\text { Rudolph the Red Nosed } \\
\text { Reindeer (chorus only) }\end{array}$ \\
\hline 22 & 4 & Student & & $\mathrm{x}$ & Winnie the Witch \\
\hline 23 & 1 & Julia & & & - \\
\hline 24 & 1 & Ruth & & $\mathrm{x}$ & The Smartest Giant in Town \\
\hline 25 & $3 \mathrm{~A}$ & Ruth & $\mathrm{x}$ & & $\begin{array}{l}\text { - } \\
\text { Singing initiated by learners } \\
\text { during portfolio work: } \\
\text { London Is A Very Big Town } \\
\text { Head, Shoulders, Knees and } \\
\text { Toes (first part only) } \\
\text { Rudolph the Red Nosed } \\
\text { Reindeer (chorus only) } \\
\text { Mosquito Song }\end{array}$ \\
\hline 26 & 4 & Student & & & - \\
\hline 27 & 1 & Julia** & $\mathrm{x}$ & & I Can Sing a Rainbow \\
\hline 28 & 1 & Ruth & & $\mathrm{x}$ & The Smartest Giant in Town \\
\hline 29 & $3 \mathrm{~A}$ & Ruth** & & $\mathrm{x}$ & The Smartest Giant in Town \\
\hline 30 & 1 & Julia** & $\mathrm{x}$ & & I Can Sing a Rainbow \\
\hline 31 & $3 \mathrm{~A}$ & Ruth & & $\mathrm{x}$ & The Smartest Giant in Town \\
\hline 32 & $3 \mathrm{~A}$ & Ruth & & $\mathrm{x}$ & $\begin{array}{l}\text { Look at Me*** } \\
\text { Go Away Floppy } \\
\text { Big Feet } \\
\text { Kipper’s Diary }\end{array}$ \\
\hline 33 & $3 \mathrm{~A}$ & Ruth & & $\mathrm{x}$ & $\begin{array}{l}\text { Look at Me*** } \\
\text { Go Away Floppy } \\
\text { Big Feet } \\
\text { Kipper’s Diary }\end{array}$ \\
\hline 34 & $3 \mathrm{~A}$ & Ruth & & $\mathrm{x}$ & The Three Little Pigs \\
\hline 35 & $3 \mathrm{~A}$ & Ruth** & & $\mathrm{x}$ & The Three Little Pigs \\
\hline 36 & $3 \mathrm{~A}$ & Ruth & & $\mathrm{x}$ & The Three Little Pigs*** \\
\hline
\end{tabular}




\begin{tabular}{|l|l|l|l|l|l|l|}
\hline 37 & $3 \mathrm{~A}$ & Ruth & & & $\mathrm{x}$ & The Three Little Pigs*** \\
\hline 38 & 3 & Ruth & & & $\mathrm{x}$ & The Three Little Pigs*** \\
\hline
\end{tabular}

* These are parallel sessions.

** Researcher taught parts of the session.

*** Children worked in groups and could choose between different activities, e.g. artwork, games, storytime.

\section{Other}

\begin{tabular}{|c|c|c|c|c|c|}
\hline Lesson & Game & $\begin{array}{l}\text { Focus } \\
\text { on words } \\
\text { \& patterns }\end{array}$ & $\begin{array}{l}\text { Cultural } \\
\text { knowledge }\end{array}$ & Portfolio & Description \\
\hline 3 & $\mathrm{x}$ & & & & Football match outdoors \\
\hline 12 & & & $\mathrm{x}$ & & Talking about schools in UK \\
\hline 13 & & & $\mathrm{x}$ & & Talking about schools in UK \\
\hline 14 & $\mathrm{X}$ & $\mathrm{x}$ & & & $\begin{array}{l}\text { Simon says } \\
\text { Describing carnival clothes }\end{array}$ \\
\hline 15 & & $\mathrm{x}$ & $\mathrm{x}$ & & $\begin{array}{l}\text { Describing carnival clothes } \\
\text { Talking about Pancake Day }\end{array}$ \\
\hline 19 & & & & $\mathrm{x}$ & $\begin{array}{l}\text { Completing self-assessment } \\
\text { forms }\end{array}$ \\
\hline 20 & $\mathrm{x}$ & $\mathrm{x}$ & & & Practising animal names \\
\hline 21 & & & & $\mathrm{x}$ & $\begin{array}{l}\text { Completing self-assessment } \\
\text { forms }\end{array}$ \\
\hline 23 & $\mathrm{x}$ & $\mathrm{x}$ & & & Practising animal names \\
\hline 25 & & & & $\mathrm{x}$ & $\begin{array}{l}\text { Completing self-assessment } \\
\text { forms }\end{array}$ \\
\hline 26 & $\mathrm{x}$ & $\mathrm{x}$ & & & $\begin{array}{l}\text { Rooms in the house, } \\
\text { Asking where someone is }\end{array}$ \\
\hline
\end{tabular}


III. Proportion of classroom discourse devoted to songs, chants and stories

Verbal interaction

\begin{tabular}{|c|c|c|c|c|c|c|c|c|}
\hline $\begin{array}{l}\text { Trans- } \\
\text { cript }\end{array}$ & Lesson & $\begin{array}{l}\text { Total } \\
\text { word } \\
\text { count }\end{array}$ & $\begin{array}{l}\text { Word count } \\
\text { (song) }\end{array}$ & $\%$ & $\begin{array}{l}\text { Word } \\
\text { count } \\
\text { (chant) }\end{array}$ & $\%$ & $\begin{array}{l}\text { Word count } \\
\text { (story) }\end{array}$ & $\%$ \\
\hline 1 & 3 & 3,500 & - & - & - & - & - & - \\
\hline 2 & 4 & 5,183 & 3,900 & 75 & - & - & - & - \\
\hline 3 & 5 & 4,684 & 4,204 & 90 & - & - & - & - \\
\hline 4 & 6 & 4,674 & - & - & 3,635 & 78 & - & - \\
\hline 5 & 7 & 5,373 & 1,032 & 19 & - & - & 4,033 & 75 \\
\hline 6 & 8 & 3,904 & 698 & 18 & - & - & 2,758 & 71 \\
\hline 7 & 9 & 4,164 & 1,477 & 35 & - & - & - & - \\
\hline 8 & 10 & 3,410 & - & - & 605 & 18 & 2,710 & 79 \\
\hline 9 & 11 & 3,825 & - & - & $\begin{array}{r}3,825 \\
(798 \& \\
3,027)\end{array}$ & $\begin{array}{l}100 \\
(21 \\
\& \\
79)\end{array}$ & - & - \\
\hline 10 & 25 & 4,364 & 426 & 10 & - & - & - & - \\
\hline 11 & 26 & 3,295 & - & - & - & - & - & - \\
\hline 12 & 29 & 4,146 & - & - & - & - & 2,990 & 72 \\
\hline 13 & 31 & 5,165 & - & - & - & - & 2,825 & 55 \\
\hline 14 & 32 & 2,750 & - & - & - & - & 883 & 32 \\
\hline 15 & 38 & 716 & - & - & - & - & 267 & 37 \\
\hline
\end{tabular}




\section{Recording time}

\begin{tabular}{|c|c|c|c|c|c|c|c|c|}
\hline $\mathrm{T}$. & L. & $\begin{array}{l}\text { Total } \\
\text { time }\end{array}$ & $\begin{array}{l}\text { Time on } \\
\text { song (mins) }\end{array}$ & $\%$ & $\begin{array}{l}\text { Time on } \\
\text { chant } \\
\text { (mins) }\end{array}$ & $\%$ & $\begin{array}{l}\text { Time on } \\
\text { story (mins) }\end{array}$ & $\%$ \\
\hline 1 & 3 & $37: 53$ & - & - & - & - & - & - \\
\hline 2 & 4 & $45: 28$ & $27: 01$ & 59 & - & - & - & - \\
\hline 3 & 5 & $35: 02$ & 26:33 & 76 & - & - & - & - \\
\hline 4 & 6 & $43: 35$ & - & - & $27: 35$ & 63 & - & - \\
\hline 5 & 7 & $47: 41$ & $08: 21$ & 17 & - & - & $33: 28$ & 70 \\
\hline 6 & 8 & $44: 15$ & $05: 20$ & 12 & - & - & $22: 48$ & 51 \\
\hline 7 & 9 & $27: 35$ & $06: 42$ & 24 & - & - & - & - \\
\hline 8 & 10 & $42: 29$ & - & - & 03:39 & 8 & $23: 54$ & 56 \\
\hline 9 & 11 & $47: 23$ & - & - & $\begin{array}{l}47: 23 \\
(10: 55 \& \\
36: 28)\end{array}$ & $\begin{array}{l}100 \\
(23 \\
\& \\
77)\end{array}$ & - & - \\
\hline 10 & 25 & $37: 58$ & 04:31 & 12 & - & - & - & - \\
\hline 11 & 26 & $41: 50$ & - & - & - & - & - & - \\
\hline 12 & 29 & $40: 54$ & - & - & - & - & $20: 59$ & 51 \\
\hline 13 & 31 & $44: 32$ & - & - & - & - & $22: 25$ & 51 \\
\hline 14 & 32 & $44: 42$ & - & - & - & - & $06: 49$ & 15 \\
\hline 15 & 38 & 05:38 & - & - & - & - & $01: 59$ & 36 \\
\hline
\end{tabular}


Appendix 8: Analysis of songs, chants and stories for repetition, visualization and acoustic cues

Texts are listed according to genre and in alphabetical order. If there are accompanying actions, these are also mentioned.

\section{Songs}

\section{Head, Shoulders, Knees and Toes}

Head, shoulders, knees and toes, knees and toes, Head, shoulders, knees and toes, knees and toes And eyes and ears and mouth and nose

Head, shoulders, knees and toes, knees and toes

\section{Actions:}

Touching each body part as it is named / when it should be named

Item Total:

Items occurring once

(yellow):

4

$\%$ : $13 \%$

\section{I can sing a rainbow}

Red and yellow and pink and green,

Purple and orange and blue.

I can sing a rainbow,

Sing a rainbow, Sing

a rainbow too!

Listen with your eyes,

Listen with your eyes,

And sing everything you see.

You can sing a rainbow,

Sing a rainbow,

Sing along with me. 
Red and yellow and pink and green,

Purple and orange and blue.

You can sing a rainbow,

Sing a rainbow,

Sing a rainbow too!

Item Total: $\quad 73$

Items occurring once: $\quad 4$

\%: $\quad 5 \%$

\section{If You're Happy and You Know It}

If you're happy and you know it, clap your hands

If you're happy and you know it, clap your hands

If you're happy and you know it

And you really want to show it

If you're happy and you know it, clap your hands

If you're happy and you know it, slap your sides

If you're happy and you know it, slap your sides

If you're happy and you know it

And you really want to show it

If you're happy and you know it, slap your sides

If you're happy and you know it, stamp your feet

If you're happy and you know it, stamp your feet

If you're happy and you know it

And you really want to show it

If you're happy and you know it, stamp your feet

Actions:

Clapping one’s hands

(whenever it is mentioned)

Slapping one’s sides

Stamping one's feet

Item Total:

Items occurring once: 0

$\%$ : 


\section{Jingle Bells (chorus only)}

Jingle bells,

jingle bells,

jingle all the way

oh what fun it is to ride

in a one-horse open sleigh

Item Total:

Items occurring once: 15

$\%$ :

$75 \%$

London Is a Very Big Town (O!Kay!, 1999)

London is a very big town,

and the double deckers and the underground,

at 99p all across the town,

London is a very big town

Item Total: $\quad 26$

Items occurring once: 8

$\%$ :

$31 \%$

\section{One, Two, Three, Four, Five}

One, Two, Three, Four, Five,

Once I caught a fish alive

Six, seven, eight, nine, ten,

Then I let him go again

Why did you let him go?

Because he bit my finger so.

Which finger did he bite?

This little finger on my right.

Item Total:

45

Items occurring once: 38

$\%$ :

$84 \%$ 
Rudolph the Red-Nosed Reindeer (chorus and one verse)

Rudolph the red-nosed reindeer

Had a very shiny nose

And if you ever saw him

you would even think it glows

All of the other reindeer

Used to laugh and call him names

They never let poor Rudolph

Join in any reindeer games

Item Total:

Items occurring once: 40

$\%:$

$93 \%$

The Mosquito Song (see also weesing.com)

Actions:

Zzz-zt (clap) Zzz-zt (clap)

Zzz---zt (clap, clap)

Clapping (see brackets)

The mosquito can bite

And it bothers me

And it itches, itches

All the night

It's a tiny bug

And it bothers me

And I scratch, scratch, scratch

All the night

Zzz-zt (clap) Zzz-zt (clap)

Zzz---zt (clap, clap)

Pretending to scratch

Pretending to scratch

Item Total:

43

Items occurring once: 8

$\%$ :

$19 \%$ 
The Weather Song (Boogie Beebies, 2005)

This morning there'll be sun

It will be windy later on

Some heavy rain is on the way

The weather will be everything today
Actions:

Spreading arms over the head and moving to the side to imitate sun

Pretending to be blown away in the wind

Listing arms and imitating rain falling down with fingers

Wriggling one’s body

Item Total: 24

Items occurring once: 19

$\%$ :

$79 \%$ 


\section{Chants}

Easter Bunny Chant (Diekmann, 2008a)

Actions:

Easter Bunny, Easter Bunny,

Hop, hop, hop

Easter Bunny, Easter Bunny,

Stop, stop, stop

Give me, give me Easter eggs

one and two and three

Easter Bunny, Easter Bunny,

All the eggs for me

Easter Bunny, Easter Bunny

Thank you very much

The chocolate eggs are in my tummy

Mmmh - yummy

Pretend to call s.o.

Hopping (when mentioned)

Pretend to call s.o.

Put hand up to signal 'stop'

Wave as if to say 'come here'

Count using your fingers

Pretend to call s.o.

Form a basket with your hands

Pretend to call s.o.

Take a bow

point to your tummy

Pat your tummy

Item Total:

51

Items occurring once: 16

$\%$ :

$32 \%$

Easter Chant (source unknown)

Easter Bunny,

Easter Bunny,

Hop, hop hop

Actions:

Easter Bunny,

Easter Bunny,

Please don't stop.

\begin{tabular}{l} 
Actions: \\
Hop (three times) \\
Stop \\
\hline
\end{tabular}

Item Total:

14

Items occurring once: 3

$\%$ :

$21 \%$ 
Football Warm-Up (Boogie Beebies, 2005)

Football

Football

Football

Actions:

Clapping (three times) after calling out 'football'

Pretend to dribble

That's it. Keep dribbling

Okay

Let's keep the ball up

Pretend to keep a ball up

That's it. Keep that ball up.

Uh. Here we go.

Let's dribble with the ball again

Keep on dribbling

Pretend to dribble

Show me your football skills. Okay.

Let's chest and head

Chest and head

Chest and head

Chest and head

Let's dribble with the ball again

Oh yeah

Here we go. Are you doing okay?

Okay, let's run after that ball

It seems to be getting away

Keep on running after that ball

That's it. We've got it

Let's dribble with it again

Pretend to dribble

Keep on dribbling

That's it.

Pretend to run (on the spot)

Pretend to dribble

Pretend to chest and head

Pretend to dribble


Now, let's save this

Save the goal

Save a goal

Save the goal

And save it

Okay

Football

Football

Football

Football

Keep it up

That's it

And keep it up

And keep it up

Are you ready to chest it

Chest it and head it

Chest it, head it

Chest it and head it

You'd better run after the ball

Keep on running

That's it

Save the goal

Save a goal

Save a goal

Yeah
Actions:

Pretend to catch the ball

Clap (three times) after calling out 'football'

Pretend to keep the ball up

Pretend to chest and head

Pretend to run after the ball

Pretend to catch the ball

Item Total: 179

Items occurring once: 23

$\%$ : 


\section{III/1 Stories}

April Weather (Diekmann, 2008b)

Look out of the window. It's sunny.

What a nice day.

Let's go for a walk.

\section{Open the door - but oh no!}

\section{It's cold.}

Go to your room.

Put on a sweater.

\section{Open the door - but oh no!}

\section{It's raining.}

Take an umbrella.

\section{Open the door - but oh no!}

It's stormy. Your umbrella flies away.

Close the door.

Sit down in the kitchen.

Have a cup of hot chocolate.

Yummy!

Actions:

put hands above the eyes, give it a thumbs up

March on the spot,

Pretend to open the door and to move back, shivering

March on the spot,

Mime putting on a jumper

Mime opening a door, move back, mime rain falling down with your hands,

Mime opening an umbrella

Mime opening a door, move back looking shocked, make a noise as if wind was blowing, mime the umbrella is being blown away

Mime closing a door, march on the spot, sit down, making holding a cup and rubbing your tummy

\begin{tabular}{|l|l|}
\hline Item total & 71 \\
\hline Recurring chunks (blue) & 1 \\
\hline Involving ... items in total (blue) & 18 \\
\hline \% of repetition & $25 \%$ \\
\hline Recurring patterns (green) & 1 \\
\hline Involving ... items in total (green) & 8 \\
\hline \% of varied repetition & $11 \%$ \\
\hline
\end{tabular}

Easter Bunny's Book *(Englisch begegnen: 16)

It's Easter time again and little Easter Bunny wants to hide its Easter egg.

\section{There is Conny the cow.}

Cow: Hello.

Easter Bunny: Hello, cow. May I hide my egg in your grass? 
Cow: Yes, little Easter Bunny, hide your egg in my grass.

There is Porky the pig.

Pig: Hello.

Easter Bunny: Hello, pig. May I hide my egg in your puddle?

Pig: Yes, little Easter Bunny, hide your egg in my puddle.

There is Peter the pony.

Pony: Hello.

Easter Bunny: Hello, pony. May I hide my egg in your hay?

Pony: Yes, little Easter Bunny, hide your egg in my hay.

There is Mini the mouse.

Mouse: Hello.

Easter Bunny: Hello, mouse. May I hide my egg in your mouse hole?

Mouse: Yes, little Easter Bunny, hide your egg in my mouse hole.

There is Helga the hen.

Hen: Hello.

Easter Bunny: Hello, hen. May I hide my egg in your nest?

Hen: Yes, little Easter Bunny, hide your egg in my nest.

There is Sam the dog.

Dog: Hello.

Easter Bunny: Hello, dog. May I hide my egg in your kennel?

Dog: Yes, little Easter Bunny, hide your egg in my kennel.

There is Kitty the cat.

Cat: Hello.

Easter Bunny: Hello, cat. May I hide my egg in your basket?

Cat: Yes, little Easter Bunny, hide your egg in my basket.

* For the analysis, the text has been used as Julia read it out, not as it was published.

\begin{tabular}{|l|l|}
\hline Item total & 207 \\
\hline Recurring chunks (blue) & 22 \\
\hline Involving ... items in total (blue) & 172 \\
\hline \% of repetition & $83 \%$ \\
\hline Recurring patterns (green) & 1 \\
\hline Involving ... items in total (green) & 21 \\
\hline \% of varied repetition & $10 \%$ \\
\hline
\end{tabular}


Graded Readers (Hunt and Brychta, 2000)

\section{Big Feet}

\section{Come and look at this.}

Come and look at this. Is it a big monster?

Come and look at this. Is it a big dinosaur?

Come and look at this. Is it a big giant?.

No. It is Dad.

\begin{tabular}{|l|l|}
\hline Item total & 39 \\
\hline Recurring chunks (blue) & 1 \\
\hline Involving ... items in total (blue) & 20 \\
\hline \% of repetition & $51 \%$ \\
\hline Recurring patterns (green) & 1 \\
\hline Involving ... items in total (green) & 15 \\
\hline \% of varied repetition & $38 \%$ \\
\hline
\end{tabular}

\section{Go Away Floppy}

Go away, Floppy.

Go away Floppy. We are skipping.

Go away, Floppy. We are painting.

Come back, Floppy. Floppy, come back.

We are sorry.

\begin{tabular}{|l|l|}
\hline Item total & 24 \\
\hline Recurring chunks (blue) & 1 \\
\hline Involving ... items in total (blue) & 9 \\
\hline \% of repetition & $38 \%$ \\
\hline Recurring patterns (green) & 2 \\
\hline Involving ... items in total (green) & 12 \\
\hline \% of varied repetition & $50 \%$ \\
\hline
\end{tabular}




\section{Kipper's Diary}

Monday. It was a wet day.

Tuesday. It was a windy day. I went to the shops.

Wednesday. It was a sunny day. I went to the pool.

Thursday. It was a hot day. I went to the park.

Friday. It was a fun day.

\begin{tabular}{|l|l|}
\hline Item total & 45 \\
\hline Recurring chunks (blue) & - \\
\hline Involving ... items in total (blue) & - \\
\hline \% of repetition & - \\
\hline Recurring patterns (green) & 2 \\
\hline Involving ... items in total (green) & 40 \\
\hline \% of varied repetition & $89 \%$ \\
\hline
\end{tabular}

\section{Look at Me}

Look at me, Mum.

Look at me, Mum. Look at me on my bike.

Look at me, Mum. Look at me on my bike.

Look at me, Mum. Oh, no!

Look at me!

\begin{tabular}{|l|l|}
\hline Item total & 33 \\
\hline Recurring chunks (blue) & 2 \\
\hline Involving ... items in total (blue) & 28 \\
\hline \% of repetition & 85 \\
\hline Recurring patterns (green) & - \\
\hline Involving ... items in total (green) & - \\
\hline \% of varied repetition & - \\
\hline
\end{tabular}


Milly the Mouse (source unknown)

It is winter. It is very cold. There is snow.

There is a tree with branches and twigs but no leaves, because it's winter. There is snow on the tree, too.

This a mouse. Her name is Milly.

Milly lives in a little house. There is lots of snow.

It is cold, so cold.

There is a house. It's a house for people,

not for a mouse. It's warm in the house.

Milly walks around the garden and goes into the house.

She goes into the hall. She goes into the dining-room.

There are one, two, three chairs. She goes to the kitchen.

There are one, two chairs. And a fridge.

The fridge is important. There is cheese in the fridge.

She goes upstairs. She goes into the living-room.

She goes into the bedroom, and she goes upstairs

into the attic. Milly goes downstairs again into the

bedroom, living-room, dining-room, kitchen and

the bathroom. She finds something.

What is it? What is lying on the floor? A hat.

It is warm. What does Milly do? Milly takes the hat and goes home. Milly goes round the garden and into her house. It's nice and warm now.

\begin{tabular}{|l|l|}
\hline Item total & 204 \\
\hline Recurring chunks (blue) & - \\
\hline Involving ... items in total (blue) & - \\
\hline \% of repetition & - \\
\hline Recurring patterns (green) & 5 \\
\hline Involving ... items in total (green) & 94 \\
\hline \% of varied repetition & $46 \%$ \\
\hline
\end{tabular}

Drawing and pictures:

Teacher starts drawing snow, a tree

Teacher shows picture of a mouse

Teacher puts a big picture of a house, one can see different rooms on two levels and the attic on the blackboard

Teacher draws two people

Teacher points to the different rooms, moves picture of the mouse from one to another

Points to hat in the picture 
Rudy’s Fall (by Ruth)

This is Rudy. Rudy likes to run. One day he is running. There is a stone. He falls: “Auuch! Auuch!”

Rudy is hurt. He touches his head:

“Auuch! And my eyes! Auuch.

And my nose! And my ears. And my knees!”

Rudy gets up. He starts running. There is a stick.

He falls: “Auuch! Auuch! My shoulders. My belly.

My toes. My hands! My fingers!” Oh Rudy!
Actions, drawings \& pictures:

Teacher pretends to run, draws picture of a stone

Teacher pretends to fall and turns the picture of Rudy so that it looks as if he was lying on the floor

Teacher touches various body parts she mentions

Draws a stick and a tree

Teacher touches body parts that she mentions

\begin{tabular}{|l|l|}
\hline Item total & 67 \\
\hline Recurring chunks (blue) & 2 \\
\hline Involving ... items in total (blue) & 10 \\
\hline \% of repetition & $15 \%$ \\
\hline Recurring patterns (green) & 3 \\
\hline Involving ... items in total (green) & 30 \\
\hline \% of varied repetition & $45 \%$ \\
\hline
\end{tabular}

The Three Little Pigs (Grundschule Englisch 23:2, 2008)

Once upon a time there were three little pigs, named Al, Bill and Colin.

One day their mother said: "You are getting big. You have to look for a new home.”

"Yes,"said the three little pigs. "We will build our own houses."

"Good,” said mother pig. "But, please, be careful when you see the big bad wolf.

He loves to eat little pigs.”

“Don't worry, mother. We'll be careful," said the three little pigs and off they went.

One went to the right, one went to the left and one went straight on.

They sang: "Who's afraid oft he big bad wolf, the big bad wolf, the big bad wolf?”

\section{The first pig, $\mathrm{Al}$, found some straw.}

“Oh, great,” he said to himself.

"I can make a good house out of straw." 
So Al built a house of straw. He was finished in one hour.

Then $\mathrm{Al}$ sat down to have some rest.

Suddenly there was a loud knock on the door.

KNOCK! KNOCK! KNOCK!

Who was that? It was the big bad wolf.

"Little pig, little pig, let me in," the wolf cried.

"Not by the hair of my chinny chin chin," Al answered back.

"Then I'll huff and I'll puff and I'll blow your house down!"

And the wolf huffed and he puffed and he blew the house of straw down.

"Oh no,"Al cried and ran away to find his brothers.

The second pig, Bill, found some twigs.

"Oh, great," he said to himself.

"I can make a good house out of twigs."

So Bill built a house of twigs. He was finished in two hours.

Then Bill sat down to have some rest.

Suddenly there was a loud knock on the door.

KNOCK! KNOCK! KNOCK!

Who was that? It was the big bad wolf.

"Little pig, little pig, let me in," the wolf cried.

"Not by the hair of my chinny chin chin," Bill answered back.

"Then I'll huff and I'll puff and I'll blow your house down!"

And the wolf huffed and he puffed and he blew the house of twigs down.

"Oh no,"Bill cried and ran away to find his brothers.

The third pig, Colin, found some bricks.

"Oh, great," he said to himself.

"I can make a good house out of bricks."

So Colin built a house of bricks. He was finished in three hours.

He put a pot of water on the fire to boil.

Then Colin sat down to have some rest.

Suddenly there was a loud knock on the door.

KNOCK! KNOCK! KNOCK!

Who was that? It was the big bad wolf.

"Little pig, little pig, let me in," the wolf cried.

"Not by the hair of my chinny chin chin," Colin answered back. 


\section{“Then I'll huff and I'll puff and I’ll blow your house down!”}

And the wolf huffed and he puffed but he couldn't blow down the house made of bricks.

Suddenly the wolf saw the chimney on the brick house.

He climbed up on the roof and crawled down the chimney ...

And fell right into the big pot of boiling water.

"Ow! Ow! Ow!" howled the wolf as he ran right out of the house.

Colin followed him out of his house of bricks and met his brothers $\mathrm{Al}$ and Bill.

“Come and live in my brick house with me”, said Colin.

Happily they agreed and began to sing:

"Who’s afraid of the big bad wolf, the big bad wolf, the big bad wolf?"

And they lived happily ever after in their nice house of bricks.

\begin{tabular}{|l|l|}
\hline Item total & 676 \\
\hline Recurring chunks (blue) & 9 \\
\hline Involving ... items in total (blue) & 180 \\
\hline \% of repetition & $27 \%$ \\
\hline Recurring patterns (green) & 9 \\
\hline Involving ... items in total (green) & 200 \\
\hline \% of varied repetition & $30 \%$ \\
\hline
\end{tabular}




\section{III/2 Picture books}

Froggy Gets Dressed (London and Remkiewicz, 1992)

\begin{tabular}{|l|l|}
\hline Item total & 459 \\
\hline Recurring chunks & 17 \\
\hline Involving ... items in total & 141 \\
\hline \% of repetition & $31 \%$ \\
\hline Recurring patterns & 4 \\
\hline Involving ... items in total & 82 \\
\hline \% of varied repetition & $18 \%$ \\
\hline
\end{tabular}

\begin{tabular}{|l|l|l|}
\hline Recurring chunks & Snow! & $2 \mathrm{x}$ \\
& No! & $2 \mathrm{x}$ \\
& Froggy! called his mother. & $3 \mathrm{x}$ \\
& "What?" yelled Froggy & $3 \mathrm{x}$ \\
& "Did you forget to put something on?” & $3 \mathrm{x}$ \\
& Oops! & $3 \mathrm{x}$ \\
& cried Froggy & $2 \mathrm{x}$ \\
& He flopped back inside - flop flop flop. & $2 \mathrm{x}$ \\
& And flopped back outside into the snow - flop flop flop. & $2 \mathrm{x}$ \\
& Pulled on his boots - zup & $2 \mathrm{x}$ \\
& Put on his hat -zat & $2 \mathrm{x}$ \\
& Tied on his scarf -zwit & $2 \mathrm{x}$ \\
& Tugged on his mittens - zum & $2 \mathrm{x}$ \\
\hline Recurring patterns & Tugged off his mittens & $2 \mathrm{x}$ \\
& Untied his scarf & $2 \mathrm{x}$ \\
Took off his hat & Pulled off his boots & $2 \mathrm{x}$ \\
\hline
\end{tabular}


The Smartest Giant in Town (Donaldson and Scheffler, 2002)

\begin{tabular}{|l|l|}
\hline Item total & 1065 \\
\hline Recurring chunks & 10 \\
\hline Involving ... items in total & 249 \\
\hline \% of repetition & $23 \%$ \\
\hline Recurring patterns & 14 \\
\hline Involving ... items in total & 293 \\
\hline \% of varied repetition & $28 \%$ \\
\hline
\end{tabular}

\begin{tabular}{|c|c|c|}
\hline Recurring chunks & $\begin{array}{l}\text { the scruffiest giant in town } \\
\text { "What's the matter?” asked George. } \\
\text { "Cheer up!" said George } \\
\text { singing to himself } \\
\text { he sang to himself } \\
\text { "My ties is a scarf for a cold giraffe” } \\
\text { "My shirt's on a boat as a sail for a goat” } \\
\text { "My shoe is a house for a little white mouse" } \\
\text { "One of my socks is a bed for a fox" } \\
\text { "But look me up and down, I'm the smartest giant in town.” }\end{array}$ & $\begin{array}{l}2 x \\
5 x \\
5 x \\
3 x \\
2 x \\
5 x \\
4 x \\
3 x \\
2 x \\
4 x\end{array}$ \\
\hline Recurring patterns & $\begin{array}{l}\text { a smart shirt/pair of trousers/belt/stripy tie } \\
\text { "I’m the smartest/coldest/cosiest giant in town.” } \\
\text { It’s my neck/sail/our house/ sleeping bag/this bog. } \\
\text { I wish I/we had a long warm scarf/a strong new sail/a nice new } \\
\text { house/a warm dry sleeping bag. } \\
\text { And he took off his stripy tie/new white shirt/one of his shiny } \\
\text { shoes/one of his socks/smart new belt. } \\
\text { It made a wonderful scarf/magnificent sail/perfect home/very } \\
\text { fine sleeping bag/excellent path. } \\
\text { “Thank you!” said the giraffe/goat/dog/fox } \\
\text { George came to a river/a tiny ruined house/a campsite/a big } \\
\text { squelchy bog. } \\
\text { On the pavement/boat/ stood a giraffe/goat who was sniffing } \\
\text { sadly/bleating loudly. }\end{array}$ & $\begin{array}{l}4 \mathrm{x} \\
3 \mathrm{x} \\
5 \mathrm{x} \\
4 \mathrm{x}\end{array}$ \\
\hline
\end{tabular}




\begin{tabular}{|l|l|l|}
\hline & Beside the house/a tent/the bog stood a white mouse/fox/dog & $3 \mathrm{x}$ \\
who was crying/howling. & $2 \mathrm{x}$ \\
& Outside his front door stood all the animals \\
the kindest giant in town & $1 \mathrm{x}$ \\
& $\begin{array}{l}\text { Your tie/shirt/shoe/one of your socks is a scarf/boat/house/bed } \\
\text { for a cold giraffe/a goat/a little white mouse/a fox }\end{array}$ & $4 \mathrm{x}$ \\
\hline
\end{tabular}

Winnie the Witch (Thomas and Paul, 1987)

\begin{tabular}{|l|l|}
\hline Item total & 508 \\
\hline Recurring chunks & 8 \\
\hline Involving ... items in total & 100 \\
\hline \% of repetition & $20 \%$ \\
\hline Recurring patterns & 8 \\
\hline Involving ... items in total & 96 \\
\hline \% of varied repetition & $19 \%$ \\
\hline
\end{tabular}

\begin{tabular}{|l|l|l|}
\hline Recurring chunks & $\begin{array}{l}\text { She could see his eyes, anyway. } \\
\text { But when Wilbur closed his eyes and went to sleep, Winnie } \\
\text { couldn't see him at all. } \\
\text { with his eyes open } \\
\text { She picked up her magic wand } \\
\text { Winnie could see him } \\
\text { climbed to the top of the tallest tree } \\
\text { and again }\end{array}$ & $2 \mathrm{x}$ \\
\hline Recurring patterns & $\begin{array}{l}\text { The house/bed/bath/carpet/bed was } \\
\text { black/black/black/green/blue. } \\
\text { The carpets/chairs/chairs were black/black/white. } \\
\text { when Wilbur sat on a chair/the carpet } \\
\text { So she sat on/tripped over him. } \\
\text { Winnie was furious/worried } \\
\text { waved it once/five times and ABRACADABRA } \\
\text { He was black/bright green. }\end{array}$ & $2 \mathrm{x}$ \\
\hline
\end{tabular}




\begin{tabular}{|l|l|l|}
\hline & $\begin{array}{l}\text { when Wilbur slept on a chair/on the floor/on the bed } \\
\text { when he sat on a chair/lay on the carpet } \\
\text { she waved her magic/-wand }\end{array}$ & $\begin{array}{l}2 \mathrm{x} \\
2 \mathrm{x}\end{array}$ \\
\hline
\end{tabular}


Appendix 9: Additional example extracts from lessons

\section{Learners' response to songs}

Lesson 9: Joining actions and singing If You Are Happy And You Know It

\begin{tabular}{|c|c|c|}
\hline Turns & Sophie & Learners \\
\hline 1 & $\begin{array}{l}\text { [...] [if you're happy and you know it, } \\
\text { clap your hands ((clap, clap))] ... can } \\
\text { you try to sing it, not just clap it? can } \\
\text { you sing with us? sing mal mit, Y, du } \\
\text { wartest immer nur, bis geklatscht wird. } \\
\text { mitsingen, okay? sing along with us, Y, } \\
\text { you just wait for everybody to clap, } \\
\text { sing along, okay? ... one, two, three, } \\
\text { four ... [if you're happy and you know } \\
\text { it clap your hands ((clap, clap)) ... if } \\
\text { you're happy and you know it, clap } \\
\text { your hands ((clap, clap)) ... if you're } \\
\text { happy and you know it, and you really } \\
\text { want to show it ... if you're happy and } \\
\text { you know it, clap your hands ((clap, } \\
\text { clap))] ... good ... [if you're } \\
\text { happy ] ... now, listen ... if you’re } \\
\text { happy and you know it, slap your sides } \\
\text { ((slap, slap)) ... [if you’re happy and } \\
\text { you know it, slap your sides ((slap, } \\
\text { slap)) ... if you're happy and you know } \\
\text { it, and you really want to show it, if } \\
\text { you’re happy and you know it, slap } \\
\text { your sides ((slap, slap))] ... it’s, slap } \\
\text { your sides }\end{array}$ & $\begin{array}{l}\text { Cn: [if you're happy and you know it clap } \\
\text { your hands ((clap, clap)) ... if you're happy } \\
\text { and you know it, clap your hands ((clap, } \\
\text { clap)) ... if you're happy and you know it, } \\
\text { and you really want to show it ... if you're } \\
\text { happy and you know it, clap your hands } \\
\text { ((clap, clap))] } \\
\text { Cn ((some)): [if you're happy ] } \\
\text { Cn ((some)): [if you're happy and you know } \\
\text { it, slap your sides ((slap, slap)) ... if you're } \\
\text { happy and you know it, and you really want } \\
\text { to show it, if you're happy and you know it, } \\
\text { slap your sides ((slap, slap))] }\end{array}$ \\
\hline 2 & & Cn: slap your sides \\
\hline
\end{tabular}


Lesson 25: Learners trying to claim the floor for singing

\begin{tabular}{|c|c|c|}
\hline Turns & Ruth & Learners \\
\hline 1 & $\begin{array}{l}\text { and which song do you know ... Y? which } \\
\text { song in English you can sing? }\end{array}$ & \\
\hline 2 & & $\begin{array}{l}\text { Cf: XXX ((some children start } \\
\text { singing)) }\end{array}$ \\
\hline 3 & $\begin{array}{l}\text { XXX stop XXX please ... so, you need a } \\
\text { sheet ... you need a sheet of paper, and you } \\
\text { write a song XXX and you write songs ... and } \\
\text { you can write all the songs you know, you can } \\
\text { sing in English, okay? so, the first one is... } \\
\text { blue red XXX }\end{array}$ & ((a child humming quietly)) \\
\hline 4 & & $\begin{array}{l}\text { Cn: XXX ((quietly talking to each } \\
\text { other)) }\end{array}$ \\
\hline 5 & who knows another one? Y? & \\
\hline \multirow[t]{2}{*}{6} & & Cn: ((humming)) \\
\hline & {$[\ldots]$} & {$[\ldots]$} \\
\hline \multirow[t]{2}{*}{7} & & $\begin{array}{l}\text { Cm: London is a very big town } \\
\text { ((various children start singing } \\
\text { quietly)) }\end{array}$ \\
\hline & {$[\ldots]$} & {$[\ldots]$} \\
\hline 8 & $\begin{array}{l}\text { we can sing one of these songs ... } \\
\text { which ...... when we are finished our list, we } \\
\text { can sing one song, you like most, okay? ... } \\
\text { but we have to finish the list first }\end{array}$ & ((one child still humming)) \\
\hline
\end{tabular}




\section{Learners' response to chants}

Lesson 10: Children joining in Easter Chant

\begin{tabular}{|c|c|c|}
\hline Turns & Julia & Learners \\
\hline 1 & $\begin{array}{l}\text { [...] ihr seid super müde ... [...] wir } \\
\text { machen das, was wir verstehen, das is’n } \\
\text { bisschen Bewegung [...] Easter Bunny, } \\
\text { Easter Bunny ... hop, [hop, hop ... } \\
\text { Easter Bunny, Easter Bunny], please } \\
\text { don't stop ... again ... [Easter Bunny, } \\
\text { Easter Bunny ... hop, hop, hop ... } \\
\text { Easter Bunny, Easter Bunny, please } \\
\text { don’t stop] ... [...] und wir machen, } \\
\text { Easter Bunny, Easter Bunny, hop, [hop, } \\
\text { hop ... Easter Bunny, Easter Bunny, } \\
\text { please don’t stop] ... } \\
\text { you are awfully tired ... we'll do } \\
\text { something that we know best, and that’s } \\
\text { a bit of moving about [...] }\end{array}$ & $\begin{array}{l}\text { [hop, hop ... Easter Bunny, Easter Bunny] } \\
\text { ((some children joining in)) } \\
\text { [Easter Bunny , Easter Bunny ((many } \\
\text { children joining in)) ... hop, hop, hop ... } \\
\text { Easter Bunny, Easter Bunny, }{ }^{\circ} \text { please don’t } \\
\left.\text { stop }{ }^{\circ}\right] \\
\text { [hop, hop ... Easter Bunny, Easter Bunny, } \\
\text { [hop, hop, hop ((most children))]] ... } \\
{\left[{ }^{\circ} \text { please don’t stop }{ }^{\circ} \text { ((some children)) }\right.}\end{array}$ \\
\hline
\end{tabular}




\section{Learners’ response to stories}

Lesson 16: Using visual clues to construct plot, The Smartest Giant in Town

\begin{tabular}{|c|c|c|}
\hline Turn & Researcher & Learners \\
\hline 1 & $\begin{array}{l}\text { [...] I wish ... I had ... a long warm } \\
\text { scarf [...] look at that ((children } \\
\text { giggling and whispering)) }\end{array}$ & \\
\hline 2 & & C?: XXX \\
\hline 3 & $\begin{array}{l}\text { I think so ... I think the giraffe is } \\
\text { wearing a tie ... whose tie is it? }\end{array}$ & \\
\hline 4 & & $\begin{array}{l}\text { Cf: Der George hat der Giraffe seine Krawatte } \\
\text { gegeben. George gave his tie to the giraffe. }\end{array}$ \\
\hline 5 & $\begin{array}{l}\text { I think so, too ... George hasn't got a } \\
\text { tie anymore ... he gave his tie away }\end{array}$ & \\
\hline 6 & & C?: oh \\
\hline 7 & yeah, Y? & \\
\hline 8 & & $\begin{array}{l}\text { Cm: dahinten is auch noch so 'ne große Frau } \\
\text { da there in the background, there is another } \\
\text { tall lady }\end{array}$ \\
\hline
\end{tabular}

Lesson 19: Retrieval of the meaning of words

\begin{tabular}{|l|l|l|}
\hline Turns & Researcher & Learners \\
\hline 1 & $\begin{array}{l}\text { George } \ldots \text { now, George only had ... } \\
\text { o:ld clothes ... so he bought some new } \\
\text { clothes ... there they are }=\end{array}$ & \\
\hline 2 & $\begin{array}{l}\text { can you remember what they are } \\
\text { called? what is this? }\end{array}$ & C?: XXX \\
\hline 3 & & $\begin{array}{l}\text { Cf: TR, der Y macht immer XXX TR, } Y, \\
\text { keeps XXXing } \\
((T E \text { whispering in the background) })\end{array}$ \\
\hline
\end{tabular}




\begin{tabular}{|c|c|c|}
\hline 5 & & Cm: AU! OW! \\
\hline 6 & & Cn: ((giggling)) \\
\hline 7 & & Cm: XXX shopping \\
\hline 8 & $\begin{array}{l}\text { in Einkauf ... yeah, hmhm ... what } \\
\text { kind of clothes are they? }\end{array}$ & \\
\hline 9 & & Cm: krawatte! tie! \\
\hline 10 & & C?: XXX ((quietly)) \\
\hline 11 & & C?: stop! ((quietly)) \\
\hline 12 & $\mathrm{XXX}$ & \\
\hline 13 & & Cm: eeh? XXX ((children whispering)) \\
\hline 14 & $\begin{array}{l}\text { okay, you know what we do? we do } \\
\text { something else [...] I'll give you a } \\
\text { word, and you tell me which number } \\
\text { it ... it is ... ehm ... SOCKS ... yeah? }\end{array}$ & \\
\hline 15 & & C?: is four \\
\hline 16 & $\begin{array}{l}\text { four } \ldots \text { socks } \ldots \text { very good } \ldots \text { socks } \ldots \\
\text { all together }\end{array}$ & \\
\hline 17 & & Cn: ${ }^{\circ}$ socks $^{\circ}$ ((children whispering)) \\
\hline 18 & ehm $\ldots$ shiny shoes $\ldots$ yeah $\ldots$ Y? & \\
\hline 19 & & Cm: one! \\
\hline & {$[\ldots]$} & \\
\hline 20 & shiny shoes & \\
\hline 21 & & Cn: shiny shoes \\
\hline
\end{tabular}

Lesson 19: Retrieving language chunks

\begin{tabular}{|l|l|l|}
\hline Turns & Researcher & Learners \\
\hline 1 & $\begin{array}{l}\text { kannst du dich auch noch erinnern, wie } \\
\text { das ging? my tie is a scarf ... } \\
\text { can you remember how it went? [...] ... }\end{array}$ & \\
\hline 2 & & Cm: for a cold giraffe \\
\hline
\end{tabular}




\begin{tabular}{|c|c|c|}
\hline 3 & [my shirt's on a boat] & \\
\hline 4 & & C?: [my shirt's on a boat] \\
\hline 5 & & Cn: as a sail for a boat ((2 children)) \\
\hline 6 & & Cm: goat! \\
\hline 7 & $\mathrm{hm}$ & \\
\hline 8 & & $\begin{array}{l}\text { Cm: my shoe [is a house for a little white } \\
\text { mouse] }\end{array}$ \\
\hline 9 & & $\begin{array}{l}\text { Cn: } \quad \text { [is a house for a little } \\
\text { white mouse] }\end{array}$ \\
\hline 10 & little white mouse $\ldots \mathrm{hmhm}=$ & \\
\hline 11 & & $\begin{array}{l}\text { Cn: = one of my socks is a bed for a fox ... } \\
\text { my belt helped a dog }\end{array}$ \\
\hline 12 & & Cm: who was crossing a bog \\
\hline
\end{tabular}


Appendix 10: Cards for learner interviews

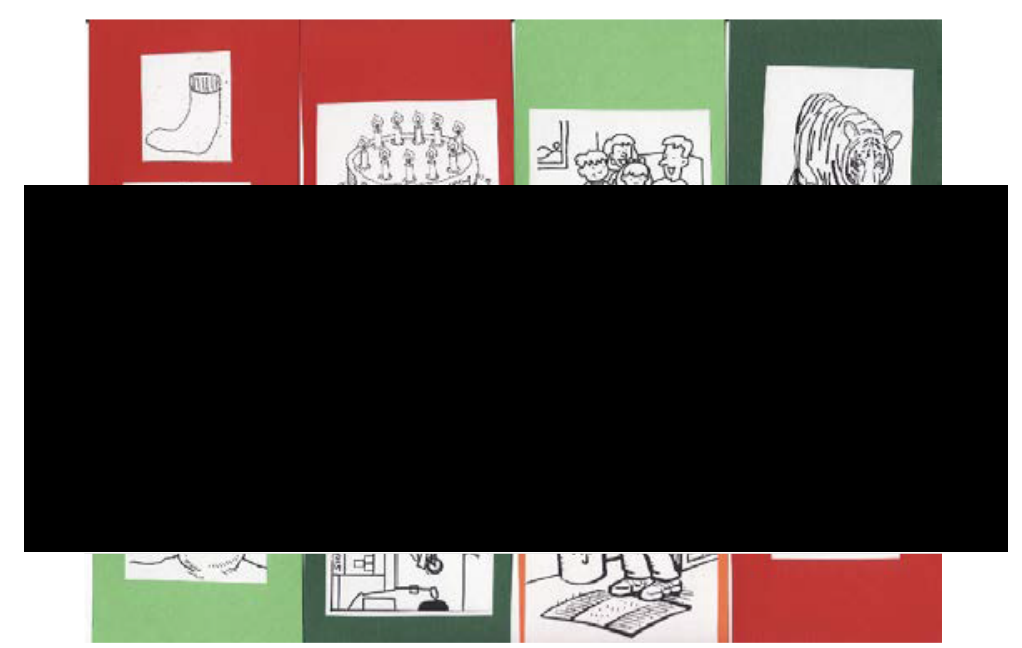

Cards 1-8

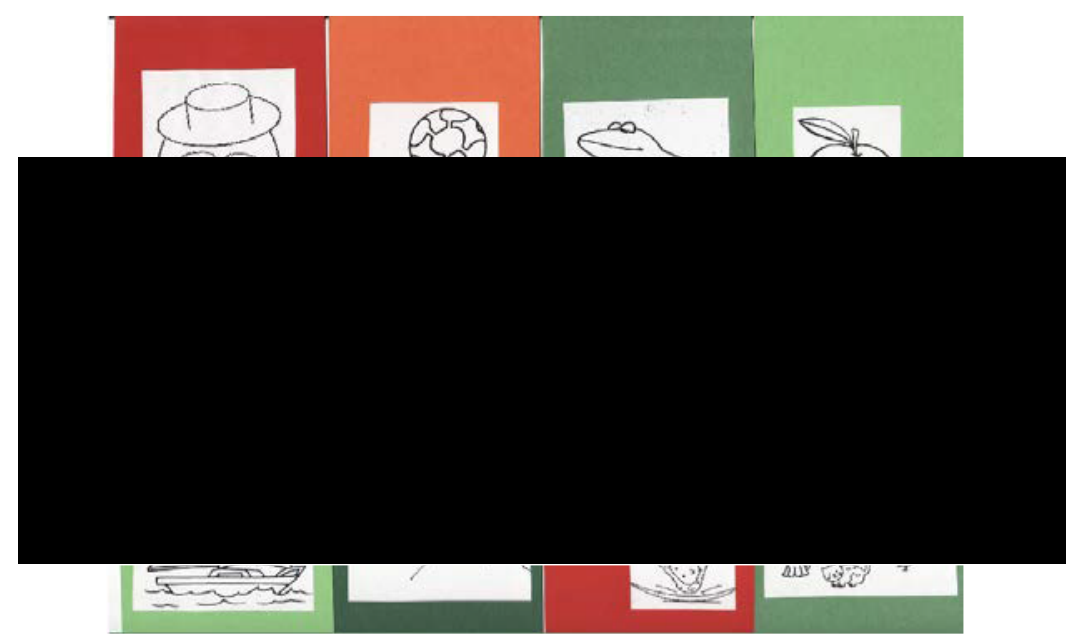

Cards 9-16

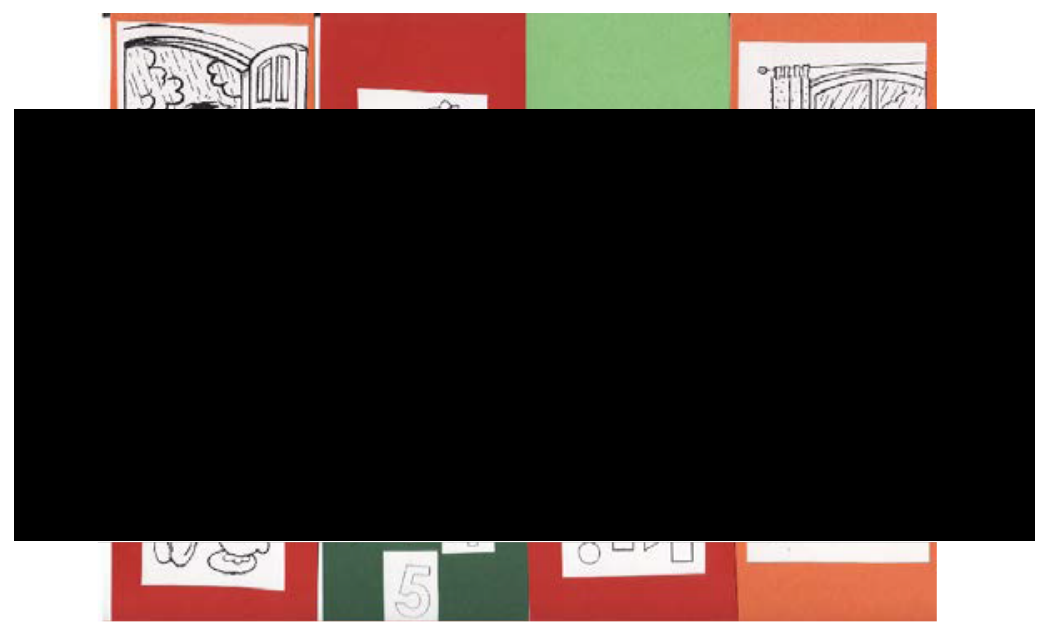

Cards 17-24 


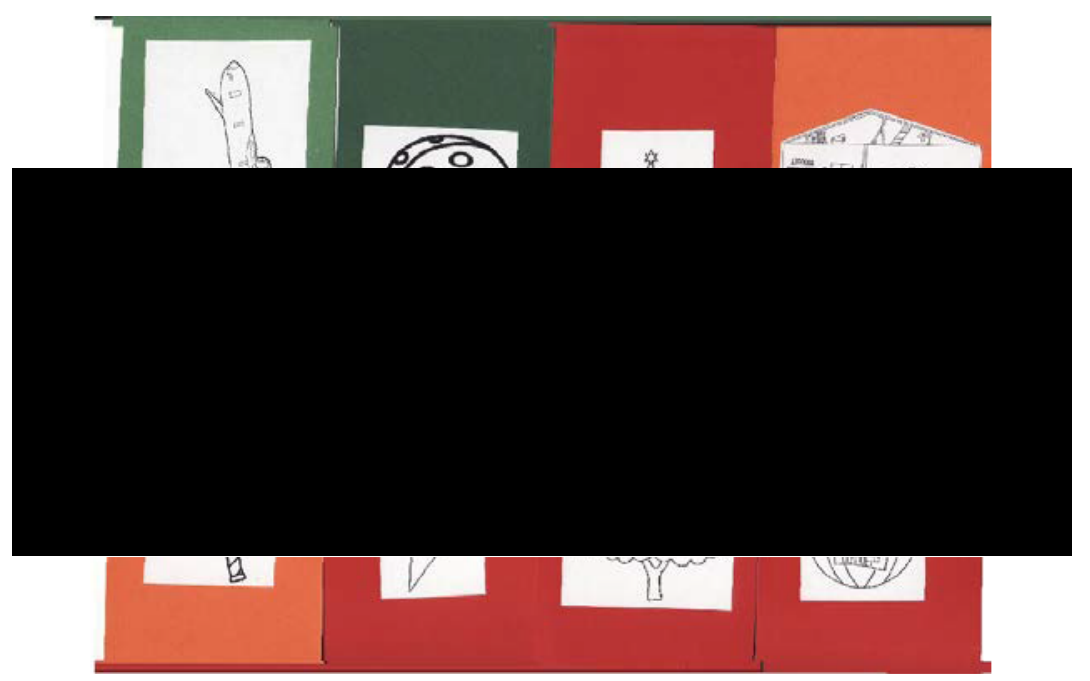

Cards 25-32

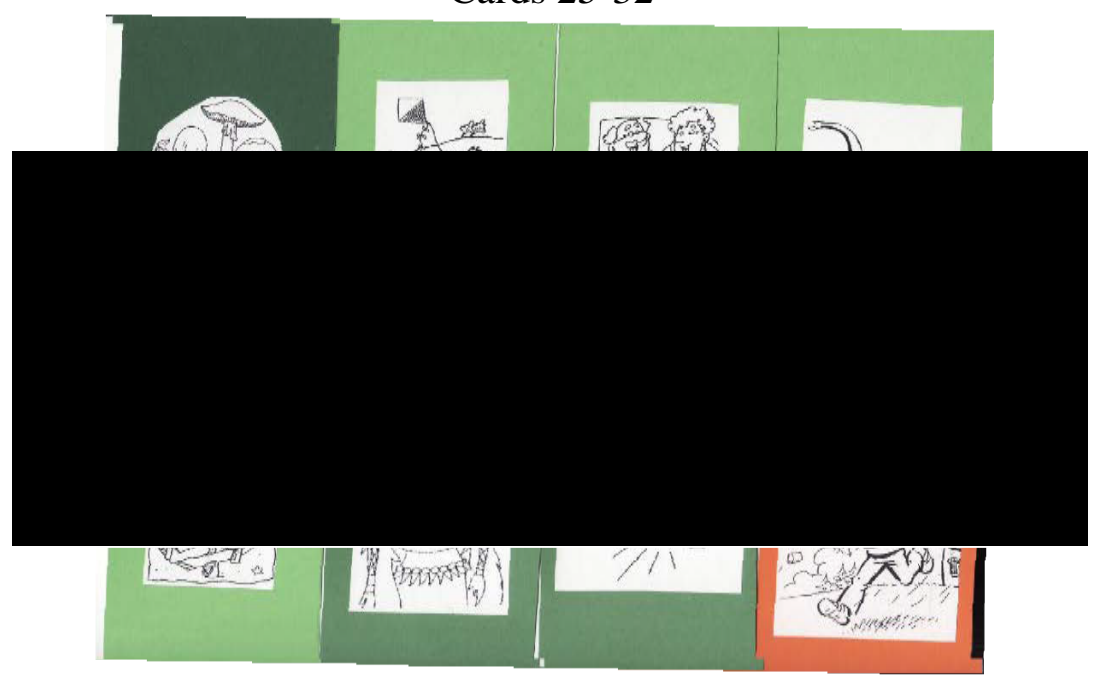

Cards 33-40

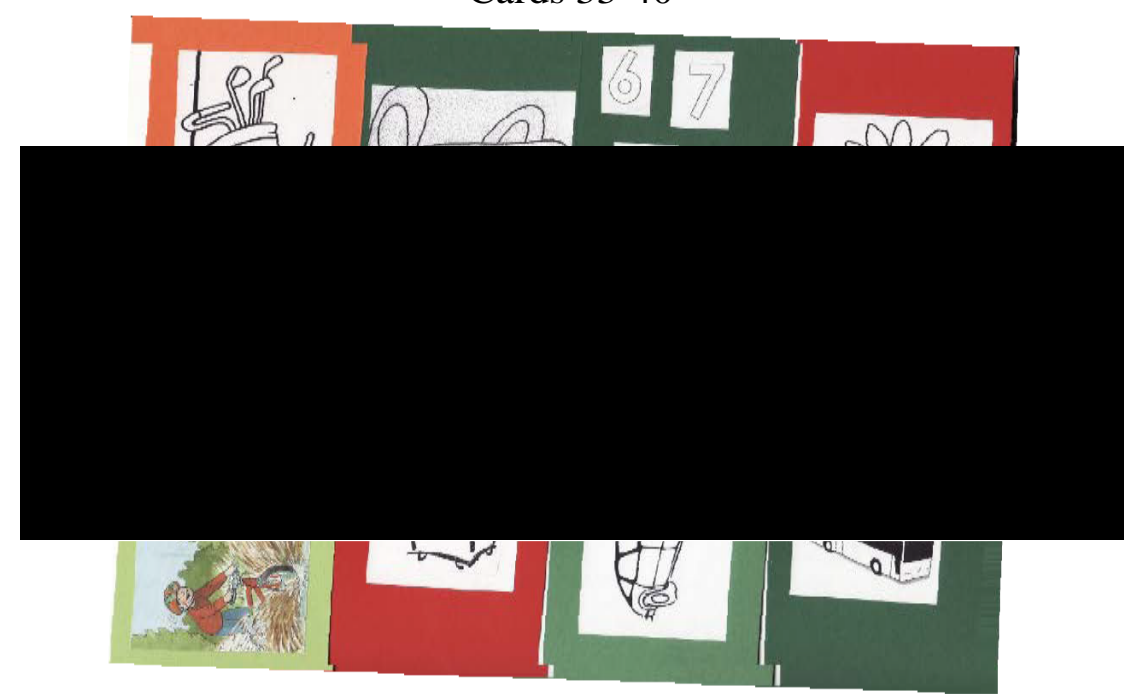

Cards 41-48 


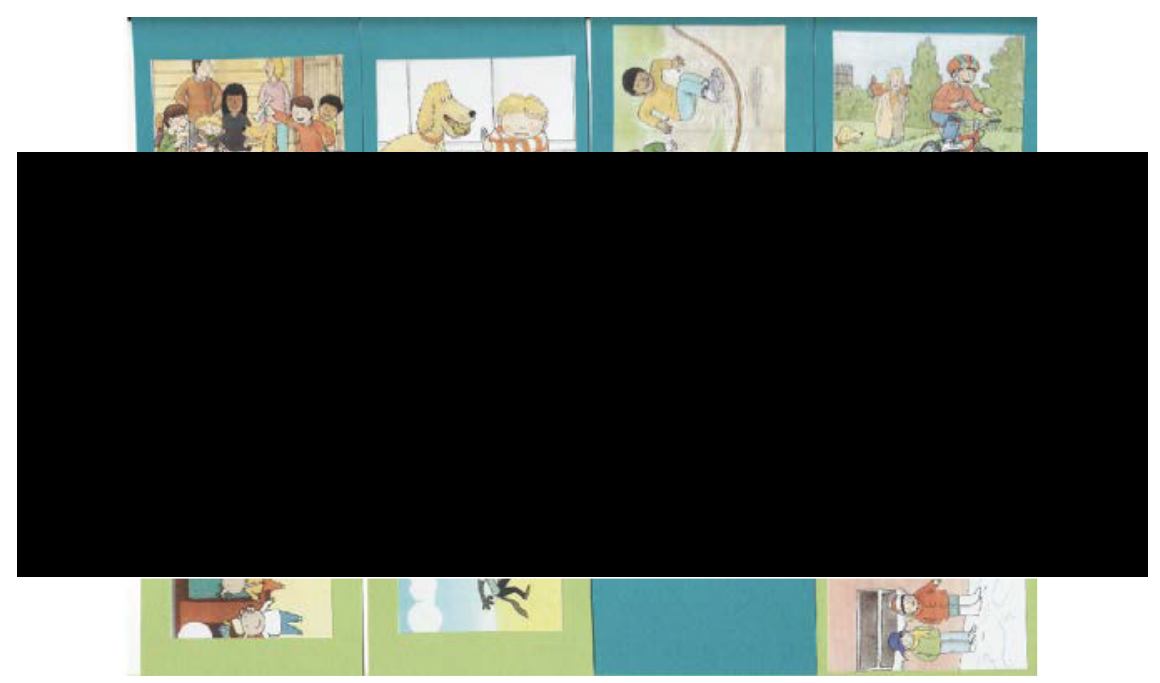

Cards 49-56

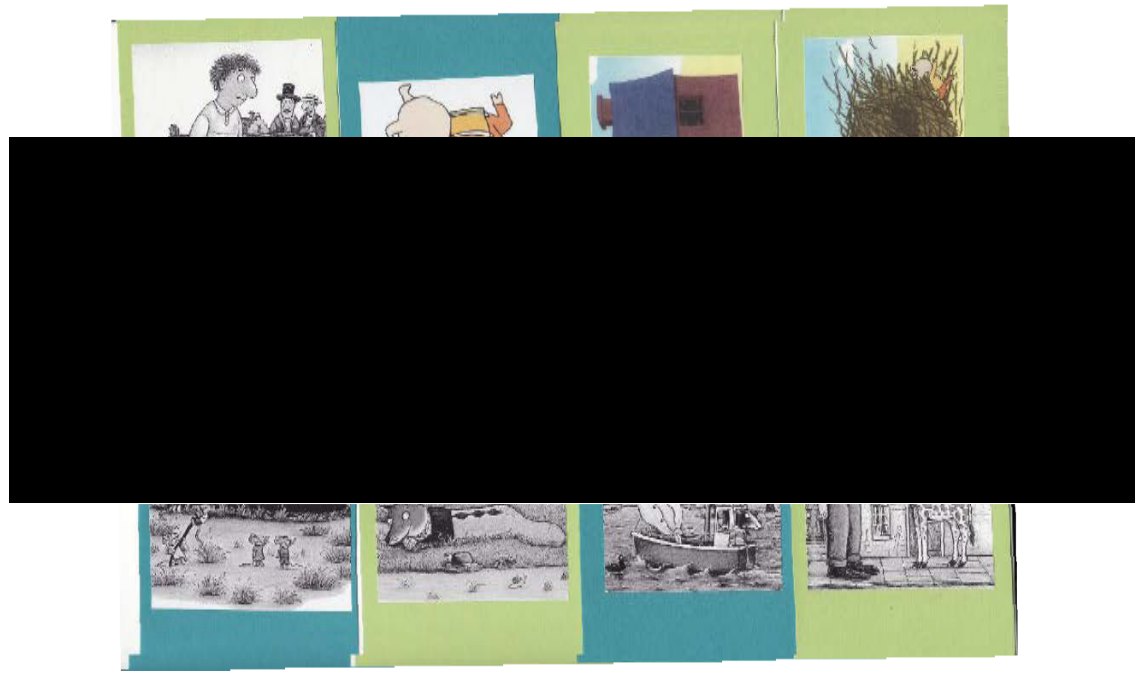

Cards 57-64

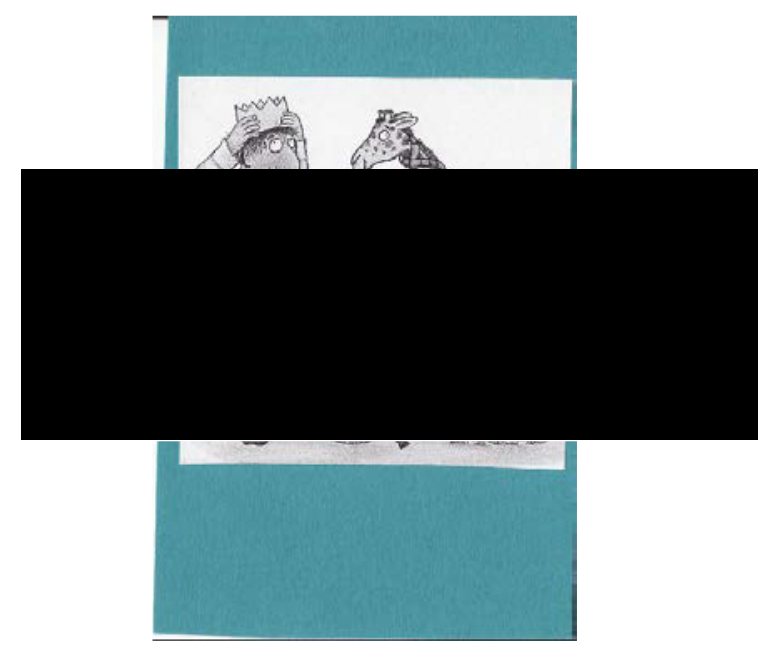

Card 65 
Appendix 11: Interview guides for teacher interviews

Semi-Structured Interview No 1 (Sophie, 23-09-2008)

\section{English translation of interview questions:}

\section{Children's enthusiasm}

During observations and the process of transcription, I noticed that children were very enthusiastic in their English lessons.

a) Are the children always so enthusiastic about English or

b) are there differences between different activities, such as singing and playful question-answer-activities?

\section{Imitation}

Children seemed very keen to imitate everything that was said in English.

a) How important is the imitation or immediate repetition of words and sentences to you in your teaching?

b) What do you prefer: joint-speaking (children and teacher speaking at the same time, for example during storytelling) or repetition?

c) Is the technique of joint-speaking commonly used in other subjects in primary schools?

\section{Priorities}

a) What do you find most important in primary EFL?

b) Are there different priorities in Year 1 and Year 4?

\section{Translation}

During observations I had the impression that translating a word from the FL into German was important to you.

a) Would you confirm this observation?

b) Why is it important?

c) Are there age-related differences, e.g. more translation in a Year 3 or Year 4 than in a Year 1?

d) Are there differences also in other areas, not just translation?

\section{CDs and tapes}

You explain potential problems with native-speaker input from a CD or tape.

a) Have you ever experienced that children had problems with these recordings? Which?

b) How often do you use CDs or tapes?

\section{DVDs}

I found it very interesting to see how children responded to authentic video clips.

a) What was your impression?

b) Did you expect the children to behave in this way?

c) Which problems did you expect?

d) Would you use CDs more often, and do you think they are helpful for the FL learning process?

\section{Authentic stories}

You used the picture book Froggy Gets Dressed during observations.

a) What kind of experiences do you have with authentic stories in theclassroom?

b) Which difficulties can teachers have, and which difficulties can learners have with them? 


\section{Learners' word learning}

a) In your experience, how do children learn new words best?

b) Which activities and which teaching methods support vocabulary learning?

\section{Children's cultural and linguisticbackground}

During observations, I noticed that children's names suggest that you have learners from different cultural backgrounds in your class.

a) Can you confirm this observation?

b) Which cultures are represented in your class?

c) How many children have a German background?

d) Do children whose mother tongue is not German have problems with English?

e) How do children who have learning difficulties respond to English?

\section{Teacher's views on teacher training and resources}

For many teachers, having to teach a FL in their primary classrooms was a bit of a surprise, which is why they felt overwhelmed, maybe due to a lack of training but also a lack of accessible teaching material.

a) How did you experience this?

b) Did you find your further training course sufficient? Did you have any other opportunities to practise your English?

c) How do you experience primary EFL on a daily basis? (Would school life be better without it?)

d) What should teachers learn in order to be prepared for primary EFL? 


\section{Original interview questions in German:}

\section{Enthusiasmus der Kinder}

Beim Hospitieren und Transkribieren ist mir aufgefallen, dass die Kinder sehr enthusiastisch am Englischunterricht teilnehmen.

a) Sind die Kinder generell so begeistert, wenn es um Englisch geht oder

b) gibt es da große Unterschiede zwischen einzelnen Aktivitäten: singen oder

Frage-Antwort-Spiel?

\section{Nachsprechen}

Ich habe auch beobachtet, dass die Kinder gerne und viel nachsprechen, sobald jemand etwas in Englisch gesagt hat.

a) Wie wichtig ist für deinen Unterricht das Nachsprechen von Wörtern oderSätzen?

b) Was bevorzugst du: das Mitsprechen (z.B. einer Geschichte) oder das Nachsprechen?

c) Gibt es die Methode des Mitsprechens auch in allgemeinerGrundschulpädagogik?

\section{Prioritäten}

a) Was ist dir besonders wichtig, worauf legst du beim Englischunterricht besonders viel Wert?

b) Gibt es da Unterschiede zwischen einer 1. und einer 4. Klasse?

\section{4. Übersetzen}

Beim Hopsitieren und Auswerten der Aufzeichnungen hatte ich den Eindruck, dass für dich das Übersetzen eine wichtige Rolle spielt.

a) Ist die Beobachtung richtig?

b) Warum wichtig?

c) Gibt es da alterspezifische Unterschiede, also mehr Übersetzung in 3. oder 4. Klasse als in 1.

Klasse?

d) Gibt es diese Unterschiede auch in anderen Bereichen, nicht nur beimÜbersetzen?

\section{CDs und Kassetten}

Du erklärst genau mögliche Schwierigkeiten bei Muttersprachleraufnahme von CD oder Kassette.

a) Hast du schon die Erfahrung gemacht, dass Kinder Schwierigkeitendamit haben?

b) Welche?

c) Wie oft werden Hörübungen gemacht?

\section{DVDs}

Für mich war es interessant zu sehen, wie Kinder auf einen authentischen DVD Clip reagieren.

a) Was war dein Eindruck?

b) Hattest du das erwartet?

c) Mit welchen Schwierigkeiten hattest du gerechnet?

d) Würdest du DVDs öfter verwenden, bringt ihr Einsatz einen Lerngewinn?

\section{Authentische Geschichten}

Während der Hospitationen hast du das Bilderbuch Froggy Gets Dressed benutzt.

a) Welche Erfahrungen hast du mit authentischen Geschichten im Unterricht?

b) Welche Schwierigkeiten hat man als Lehrer damit, welche gibt es für Kinder? 


\section{Erfahrungen zum Wortschatzerwerb bei Kindern}

a) Wie lernen Kinder deiner Erfahrung nach am besten neue Wörter?

b) Bei welchen Aktivitäten oder bei welcherMethodik?

\section{Herkunft und Voraussetzungen der Kinder}

Bei den Hospitationen habe ich gemerkt, dass Kinder mit unterschiedlichem kulturellen Hintergrund in der Klasse sind.

a) Ist diese Beobachtung richtig?

b) Welche Kulturen sind vertreten?

c) Wie viele Kinder sind deutscher Herkunft?

d) Haben Kinder, für die Deutsch eine Fremdsprache ist, Probleme mit dem Englischen?

e) Wie reagieren Kinder, die Lernschwierigkeiten haben auf den Englischunterricht?

\section{Befindlichkeit des Lehrers}

Für viele Lehrer kam die Forderung, eine Fremdsprache zu unterrichten ja sehr überraschend. Viele Lehrer haben sich auch allein gelassen gefühlt, vielleicht wegen eines Mangels an Fortbildungsmöglichkeiten bzw. an zugänglichem Material.

a) Wie hast du das empfunden?

b) War die Fortbildung ausreichend? Hattest du die Möglichkeit, dein Englisch noch anderweitig zu trainieren?

c) Wie erlebst du den Englischunterricht in deinem Arbeitsalltag? (Wäre es besser ohne?)

d) Was sollten Lehrer alles lernen oder mit auf den Weg bekommen, damit sie vorbereitet sind auf den Englischunterricht in der Grundschule? 
Semi-Structured Interview No 2 (Ruth, 26-10-2010)

\section{English translation of interview questions:}

\section{Songs}

Again and again I observed your Year 3 learners being able to sing several songs from memory and without preparation, which I found impressive. One time they sang 5 songs, one after the other, some of them containing quite difficult vocabulary. You have already told me that they had not sung most of these songs in English during that school year.

a) Does that mean that the children could remember songs that they had practised in school last about 9 months before?

b) Do you know how often these songs had been practised andhow?

c) Did you notice anything that showed that the children knew the meaning of the text or of individual words?

d) Have you experienced children using individual words or language chunks from songs in other situations?

\section{Storytelling}

I noticed that you do not use any German during storytelling, although you do use some before and after. I observed that when you told the story of Milly the Mouse, for example, but also other stories.

a) Is that a strategy that you use and if so,

b) what are the reasons?

There was something that was new to me at the time, something that I found very effective, and that was the technique that you used for the the picture book The Smartest Giant in Town: you showed your children the pictures first, you let them talk about them and repeated some of their German words in English.

a) Is that a technique that you had used many times before, or was that something newyou tried?

b) Have you told stories in this way again,

c) and how did it go?

During all the storytelling sessions that I observed, children were always very focused, sometimes for more than 30 minutes. Is that something that you experience too, or have you also experienced children behaving differently?

a) In your experience, what are preconditions for children to listenattentively?

b) Have you experienced situations in which children recycled words from stories for other situations?

The learner interviews have shown that children are able to remember stories long after the storytelling sessions: for example, learners were able to reproduce words from The Three Little Pigs and they were able to reconstruct the plot of The Smartest Giant in Town.

a) Have you had similar experiences?

b) Under which conditions do children use words from stories in your experience?

c) Do you think repeated encounters with the story would help to support the intake of new words?

d) How do children respond to repeated encounters in your experience?

e) Do you anticipate any problems with motivation?

f) Do you think that listening to the story on CD again might be effective and feasible as part of the daily routine in school? 


\section{Workshop lessons}

The idea to let children choose their own material to work with during lesson time was a new idea, was it not?

a) Which experience did you have with this new approach?

b) Have you used workshop session again?

I found it impressive that many children chose to work with picture books or graded readers, such as Winnie the Witch, Big Feet or Look at Me.

a) Have you used any of these books again?

b) How did it go?

\section{Teacher Training}

You have supervised teacher trainees.

a) What knowledge or skills do teacher trainees lack?

b) What should be considered in their training?

\section{Teaching experience}

English is still a relatively new subject area in primary school.

a) Which year groups have you taught repeatedly?

b) Have you changed anything in the choice of materials or your style of teaching over the years?

c) What? 


\section{Original interview questions in German:}

\section{Lieder}

Was mich in der dritten Klasse immer wieder beeindruckt hat, war die Tatsache, dass die Kinder mehrere Lieder auswendig aus dem Stand heraus in Englisch singen konnten. In der einen Situation waren es etwa 5 Lieder mit zum Teil kompliziertem Vokabular. Du sagtest ja schon, dass viele der Lieder nicht in dem jeweiligen Schuljahr in Englisch gesungen wurden.

a) Heißt das, dass die Kinder sich an Lieder erinnern konnten, die sie ca. 9 Monate vorher zum letzten Mal geübt hatten?

b) Weißt du, wie oft diese Liedtexte eingeübt worden sind und wie?

c) Gibt es Anzeichen dafür, dass man sagen kann, die Kinder kannten die Bedeutung des Textes / einzelner Wörter?

d) Hast du es erlebt, dass Wortfetzen aus Liedern in anderen Situationen benutzt worden sind?

\section{Storytelling}

Beim Geschichtenerzählen im Englischen, z. B. die Geschichte von Milly, der Maus, ist mir aufgefallen, dass obwohl du vorher und nachher schon auch mal Deutsch im Unterricht sprichst, die Zeit des Geschichtenerzählens kein Sprachwechsel vorkommt. Das wiederholt sich auch bei anderen Geschichten.

a) Passiert das bewusst?

b) Gibt es dafür einen bestimmten Grund?

Was für mich völlig neu war, was ich aber sehr effektiv fand, war die Art des Storytellings, die du beim Smartest Giant in Town verwendet hast: zuerst das Bild, die Kinder in Deutsch etwas sagen lassen und dann in Englisch die Wörter wiederholen.

a) Ist das eine Methode, die du vorher schon oft ausprobiert hast oder war das etwas Neues?

b) Hast du seitdem oft wieder so Geschichten erzählt?

c) Wie war das?

Bei allen Storytelling Sessions, die ich mitverfolgt habe, waren die Kinder immer konzentrierte Zuhörer und das manchmal über ca. 30 Minuten lang.

a) Erlebst du das auch meist so oder gibt es da auch andere Erfahrungswerte?

b) Was ist deiner Erfahrung nach Voraussetzung, dass Kinder so konzentriert zuhören?

c) Hast du schon erlebt, dass Kinder Wörter aus Geschichten in anderen Situationen benutzen?

Die Interviews mit den Kindern haben gezeigt, dass die Kinder auch lange nach den Storytelling Sessions sich an die Geschichten erinnern können: bei Geschichten wie The Three Little Pigs konnten sie Wörter reproduzieren, beim Smartest Giant in Town konnten sie die Storyline rekonstruieren.

a) Hast du ähnliche Erfahrungen machen können?

b) Unter welchen Umständen werden Wörter aus Geschichten zu produktivem Wortschatz?

c) Wäre das wiederholte Erzählen einer Geschichte eine Variante, um das Aufnehmen neuen Wortschatzes zu begünstigen?

d) Wie reagieren Kinder aufWiederholungen?

e) Gibt es Motivationsprobleme?

f) Ist die Variante, eine Geschichte auf CD wieder zu hören im Schulalltag umsetzbar und effektiv? 


\section{Werkstattstunden}

Die Idee, die Kinder selbständig Material aussuchen zu lassen, war ja neu, oder?

a) Welche Erfahrungen hast du damit gemacht?

b) Hast du es wieder ausprobiert?

Für mich war beeindruckend, dass eine ganze Menge Kinder, sich Geschichten ausgesucht haben, z.B. Winnie the Witch, Big Feet, Look at Me.

a) Hast du diese Bücher wieder verwendet?

b) Wie ging das, war das sinnvoll?

\section{Lehrerausbildung}

Du warst auch schon als Mentor für Referendare: eingesetzt.

a) Was fehlt angehenden Lehrern?

b) Worauf sollte in der Ausbildung mehr geachtet werden?

\section{Lehrerfahrung}

Englisch ist immer noch ein relativ neues Fach an der Grundschule.

a) Welche Klassenstufen hast du schon mehrmals unterrichtet, wie oft?

b) Hat sich an der Auswahl des Materials oder am Unterrichtsstil durch Erfahrung etwas verändert?

c) Was? 
Appendix 12: Analysis of contextual features in interviews

All interviews with participants were analysed for contextual information and discourse structure. This is a selection of extracts to illustrate typical features of interviewees' response.

1. Learner Interview 1/2009: Children ask specific questions on interview procedure, which reveal their interest in and their expectations of the interview situation

\begin{tabular}{|l|l|l|}
\hline Turn & Interviewer & Interviewed children \\
\hline 1 & $\begin{array}{l}\text { [...] ich kopier' das für euch, so dass } \\
\text { ihr des ausmal'n könnt und des dann } \\
\text { wirklich auch-, wenn das kopiert is, } \\
\text { sollte man dann auch die Kreisform } \\
\text { besser erkennen } \\
\text { [...]I will make a copy for you so that } \\
\text { you can colour it in and that it is } \\
\text { really-, if it is copied, then the circle } \\
\text { shape will come out better }\end{array}$ & \\
\hline 2 & $\begin{array}{l}\text { Kopie davon, weil man die [Kopie } \\
\text { besser ausmal'n kann als das } \\
\text { aufgeklebte } \\
\text { I will give that to you, I will give you a }\end{array}$ & $\begin{array}{l}\text { C1: ja und könn' wir das dann auch noch } \\
\text { behalten? }\end{array}$ \\
\hline 3 & $\begin{array}{l}\text { das bring' ich euch wieder mit, ja } \\
\text { I will give it to you again, yes }\end{array}$ & $\begin{array}{l}\text { C1: und was mach'n Sie dann mit den } \\
\text { kopierten? }\end{array}$ \\
\hline 4 & and what are you going to do with the copy? \\
\hline 5 & & \\
\hline
\end{tabular}




\begin{tabular}{|c|c|c|}
\hline & $\begin{array}{l}\text { copy of that, because you can [colour in } \\
\text { the copy much better than the original } \\
\text { with the stuck on paper }\end{array}$ & \\
\hline 6 & & C?:[((giggling)) \\
\hline 7 & & $\begin{array}{l}\text { C1: und was mit dem aufgeklebten, [was } \\
\text { machen Sie mit dem? } \\
\text { and what about the one with the stuck on, } \\
\text { [what are you going to do with that? }\end{array}$ \\
\hline 8 & & C?: [((making funny noises, humming)) \\
\hline 9 & $\begin{array}{l}\text { das könnt' ihr auch wieder hab’n- } \\
\text { you can have it back }\end{array}$ & \\
\hline 10 & & C1?: XXX \\
\hline 11 & & $\begin{array}{l}\text { C2?: [ich auch } \\
\text { me, too }\end{array}$ \\
\hline 12 & & $\begin{array}{l}\text { C1?: [ach so, ich hab gedacht, das heben Sie } \\
\text { irgendwie auf, oder so } \\
\text { [ah, okay, I thought you keep that somehow, } \\
\text { or so } \\
\text { ((shuffling paper)) }\end{array}$ \\
\hline 13 & $\begin{array}{l}\text { ja, ich behalt mir auch 'ne Kopie, } \\
\text { wenn ich das darf ... ja? } \\
\text { yes, I would keep a copy if I may ... } \\
\text { yes? }\end{array}$ & \\
\hline 14 & & C1?: hmhm \\
\hline 15 & okay & \\
\hline 16 & & C1?: hmhm \\
\hline
\end{tabular}

The above extract is a very typical account of children asking specific questions on interview procedures. Detailed questions about data processing or about the recording device occurred in every one of the five interviews. 
2. Learner Interview 1/2009: Child's request to show her language skills

\begin{tabular}{|c|c|c|}
\hline Turn & Interviewer & Interviewed children \\
\hline 1 & $\begin{array}{l}=\text { okay! ... ehm ....... ehm .... wisst } \\
\text { ihr noch zum Beispiel, was des hier } \\
\text { für Zimmer war'n? = } \\
=[\ldots] \text { do you know, for example, } \\
\text { which rooms these are? }\end{array}$ & \\
\hline 2 & & $\begin{array}{l}\text { Cf1: = ja, ich weiß es! } \\
=y e s, ~ I ~ k n o w ~ t h a t !\end{array}$ \\
\hline 3 & $\begin{array}{l}\text { ja? was war'n des?- } \\
\text { yes? what are they?- }\end{array}$ & \\
\hline 4 & & $\begin{array}{l}\text { Cf1: darf ich auch alle sagen, weil ich noch alle } \\
\text { weiß? } \\
\text { may I also name all of then, because I still } \\
\text { know them? }\end{array}$ \\
\hline 5 & okay & \\
\hline 6 & & Cf1: ehm $\ldots$ [d]is is the l[e]ving room $=$ \\
\hline 7 & $=$ living room & \\
\hline 8 & & Cf1: [d]is is the kitchen \\
\hline 9 & hmhm & \\
\hline 10 & & $\begin{array}{l}\text { Cf1: [d]is is the bedroom, [d]is is the ... } \\
\text { dining-room ... [d]is is the [bedroom ... ja! }\end{array}$ \\
\hline 11 & & Cf2: [bedroom \\
\hline 12 & super! & \\
\hline
\end{tabular}

Apart from the child's desire to show off her knowledge, this extract could also be interpreted as a child's attempt to be helpful in order to please the adult interviewer (Pinter, 2006; Pinter, Kuchah and Smith, 2013). 
3. Learner Interview 1/2009: Children expressing dislike openly

\begin{tabular}{|c|c|c|}
\hline Turn & Interviewer & Interviewed children \\
\hline 1 & & $\begin{array}{l}\text { Cf1: oh::: , mir gefällt mein Mandala nich! = } \\
\text { oh:::, I don't like my mandala }\end{array}$ \\
\hline 2 & $\begin{array}{l}\text { = dir gefällt dein Mandala nich? ... } \\
\text { warum nich? ... XXX man kann das } \\
\text { so mach'n ... 'okay }{ }^{\circ} \text { you don't like } \\
\text { it? ... why not? ... XXX you can do } \\
\text { it like that ... }{ }^{\circ} \text { okay }{ }^{\circ}\end{array}$ & \\
\hline 3 & & Cf2: oh ja! \\
\hline 4 & & $\begin{array}{l}\text { Cf1: ich find das (halt) komisch, wenn des } \\
\text { XXX is ja auf'm Bauernhof ... da (gehör'n } \\
\text { ja) ganz viele Tiere auf das Blatt I just find it } \\
\text { strange when this XXX is on a farm ... there } \\
\text { (should be) many animals on the sheet of } \\
\text { paper }\end{array}$ \\
\hline 5 & $\begin{array}{l}\text { hmhm ... meinst die Bauernhoftiere } \\
\text { eher? hmhm ... do you mean farm } \\
\text { animals? }\end{array}$ & \\
\hline 6 & & $\begin{array}{l}\text { Cf1: nee::: (ich mein') alle Tiere auf ein 'n } \\
\text { klein' XXX no::: (I mean) all animals on a } \\
\text { small XXX }\end{array}$ \\
\hline 7 & ${ }^{\circ} \mathrm{XXX} ?^{\circ}$ & \\
\hline 8 & & $\begin{array}{l}\text { Cf1: aber nich so was, sondern eben im Haus } \\
\text { sind noch andere Tiere } \\
\text { but not like this, but there are other animals in } \\
\text { the house }\end{array}$ \\
\hline 9 & $\begin{array}{l}\text { ach so meinst'e das- okay, that's } \\
\text { what you mean }\end{array}$ & \\
\hline
\end{tabular}

This extracts illustrates that children also expressed their disappointment openly when something did worry them. They seem relaxed with the interview situation, and not intimidated by the presence of the researcher. 
4. Teacher Interview 1/2008: Touching on a sensitive issue

\begin{tabular}{|c|c|c|}
\hline Turn & Interviewer & Interviewed Teacher: Sophie \\
\hline 1 & $\begin{array}{l}{[\ldots] \text { wie wichtig is das Übersetzen? }} \\
{[\ldots] \text { how important is translation? }}\end{array}$ & \\
\hline 2 & & $\begin{array}{l}\text { h::: ((exhaling)) ... also, das is sehr } \\
\text { unterschiedlich gehandhabt ... einige woll’n } \\
\text { das gar nich = } \\
\text {... well, that is handled very differently ... some } \\
\text { don't want it at all = }\end{array}$ \\
\hline 3 & $=\mathrm{hmhm}=$ & \\
\hline 4 & & $\begin{array}{l}\text { und finden das ganz verpönt, dass man nichts } \\
\text { übersetzen soll ... ich finde, bestimmte } \\
\text { Sachverhalte muss man auch übersetzen, also } \\
\text { was ich halt immer schade finde is, wenn- das } \\
\text { mach'n auch Studenten oft, dass sie gleich } \\
\text { anfang' Arbeitsanweisungen sofort auf Deutsch } \\
\text { zu erklären, weil se Angst hab’n, auf Englisch } \\
\text { wird's nich verstanden- } \\
\text { and find that unacceptable and that nothing } \\
\text { should be translated ... I think that some things } \\
\text { have to be translated, well, something that I } \\
\text { find is a shame is when students start giving } \\
\text { instructions in German straight away because } \\
\text { they are afraid that nobody will understand } \\
\text { them in English- }\end{array}$ \\
\hline 5 & ah, okay & \\
\hline 6 & & $\begin{array}{l}\text { ich finde es wichtig, das auf Englisch auf jeden } \\
\text { Fall zuerst zu sagen ... und auch zu zeig’n, so } \\
\text { dass gar nich viel übersetzt werden muss, aber } \\
\text { wenn bestimmte Schlüsselwörter, die einfach } \\
\text { notwendig sind, wenn die den Kindern } \\
\text { unbekannt sind, könn’ sie dann nich weiter } \\
\text { folgen = }\end{array}$ \\
\hline
\end{tabular}




\begin{tabular}{|l|l|l|}
\hline & & $\begin{array}{l}\text { I think it is important to say it in English first ... } \\
\text { and also to gesture so that you do not have to } \\
\text { translate much, but if certain key words that are } \\
\text { important, when they are unknown to the } \\
\text { children, they can't follow }=\end{array}$ \\
\hline 7 & $=\mathrm{hm}=$ & \\
\hline
\end{tabular}

Sophie's initial response very much highlights the fact that the interviewer touched a sensitive issue. She shows her uneasiness by exhaling and taking some time to think (Turn 2), and by stating that there are different opinions on the subject, rather than disclosing her own view straight away (4). The verbal acknowledgment by the interviewer that signals understanding (5) is responded to by another, more detailed explanation on the part of Sophie (6). The verbal sign that the interviewer offers now (7), however, is minimal and ambivalent. Sophie does not seem to be sure if she is properly understood and provides examples for clarification:

Negotiating meaning \& resolving misunderstanding

\begin{tabular}{|c|c|c|}
\hline Turn & Interviewer & Interviewed Teacher: Sophie \\
\hline 1 & & $\begin{array}{l}\text { also, ich würde nich jede Sache übersetzen = } \\
\text { well, I wouldn't translate everything }=\end{array}$ \\
\hline 2 & $=$ nee $=$ & \\
\hline 3 & & $\begin{array}{l}=\text { auch Geschichten nich übersetzen }= \\
=\text { wouldn't translate stories either }=\end{array}$ \\
\hline 4 & $=$ nee $=$ & \\
\hline 5 & & $\begin{array}{l}=\text { aber bestimmte, wichtige Schlüsselwörter ... } \\
\text { ohne die es- = but certain key words ... without } \\
\text { which it- }\end{array}$ \\
\hline 6 & $\begin{array}{l}\text { also praktisch ... um den Kindern } \\
\text { noch 'n andern Halt zu geben, um } \\
\text { sich das besser zu merken = } \\
\text { well, in order to give children } \\
\text { something to cling on so that they } \\
\text { can remember better = }\end{array}$ & \\
\hline
\end{tabular}




\begin{tabular}{|c|c|c|}
\hline 7 & & $=$ genau $=$ \\
\hline 8 & $=$ ja, ne? $=$ & \\
\hline 9 & & $\begin{array}{l}\text { = weil, wenn's um einen ganz bestimmten } \\
\text { Begriff geht und der is so zentral, dass ohne } \\
\text { den das Verständnis [nich gewährleistet is ... } \\
\text { und ganz schwache Kinder hab'n wirklich } \\
\text { keine Ahnung, was es bedeutet, dann is für die } \\
\text { die Stunde irgendwie ... so'n bisschen } \\
\text { gelaufen, also das is = because when it is about } \\
\text { a certain term and that word is essential [for } \\
\text { understanding ... and some children who are } \\
\text { not so good at English don't have a clue, then } \\
\text { for them the lesson is over, well that is }\end{array}$ \\
\hline 10 & $\begin{array}{l}\text { [hm ....... ja ja, dann verlier'n } \\
\text { se den Faden an der Stelle, ne? = } \\
\text { yes yes, then it is difficult for them } \\
\text { to follow, isn't it? = }\end{array}$ & \\
\hline 11 & & $=$ ja \\
\hline
\end{tabular}

Here, various incidents of latching $(1,2,3,4,6,7,8)$, an interruption in Turn 5 and examples of overlapping speech $(9,10)$ indicate an acceleration of the conversation. Interviewer and interviewee are trying to reach common ground. There is also evidence of rephrasing answers $(6,9,10)$ that illustrate efforts for shared understanding and cooperation.

Patterns of mutual support and encouragement to reach common ground were observed in both teacher interviews. 
This is an overview of individual words as well as chunks of language that were produced by the children independently or with help from the interviewer.

In the last column, only words that were actually repeated by the children after they had asked for them are listed. In cases that children only asked for words in English, but did not produce them, these were not added to the list. If children asked for individual words within one phrase that they otherwise produced without help, these words are printed in italics.

Words or phrases that are repeated in one interview are not listed again, but variations of a word or phrase are. Children's responses in different interviews are listed chronologically in separate blocks. Whenever words were mispronounced, phonetic script was used. Words in single brackets were not properly understood.

Words and chunks of language in grey were produced by a trilingual child who spoke American English and Spanish at home. Language printed in blue can be identified as language that was practised during storytelling in observational periods in 2008 and 2009; whereas language printed in red refers to pop songs that children probably knew from radio and television.

Children's FL production in the interviews in order of appearance within one category

\begin{tabular}{|c|c|c|}
\hline Category & Language produced independently & $\begin{array}{l}\text { Language produced } \\
\text { with help of adult } \\
\text { interviewer }\end{array}$ \\
\hline animals & $\begin{array}{l}\text { this is a crocodile, this is a cat, this is a mouse, this is a } \\
\text { dog, this is a bird, this is a h[os], [d]is is a tiger, this is a } \\
\text { bear, these is a elephant and it's big, this is a mouse ... a } \\
\text { little mouse, this is a gu[i:]nea pig, three sheeps, this is a } \\
\text { kangaroo, the Frosch, the frog and he is, a monkey, the } \\
\text { monkey has fun, this is a rhino, this is ... a ... snail, this is } \\
\text { a fish, mouse, snail, snake, a cat, chicken, sheep }\end{array}$ & $\begin{array}{l}\text { dolphin, sh[ei]p, } \\
\text { polar bear, ladybird }\end{array}$ \\
\hline & frog is green, this is a tiger ... it is very, this is a bird, she & the frog is green, \\
\hline
\end{tabular}




\begin{tabular}{|c|c|c|}
\hline & $\begin{array}{l}\text { can fly ... very ... very ... hhh ... in the air, birds, snake, } \\
\text { tiger, a lion, rabbit, turtle } \\
\text { [t]is is ... [t]e...three little pi[k] ... Geschichte, da is'n } \\
\text { little pi[k] und a big ba[t] wolf, [d]e three little pigs, } \\
\text { who’s afraid of the big bad wolf, the big bad wolf, the } \\
\text { big bad wolf ((singing)), [g]iraffe, giraffe, [dzai]raffe, } \\
\text { [d]is is a tiger, a big tiger, this is a big ba[t] wolf ... } \\
\text { mit ... one little pi[k], rabbit } \\
\text { this is a dog, dog, dog and boy, pig ... pig, Mrs Pig, } \\
\text { wolf, [d]is a wolf ... yeah ... and this is a Bill, g[i:]raffe, } \\
\text { sheep, a fox ... and a cat, snake, a dog ... and a boy } \\
\text { this is the three little pi[k]s ... plus your mother, this is } \\
\text { one pi[k] and one w[o]lf, [d]is is the three little pigs, } \\
\text { who’s afraid of the big bad wolf ... the big bad wolf ... } \\
\text { the big bad wolf ((singing)), go away Floppy, dinosaur, } \\
\text { dinosaur, lady bug, this is a ladyb[0:], this is a wolf and } \\
\text { a- one pi[k] ... and the wolf, this is a story ... go away } \\
\text { a bird in the sky (?) }\end{array}$ & $\begin{array}{l}\text { three little pigs, } \\
\text { snail } \\
\text { the story ... the } \\
\text { three little pig, bird, } \\
\text { a long neck }\end{array}$ \\
\hline clothes & $\begin{array}{l}\text { [d]is is a umbrella, this is a scarf and it k[eps] warm } \\
\text { this is a sock and a woolly hat, when you put this on ... } \\
\text { then...is ... eh ... don't so cold } \\
\text { a hat } \\
\text { - } \\
\text { this is [d]e winter ... clothes, sock, a hat, and a sock }\end{array}$ & - \\
\hline colours & - & - \\
\hline
\end{tabular}




\begin{tabular}{|c|c|c|}
\hline & $\begin{array}{l}\text { orange, black and white, (it's) orange } \\
\text { - }\end{array}$ & $\begin{array}{l}- \\
- \\
- \\
-\end{array}$ \\
\hline $\begin{array}{l}\text { communicative } \\
\text { strategies }\end{array}$ & $\begin{array}{l}\text { - } \\
\text { I don’t know } \\
\text { - } \\
\text { oh no ...everybody, yes, yes } \\
\text { sorry Floppy }\end{array}$ & $\begin{array}{l}- \\
- \\
- \\
- \\
-\end{array}$ \\
\hline food & $\begin{array}{l}\text { this is a banana, this is ice-cream and ice-cream is very } \\
\text { yummy } \\
\text { this is a birthday cake ... I can [i]t [d]is ... it is very } \\
\text { yummy, the apple is green, the apple is green ... or } \\
\text { yellow ... or red, this is the carrots, orange carrot, this is } \\
\text { a red strawberry, plum, orange, mel[ou]n, pear, lemons, } \\
\text { and Lisa ... ehm .. eats cookies ... and ... ehm ... eh, hot } \\
\text { chocolate, yum, yum } \\
\text { supermark[t] ... fl[ou]r and des is'n bacon, this is one ... } \\
\text { this is ... one apple } \\
\text { [k^bis] } \\
\text { [d]is is a ice }\end{array}$ & $\begin{array}{l}\text { this is a strawberry } \\
\text { the pumpkin is } \\
\text { orange, the ice- } \\
\text { cream is cold, very } \\
\text { cold, water melon } \\
\text { - } \\
\text { pumpkin } \\
\text { ice cream }\end{array}$ \\
\hline home & this is a house & castle, farm, \\
\hline
\end{tabular}




\begin{tabular}{|c|c|c|}
\hline & $\begin{array}{l}\text { [d]is is a house, Wilbur's house, this is ... house ... in the } \\
\text { house is a little mouse ... and ... he ... the house, is a little } \\
\text { house, a house for a little little mouse, kitchen, the kids' } \\
\text { bedroom, d[e]ning room, living room, in the night ... in } \\
\text { the XXX ... Burg, Edinburgh, this is a castle, lazy town } \\
\text { this is a city, this is a b[^g], a castle, Holz house, this } \\
\text { is ... (s)tr[ou], and I huff ... and I puff and I blow your } \\
\text { house down } \\
\text { (and to) blow your house down, straw, twigs } \\
\text { straw, hay, straw, this is a castle on a mountain, blows ... } \\
\text { the house of, to the ground, twigs, [d]is is a ...[ }\left[\int\right] \text { air, this } \\
\text { is the wolf trying to blow away the house of stones, (no) let } \\
\text { me in, let me, knock knock ... let me in ... let me in, (not by) } \\
\text { the hair of my chinny chin chin }\end{array}$ & $\begin{array}{l}\text { puff ... and I blow } \\
\text { your house down } \\
\text { straw } \\
\text { armchair, then I'll } \\
\text { huff and I'll puff } \\
\text { and I blow(s) the } \\
\text { house down }\end{array}$ \\
\hline numbers & $\begin{array}{l}\text { this is number one, that's the Arabic numbers, one ... } \\
\text { two ... three ... four ... five } \\
\text { - } \\
\text { eight, one two three four five, six seven eight nine ten, } \\
\text { eleven twelve, fifteen sixteen, twenty, nine(teen) thirty- } \\
\text { one thirty-two thirty-three ... thirty-four thirty-five, } \\
\text { thirty-six, thirty-seven, thirty-eight thirty-nine forty } \\
\text { forty-one } \\
\text { three } \\
\text { one two three four five }\end{array}$ & number, fourteen \\
\hline people & $\begin{array}{l}\text { this is a girl and she is, this is princess, [d]is is a } \mathrm{f}[\mathrm{e}] \mathrm{ry} \text {, } \\
\text { this is a sad, this is a family }\end{array}$ & fairy, sad \\
\hline
\end{tabular}




\begin{tabular}{|c|c|c|}
\hline & $\begin{array}{l}\text { that's a music man, (on) playing guitar, the family sit on } \\
\text { the sofa ... and they show pictures in the book, reading ... } \\
\text { reading, clown, pokerface, this is a clown face, the } \\
\text { ghosts ... ehm ... spooky ... on the ...ehm ... ([brag]) ... in } \\
\text { the night } \\
\text { this sin grandma and ... grandpa, family, we are family ... } \\
\text { I XXX my sisters and me ((singing)), this is the story of } \\
\text { the giant, giant, king of the w[o]rld, [t]is is a family, and } \\
\text { two sticks als Hand, loser, ghosts, I'm ten years old } \\
\text { flat feet, big feet, boy and Hund, a girl, dad, mum, we } \\
\text { are family ... I brought all my sisters with me ((singing)), } \\
\text { my sisters and me, boys } \\
\text { this is a g[e]l and a ... ja [e]mbrella, this is the house of } \\
\text { Milly (and) her hat }\end{array}$ & $\begin{array}{l}\text { presents } \\
\text { a boy, sad, the } \\
\text { giant, look at me, } \\
\text { look at me, mum } \\
\text { big feet }\end{array}$ \\
\hline plants & $\begin{array}{l}\text { [d]is is a blum, } r[\mathrm{os}] \text {, tree } \\
\text { the tree is green ... big and brown } \\
\text { - } \\
\text { [d]is is a [blu:d], flower }\end{array}$ & $\begin{array}{l}\text { flower, mushroom } \\
\text { the stem is brown } \\
\text { - } \\
\text { - }\end{array}$ \\
\hline school & this is a pen & - \\
\hline
\end{tabular}




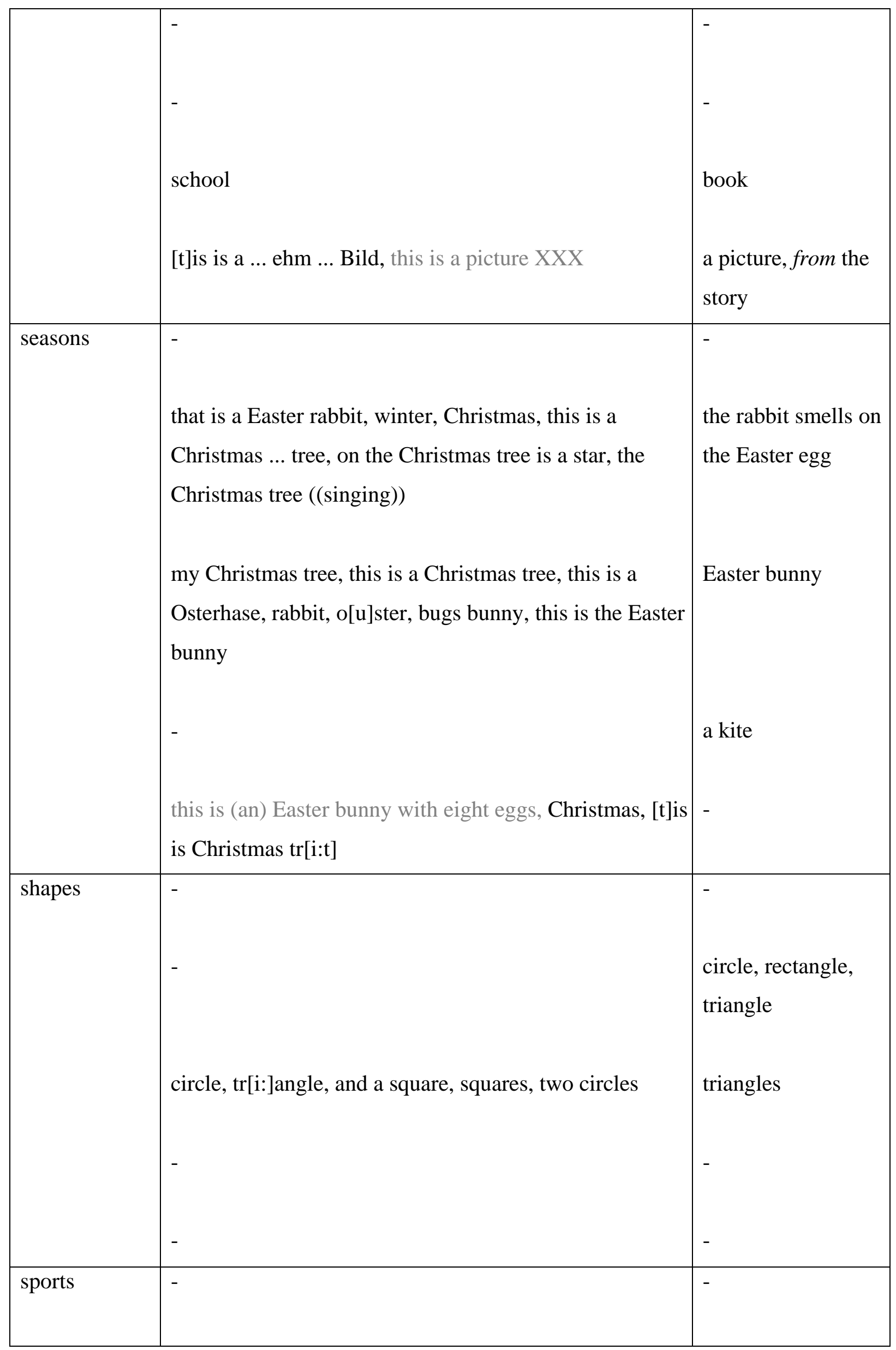




\begin{tabular}{|c|c|c|}
\hline & $\begin{array}{l}\text { I'm playing the football, soccer, I'm sailing ((singing)), } \\
\text { - } \\
\text { th[e]s is a football, football ... football ((chanting)) } \\
\text { this is foot and the ball, football, soccer }\end{array}$ & $\begin{array}{l}\text { [d]is is a tennis bat, } \\
\text { this is a tennis bat } \\
\text { and a tennis ball, } \\
\text { the sailing boat ... } \\
\text { of the water, is in } \\
\text { the water } \\
\text { - } \\
\text { trainer, football } \\
\text { trainer }\end{array}$ \\
\hline transport & $\begin{array}{l}\text { [d]is is a d[u]bledecker b[u]s, this is a auto, plane } \\
\text { the airb[u]s is ... very } \\
\text { [t]is is a car, a car, the car ... and a bike riding ... oder } \\
\text { bike, a bike, and two bike, [d]is is a [sif], this is in water, } \\
\text { I am flying, flyer, [d]is is a plane } \\
\text { b[u]s, s[hef] } \\
\text { this is a bus, sailing boat, this is a car, car, this is a } \\
\text { story ... von ... XXX bikes }\end{array}$ & $\begin{array}{l}\text { - } \\
\text { fast, motorbike, } \\
\text { engine } \\
\text { sailing boat, plane, } \\
\text { I'm on the plane } \\
\text { bus, boat, ship } \\
\text { - }\end{array}$ \\
\hline weather & $\begin{array}{l}\text { - } \\
\text { it is raining and Lisa ... and ... Lisa is, it is raining men } \\
\text { ((singing)), snowman ... stands in the snow ... with a } \\
\text { long nose ... with a long carrot ... it snows ... and (here } \\
\text { it’s) sticks, sun, Lisa ... take an umbrella and will go out }\end{array}$ & $\begin{array}{l}\text { - } \\
\text { Lisa is sad, look on } \\
\text { the window ... on } \\
\text { outside ... it is } \\
\text { raining, and it is } \\
\text { snowing, moon, the } \\
\text { moon ... eh ... shine }\end{array}$ \\
\hline
\end{tabular}




\begin{tabular}{|l|l|l|}
\hline snowman & - & on the ... (w[e]rld) \\
that's (the) sun, this is a girl and it rainy & $\begin{array}{l}\text { two clouds, two } \\
\text { clouds ... one sun }\end{array}$ \\
$\begin{array}{l}\text { today is rainy, cloud, [d]is is a cloud and sun, [t]is is a } \\
\text { snowman }\end{array}$ & - \\
\hline
\end{tabular}

No. of words produced independently: $\quad 1,244$

of which individual words: $\quad \mathbf{8 0}$

of which nouns: $\quad 69$

of which items as part of two-word

combinations: $\quad 36$

of which words as part of multi-item

combinations: $\quad 1,108$

of which items that were combinations of English \& German and difficult

to understand: 